\title{
The adaptive side of psychopathy
}

Citation for published version (APA):

Durand, G. (2019). The adaptive side of psychopathy: Investigating adaptive characteristics associated with the psychopathic personality. [Doctoral Thesis, Maastricht University]. Maastricht University. https://doi.org/10.26481/dis.20190905gd

Document status and date:

Published: 01/01/2019

DOI:

10.26481/dis.20190905gd

Document Version:

Publisher's PDF, also known as Version of record

\section{Please check the document version of this publication:}

- A submitted manuscript is the version of the article upon submission and before peer-review. There can be important differences between the submitted version and the official published version of record.

People interested in the research are advised to contact the author for the final version of the publication, or visit the DOI to the publisher's website.

- The final author version and the galley proof are versions of the publication after peer review.

- The final published version features the final layout of the paper including the volume, issue and page numbers.

Link to publication

\footnotetext{
General rights rights.

- You may freely distribute the URL identifying the publication in the public portal. please follow below link for the End User Agreement:

www.umlib.nl/taverne-license

Take down policy

If you believe that this document breaches copyright please contact us at:

repository@maastrichtuniversity.nl

providing details and we will investigate your claim.
}

Copyright and moral rights for the publications made accessible in the public portal are retained by the authors and/or other copyright owners and it is a condition of accessing publications that users recognise and abide by the legal requirements associated with these

- Users may download and print one copy of any publication from the public portal for the purpose of private study or research.

- You may not further distribute the material or use it for any profit-making activity or commercial gain

If the publication is distributed under the terms of Article $25 \mathrm{fa}$ of the Dutch Copyright Act, indicated by the "Taverne" license above, 



\section{The adaptive side of psychopathy}

Investigating adaptive characteristics associated with the psychopathic personality

Guillaume Durand 
Cover Guillaume Durand

\section{Copyright Guillaume Durand, 2019}

All rights reserved. No part of this publication may be reproduced or transmitted in any form or by any means, electronic or mechanical, including photocopy, recording, or any information storage or retrieval system, without permission of the author. 


\section{The adaptive side of psychopathy}

Investigating adaptive characteristics associated with the psychopathic personality

\section{DISSERTATION}

to obtain the degree of Doctor at Maastricht University, on the authority of Rector Magnificus, Prof. Dr. Rianne M. Letschert, in accordance with the decision of the Board of Deans, to be defended in public on Thursday 5

September 2019 at 12:00 hours

by

Guillaume Durand 


\section{Supervisor}

Prof. dr. B. P.F. Rutten

Co-supervisor

Dr. J. Lobbestael

\section{Assessment Committee}

Prof. dr. K.R.J. Schruers (Chairman)

Prof. dr. J.M.L.G. à Campo

Dr. N.M. Geschwind

Prof. dr. H.L.I. Nijman

Prof. dr. R.J. Verkes 


\section{Table of Contents}

$\begin{array}{lll}\text { Chapter } 1 & \text { General Introduction } & 7\end{array}$

Chapter 2 Demystification of the Relationship Between 19

Psychopathy and Happiness

Chapter 3 The Effects of Psychopathic Traits on Fear of Pain, 43 Anxiety, and Stress

Chapter 4 Negative Attitudes Towards Psychopaths: The Role 63 of One's Own Psychopathic Traits

Chapter 5 The interplay of Gender, Parental Behaviors, and

Child Maltreatment in Relation to Psychopathic Traits

Chapter 6 Genetic Moderation of Cognitive Performance after 105 Exposure to Social Stress

Chapter 7 The Durand Adaptive Psychopathic Traits

Questionnaire: Development and Validation

Chapter 8 Incremental Validity of the Durand Adaptive

155

Psychopathic Traits Questionnaire Above Self-

Report Psychopathy Measures in Community

Samples

Chapter 9 A French Translation and Validation of the Durand Adaptive Psychopathic Traits Questionnaire: An Investigation with Community Samples from France and Canada

Chapter 10 Exploring the Relationship Between Cognitive Abilities and Adaptive Psychopathic Traits

Chapter 11 General Discussion

Summary

Appendix

Valorization Addendum

Acknowledgments

Curriculum Vitae 

Chapter 1

General Introduction 


Psychopathy is regularly described in the scientific literature as a personality disorder characterized by traits related to interpersonal-affective features (i.e. lack of empathy, superficial charm, callous-unemotional traits, egocentricity) and antisocial features (i.e. impulsivity and aggression) (Berg et al., 2013; Gao, Glenn, Schug, Yang, \& Raine, 2009). While there are no official statistics on the prevalence of psychopathy in the general population, it is estimated to be around 1\% (Cooke, 1998). Most evidences suggest that psychopathy is the result of an interplay between genetic make-up and environment (Hicks et al., 2012). Inmates diagnosed with psychopathy are commonly guilty of drug usage, violence, as well as domestic assault and abuse (Camp, Skeem, Barchard, Lilienfeld, \& Poythress, 2013; Hall, Benning, \& Patrick, 2004). Although recent studies do not support the association between psychopathy and both violent and criminal behaviors (Berg et al., 2013; Camp et al., 2013; Hall \& Benning, 2006), psychopaths are generally feared in the general population (Edens, Colwell, Desforges, \& Fernandez, 2005; Edens, Marcus, Lilienfeld, \& Poythress, 2006; Helfgott, 1997). Considering the bias against psychopaths in judicial settings, whereas defendants classified as psychopaths generally face harsher sentences, it is mandatory to ensure that the psychopathy diagnosis stems from a valid psychological assessment (Cox, Clark, Edens, Smith, \& Magyar, 2013).

\section{Assessment of Psychopathy}

The diagnosis of psychopathy is commonly achieved through the Psychopathy Checklist-Revised (PCL-R; Hare, 2003). The PCL-R is considered the gold standard to diagnose psychopathy, and combines data generated from a one on one interview by a certified assessor with reports from alternative sources, such as police files (Ray, Weir, Poythress, \& Rickelm, 2011). In the early stage of its development, the PCL included two factors: Factor 1 encompassing affective-interpersonal characteristics, and Factor 2 including socially deviant behaviors. Later on, a revision including four facets was developed, which divided each factor in two: Facet 1 including interpersonal items, Facet 2 including affective items, Facet 3 including behavior lifestyle items, and Facet 4 including antisocial items (Hare \& Neumann, 2005). Despite its extensive validation, the PCL-R mainly focuses on criminal behaviors, which lowers its applicability in the general population (Hall \& Benning, 2006; Ray et al., 2011).

In an attempt to investigate psychopathy in the general population, several self-report instruments were developed. Among the first instruments was the Levenson Self-Report Psychopathy scale (LSRP; Levenson, Kiehl, \& Fitzpatrick, 1995). The LSRP was developed to capture similar elements to 


\section{Chapter 1 | General Introduction}

the initial two-factor model of the PCL-R within college students and the general population (Ross, Bye, Wrobel, \& Horton, 2008). The LSRP Factor 1 includes elements related to manipulative and egoistical traits, while Factor 2 assesses elements related to impulsivity. Similarly to the PCL-R, the LSRP focuses exclusively on maladaptive traits.

\section{Maladaptive and Adaptive Components of Psychopathy}

There is a strong focus on the maladaptive side of psychopathy within the scientific literature. When introducing the concept of psychopathy in a scientific article, many authors focus exclusively on the maladaptive side, with no early mention of adaptive traits (Boddy, 2014; Cima \& Van Oorsouw, 2013; Gaughan, Miller, \& Lynam, 2012; Hosker-Field, Molnar, \& Book, 2016; Love \& Holder, 2014; Newman, MacCoon, Vaughn, \& Sadeh, 2005; Takahashi, Takagishi, Nishinaka, Makino, \& Fukui, 2014). This is probably due to the fact that the inclusion of adaptive traits as key components of psychopathy is highly debated. Adaptive traits are defined as "a trait that maximizes an individual's survival probability within a set environment" (Durand, 2017). In the current literature, adaptive traits in the field of psychopathy is commonly observed in terms of fearless dominance and boldness (Berg et al., 2013).

Numerous researchers refute the inclusion of adaptive traits, such as fearless dominance and low anxiety, as a central component of psychopathy (Lynam \& Miller, 2012; Marcus, Fulton, \& Edens, 2012; Miller \& Lynam, 2012; Miller, Maples-Keller, \& Lynam, 2015; Visser, Ashton, \& Pozzebon, 2012), while other researchers support the central role of adaptive features (Lilienfeld, Patrick, et al., 2012; Lilienfeld, Watts, \& Smith, 2015; Murphy, Lilienfeld, Skeem, \& Edens, 2016; Patrick, Venables, \& Drislane, 2013; Smith, Watts, \& Lilienfeld, 2014).

The inclusion of adaptive personality traits as part of the psychopathic personality was first introduced by Cleckley (1941). Based on his clinical experience with psychopaths, Cleckley (1988) proposed a set of 16 characteristics identifying psychopaths: superficial charm, absence of delusion and irrational thinking, absence of nervousness, unreliability, untruthfulness, lack of remorse or shame, inadequately motivated antisocial behavior, poor judgement, pathologic egocentricity, poverty in major affective reactions, specific loss of insights, unresponsiveness in general interpersonal relations, fantastic and uninviting behavior with or without drinks, low suicide rate, impersonal and imbalanced sexual life, and a lack of life plan (pp. 338339). While it is apparent that many of those characteristics are fully maladaptive on a personal and social level, some characteristics, such as absence of delusion and nervousness, can arguably be considered beneficial 
to the individual. Furthermore, although criminal behaviors and violence have often been considered as a central to psychopathy, it was not part of the original list developed by Cleckley (Berg et al., 2013).

\section{Models of Adaptive Psychopathy}

In order to further examine the concept of successful psychopathy, Gao and Raine (2010) developed a neurobiological model of psychopathy derived from a literature review investigating the results obtained from five sample types (general population, employment agencies, university students, industrial, and serial killers). This model hypothesizes that the difference between successful and unsuccessful psychopathy is derived from neurobiological differences. Based on the findings of previous studies, the authors reported that, while all types of psychopathy shared a certain set of traits (i.e. lack of empathy, arousal, and sensation seeking), individuals classified as functional psychopaths showed higher levels of decision-making skills and cognitive empathy, enhanced cognitive functions, and showed a preference for relational aggression over physical aggression. Further research found additional characteristics commonly shared within successful psychopaths, such as higher levels of extroversion, conscientiousness, leadership, communication skills, and resilience to anxiety and stress (Lilienfeld, Waldman, et al., 2012; Mullins-Sweatt, Glover, Derefinko, Miller, \& Widiger, 2010; Smith et al., 2014).

In an attempt to explain the possible inclusion of adaptive components in functional psychopathy, numerous models have been developed over time (Lilienfeld et al., 2015). First, the differential-severity model considers psychopathy to be a unitary construct and assumes that successful psychopathy is a milder manifestation of the psychopathic personality. Second, the moderated-expression model considers successful psychopathy as an atypical manifestation of the psychopathic personality due to the emergence of protective factors (i.e. stress resilience, social charm), which in turn moderate the expression of maladaptive personality traits. As opposed to the previous models, the third differential-configuration model conceptualizes psychopathy as a multidimensional construct. In this model, successful and unsuccessful psychopathy share common traits (i.e. lack of empathy) while also including distinctive features not present in the other dimension.

\section{Assessment of Adaptive Psychopathic Traits}

While the PCL-R and the LSRP do not include an adaptive component focusing on traits related to successful psychopathy, two common self-report instruments, namely the Psychopathic Personality Inventory (PPI) and the 


\section{Chapter 1 | General Introduction}

Triarchic Psychopathy Measure (TriPM), do include a factor that could be considered adaptive. The PPI includes eight psychopathic traits divided in two factors: Fearless Dominance (FD/PPI-I) and Impulsive Antisociality (IA/PPI-II) (Lilienfeld \& Widows, 2005). Numerous studies reported an association between PPI-I and numerous adaptive traits, such as emotional stability (Uzieblo, Verschuere, Van den Bussche, \& Crombez, 2010), stress, fear, and anxiety resilience (Dindo \& Fowles, 2011), lower provoked violence (Camp, Skeem, Barchard, Lilienfeld, \& Poythress, 2013), and superior attentional control (Baskin-Sommers, Zeier, \& Newman, 2009). Similarly to the PPI, the TriPM defines psychopathy in three factors: disinhibition, meanness, and boldness (Patrick, 2010). Disinhibition and meanness assess the maladaptive side of psychopathy, and are strongly associated with PPI-II $(r=.66$ and .54 respectively) (Hall et al., 2014). Alternatively, boldness focuses on adaptive traits, such as social charm, fearlessness, and stress resilience, and is strongly associated to PPI-I ( $r=.82$ ) (Hall et al., 2014). While both of these instruments include adaptive characteristics, research did not support an association between those instruments and conscientiousness, which is a personality trait commonly associated with functional psychopathy (Blagov, Patrick, Oost, Goodman, \& Pugh, 2015; Lilienfeld et al., 2015).

\section{Purpose of the Dissertation}

Based on the aforementioned findings, there are two unresolved issues. First, despite the numerous traits which could be considered adaptive and that have been associated with psychopathy, there is a lack of a consensus on which traits are part of the psychopathic personality, and which traits are associated to the construct without being part of the core construct of psychopathy. Second, due to their lack of association with conscientiousness, both the PPI and the TriPM may not be the optimal instruments to identify individuals displaying high levels of successful psychopathic traits. The proposed thesis aims to provide additional insights in the field of psychopathy by exploring a wide range of adaptive correlates potentially related to psychopathy, and by providing an alternative instrument to assess successful psychopathy, namely the Durand Adaptive Psychopathic Traits Questionnaire (DAPTQ).

\section{Outline of the Thesis}

The Chapter 2 focuses on the association between psychopathic traits and variables related to happiness (Durand, 2018b). The PPI-SF was used in conjunction of measures of stable and fluctuating happiness, meaning in life, personal growth, and hope, with the purpose of determining how PPI Total, PPI-I, and PPI-II were associated with the aforementioned variables. Chapter 
3 used a similar paradigm as the study of Chapter 2 to investigation the relationship between PPI-SF and its factors with fear of pain and pain catastrophizing, state and trait anxiety, as well as perceived stress (Durand \& Plata, 2017). Chapter 4 investigated the relationship between the TriPM and measures of stigmatization and attribute of characteristics towards psychopaths (Durand, Plata, \& Arbone, 2017). The purpose was to determine if boldness was related to adaptive outcomes, such as fewer stigmatizing attitudes towards others. Chapter 5 also focused on the TriPM, and especially the boldness subscale, and its relation to resilience of childhood traumas (Durand \& de Calheiros Velozo, 2018). Chapter 6 focused on a primary characteristic observed in adaptive psychopathic traits, namely stress resilience, by investigating the relationship between cognitive performances under social stress and its overall moderation by the expression of various genes.

Based upon the results of the precedent chapters, as well as the literature reviews performed for each study, a questionnaire was developed, the Durand Adaptive Psychopathic Traits Questionnaire (DAPTQ), focusing on adaptive traits which have shown an association with the psychopathic personality (Durand, 2017). Chapter 7 details the development of the DAPTQ and provides preliminary results of its construct validity. As mentioned previously, the PPI and the TriPM, while including an adaptive factor, may not cover the wide range of adaptive traits observed in successful psychopaths. In its early development, the DAPTQ was divided in nine factors, namely: Leadership, Logical Thinking, Composure, Creativity, Fearlessness, Money Smart, Focus, Extroversion, and Management. The Chapter 8 focused on supporting the incremental validity of the DAPTQ over the PPI-SF and the TriPM across a wide range of variables typically observed in successful psychopaths, such as conscientiousness (Durand, 2018c). The Chapter 9 focused on developing a translated version of the DAPTQ and confirmed its validity as similar to the DAPTQ - English version (Durand, 2018a). Chapter 10 focuses on examining the association between cognitive abilities, the DAPTQ, and psychopathic traits. Lastly, Chapter 11 summarize the results of all studies and discuss the implications for future research of the findings of these studies. 


\section{Chapter 1 | General Introduction}

\section{References}

Baskin-Sommers, A. R., Zeier, J. D., \& Newman, J. P. (2009). Self-reported attentional control differentiates the major factors of psychopathy. Personality and Individual Differences, 47(6), 626-630.

Berg, J. M., Smith, S. F., Watts, A. L., Ammirati, R., Green, S. E., \& Lilienfeld, S. O. (2013). Misconceptions regarding psychopathic personality: implications for clinical practice and research. Neuropsychiatry, 3, 63-74.

Blagov, P. S., Patrick, C. J., Oost, K. M., Goodman, J. A., \& Pugh, A. T. (2015). Triarchic Psychopathy Measure: Validity in Relation to Normal-Range Traits, Personality Pathology, and Psychological Adjustment. Journal of Personality Disorders, 30(1), 1-11.

Boddy, C. R. (2014). Corporate Psychopaths, Conflict, Employee Affective Well-Being and Counterproductive Work Behaviour. Journal of Business Ethics, 121(1), 107-121.

Camp, J. P., Skeem, J. L., Barchard, K., Lilienfeld, S. O., \& Poythress, N. G. (2013). Psychopathic predators? Getting specific about the relation between psychopathy and violence. Journal of Consulting and Clinical Psychology, 81(3), 467-480.

Cima, M., \& Van Oorsouw, K. (2013). The relationship between psychopathy and crime-related amnesia. International Journal of Law and Psychiatry, 36(1), 2329.

Cleckley, H. (1941). The mask of sanity; an attempt to reinterpret the so-called psychopathic personality. Jama, 117(6), 493.

Cleckley, H. (1988). The Mask of Sanity: An Attempt to Clarify Some Issues About the So Called Psychopathic Personality. (W. a Dolan, Ed.) (5th ed.).

Dindo, L., \& Fowles, D. (2011). Dual temperamental risk factors for psychopathic personality: evidence from self-report and skin conductance. Journal of Personality and Social Psychology, 100(3), 557-566.

Durand, G. (2017). The Durand Adaptive Psychopathic Traits Questionnaire: Development and Validation. Journal of Personality Assessment, 1-10.

Durand, G. (2018a). A French translation and validation of the Durand Adaptive Psychopathic Traits Questionnaire: An investigation with community samples from France and Canada. PLOS ONE, 13(9), e0204214.

Durand, G. (2018b). Demystification of the Relationship Between Psychopathy and Happiness. Journal of Happiness Studies, 19(2), 381-395.

Durand, G. (2018c). Incremental Validity of the Durand Adaptive Psychopathic Traits Questionnaire Above Self-Report Psychopathy Measures in Community Samples. Journal of Personality Assessment, 1-10.

Durand, G., \& de Calheiros Velozo, J. (2018). The interplay of gender, parental behaviors, and child maltreatment in relation to psychopathic traits. Child Abuse \& Neglect, 83(C), 120-128.

Durand, G., \& Plata, E. M. (2017). The effects of psychopathic traits on fear of pain , 
anxiety, and stress. Personality and Individual Differences, 119(C), 198-203.

Durand, G., Plata, E. M., \& Arbone, I.-S. (2017). Negative attitudes towards psychopaths: The role of one's own psychopathic traits. Personality and Individual Differences, 109(C), 72-76.

Gao, Y., Glenn, A. L., Schug, R. a., Yang, Y., \& Raine, A. (2009). The neurobiology of psychopathy: A neurodevelopmental perspective. Canadian Journal of Psychiatry, 54(12), 813-823.

Gao, Y., \& Raine, A. (2010). Successful and Unsuccessful Psychopaths: A Neurobiological Model. Behavioral Sciences \& the Law, 28, 194-210.

Gaughan, E. T., Miller, J. D., \& Lynam, D. R. (2012). Examining the Utility of General Models of Personality in the Study of Psychopathy: A Comparison of the HEXACO-PI-R and NEO PI-R. Journal of Personality Disorders, 26(4), 513-523.

Hall, J., \& Benning, S. (2006). The "successful" psychopath: adaptive and subclinical manifestations of psychopathy in the general population. In C. J. Patrick (Ed.), Handbook of psychopathy (Guilford P, pp. 459-478). NY, USA.

Hall, J., Drislane, L. E., Patrick, C. J., Morano, M., Lilienfeld, S. O., \& Poythress, N. G. (2014). Development and validation of Triarchic Construct Scales from the Psychopathic Personality Inventory. Psychological Assessment, 26(2), 447-61.

Hare, R. D. (2003). The Hare Psychopathy Checklist- Revised. Muliti-Health Systems.

Hare, R. D., \& Neumann, C. S. (2005). Structural models of psychopathy. Current Psychiatry Reports, 7(1), 57-64.

Hicks, B. M., Carlson, M. D., Blonigen, D. M., Patrick, C. J., lacono, W. G., \& MGue, M. (2012). Psychopathic personality traits and environmental contexts: Differential correlates, gender differences, and genetic mediation. Personality Disorders: Theory, Research, and Treatment, 3(3), 209-227.

Hosker-Field, A. M., Molnar, D. S., \& Book, A. S. (2016). Psychopathy and risk taking: Examining the role of risk perception. Personality and Individual Differences, 91, 123-132.

Levenson, M. R., Kiehl, K. A., \& Fitzpatrick, C. M. (1995). Assessing Psychopathic Attributes in a Noninstitutionalized Population. Journal of Personality and Social Psychology, 68(1), 151-158.

Lilienfeld, S. O., Patrick, C. J., Benning, S. D., Berg, J., Sellbom, M., \& Edens, J. F. (2012). The role of fearless dominance in psychopathy: Confusions, controversies, and clarifications. Personality Disorders: Theory, Research, and Treatment, 3(3), 327-340.

Lilienfeld, S. O., Waldman, I. D., Landfield, K., Watts, A. L., Rubenzer, S., \& Faschingbauer, T. R. (2012). Fearless dominance and the U.S. presidency: Implications of psychopathic personality traits for successful and unsuccessful political leadership. Journal of Personality and Social Psychology, 103(3), 489505.

Lilienfeld, S. O., Watts, A. L., \& Smith, S. F. (2015). Successful Psychopathy: A Scientific Status Report. Current Directions in Psychological Science, 24(4), 298-303. 


\section{Chapter 1 | General Introduction}

Lilienfeld, S. O., \& Widows, M. (2005). Psychopathic personality inventory-revised: Professional manual. Lutz, FL: Psychological Assessment Resources.

Love, A. B., \& Holder, M. D. (2014). Psychopathy and subjective well-being. Personality and Individual Differences, 66, 112-117.

Lynam, D. R., \& Miller, J. D. (2012). Fearless dominance and psychopathy: A response to Lilienfeld et al. Personality Disorders: Theory, Research, and Treatment, 3(3), 341-353.

Marcus, D. K., Fulton, J. J., \& Edens, J. F. (2012). The two-factor model of psychopathic personality: Evidence from the Psychopathic Personality Inventory. Personality Disorders: Theory, Research, and Treatment, 3(2), 140-154.

Miller, J. D., \& Lynam, D. R. (2012). An examination of the Psychopathic Personality Inventory's nomological network: A meta-analytic review. Personality Disorders: Theory, Research, and Treatment, 3(3), 305-326.

Miller, J. D., Maples-Keller, J. L., \& Lynam, D. R. (2015). An Examination of the Three Components of the Psychopathic Personality Inventory: Profile Comparisons and Tests of Moderation. Psychological Assessment.

Mullins-Sweatt, S. N., Glover, N. G., Derefinko, K. J., Miller, J. D., \& Widiger, T. a. (2010). The search for the successful psychopath. Journal of Research in Personality, 44(4), 554-558.

Murphy, B., Lilienfeld, S., Skeem, J., \& Edens, J. F. (2016). Are fearless dominance traits superfluous in operationalizing psychopathy? Incremental validity and sex differences. Psychological Assessment, 28(12), 1597-1607.

Newman, J. P., MacCoon, D. G., Vaughn, L. J., \& Sadeh, N. (2005). Validating a distinction between primary and secondary psychopathy with measures of Gray's BIS and BAS constructs. Journal of Abnormal Psychology, 114(2), 319323.

Patrick, C. (2010). Triarchic psychopathy measure (TriPM). PhenX Toolkit Online Assessment Catalog.

Patrick, C. J., Venables, N. C., \& Drislane, L. E. (2013). The role of fearless dominance in differentiating psychopathy from antisocial personality disorder: comment on Marcus, Fulton, and Edens. Personality Disorders, 4(1), 80-2.

Ray, J. V., Weir, J. W., Poythress, N. G., \& Rickelm, A. (2011). Correspondence Between the Psychopathic Personality Inventory and the Psychopathic Personality Inventory-Revised: a Look At Self-Reported Personality Traits. Criminal Justice and Behavior, 38(4), 375-385.

Ross, S. R., Bye, K., Wrobel, T. A., \& Horton, R. S. (2008). Primary and secondary psychopathic characteristics and the schedule for non-adaptive and adaptive personality (SNAP). Personality and Individual Differences, 45(3), 249-254.

Smith, S. F., Watts, A. L., \& Lilienfeld, S. O. (2014). On the trail of the elusive successful psychopath. The Psychologist, 27(7), 506-511.

Takahashi, T., Takagishi, H., Nishinaka, H., Makino, T., \& Fukui, H. (2014). Neuroeconomics of psychopathy: Risk taking in probability discounting of gain and loss predicts psychopathy. Neuroendocrinology Letters, 35(6), 510-517. 


\section{General Introduction | Chapter 1}

Uzieblo, K., Verschuere, B., Van den Bussche, E., \& Crombez, G. (2010). The Validity of the Psychopathic Personality Inventory--Revised in a Community Sample. Assessment, 17(3), 334-346.

Visser, B. a., Ashton, M. C., \& Pozzebon, J. a. (2012). Is Low Anxiety Part of the Psychopathy Construct? Journal of Personality, 80(3), 725-747. 



\section{Chapter 2}

Demystification of the Relationship Between Psychopathy and Happiness

Durand, G. (2018). Demystification of the Relationship Between

Psychopathy and Happiness. Journal of Happiness Studies, 19(2), 381-395. 


\section{Chapter 2 | Psychopathy and Happiness}

\section{Abstract}

Recent findings have provided evidence for a negative correlation between psychopathy and happiness. In order to determine if this correlation is generalizable to all subtypes of psychopathy, participants from the community $(N=572)$ were recruited to examine the association between levels of psychopathic traits by subtypes and happiness-related features among males and females. Examination of the Fearless-Dominance (PPI-I) and ImpulsiveAntisociality (PPI-II) subscales of the Psychopathic Personality InventoryShort Form provided evidence for two distinct patterns when comparing psychopathic personality traits to happiness-related features. Specifically, PPI-I was positively correlated with higher durable happiness, presence of a meaning in life, personal growth and hope, and correlated negatively with fluctuating happiness. In contrast, PPI-II was negatively correlated with durable happiness, presence of a meaning in life, personal growth and hope, and correlated positively with fluctuating happiness and searching for a meaning in life. Despite a few differences, the association between measures of well-being and psychopathic subtypes was similar between genders. The results highlight the importance of performing analyses by psychopathy subtypes, as results in psychopathy can be masked due to the opposite associations observed between psychopathy subtypes and their respective constructs. 


\section{Introduction}

Psychopathy is a personality disorder characterized by antisocial behavior and a wide range of deviant personality traits, including lack of empathy or remorse, callousness, aggressiveness, manipulation, egocentricity and impulsivity (Berg et al. 2013a, b; Perez 2012). While there are no official statistics on the prevalence of psychopathy, it is estimated to be around $1 \%$ in the general population (Cooke 1998). The diagnosis is known to be much more frequent in males than females (Benning et al. 2005a, b; Gao and Raine 2010). Incarcerated psychopaths are commonly guilty of violence, drug usage, domestic abuse and assault (Camp et al. 2013; Hall et al. 2004). Furthermore, psychopathy has until recently been considered untreatable (Patrick et al. 2009). However, examination of previous studies claiming the impossibility of treating psychopaths revealed that none of these studies had a proper research design; hence weakening the notion that psychopathy is untreatable (D'Silva et al. 2004). Preliminary results of recent studies were able to further disprove the impossibility of treating clinically diagnosed psychopaths by the use of schema therapy, which consists of an intensive form of individual psychotherapy combining cognitive, behavioral, and humanistic approaches (Bernstein et al. 2012; Chakhssi et al. 2014).

Although psychopaths are commonly viewed as criminals, Cleckley (1941) introduced the controversial concept of successful psychopaths. Successful psychopaths are individuals who more easily achieve high ranking positions in the society due to their emotional anomalies, such as social charm, low neuroticism, and shallow effect (Coid et al. 2012; Patrick et al. 2009; Sadeh and Verona 2008). In line with this suggestion, empirical evidence from large scale studies (Berg et al. 2013a, b; Gervais et al. 2013; Tonnaer et al. 2013) suggests that psychopathic traits are not dichotomous but rather dimensional in nature. Examples of adaptive psychopathic traits are high pain tolerance (Hare 1965), high interest for seeking rewards (Hare and Thorvaldson 1970), lower fear of pain (Hare 1966), and higher stress immunity (Hare et al. 1978). Such traits allow psychopathic individuals to function better in stressful environments, for example, allowing them to successfully fulfill executive functions in hypercompetitive workplaces.

The difference between a non-successful psychopath and a successful psychopath could be due to the strength of their subtype's expression. Several studies have conceptualized psychopathy as consisting of two major factors: Factor 1 (i.e. primary psychopathy) which represents affective-interpersonal and adaptive features, and Factor 2 (i.e. secondary psychopathy) which represents social deviance and maladaptive features (Benning et al. 2003; Cleckley 1941; Cox et al. 2013; Harpur et al. 1989; Lykken 1995; Ray et al. 
2009). Further studies examined the possibility of dividing both factors in two, creating a four-facet model (Hare and Neumann 2005; Williams et al. 2007). This four-facet model was based on the two factors of the Psychopathy Checklist-Revised (PCL-R), which has typically been used in institutionalized settings (Hare et al. 1990). Other measures of the psychopathic personality, such as the Psychopathic Personality Inventory (PPI), are divided upon a two factors model and are considered reliable to assess psychopathic personality traits within undergraduates and community samples (Lilienfeld and Andrews 1996; Patrick et al. 2009). However, while the second factor, assessing secondary psychopathy or psychopathic traits, from the PCL-R and the PPI are highly correlated to one another, evidences suggest a very low correlation between their primary factors, as they do not assess the same type of primary psychopathic traits (Poythress et al. 2010).

Considering the positive traits of successful psychopaths, along with a lack of remorse and egocentricity, one might propose that these individuals are satisfied and happy with themselves. Results of a recent study (Love and Holder 2014) suggest otherwise. In this study, undergraduate participants completed a number of questionnaires, including the Oxford Happiness Inventory (Francis et al. 1998), the Subjective Happiness Scale (Lyubomirsky 2004) the Levenson Psychopathy Self-Report Scale (Levenson et al. 1995) and the Self-Report Psychopathy Scale (Williams et al. 2007). Correlation analysis of these questionnaires indicated a negative association between psychopathy and subjective well-being, as well as positive affect, happiness, and life satisfaction. The investigators attributed these findings to the poor interpersonal relationships linked with psychopathic traits. However, the authors did not perform separate analyses by psychopathic subtypes or gender, which may have yielded different results (Anestis et al. 2011). Such distinctions are necessary as Factor 1 is associated with low levels of fear and emotional dysregulation, while Factor 2 is associated with impulsivity, anxiety and aggressive behavior (Berg et al. 2013a, b). Individuals higher on Factor 1 are therefore more similar to successful psychopaths and might be happier than individuals higher on Factor 2 traits.

While few studies have investigated well-being-related features in psychopathy, past findings support the notion of a negative correlation between these features and psychopathy. For instance, individuals displaying higher scores on psychopathy scales also show less expression of a meaning in life (Bartels and Pizarro 2011). A strong negative correlation was also found between the expression of callous and unemotional traits and a lack of hope in life (Berg et al. 2013a, b). While these results stem from various studies analyzing several constructs related to psychopathy, no study to our 
knowledge has systematically investigated measures of well-being (i.e. happiness, meaning in life, personal growth, and hope) in relation to the expression of psychopathic personality traits by subtype.

In addition to investigating the role of psychopathic subtypes in well-being, the role of gender was considered because gender differences have been reported in studies of both well-being and psychopathy. Males have been reported to score substantially higher than females on most psychopathic personality assessment scales (Cale and Lilienfeld 2002; Lee and Salekin 2010; Nikolova 2013). However, few of the commonly used instruments to assess psychopathy or psychopathic personality traits assess or interpret results based on gender, creating a potential gender bias (Nikolova 2013). Gender differences are also observed on variables related to psychological well-being (Dambrun 2007; Emslie et al. 2002). Females tend to display higher psychological distress, lower resilience to stressful events, and higher lifetime rates of clinical depression, alongside lower general self-esteem (Dambrun 2007; George et al. 1996; Kudielka and Kirschbaum 2005; Martinez and Dukes 1997). These results highlight the potential gender bias when assessing measures related to well-being in a group of participants without analyzing results by gender.

\section{The Current Study}

The purpose of this study is to examine alternative views between psychopathic personality traits and well-being. Since the majority of earlier studies in the field of psychopathy were performed on inmates (Berg et al. 2013a, b), a strong stigmatizing association developed between criminal offenses and psychopathy, leading to the belief that psychopathy is categorized by negative aspects (Furnham et al. 2009; Vitacco 2007). Therefore, in the present study, positive characteristics, such as happiness, were investigated in a community sample to determine the legitimacy of the relationship between lowered expression of well-being features and the expression of psychopathic personality traits. Given that psychopathy may be conceptualized on a continuum, and most individuals display psychopathic traits to different degrees, this study examined patterns between subtypes of psychopathic personality traits and well-being features as proposed by Love and Holder (2015) and Berg et al. (2013a, b).

The present study investigates the relationship between psychopathic traits and happiness-related characteristics such as durable and fluctuating happiness, meaning in life, personal growth and hope. Durable happiness includes characteristics such as contentment and inner peace. Fluctuating happiness represents sudden increase in happiness, followed by a sudden 
decrease. Meaning in life can be described as the presence of a meaning in life or the search for a meaning in life. Hope includes constructs such as focusing on a goal and planning for a goal. Together, these constructs form an extended range of happiness-related characteristics.

Three hypotheses have been formulated for this study. First, we seek to confirm a gender difference within the PPI-SF and explore potential gender differences within measures of happiness-related features. Second, we expect a positive correlation between the expression of the adaptive component of the psychopathic personality and measures of happiness and well-being. Third, we expect a negative correlation between the expression of the maladaptive component of the psychopathic personality and happinessrelated measures. As different patterns among subtypes and happinessfeatures may arise based on gender, males and females were analyzed independently.

\section{Methods}

\section{Participants}

A total of 597 participants from the general population were recruited and instructed to anonymously fill-in an online questionnaire. Recruitment was performed via social media and websites dedicated to the promotion of psychological studies. The study was advertised with the title "Personality and Attitude Towards Life". Inclusion criteria were formulated to optimize the comparability of our results with previous findings (Lee and Salekin 2010; Lilienfeld et al. 2014). These criteria included an age limit, i.e. between 18 and 40 years, and post high-school education. The final population sample included $55 \%$ males $(N=316)$ and $45 \%$ females $(N=256)$. The mean age of the sample was $24.19(S D=5.28)$. The most common primary language was English (37.4\%), followed by other (26.6\%), German (16.3\%), Dutch (7\%), French $(6.8 \%)$ and Spanish (5.1\%). Considering the highest level of education achieved, participants were mainly attending college (32\%), were college graduates $(27.8 \%)$, other $(17.3 \%)$, master graduates $(14.5 \%)$ or technical school students (5.6\%). Participants were predominantly single $(68.7 \%)$, living with another $(18.9 \%)$ or married $(8.2 \%)$. Participants were mostly located in Europe (58\%), the USA (14.2\%), Asia/Middle East (12.2\%), Africa (4.7\%) and Canada (4.4\%). To account for immigrants who were not native to their thencurrent location, participants' ethnicity was also investigated. The majority of participants were Caucasian (74.3\%), Asian (11.5\%) or Hispanic (7.3\%). A total of $95.1 \%$ of the participants fully completed the study. 


\section{Materials}

\section{Psychopathic Personality Inventory-Short Form (PPI-SF;} Lilienfeld and Widows, 2005)

The PPI-SF is a self-administered questionnaire of 56 items, rated on a 4point Likert-type scale $(1=$ false, $2=$ mostly false, $3=$ mostly true, $4=$ true $)$. It gives a total score and 8 subscale scores using items such as "A lot of people in my life have tried to stab me in the back". The subscales are composed of the 7 most highly correlated items from the Psychopathic Personality Inventory (PPI; Lilienfeld and Andrews 1996): Machiavellian Egocentricity, Social Potency, Fearlessness, Coldheartedness, Impulsive Nonconformity, Blame Externalization, Carefree Nonplanfulness and Stress Immunity. The short form of the PPI has a good correlation with the long version, the Psychopathic Personality Inventory-Revised $(r=.89)$ (Lilienfeld and Widows 2005). The PPI is also considered a reliable measure for assessing psychopathic personality traits in a non-incarcerated population (Kastner et al. 2012; Lee and Salekin 2010). Although the questionnaire does not possess normative scores on its own, a previous study on undergraduate students established an average of 130.56 for males and 121.01 for females (Lee and Salekin 2010).

The PPI consists of two subtypes, namely Fearless-Dominance (PPI-I) and Impulsive-Antisociality (PPI-II) (Benning et al. 2003). PPI-I is composed of the Stress Immunity, Social Potency and Fearlessness subscales, and represents the adaptive nature of the psychopathic personality. Alternatively, PPI-II is composed of the Blame Externalization, Machiavellian Egocentricity, Carefree Nonplanfulness and Impulsive Nonconformity subscales, and represents the maladaptive side of the psychopathic personality. The Coldheartedness subscale does not fall into either of the two aforementioned subtypes. This subtype classification has been used in previous studies (Benning et al. 2005a, b; Berardino et al. 2005; Patrick et al. 2006).

\section{Subjective Fluctuating Happiness Scale and Subjective Authentic-Durable Happiness Scale (SFHS and SA-DHS; Dambrun et al., 2012)}

The 10-item SFHS and the 13-item SA-DHS assess two components of happiness: the fluctuation of happiness traits from time to time, and the stable happiness state of an individual. Fluctuation in traits as measured with the SFHS refers to the degree of change in happiness over time and how an individual can become happy in certain situations using items such as "I have often known periods of euphoria, but they are almost always followed by much less exciting periods". Stable-state happiness, as measured with the SA-DHS, 
refers to the baseline level of happiness of an individual and how this happiness enables the individual to cope with life in general using items such as "In your life, what is your regular level of pleasure". Items for the two questionnaires are rated on a 7-point Likert-type scale. Cronbach's alpha for the SFHS ranges from .85 to .92 depending on the sample. The SA-DHS also has a high internal consistency that ranges from .87 to .95 , depending on the sample. During the development of the questionnaires, means were computed for both scales, with an average of 3.78 for the SFHS and 4.33 for the SADHS.

\section{Meaning in Life Questionnaire (MLQ; Steger et al., 2006)}

The MLQ is a 10-item self-report measure that assesses the presence and search for a meaning in life. It is rated on a 7-point Likert-type scale, ranging from Absolutely Untrue to Absolutely True. The subscale of Presence is composed of fives items such as "I have a good sense of what makes my life meaningful" and "I have discovered a satisfying life purpose". The subscale of Search is also composed of five items, such as "I am looking for something that makes my life feel meaningful" and "I am searching for meaning in my life". Both subscales show good internal consistency ( $\alpha=.90$ and $\alpha=.87$ ). The average of the final group during the development of the questionnaire established a normative mean of 23.8 for the Presence subscale and 23.4 for the Search subscale.

\section{Personal Growth Initiative Scale (PGIS; Robitschek, 1998)}

The PGIS is a 9-item self-report measure assessing the motivation of an individual to change and develop as a person, using items such as "I have a good sense of where I am headed in my life". The items are rated on a 6-point Likert-type scale, ranging from Definitely Disagree to Definitely Agree. Cronbach's alpha ranges from .78 to .90 , and has proven reliable convergent and discriminant validity, along with adequate test/retest reliability (Robitschek 1998; Shorey et al. 2007). Means at 1-, 4-and 8-week test-retest during the development of the questionnaire ranged from 31.33 to 33.13 .

\section{Adult Hope Scale (AHS; Snyder et al., 1991)}

The AHS is a 12-item self-report measure with 4 items assessing agency (e.g.: I energetically pursue my goals), 4 items assessing pathways (e.g.: There are lots of ways around any problem.), and 4 items acting as distracters (e.g.: I feel tired most of the time.). This questionnaire measures Snyder's cognitive model of hope focusing on agency (directing energy towards a goal) and pathways (planning to meet goals). The responses available range from $1=$ 
Definitely False to $8=$ Definitely True. Its internal consistency range is from .74 to .84 and has been used in undergraduate samples and adult community populations (Shorey et al. 2007; Snyder et al. 1991).

\section{Procedures}

Written information about the procedure and goals of the study was given at the beginning. The participant then provided informed consent and completed the questionnaires. Upon completion, participants received a full debriefing, explaining that the personality traits researched are antisocial traits correlated with happiness related measures. At the end of the experiment, participants were informed they could register their e-mail address to participate in a lottery where they could win 100 Euros. Ethics approval was obtained from the Psychology Ethics Committee of Maastricht University, case number: 156-0209-2015.

\section{Statistical Analyses}

In order to account for potential unreliable data, which can arise within online studies in the community, a Variable Response Inconsistency (VRIN) procedure was implemented. This procedure identifies the 10 pairs of items from the PPI-SF with the highest correlation among them (Tellegen 1982). Twenty-five outliers with a total VRIN $\geq 8$ were identified and excluded from the study, leaving 572 participants for the main analyses. There were no missing answers within each respective questionnaire for every participant. Examination of the Skewness range (-.829 to .214$)$ confirmed the presence of a normal distribution within all questionnaires and subscales.

The analyses were performed using the statistical package SPSS version 21.00. Analyses of variance (ANOVA) were computed in order to assess gender differences between all the questionnaires. Bivariate Pearson correlations (two-tailed) were then conducted between each dependent variable. Due to anticipated gender differences, analyses were performed separately for males and females.

\section{Results}

\section{General Descriptive Results and Gender Differences}

The descriptive data of all questionnaires, as well as the internal consistency reliability and effect sizes by gender, are reported in Table 1. Several significant differences were found between males and females regarding psychopathic personality traits and measures of happiness features. First, males scored higher on the PPI-SF total $[F(1,570)=24.75, p<.001]$, on PPII $[F(1,570)=22.88, p<.001]$, and several subscales: Machiavellian 
Egocentricity $[F(1,570)=7.34, p=.007]$, Fearlessness $[F(1,570)=25.60, p$ $<.001]$, Coldheartedness $[F(1,570)=7.55, p=.006]$, Impulsivity Nonconformity $[F(1,570)=8.99, p=.003]$ and Stress Immunity $[F(1,570)=$ 28.11, $p<.001]$. Males also scored significantly higher on the Inner Peace component of the Durable Happiness Scale $[F(1,568)=10.77, p=.001]$, while females scored higher on the general Fluctuating Happiness Scale $[F(1,569)$ $=12.90, p<.001]$. One more gender difference was found in the AHS, where males scored significantly higher on the Pathway component $[F(1,542)=$ $13.40, p<.001]$.

\section{Main Analysis Males}

Correlations between the PPI-SF and its subscales and the happiness-related measures can be found in Table 2. Examination of the PPI-SF total score does not show any correlation between the expression of psychopathic personality traits and happiness or meaning in life. However, weak positive correlations were found on the PGIS $(r=.14)$, AHS $(r=.20)$, and the pathway subscale $(r$ $=.28$ ). Closer examination of the PPI-SF subscales reveals two distinct tendencies. PPI-I has a weak to moderate positive correlation with all measures of durable happiness $(r=.27$ to .36$)$ and a weak negative correlation with fluctuating happiness $(r=-.21)$. Moderate positive correlations are also found on the MLQ presence subscale $(r=.31)$, the PGIS $(r=.43)$, and all measures of hope $(r=.42$ to .49$)$. The opposite trend is found in PPI-II on almost all measurements. PPI-Il yields weak to moderate negative correlations with all measures of durable happiness $(r=-.28$ to -.32$)$ but shows a moderate positive correlation to fluctuating happiness $(r=.44)$. PPIII displays a weak negative correlation with the presence of a meaning in life $(r=-.21)$ and a weak positive correlation with the search of a meaning in life $(r=.21)$. PPI-II also has a weak negative correlation with the PGIS $(r=-.21)$, the AHS total $(r=-.17)$, and the agency subscale $(r=-.23)$. 


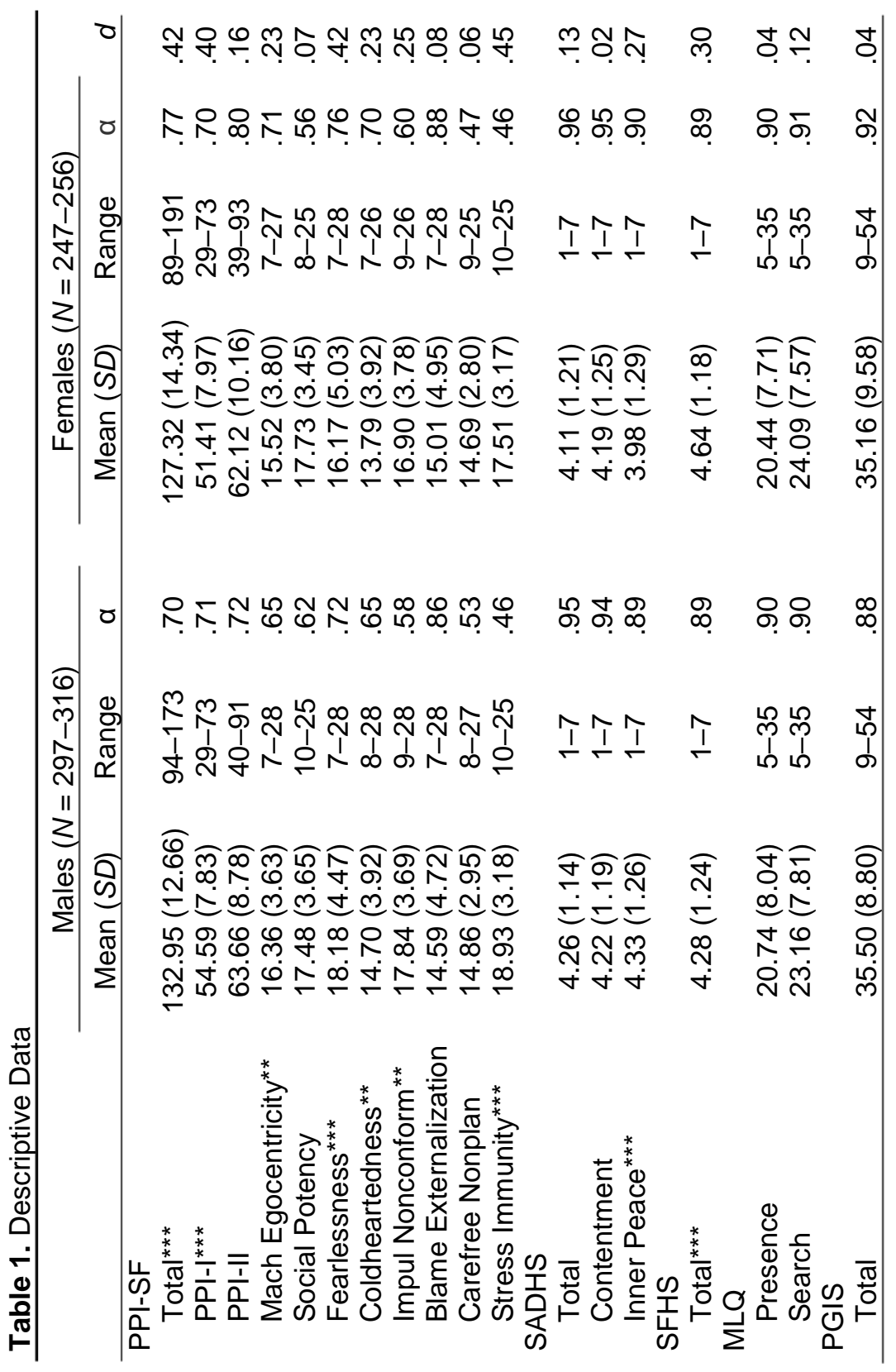




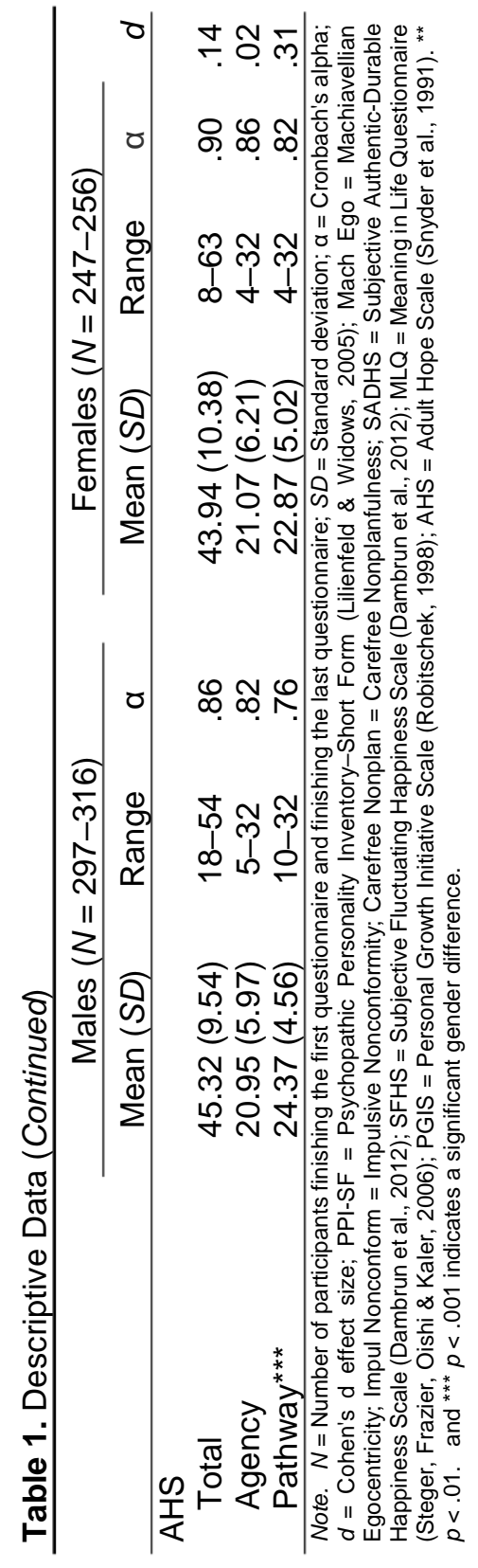


Table 2. Correlations between psychopathic personality traits and happiness related features in males

\begin{tabular}{llll}
\hline Scales & PPI-SF Total & PPI-I & PPI-II \\
\hline SADHS Total $(N=314)$ & .01 & $.35^{\star *}$ & $-.32^{\star *}$ \\
Contentment $(N=314)$ & .02 & $.36^{* *}$ & $-.32^{* *}$ \\
Inner Peace $(N=314)$ & .00 & $.27^{* *}$ & $-.28^{\star *}$ \\
SFHS Total $(N=315)$ & .06 & $-.21^{* *}$ & $.44^{* *}$ \\
MLQ-Presence $(N=311)$ & .04 & $.31^{* *}$ & $-.21^{\star *}$ \\
MLQ-Search $(N=311)$ & .07 & -.03 & $.21^{* *}$ \\
PGIS Total $(N=305)$ & $.14^{*}$ & $.43^{* *}$ & $-.21^{\star *}$ \\
AHS Total $(N=297)$ & $.20^{* *}$ & $.49^{* *}$ & $-.17^{\star *}$ \\
Agency $(N=297)$ & .10 & $.42^{* *}$ & $-.23^{\star *}$ \\
Pathway $(N=297)$ & $.28^{* *}$ & $.47^{* *}$ & -.05 \\
\hline
\end{tabular}

Note. Pearson bivariate correlation, two-tailed, cases excluded pairwise. $N=$ number of participants who completed the respective questionnaire. PPI-SF $=$ Psychopathic Personality Inventory-Short Form (Lilienfeld \& Widows, 2005); SADHS = Subjective Authentic-Durable Happiness Scale (Dambrun et al., 2012); SFHS = Subjective Fluctuating Happiness Scale (Dambrun et al., 2012); MLQ = Meaning in Life Questionnaire (Steger, Frazier, Oishi \& Kaler, 2006); PGIS = Personal Growth Initiative Scale (Robitschek, 1998); AHS = Adult Hope Scale (Snyder et al., 1991). ${ }^{*} p<.05,{ }^{* \star} p<.01$

\section{Main Analysis Females}

Correlations between the PPI-SF and its subscales to happiness-related features can be found in Table 3. The PPI-SF total shows a weak negative correlation with the SADHS total $(r=-.15)$ and the contentment subscale $(r=$ $-.17)$, but displays a weak positive correlation with the SFHS $(r=.20)$. The PPI-SF total is weakly negatively correlated with the presence of a meaning in life $(r=-.13)$ and has a weak positive correlation with the pathway subscale of the AHS $(r=.13)$. Examination of PPI-SF subtypes reveals similar results to those obtained for males. Indeed, PPI-I shows weak positive correlations with all measures of durable happiness $(r=.20$ to .21$)$ and a weak negative correlation to fluctuating happiness $(r=-.15)$. PPI-I is also weakly correlated with the presence of a meaning in life $(r=.24)$ and moderately correlated with personal growth $(r=.35)$, as well as with all measures of hope $(r=.35$ to .44$)$. Opposite results are once again found for the PPI-II subscale. PPI-II shows a moderate negative correlation to all measures of durable happiness $(r=-.32$ to -.42$)$, but is strongly correlated with fluctuating happiness $(r=.50)$. It also displays a moderate negative correlation to the presence of a meaning in life $(r=-.39)$ and a weak positive correlation to the search subscale of the MLQ $(r=.27)$. PPI-II shows a moderate negative correlation with personal growth 
$(r=-.33)$, and weak to moderate negative correlations with all measures of hope $(r=-.20$ to -.33$)$.

Table 3. Correlations between psychopathic personality and happiness related features in females

\begin{tabular}{|c|c|c|c|}
\hline Scales & PPI-SF Total & PPI-I & PPI-II \\
\hline SADHS Total $(N=256)$ & $-.15^{\star}$ & $.21^{* *}$ & $-.40^{* *}$ \\
\hline Contentment $(N=256)$ & $-.17^{\star *}$ & $.20^{* *}$ & $-.42^{\star *}$ \\
\hline Inner Peace $(N=256)$ & -.09 & $.21^{* *}$ & $-.32^{\star *}$ \\
\hline SFHS Total $(N=256)$ & $.20^{\star *}$ & $-.15^{\star}$ & $.50^{* *}$ \\
\hline MLQ-Presence $(N=253)$ & $-.13^{*}$ & $.24^{* *}$ & $-.39^{* *}$ \\
\hline MLQ-Search $(N=253)$ & .07 & -.08 & $.27^{* *}$ \\
\hline PGIS Total $(N=249)$ & -.02 & $.35^{\star *}$ & $-.33^{* *}$ \\
\hline AHS Total $(N=247)$ & .05 & $.42^{* *}$ & $-.29^{* *}$ \\
\hline Agency $(N=247)$ & -.02 & $.35^{\star \star}$ & $-.33^{\star *}$ \\
\hline Pathway $(N=247)$ & $.13^{*}$ & $.44^{\star *}$ & $-.20^{\star *}$ \\
\hline
\end{tabular}

\section{Discussion}

The present study sought to confirm the gender differences within the PPI-SF and happiness-related features, and also to determine if the expression of psychopathic personality traits is negatively correlated to measures of wellbeing and happiness. Gender differences were found on the PPI-SF total score, on multiple PPI-SF subscales, and on various measures of well-being. Furthermore, as expected, PPI-I was positively correlated to all measures with the exception of fluctuating happiness, with which PPI-I showed a negative correlation, and searching for a meaning in life, with which PPI-I showed no correlation. PPI-II displayed the opposite pattern, where all measures but two were negatively correlated to this subtype, with the exception of a positive correlation with fluctuating happiness and a search for a meaning in life. Indeed, beside an absence of correlation between the pathway subscale and PPI-II within males, both genders displayed similar correlations with regards to PPI-I and PPI-II. However, examination of the PPI-SF total score revealed a few differences between genders in relation to correlations with happinessrelated features. Males did not display any correlation between the PPI-SF 
and happiness features, except personal growth, hope, and planning to meet goals. Females displayed negative correlations between the PPI-SF and durable happiness, contentment, and presence of a meaning in life, as well as a positive correlation with fluctuating happiness and planning to meet goals. The findings of this community-based study hence emphasize the importance of conducting analyses in the field of psychopathy by subtypes and gender.

Consistent with previous findings, males scored higher than females on the PPI-SF and several of its subscales (Cale and Lilienfeld 2002; Hicks et al. 2012; Lee and Salekin 2010). The reason behind the difference of psychopathic personality trait scores is not well established, although several hypotheses have been promoted. Several questionnaires assessing psychopathy and/or psychopathic personality traits focus on physical aggression and physical activities, which might be more typical of males, rather than indirect aggression and less physical activities, which may be more typical of females (Grann 2000; Vitale et al. 2002). Indeed, items of the PPISF such as "If I were a fire-fighter, I think I might actually enjoy the excitement of trying to rescue someone from the top floor of a burning building" explores a situation involving high-risk physical action, which may create a bias towards males scores. Alternatively, these differences might be caused from unknown genetic or environmental gender influences (Berg et al. 2013a, b).

Gender differences were also observed on three scales related to wellbeing. Males scored significantly higher than females on the inner peace subscale of the SADHS and pathway component of the AHS, while females displayed higher levels of fluctuating happiness than males. Previous studies have found a higher level of psychological distress, anxiety and stress in females than males (Dambrun 2007; Emslie et al. 2002). Males' lower scores in the fluctuating happiness scale might indicate that they have better emotional control than females. A meta-analytic review on emotional expression in children concluded that, while males tend to express more externalizing emotions (such as anger) than females at a young age, in adolescence this pattern changes so that females express more externalizing emotions than males (Chaplin and Aldao 2013). It is possible that this difference in the emotional profiles of males and females remains during adulthood, explaining the higher fluctuation in happiness and lower inner peace and goal planning within females.

While the strength of the correlations between the PPI-SF subtypes and happiness features differed slightly by gender, both males and females displayed a very similar pattern in psychopathic traits subtypes and well-being measurements. The correlations between PPI-I and happiness features supports the notion of successful psychopathy. Indeed, PPI-l's positive 
correlation with durable happiness and negative correlation with fluctuating happiness supports the alleged emotional control of Factor 1 psychopathic individuals (Berg et al. 2013a, b; Patrick et al. 2009; Witt et al. 2009). Furthermore, the correlation between PPI-I and the presence of a meaning in life, personal growth, hope, and goal-related behaviours further emphasize the benefits of Factor 1 psychopathic traits. It is possible that the psychopathic traits related to Factor 1 of the PPI-SF, such as social potency and extroversion, contribute to a higher degree of self-esteem and hence, wellbeing (Lilienfeld et al. 2012). The nature of attachment among those with elevated psychopathic traits may also play a role. A previous communitybased investigation assessing the relationship between attachment anxiety and happiness in adults supports a negative correlation $(r=-.39)$ between the two constructs (Wei et al. 2011). While psychopathic individuals might display a more superficial type of attachment, the primary psychopathy traits related to lower anxiety and higher social potency might be due to a general notion of reduced attachment anxiety, which is consistent with higher degrees of happiness and well-being.

While the aforementioned results are not consistent with the previously reported negative association between psychopathic personality traits and well-being, the results from PPI-II and measures of well-being support the negative correlations reported in psychopathic individuals (Love and Holder 2014). The negative correlation of PPI-II with durable happiness and positive correlation with fluctuating happiness is consistent with the notion of emotional instability reported in secondary psychopathy (Douglas et al. 2012; Patrick et al. 2009). Furthermore, while the lack of a meaning in life can reflect an overall lower sense of well-being, the search for a meaning in life is unexpected. Secondary psychopathy has been linked to several maladaptive constructs such as reactive aggression, impulsiveness and temperamentality (Benning et al. 2005a, b; Berg et al. 2013a, b). The search for a meaning in life can indicate that individuals with high levels of PPI-II traits desire to seek more happiness in life. Once again, while females showed a negative correlation between PPI-II and the pathway component that males did not, results of both genders show the same negative pattern between PPI-II and measures of happiness, meaning in life, personal growth and hope.

\section{Conclusion}

This study comprehensively investigated constructs of happiness and related emotions in regard to gender and psychopathic traits. These findings emphasize the importance of performing separate analyses by gender and by psychopathy subtypes in order to fully comprehend the different emotional 
trends related to the expression of psychopathic traits. These findings support the importance of considering psychopathy a dimensional construct as opposed to a categorical one. The results demonstrate that a higher expression of PPI-I related traits correlate with several adaptive features in terms of happiness-related emotional constructs, whereas a higher expression of PPI-II related traits correlate with several maladaptive characteristics.

This study was designed to include previous recommendations in the field of psychopathy and happiness, most notably by performing analyses by gender and psychopathic subtype on individuals from the community (Love and Holder 2014, 2015). Despite these improvements, this study was nevertheless limited in a few respects. First, an online self-report questionnaire was used. While self-report measurements are commonly used, clinical and experimental evaluation might give better results. Also, only one method for evaluating the psychopathic personality was used. While the PPISF is a widely used instrument, other questionnaires for assessing psychopathic traits, such as the Levenson Self-Report Psychopathy Scale, the Triarchic Psychopathy Measure, and the Short-Dark Triad could provide further information with regards to the correlation between psychopathy and happiness (Jones and Paulhus 2014; Levenson et al. 1995; Patrick 2010). Finally, the present study does not examine psychopathy itself, but the expression of psychopathic personality traits. Replicating this study on clinically diagnosed psychopaths, by the use of the PCL-R, could allow a better understanding of the relationship between psychopathy and happiness.

Although these results are promising, they need to be replicated in an experimental setting in order to assess their validity. Nevertheless, this study presents the first attempt to investigate happiness, hope, personal growth, and meaning in life by both gender and psychopathic factors. Examination of the results clearly shows that levels of happiness vary greatly between individuals. Fortunately, improving one's happiness is within everyone's reach and can be done in multiple ways, such as improving health-related behavior, engaging in physical activities, and increasing socialization (Veenhoven 2008). 


\section{References}

Anestis, J. C., Caron, K. M., \& Carbonell, J. L. (2011). Examining the impact of gender on the factor structure of the Psychopathic Personality Inventory-Revised. Assessment, 18(3), 340-9.

Bartels, D. M., \& Pizarro, D. A. (2011). The mismeasure of morals: Antisocial personality traits predict utilitarian responses to moral dilemmas. Cognition, 121(1), 154-161.

Benning, S. D., Patrick, C. J., Blonigen, D. M., Hicks, B. M., \& lacono, W. G. (2005). Estimating facets of psychopathy from normal personality traits: a step toward community epidemiological investigations. Assessment, 12(1), 3-18.

Benning, S. D., Patrick, C. J., Hicks, B. M., Blonigen, D. M., \& Krueger, R. F. (2003). Factor structure of the psychopathic personality inventory: validity and implications for clinical assessment. Psychological Assessment, 15(3), 340-350.

Benning, S. D., Patrick, C. J., Salekin, R. T., \& Leistico, A.-M. R. (2005). Convergent and discriminant validity of psychopathy factors assessed via self-report: a comparison of three instruments. Assessment, 12(3), 270-289.

Berardino, S. D., Meloy, J. R., Sherman, M., Jacobs, D., Berrardino, S. D., Meloy, J. R., ... Jacobs, D. (2005). Validation of the psychopathic personality inventory on a female inmate sample. Behavioral Sciences and the Law, 23(6), 819-836.

Berg, J. M., Lilienfeld, S. O., Reddy, S. D., Latzman, R. D., Roose, A., Craighead, L. W., ... Raison, C. L. (2013). The Inventory of Callous and Unemotional Traits: A Construct-Validational Analysis in an At-Risk Sample. Assessment, 20(5), 532544.

Berg, J. M., Smith, S. F., Watts, A. L., Ammirati, R., Green, S. E., \& Lilienfeld, S. O. (2013). Misconceptions regarding psychopathic personality: implications for clinical practice and research. Neuropsychiatry, 3, 63-74.

Bernstein, D. P., Nijman, H. L. I., Karos, K., Keulen-de Vos, M., de Vogel, V., \& Lucker, T. P. (2012). Schema Therapy for Forensic Patients with Personality Disorders: Design and Preliminary Findings of a Multicenter Randomized Clinical Trial in the Netherlands. International Journal of Forensic Mental Health, 11, 312-324.

Cale, E. M., \& Lilienfeld, S. O. (2002). Sex differences in psychopathy and antisocial personality disorder: A review and integration. Clinical Psychology Review.

Camp, J. P., Skeem, J. L., Barchard, K., Lilienfeld, S. O., \& Poythress, N. G. (2013). Psychopathic predators? Getting specific about the relation between psychopathy and violence. Journal of Consulting and Clinical Psychology, 81(3), 467-480.

Chakhssi, F., Kersten, T., de Ruiter, C., \& Bernstein, D. P. (2014). Treating the untreatable: A single case study of a psychopathic inpatient treated with Schema Therapy. Psychotherapy (Chicago, III.), 51(3), 447-61.

Chaplin, T. M., \& Aldao, A. (2013). Gender differences in emotion expression in children: a meta-analytic review. Psychological Bulletin, 139(4), 735-65.

Cleckley, H. (1941). The mask of sanity; an attempt to reinterpret the so-called psychopathic personality. Jama, 117(6), 493.

Coid, J., Freestone, M., \& Ullrich, S. (2012). Subtypes of psychopathy in the British household population: Findings from the national household survey of 
psychiatric morbidity. Social Psychiatry and Psychiatric Epidemiology, 47(6), 879-891.

Cooke, D. J. (1998). Cross-cultural aspects of psychopathy. Psychopathy: Antisocial, criminal, and violent behavior, 260-276.

Cox, J., Edens, J. F., Magyar, M. S., Lilienfeld, S. O., Douglas, K. S., \& Poythress, N. G. (2013). Using the Psychopathic Personality Inventory to identify subtypes of antisocial personality disorder. Journal of Criminal Justice, 41(2), 125-134.

D'Silva, K., Duggan, C., \& McCarthy, L. (2004). Does treatment really make psychopaths worse? A review of the evidence. Journal of Personality Disorders, 18(2), 163-177.

Dambrun, M. (2007). Gender differences in mental health: The mediating role of perceived personal discrimination. Journal of Applied Social Psychology, 37(5), 1118-1129.

Dambrun, M., Ricard, M., Després, G., Drelon, E., Gibelin, E., Gibelin, M., ... \& Bray, E. (2012). Measuring happiness: from fluctuating happiness to authenticdurable happiness. Frontiers in psychology, 3.

Douglas, H., Bore, M., \& Munro, D. (2012). Distinguishing the Dark Triad: Evidence from the Five-Factor Model and the Hogan Development Survey. Psychology, 03(03), 237-242.

Emslie, C., Fuhrer, R., Hunt, K., Maclntyre, S., Shipley, M., \& Stansfeld, S. (2002). Gender differences in mental health: Evidence from three organisations. Social Science and Medicine, 54(4), 621-624.

Francis, L. J., Brown, L. B., Lester, D., \& Philipchalk, R. (1998). Happiness as stable extraversion: A cross-cultural examination of the reliability and validity of the Oxford Happiness Inventory among students in the U.K., U.S.A., Australia, and Canada. Personality and Individual Differences, 24(2), 167-171.

Furnham, A., Daoud, Y., \& Swami, V. (2009). "How to spot a psychopath." Social Psychiatry and Psychiatric Epidemiology, 44(6), 464-472.

Gao, Y., \& Raine, A. (2010). Successful and Unsuccessful Psychopaths: A Neurobiological Model. Behavioral Sciences \& the Law, 28, 194-210.

George, M. S., Ketter, T. A., Parekh, P. I., Herscovitch, P., \& Post, R. M. (1996). Gender differences in regional cerebral blood flow during transient self-induced sadness or happiness. Biological Psychiatry, 40(9), 859-871.

Gervais, M. M., Kline, M. A., Ludmer, M., George, R., \& Manson, J. H. (2013). The strategy of psychopathy: primary psychopathic traits predict defection on lowvalue relationships. Proceedings of the Royal Society - Biological Sciences, 280(February), 20122773.

Grann, M. (2000). The PCL-R and Gender. European Journal of Psychological Assessment, 16(3), 147-149.

Hall, J., Benning, S. D., \& Patrick, C. J. (2004). Criterion-Related Validity of the ThreeFactor Model of Psychopathy: Personality, Behavior, and Adaptive Functioning. Assessment, 11(1), 4-16.

Hare, R. D. (1965). Psychopathy, Fear Arousal and Anticipated Pain. Psychological Reports, 16, 499-502. 


\section{Chapter 2 | Psychopathy and Happiness}

Hare, R. D. (1966). Psychopathy and choice of immediate versus delayed punishment. Journal of Abnormal Psychology, 71, 25-29.

Hare, R. D., Frazelle, J., \& Cox, D. N. (1978). Psychopathy and physiological responses to threat of an aversive stimulus. Psychophysiology, 15(2), 165-172.

Hare, R. D., Harpur, T. J., Hakstian, A. R., Forth, A. E., \& et al. (1990). The revised Psychopathy Checklist: Reliability and factor structure. Psychological Assessment.

Hare, R. D., \& Neumann, C. S. (2005). Structural models of psychopathy. Current Psychiatry Reports, 7(1), 57-64.

Hare, R. D., \& Thorvaldson, S. A. (1970). Psychopathy and response to electrical stimulation. Journal of Abnormal Psychology, 76, 370-374.

Harpur, T. J., Hare, R. D., \& Hakstian, A. R. (1989). Two-factor conceptualization of psychopathy: Construct validity and assessment implications. Psychological Assessment, 1, 6-17.

Hicks, B. M., Carlson, M. D., Blonigen, D. M., Patrick, C. J., lacono, W. G., \& MGue, M. (2012). Psychopathic personality traits and environmental contexts: Differential correlates, gender differences, and genetic mediation. Personality Disorders: Theory, Research, and Treatment, 3(3), 209-227.

Jones, D. N., \& Paulhus, D. L. (2014). Introducing the Short Dark Triad (SD3) A Brief Measure of Dark Personality Traits. Assessment, 21(1), 28-41.

Kastner, R. M., Sellbom, M., \& Lilienfeld, S. O. (2012). A comparison of the psychometric properties of the psychopathic personality inventory full-length and short-form versions. Psychological Assessment, 24(1), 261-267.

Kudielka, B. M., \& Kirschbaum, C. (2005). Sex differences in HPA axis responses to stress: A review. Biological Psychology, 69(1), 113-132.

Lee, Z., \& Salekin, R. T. (2010). Psychopathy in a noninstitutional sample: Differences in primary and secondary subtypes. Personality Disorders: Theory, Research, and Treatment, 1(3), 153-169.

Levenson, M. R., Kiehl, K. A., \& Fitzpatrick, C. M. (1995). Assessing Psychopathic Attributes in a Noninstitutionalized Population. Journal of Personality and Social Psychology, 68(1), 151-158.

Lilienfeld, S., Latzman, R. D., Watts, A. L., Smith, S. F., \& Dutton, K. (2014). Correlates of psychopathic personality traits in everyday life: Results from a large community survey. Frontiers in Psychology, 5, 1-11.

Lilienfeld, S. O., \& Andrews, B. P. (1996). Development and Preliminary Validation of a Self-Report Measure of Psychopathic Personality Traits in Noncriminal Populations. Journal of Personality Assessment, 66(3), 488-524.

Lilienfeld, S. O., Waldman, I. D., Landfield, K., Watts, A. L., Rubenzer, S., \& Faschingbauer, T. R. (2012). Fearless dominance and the U.S. presidency: Implications of psychopathic personality traits for successful and unsuccessful political leadership. Journal of Personality and Social Psychology, 103(3), 489505.

Lilienfeld, S., \& Widows, M. (2005). Psychopathic personality inventory-revised: Professional manual. Lutz, FL: Psychological Assessment Resources. 
Love, A. B., \& Holder, M. D. (2014). Psychopathy and subjective well-being. Personality and Individual Differences, 66(June), 112-117.

Love, A. B., \& Holder, M. D. (2015). Can Romantic Relationship Quality Mediate the Relation Between Psychopathy and Subjective Well-Being? Journal of Happiness Studies, 1-23.

Lykken, D. (1995). The antisocial personalities. Psychology Press.

Lyubomirsky, S. (2004). Subjective Happiness Scale ( SHS ), 51(10), 7-7.

Martinez, R. O., \& Dukes, R. L. (1997). The effects of ethnic identity, ethnicity, and gender on adolescent well-being. Journal of Youth and Adolescence, 26(5), 503-516.

Nikolova, N. L. (2013). The Psychopathic Personality Inventory-Revised: Evaluation of Its Psychometric Properties , Incremental Validity , and Moderating Effects of Gender in a Correctional Sample. Simon Fraser University.

Patrick, C. (2010). Triarchic psychopathy measure (TriPM). PhenX Toolkit Online Assessment Catalog.

Patrick, C. J., Edens, J. F., Poythress, N. G., Lilienfeld, S. O., \& Benning, S. D. (2006). Construct validity of the psychopathic personality inventory two-factor model with offenders. Psychological Assessment, 18(2), 204-208.

Patrick, C. J., Fowles, D. C., \& Krueger, R. F. (2009). Triarchic conceptualization of psychopathy: Developmental origins of disinhibition, boldness, and meanness. Development and Psychopathology, 21(03), 913.

Perez, P. R. (2012). The etiology of psychopathy: A neuropsychological perspective. Aggression and Violent Behavior, 17(6), 519-522.

Poythress, N. G., Lilienfeld, S. O., Skeem, J. L., Douglas, K. S., Edens, J. F., Epstein, M., \& Patrick, C. J. (2010). Using the PCL-R to help estimate the validity of two self-report measures of psychopathy with offenders. Assessment, 17(2), 206219.

Ray, J. V., Poythress, N. G., Weir, J. M., \& Rickelm, A. (2009). Relationships between psychopathy and impulsivity in the domain of self-reported personality features. Personality and Individual Differences, 46(2), 83-87.

Robitschek, C. (1998). Personal growth initiative: The construct and its measure. Measurement \& Evaluation in Counseling \& Development (American Counseling Association), 30(4), 183.

Sadeh, N., \& Verona, E. (2008). Psychopathic personality traits associated with abnormal selective attention and impaired cognitive control. Neuropsychology, 22(5), 669-680.

Shorey, H. S., Little, T. D., Snyder, C. R., Kluck, B., \& Robitschek, C. (2007). Hope and personal growth initiative: A comparison of positive, future-oriented constructs. Personality and Individual Differences, 43(7), 1917-1926.

Snyder, C. R., Harris, C., Anderson, J. R., Holleran, S. A, Irving, L. M., Sigmon, S. T., ... Harney, P. (1991). The will and the ways: development and validation of an individual-differences measure of hope. Journal of Personality and Social Psychology, 60(4), 570-585. 


\section{Chapter 2 | Psychopathy and Happiness}

Steger, M. F., Frazier, P., Oishi, S., \& Kaler, M. (2006). The meaning in life questionnaire: Assessing the presence of and search for meaning in life. Journal of Counseling Psychology, 53(1), 80-93.

Steger, M. F., Kashdan, T. B., Sullivan, B. A., \& Lorentz, D. (2008). Understanding the search for meaning in life: Personality, cognitive style, and the dynamic between seeking and experiencing meaning. Journal of Personality, 76(2), 199-228.

Tellegen, A. (1982). Brief Manual for the Differential Personality Questionnaire. Unpublished Manuscript, 1010-1031.

Tonnaer, F., Cima, M., Sijtsma, K., Uzieblo, K., \& Lilienfeld, S. O. (2013). Screening for psychopathy: Validation of the psychopathic personality inventory-short form with reference scores. Journal of Psychopathology and Behavioral Assessment, 35(2), 153-161.

Veenhoven, R. (2008). Healthy happiness: effects of happiness on physical health and the consequences for preventive health care. Journal of Happiness Studies, 9(3), 449-469.

Vitacco, M. J. (2007). Handbook of Psychopathy. Psychiatric Services (Vol. 58).

Vitale, J. E., Smith, S. S., Brinkley, C. A., \& Newman, J. P. (2002). The Reliability and Validity of the Psychopathy Checklist-Revised in a Sample of Female Offenders. Criminal Justice and Behavior, 29(2), 202-231.

Wei, M., Liao, K. Y. H., Ku, T. Y., \& Shaffer, P. A. (2011). Attachment, Self-Compassion, Empathy, and Subjective Well-Being Among College Students and Community Adults. Journal of Personality, 79(1), 191-221.

Williams, K. M., Paulhus, D. L., \& Hare, R. D. (2007). Capturing the four-factor structure of psychopathy in college students via self-report. Journal of Personality Assessment, 88(2), 205-19.

Witt, E. A, Donnellan, M. B., Blonigen, D. M., Krueger, R. F., \& Conger, R. D. (2009). Assessment of Fearless Dominance and Impulsive Antisociality via normal personality measures: convergent validity, criterion validity, and developmental change. Journal of Personality Assessment, 91(3), 265-276. 




\section{Chapter 3}

The Effects of Psychopathic Traits on Fear of Pain, Anxiety, and Stress

Durand, G., \& Plata, E. M. (2017). The effects of psychopathic traits on fear of pain, anxiety, and stress. Personality and Individual Differences, 119(C), 198-203. 


\section{Chapter 3 | Psychopathy and Fear of Pain}

\section{Abstract}

The relationship between psychopathy and internalizing behaviours, such as fear of pain, anxiety, and stress, is highly debated due to conflicting results found across a wide array of studies. We hypothesized that the two factors of the Psychopathic Personality Inventory would correlate to measures of fer of pain, anxiety, and stress in opposite directions, whereas the aforementioned constructs would be negatively associated with Fearless Dominance and positively associated with Impulsive Antisociality. Using community participants $(N=529)$, we indeed found weak to moderate negative correlations between Fearless Dominance and all measures of fear of pain, anxiety, and stress in both genders. While a positive correlation between Impulsive Antisociality and pain catastrophization (i.e. the extent to which an individual exaggerates the negativity of a painful experience) was only observed in males, weak to moderate positive relationships were observed between Impulsive Antisociality and measures of anxiety and stress in both genders. Overall, these results support the association between internalizing behaviors and Impulsive Antisociality, whereas higher levels of Impulsive Antisociality was reflected by higher levels of fear and stress, while higher levels of Fearless Dominance were related to higher resilience to fear and stress. The results further support the importance of dividing analyses by psychopathy subtypes, as results in psychopathy may be masked by the opposite findings observed in Fearless Dominance and Impulsive Antisociality. 


\section{Introduction}

Psychopathy is a disorder defined by a display of excessive antisocial traits combined with partial or total lack of empathy, callousness, aggression, manipulative behaviour and a parasitic lifestyle (Berg et al., 2013). Although psychopathy has been considered categorical for many decades, recent evidence suggests that this disorder should be regarded as being on a continuum ranging from a low to high display of psychopathic traits (Berg et al., 2013; Lilienfeld \& Andrews, 1996).

A diagnosis of psychopathy can only be established with the Psychopathy Checklist-Revised (PCL-R; Hare, 2003). Individuals are assessed on two components of psychopathy. Factor 1 is associated with emotional and interpersonal personality traits, such as lack of empathy, emotional callousness, remorselessness, and Machiavellianism. Factor 2 is associated with the social deviance of psychopathy, which is characterized by criminal behaviour, impulsivity, anxiety, and neuroticism. While the PCL-R mainly focuses on maladaptive behaviours and personality traits, other instruments such as the Psychopathic Personality Inventory (PPI) give more consideration to the adaptive features of psychopathy (Lilienfeld \& Andrews, 1996). The PPI does not diagnose psychopathy, but rather assesses the strength of psychopathic personality traits among eight components. These are categorized into two facets: Fearless Dominance (PPI-I) and Impulsive Antisociality (PPI-II). PPI-I focuses on adaptive components such as social potency, fearlessness, stress and anxiety immunity, and interpersonal boldness. Alternatively, PPI-II focuses on maladaptive components, such as meanness, egoism, blame externalization, and impulsivity. While past studies have found strong correlations between the PCL-R Factor 2 and PPI-II, only weak to non-existent correlations between the PCL-R Factor 1 and PPI-I have been reported (Hughes, Stout, \& Dolan, 2013).

Psychopathy has also been linked to other characteristics, such as pain tolerance, which has received significant attention due to associated controversial results. Hare (Hare \& Thorvaldson, 1970; Hare, 1965, 1966, 1968) performed several experiments on psychopathic inmates to analyse their response to pain. By using an electrical shocking device, Hare concluded that psychopaths are not conditioned by the fear of pain, are not threatened by pain, report an overall lower level of pain than non-psychopaths, and are willing to receive a higher amount of pain when incentives are used. Despite these findings, a later investigation done by Fedora and Reddon (1993) produced differing results. In this study, the authors found increased pain tolerance among inmates in comparison to the general population, but not between psychopaths and non-psychopaths in the inmate population. The 


\section{Chapter 3 | Psychopathy and Fear of Pain}

authors explain that these results might be due to differential learning in inmates, where the forensic population must endure harsher treatment than the general population. However, although these findings were of borderline statistical significance, a subsequent study revealed that individuals from the community displaying high levels of psychopathic traits tend to endure higher levels of pain through electric stimulation and pressure (Miller, Rausher, Hyatt, Maples, \& Zeichner, 2014). Considering the inconsistency of the findings resulting from experimental pain, and the lack of information on other types of pain, such as medical pain (i.e. pain resulting from a disease), the relationship between psychopathic traits or psychopathy and pain tolerance remains unclear.

Further studies have been performed to test the relationship between pain sensitivity, anxiety and psychopathy. One of these studies compared young delinquents diagnosed with high anxiety to a group of inmates with high levels of psychopathic traits (Schalling \& Levander, 1964). Participants received moderate amounts of electrical pain. Results concluded that anxietyprone delinquents were much more sensitive to pain than psychopathic inmates. A different study on anxiety and psychopathic subtypes concluded that non-neurotic psychopaths had a better tolerance for anxiety than nonpsychopathic individuals, while neurotic psychopaths had a lower tolerance for anxiety than the same controls (Lykken, 1957). These findings are inconsistent with subsequent research, where weak (Hare, 1991) to nonexistent (Hare, 1972) correlations were found between psychopathy and anxiety. Additionally, a more recent study found a marginal positive correlation between PCL-R Factor 2 psychopathy and anxiety, but no correlation between PCL-R Factor 1 psychopathy and anxiety (Hale, Goldstein, Abramowitz, Calamari, \& Kosson, 2004). Once again, the inconsistency among these results makes it difficult to establish a definite relationship between psychopathic traits and anxiety.

Apart from anxiety, stress has also been investigated with regard to its association with psychopathy. Correlational studies using criminal offenders concluded that individuals with higher PCL-R Factor 1 psychopathy had a lower stress reaction and a decreased risk of post-traumatic stress disorder than individuals with high PCL-R Factor 2 psychopathy (Hicks, Markon, Patrick, Krueger, \& Newman, 2004; Willemsen, De Ganck, \& Verhaeghe, 2011). Similar results were found in a non-institutionalized sample, where a correlation between lower perceived stress and higher PPI-I psychopathic traits was established. The reverse was found for individuals with higher PPIII scores, as there was a positive correlation between high PPI-II and perceived stress (Smith, Edens, \& Vaughn, 2011). The findings obtained from 
the aforementioned studies suggest potential causes for discrepancies among results concerning psychopathy, pain, and anxiety.

Many potential covariates could affect the aforementioned results, such as gender and intelligence. Previous studies reported that males generally score higher than females on psychopathic traits tests (Lee \& Salekin, 2010), and that females are generally more sensitive to pain, while also displaying higher levels of stress and anxiety (Dambrun, 2007; Jones \& Zachariae, 2002). While the influence of gender on psychopathy and anxiety has been confirmed in multiple studies, the results regarding the role of intelligence in psychopathy vary considerably. Weak to moderate negative correlations were found between intelligence and psychopathy as assessed by the Psychopathy Checklist: Screening Version (PCL:SV) $(r=-.18$ to -.38$)$ (Neumann \& Hare, 2008). However, no correlation was found between intelligence and the PPI (Wall, Sellbom, \& Goodwin, 2013). It is therefore possible that reducing the variability of intelligence within the population studied will improve the reliability of the data when examining psychopathic traits and associated characteristics.

\section{The Current Study}

At the moment, the relationship between the expression of psychopathic traits and tolerance levels to pain, anxiety, and stress is unclear due to the various studies supporting different conclusions. If we consider psychopathy as being on a continuum, it is possible to assess the relationship between the expression of psychopathic traits and various variables such as fear of pain, anxiety, and stress through correlations. The purpose of this study is therefore to examine the strength of the relationship between psychopathic traits and the fear of pain, anxiety, and stress in a community sample. We hypothesize that PPI-I will display a negative correlation with measurements of fear of pain, anxiety, and stress. We also hypothesize that PPI-II will display a positive correlation with the aforementioned measurements. Due to potential gender differences, males and females were analysed independently. These results may provide further support regarding the importance of investigating psychopathic traits by factors, due to the conflicting results obtained when investigating psychopathic traits as a unitary construct.

\section{Methods}

\section{Participants}

This study was approved by the Ethical Committee of Psychology of Maastricht University. Ethical consent was obtained from all participants prior beginning the study. Six hundred and thirty participants were recruited from 


\section{Chapter 3 | Psychopathy and Fear of Pain}

the community via social media and websites dedicated to the recruitment of participants for psychological studies. In order to attempt to control intelligence as a covariate, subjects were required to have obtained post-high school education and be between 18 and 40 years old. We accounted for potentially unreliable data by calculating the Variable Response Inconsistency (VRIN). This analysis, which is comprised of the sum of the 10 pairs of items from the PPI-SF with the highest correlations between them (Lilienfeld \& Widows, 2005; Tellegen, 1982), identified 22 outliers with a VRIN $\geq 8$. Examination of Stem-and-Leaf plots in every scales and subscales identified an additional 28 outliers. Of these 580 participants, 51 were removed due to incomplete questionnaires, leaving a total of 529 participants $(58 \%$ males, $N=308$, and $42 \%$ females, $N=221)$. The mean age was 23.95 years $(S D=4.83)$, with a range of 18 to 40 years. Most participants were college graduates (33.3\%), followed by those currently receiving college education (29.1\%), having a Master level education (16.6\%), and individuals with other types of education (13.6\%). Most participants were located in Europe (60.5\%), followed by North America (14.2\%), Asia/Middle East (13.4\%), Africa (4.7\%), Central/South America (4.4\%), and in Oceania (1.7\%).

\section{Materials}

\section{Psychopathic Personality Inventory-Short Form (PPI-SF; Lilienfeld \& Widows, 2005)}

The PPI-SF is a self-report assessment consisting of 56 items rated on a 4point Likert scale ( $1=$ false, $2=$ mostly false, $3=$ mostly true, $4=$ true), giving a total score and eight subscale scores. The PPI-SF consists of seven items from each of the eight scales of the PPI which have high correlations with their relative subscales, which consists of Machiavellian Egocentricity, Social Potency, Fearlessness, Coldheartedness, Impulsive Nonconformity, Blame Externalization, Carefree Nonplanfulness and Stress Immunity. Seven of the 8 subscales are classified into two factors. PPI-I consists of Social Potency, Fearlessness, and Stress Immunity. PPI-II includes Machiavellian Egocentricity, Impulsive Nonconformity, Blame Externalization, and Carefree Nonplanfulness. The Coldheartedness scale does not load onto either PPI-I or PPI-II. Previous studies using the PPI-SF established its internal consistency to be between $\alpha=.70$ to .94 (Cale \& Lilienfeld, 2006).

\section{Fear of Pain Questionnaire-III (FPQ-III; Mcneil \& Rainwater, 1998)}

The FPQ-III is a 30 -item self-report questionnaire assessing an individual's fear of pain. The items, which are descriptions of painful situations, are answered on a 5 -point Likert scale $(1=$ Not at all to $5=$ Extreme). These items 
are divided among 3 subscales, Minor Pain, Severe Pain and Medical Pain. The scores for each subscale range from 10 to 50 , and thus the total score ranges from 30 to 150 . The internal consistency for each subscale is satisfactory: Minor Pain $(\alpha=.86)$, Severe Pain $(\alpha=.88)$ and Medical Pain ( $\alpha$ $=.88$ ) (Roelofs, Peters, Deutz, Spijker, \& Vlaeyen, 2005). Construct validation of the questionnaire was done by correlating the FPQ to visual analogue scale (VAS) assessing fear during three experimental painful stimuli (electrical stimulation, thermal pain, and ischemic pain). FPQ total score, alongside its 3 subscales, were moderately to strongly correlated to all 3 painful stimuli ( $r$ $=.27$ to .53) (Roelofs et al., 2005). Additionally, the FPQ ( $r=-.28$ to -.33 ), alongside the severe $(r=-.28)$ and the medical $(r=-.32)$ subscales, showed negative correlations with pain tolerance to electrical stimulation and thermal pain, which was not seen in the minor scale.

\section{Pain Catastrophizing Scale (PCS; Sullivan, Bishop, \& Pivik, 1995)} The PCS is a 13-item self-reported questionnaire assessing the extent to which an individual exaggerates the negativity of a painful experience. It is rated on a 5-point Likert scale, ranging from 0 (Not at all) to 4 (All the time). The questionnaire is divided into three clusters: Rumination, Magnification and Helplessness. Internal consistency, which is derived from a community sample, is excellent, with a Cronbach's alpha of $\alpha=.95$ for the total score and $\alpha=.88$ to .95 for the subscales (Osman et al., 2000). A previous study in healthy individuals found a strong correlation between the PCS and pain scores induced by heat stimulation $(r=.48)$ and a moderate correlation between PCS and muscle pain stimulation $(r=.31)$ (Weissman-Fogel, Sprecher, \& Pud, 2008).

\section{State-Trait Anxiety Inventory (STAl; Spielberger, Gorsuch, \& Lushene, 1970)}

The STAI is a self-report questionnaire with 40 items, divided between two subscales of 20 items each: State Anxiety and Trait Anxiety. The questionnaire is answered on a 4 -point Likert scale $(1=$ Not at all, $4=$ Very much so). The State Anxiety subscale (Y-1) measures how the participant feels at the moment they are filling the questionnaire with items such as "I feel at ease" or "I feel upset". The Trait Anxiety subscale (Y-2) measures how the participant generally feels in everyday life, including items such as "I lack selfconfidence" or "I am a steady person". A meta-analysis has confirmed the good validity and internal consistency of the STAI, with Cronbach's alpha ranging from $\alpha=.88$ to .93 for the $Y-1$ scale and $\alpha=.89$ to .91 for the $Y-2$ scale (Vigneau \& Cormier, 2008). Previous research was able to establish a 


\section{Chapter 3 | Psychopathy and Fear of Pain}

significant correlation between STAI scores and peak amylase levels during the viewing of an anxiety-inducing video ( $r=.53)$ (Takai et al., 2004).

\section{Perceived Stress Scale, 10-item version (PSS-10; Cohen \& Williamson, 1988)}

The PSS-10 is a revised version of the Perceived Stress Scale (PSS) (Cohen, Kamarck, \& Mermelstein, 1983). It is a 10-item self-report questionnaire measuring how stressful the participant considers everyday situations. The questionnaire is answered on a 5-point Likert scale ( $0=$ Never, $4=$ Very often), with a total score ranging from 0 to 40 where a high score indicates a high level of perceived stress. While the PSS has not been supported with experimental validation, several studies support its validity when compared to other measurements of stress, with an internal consistency ranging from a $=.84$ to .86 (Cohen et al., 1983; Lee, 2012).

\section{Statistical Analyses}

All analyses were conducted using the SPSS statistical package version 23. A Multivariate Analysis of Variance (MANOVA) was computed to examine the effect of gender differences across all the questionnaires. Then, two bivariate Pearson correlations were computed; one per gender. Bivariate Pearson correlations were favoured in order to get a broader picture of the relationship between psychopathic traits and measurements of fear of pain, anxiety, and stress. In order to account for multiple testing, statistical significance for correlational analyses was set by using a Bonferroni correction $(\alpha=.05 / 52$ variables) equal to $p<.001$.

\section{Results}

\section{General Descriptive Results and Gender Differences}

The descriptive data of all questionnaires, as well as the internal consistency reliability and effect sizes by genders, are reported in Table 1. Several significant differences were found between genders regarding psychopathic traits and measures of pain, anxiety, and stress. First, males scored higher on the PPI-SF total $[F(1,528)=39.76, p<.001]$, on PPI-I $[F(1,528)=36.90, p$ $<.001]$, on PPI-II $[F(1,528)=8.11, p<.005]$, and on several subscales of the PPI-SF: Machiavellian Egocentricity $[F(1,528)=14.23, p<.001]$, Fearlessness $[F(1,528)=29.80, p<.001]$, Coldheartedness $[F(1,528)=$ $10.21, p<.001]$, and Stress Immunity $[F(1,528)=51.15, p<.001]$. Alternatively, females scored higher than males on the $\mathrm{FPQ}[F(1,528)=14.04$, $p<.001]$, the PCS $[F(1,528)=20.37, p<.001]$, the STAI $[F(1,528)=8.59, p$ 
$=.004]$, and the PSS $[F(1,528)=18.56, p<.001]$, alongside all the scales respective subscales, with the exception of State Anxiety from the STAI.

Correlations between the PPI-SF and its subscales and measurements of pain, anxiety, and stress in males can be found in Table 2. Examination of the PPI-SF total score reveals a few weak negative correlations with the FPQ and two of its subscales ( $r=-.19$ to -.23 ), alongside a weak negative correlation with the rumination subscale of the PCS $(r=-.18)$. Deeper examination of the PPI-SF scales reveals two patterns. First, the PPI-I is weakly to moderately negatively correlated with all measurements, including the subscales, assessing fear of pain, pain catastrophization, anxiety, and perceived stress $(r=-.22$ to -.41$)$. Alternatively, weak to moderate positive associations were observed between PPI-II and the PCS, the STAI, and the PSS, at the exception of the rumination subscale $(r=.19$ to .40$)$. No correlation was found between PPI-II and the FPQ total or any of its scales.

Examination of the correlations obtained in the females group display several similarities to the males' group. First, the PPI-SF total score once again display weak negative correlations with the $\mathrm{FPQ}$ and two of its subscales $(r=-.27$ to -.31$)$, as well as a weak negative correlation with the rumination subscale $(r=-.22)$ from the PCS. As seen in males, results show weak to moderate negative correlations in females between PPI-I and all measurements ( $r=-.22$ to -.40 ), at the exception of two subscales. Indeed, no correlation was found between PPI-I and the minor pain subscale or the magnification subscale. Opposite results similar to the males' group were found once again for the PPI-II subscale, with weak to moderate positive correlations between PPI-II and STAI and its subscales, as well as with the PSS total score. Once again, no association was found between PPI-II and FPQ. However, in contrast to males, PPI-II in females was not correlated to the PCS or any of its subscales. 


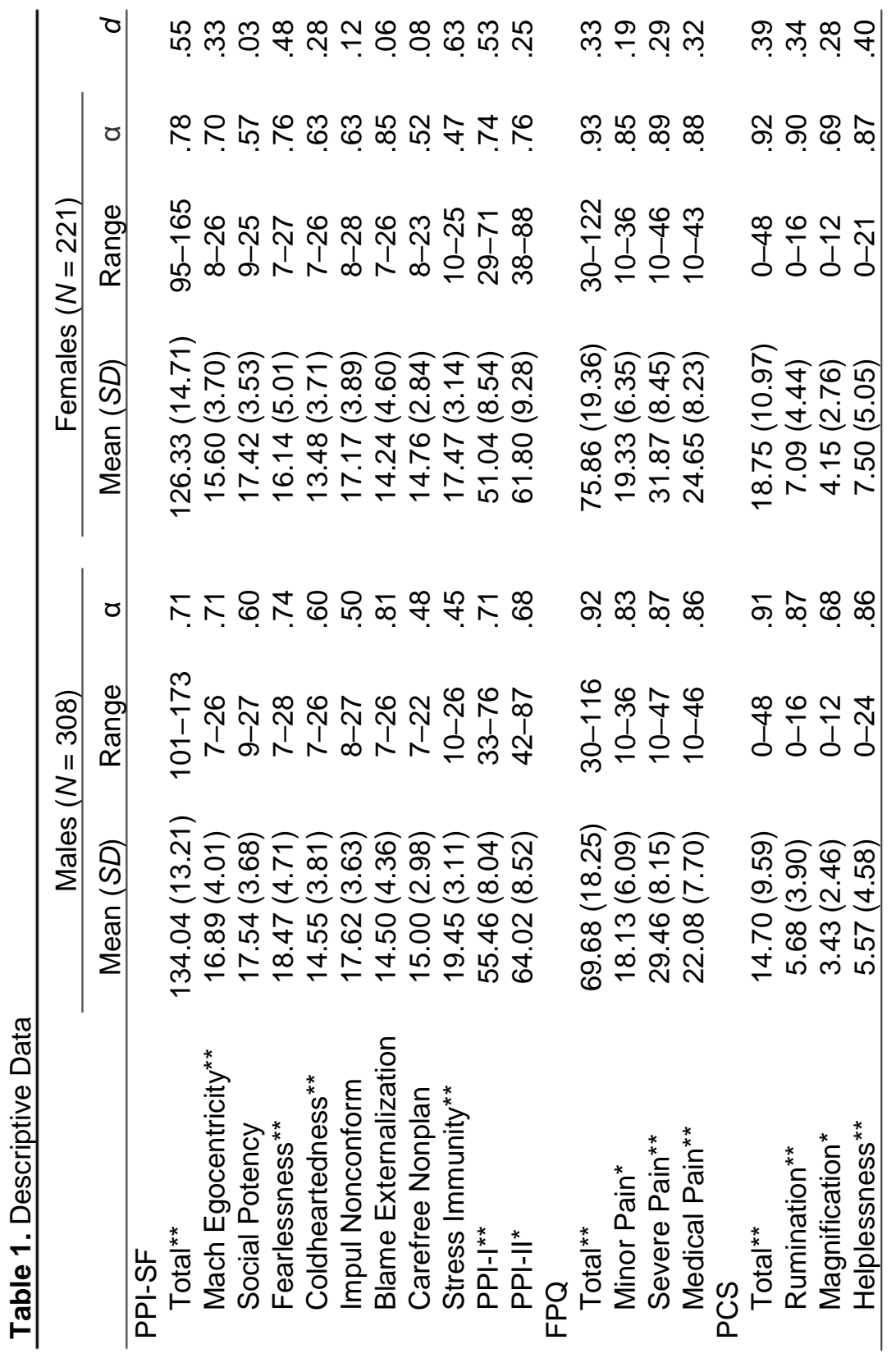




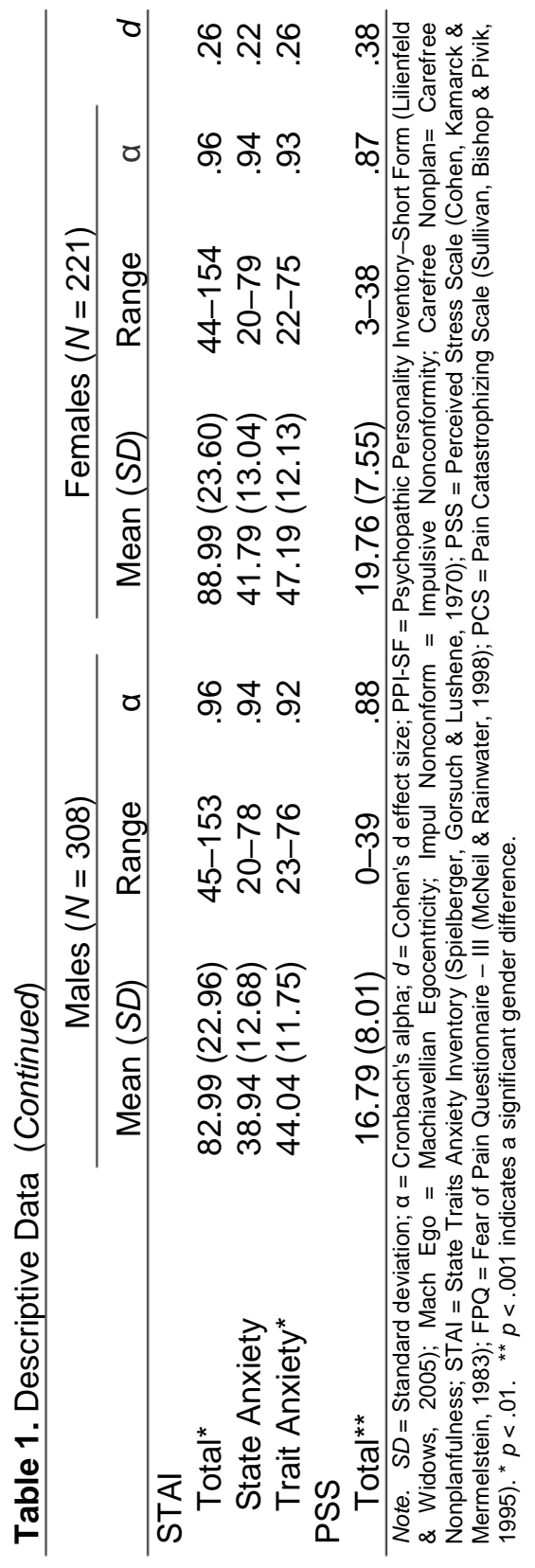


Table 2. Correlations between psychopathic personality traits and measurements of pain, anxiety, and stress

\begin{tabular}{|c|c|c|c|c|c|c|}
\hline & \multicolumn{3}{|c|}{ Males $(N=308)$} & \multicolumn{3}{|c|}{ Females $(N=221)$} \\
\hline \multirow[b]{2}{*}{ Scales } & \multicolumn{3}{|c|}{ PPI-SF } & \multicolumn{2}{|c|}{ PPI-SF } & \multirow[b]{2}{*}{ PPI-II } \\
\hline & Total & PPI-I & PPI-II & Total & PPI-I & \\
\hline \multicolumn{7}{|l|}{ FPQ } \\
\hline Total & $-.23^{*}$ & $-.33^{*}$ & .06 & $-.27^{\star}$ & $-.32^{*}$ & -.04 \\
\hline Minor Pain & -.14 & $-.23^{\star}$ & .10 & -.05 & -.18 & .15 \\
\hline Severe Pain & $-.19^{*}$ & $-.25^{\star}$ & .00 & $-.31 *$ & $-.32^{*}$ & -.10 \\
\hline Medical Pain & $-.22^{*}$ & $-.34^{\star}$ & .05 & $-.29^{*}$ & $-.29^{*}$ & -.10 \\
\hline \multicolumn{7}{|l|}{ PCS } \\
\hline Total & -.15 & $-.33^{*}$ & $.20^{*}$ & -.17 & $-.26^{*}$ & .11 \\
\hline Rumination & $-.18^{*}$ & $-.30^{\star}$ & .14 & $-.22^{\star}$ & $-.28^{*}$ & .05 \\
\hline Magnification & -.08 & $-.22^{\star}$ & $.19^{*}$ & -.13 & -.18 & .09 \\
\hline Helplessness & -.12 & $-.31^{*}$ & $.21^{*}$ & -.11 & $-.22^{*}$ & .15 \\
\hline \multicolumn{7}{|l|}{ STAI } \\
\hline Total & -.11 & $-.41^{*}$ & $.34^{*}$ & -.07 & $-.38^{*}$ & $.36^{*}$ \\
\hline State Anxiety & -.14 & $-.37^{\star}$ & $.25^{\star}$ & -.07 & $-.32^{*}$ & $.29^{\star}$ \\
\hline Trait Anxiety & -.07 & $-.41^{*}$ & $.40^{*}$ & -.07 & $-.40^{*}$ & $.38^{*}$ \\
\hline \multicolumn{7}{|l|}{ PSS } \\
\hline Total & -.08 & $-.35^{\star}$ & $.34^{*}$ & -.04 & $-.31^{*}$ & $.34^{*}$ \\
\hline
\end{tabular}

\section{Discussion}

The present study examined the correlation between psychopathic traits and a diverse range of pain-related characteristics, including fear of pain, anxiety, and stress in a community sample between genders. The results partially support our two hypotheses, which claimed that individuals with higher levels of PPI-I traits will display lower fear of pain, anxiety, and stress, and that individuals with higher levels of PPI-II traits will report higher levels of the same variables.

Our results pertaining to the relationship between PPI-I and displaying a greater immunity to fear of pain, anxiety, and stress support previous results associating these attributes to psychopaths within both males and females (Hare, 1965; Schalling \& Levander, 1964; Willemsen et al., 2011). The negative association between PPI-I and fear and catastrophization of pain is supported by previous findings demonstrating a deficient emotional affect in psychopathy with regard to neurological responses, which may be responsible for psychopaths' inability to form emotional associations (Flor, Birbaumer, Hermann, Ziegler, \& Patrick, 2002). This explanation, which has previously been suggested to explain why psychopaths did not come to associate neutral stimuli with painful stimuli even after fear conditioning, may explain why 
psychopaths have a lower fear of pain. Fear generally arises from past experiences or information regarding a negative experience (Olsson \& Phelps, 2007). Considering the difficulty of conditioning psychopaths in an experimental setting with a negative stimulus, the present results demonstrating an association between a lack of fear towards pain and elevated psychopathic traits remain consistent with the literature. Results in males and females were highly similar, with the exception of a lack of correlation in females between PPI-I and minor pain, as well as with pain catastrophization magnification. This difference might be due to our conservative statistical significance, which was set at .001 .

Similarly, a higher display of PPI-I related traits were associated with lower levels of anxiety and stress in both genders. The role of anxiety and stress within the construct of psychopathy has been highly debated, with numerous studies failing to support their association (Derefinko, 2015; Visser, Ashton, \& Pozzebon, 2012). However, closer examination reveals that the absence of association between anxiety and stress with regards to psychopathy may be due to the subdivision of psychopathy. Indeed, previous studies categorizing psychopathy into two factors support a negative relationship between Fearless Dominance and anxiety and stress, as well as a positive relationship between Impulsive Antisociality and anxiety and stress (Derefinko, 2015). Considering the aforementioned fearless nature of psychopathic individuals, it is possible that individuals displaying higher levels of Fearless Dominance will exhibit lower emotional reactivity in forms other than fearlessness, such as immunity to anxiety and stress.

As expected, the analysis of results for PPI-II and fear of pain, anxiety and stress displayed an opposite pattern to the results obtained for the PPI-I, with a notable difference between genders. The lack of relationship between PPI-II and fear of pain between both males and females is unexpected. It is possible that a negative relationship between PPI-II and fear of pain will emerge only in experimental settings rather than in a questionnaire study. Indeed, the correlations previously obtained between the FPQ scores and experimental pain varied greatly between stimuli, ranging from weak to strong correlations (Roelofs et al., 2005). Higher levels of PPI-II traits may be responsible for overestimating an individual's pain threshold. Additionally, while previous findings on fear, anxiety, and psychopathic traits are generally significant for both factors, correlations tend to be moderate for PPI-I and weak for PPI-II (Benning, Patrick, Salekin, \& Leistico, 2005). Self-reported fear of pain might therefore be more consistent within self-assured individuals (PPI-I), as opposed to neurotic and impulsive individuals (PPI-II). 


\section{Chapter 3 | Psychopathy and Fear of Pain}

Furthermore, while an association between PPI-II and pain catastrophizing was found in males, no significant association was found within females. PPI-II has been associated with neuroticism in a number of studies (Benning et al., 2005; Yildirim \& Derksen, 2013, 2015). A positive relationship between elevated neuroticism and catastrophic thoughts about pain has also been established (Wong et al., 2015). While these previous findings support our results for the males, the lack of correlation between PPIII and PCS in females could be due to the generally higher scores of females on the PCS compared to males, as well as the generally reported higher anxiety and stress in all females, independently of psychopathic traits (Dambrun, 2007).

The positive associations found between PPI-II and anxiety and stress within both genders are in line with previous research (Gao \& Tang, 2013; Lee \& Salekin, 2010). Considering that PPI-II encompasses the impulsive and reactive nature of the psychopathic personality, a higher propensity to anxiety and stress is in line with the wider array of negative emotions exhibited by PPI-II in comparison to PPI-I.

\section{Limitations, Future Directions, and Conclusions}

Our study possesses some limitations. First, in order to control for intelligence, we limited participation in the study to individuals between 18 and 40 years old with post high school education. Considering several studies on the topic investigated psychopathy in criminal offenders, and past research support a negative relationship between intelligence and criminality, the divergence of results might stem from the confounding factor of intelligence or higher education, especially since most self-reported questionnaires of psychopathic traits were developed within college students (Beaver et al., 2013). Second, this study was realized through the use of self-reported questionnaires. While several of the questionnaire used in the present study were validated in experimental settings, correlations never exceeded $r=.53$, limiting their power to detect associations between psychopathy and fear of pain, anxiety, and stress. Third, the reported results were simple correlations. Future studies should focus on the variables displaying significant correlations in the present study and integrate those variables in multivariate models in order to attempt identify the cause and effect relationship. Nevertheless, the results obtained in the present study support resilience and risk factor of fear of pain, stress, and anxiety within high scorers of PPI-I and PPI-II, suggesting to further investigate those variables independently in laboratory settings.

Overall, our study findings are generally similar to previous theories and research (Berg et al., 2013; Hicks et al., 2004; Karpman, 1941; Lee \& Salekin, 
2010), supporting the fearless nature related to PPI-I and the fearful, anxious nature associated with PPI-II. While our results were highly consistent within PPI-I, the unexpected results showing no association between PPI-II and fear of pain in both genders should be interpreted with caution, alongside the lack of association between PPI-II and pain catastrophization in females. Nevertheless, the present study succeeded in presenting additional evidence for the duality of psychopathy and underlining the importance of psychopathic trait classification by subtypes and genders in psychopathy-related research. 


\section{Chapter 3 | Psychopathy and Fear of Pain}

\section{References}

Beaver, K. M., Schwartz, J. A., Nedelec, J. L., Connolly, E. J., Boutwell, B. B., \& Barnes, J. C. (2013). Intelligence is associated with criminal justice processing: Arrest through incarceration. Intelligence, 41 (5), 277-288.

Benning, S. D., Patrick, C. J., Salekin, R. T., \& Leistico, A.-M. R. (2005). Convergent and discriminant validity of psychopathy factors assessed via self-report: a comparison of three instruments. Assessment, 12 (3), 270-289.

Berg, J. M., Smith, S. F., Watts, A. L., Ammirati, R., Green, S. E., \& Lilienfeld, S. O. (2013). Misconceptions regarding psychopathic personality: implications for clinical practice and research. Neuropsychiatry, 3 (1), 63-74.

Cale, E. M., \& Lilienfeld, S. O. (2006). Psychopathy factors and risk for aggressive behavior: A test of the "threatened egotism" hypothesis. Law and Human Behavior, 30 (1), 51-74.

Cohen, S., Kamarck, T., \& Mermelstein, R. (1983). Perceived stress scale. Journal of Health and Social Behavior, 24 (4), 386-396.

Cohen, S., \& Williamson, G. (1988). Perceived stress in a probability sample of the United States. In The social psychology of health. The Claremont Symposium on Applied Social Psychology. (Sage, pp. 31-67). Newbury Park, CA.

Dambrun, M. (2007). Gender differences in mental health: The mediating role of perceived personal discrimination. Journal of Applied Social Psychology, 37 (5), 1118-1129.

Derefinko, K. J. (2015). Psychopathy and Low Anxiety: Meta-Analytic Evidence for the Absence of Inhibition, Not Affect. Journal of Personality, 83 (6), 693-709.

Fedora, O., \& Reddon, J. R. (1993). Psychopathic and nonpsychopathic inmates differ from normal controls in tolerance levels of electrical stimulation. Journal of Clinical Psychology, 49 (3), 326-331.

Flor, H., Birbaumer, N., Hermann, C., Ziegler, S., \& Patrick, C. J. (2002). Aversive Pavlovian conditioning in psychopaths: Peripheral and central correlates. Psychophysiology, 39 (4), 505-518.

Gao, Y., \& Tang, S. (2013). Psychopathic personality and utilitarian moral judgment in college students. Journal of Criminal Justice, 41 (5), 342-349.

Hale, L. R., Goldstein, D. S., Abramowitz, C. S., Calamari, J. E., \& Kosson, D. S. (2004). Psychopathy is related to negative affectivity but not to anxiety sensitivity. Behaviour Research and Therapy, 42 (6), 697-710.

Hare, R. D. (1965). Psychopathy, Fear Arousal and Anticipated Pain. Psychological Reports, 16 (2), 499-502.

Hare, R. D. (1966). Psychopathy and choice of immediate versus delayed punishment. Journal of Abnormal Psychology, 71 (1), 25-29.

Hare, R. D. (1968). Detection Threshold for Electric Shock in Psychopaths. Journal of Abnormal Psychology, 73 (3), 268-272.

Hare, R. D. (1972). Psychopathy and physiological responses to adrenalin. Journal of Abnormal Psychology, 79 (2), 138-147. 
Hare, R. D. (1991). The Hare Psychopathy Checklist-revised (MultiHealt). Toronto.

Hare, R. D. (2003). The Hare Psychopathy Checklist- Revised. Muliti-Health Systems.

Hare, R. D., \& Thorvaldson, S. A. (1970). Psychopathy and response to electrical stimulation. Journal of Abnormal Psychology, 76 (3), 370-374.

Hicks, B. M., Markon, K., Patrick, C. J., Krueger, R., \& Newman, J. P. (2004). Identifying Psychopathy Subtypes on the Basis of Personality Structure. Psychological Assessment, 16 (3), 276-288.

Hughes, M. A., Stout, J. C., \& Dolan, M. C. (2013). Concurrent Validity of The Psychopathic Personality Inventory-Revised and The Psychopathy Checklist: Screening Version in an Australian Offender Sample. Criminal Justice and Behavior, 40 (7), 802-813.

Jones, A., \& Zachariae, R. (2002). Gender, Anxiety, and Experimental Pain Sensitivity: An Overview. Jamwa, 57(February 2002), 91-94.

Karpman, B. (1941). On the need of separating psychopathy into two distinct clinical types: the symptomatic and the idiopathic. Journal of Criminal Psychopathology, 3, 112-137.

Lee, E.-H. (2012). Review of the psychometric evidence of the perceived stress scale. Asian Nursing Research, 6 (4), 121-127.

Lee, Z., \& Salekin, R. T. (2010). Psychopathy in a noninstitutional sample: Differences in primary and secondary subtypes. Personality Disorders: Theory, Research, and Treatment, 1 (3), 153-169.

Lilienfeld, S. O., \& Andrews, B. P. (1996). Development and Preliminary Validation of a Self-Report Measure of Psychopathic Personality Traits in Noncriminal Populations. Journal of Personality Assessment, 66 (3), 488-524.

Lilienfeld, S. O., \& Widows, M. (2005). Psychopathic personality inventory-revised: Professional manual. Lutz, FL: Psychological Assessment Resources.

Lykken, D. T. (1957). A study of anxiety in the sociopathic personality. Journal of Abnormal Psychology, 55 (1), 6-10.

Mcneil, D. W., \& Rainwater, A. J. (1998). Development of the Fear of Pain Questionnaire - III. Journal of Behavioral Medicine, 21 (4), 389-410.

Miller, J. D., Rausher, S., Hyatt, C. S., Maples, J., \& Zeichner, A. (2014). Examining the relations among pain tolerance, psychopathic traits, and violent and nonviolent antisocial behavior. Journal of Abnormal Psychology, 123 (1), 20513.

Neumann, C. S., \& Hare, R. D. (2008). Psychopathic traits in a large community sample: Links to violence, alcohol use, and intelligence. Journal of Consulting and Clinical Psychology, 76 (5), 893-899.

Olsson, A., \& Phelps, E. A. (2007). Social learning of fear. Nature Neuroscience, 10 (9), 1095-1102.

Osman, A., Barrios, F. X., Gutierrez, P. M., Kopper, B. A., Merrifield, T., \& Grittmann, L. (2000). The Pain Catastrophizing Scale: Further Psychometric Evaluation with Adult Samples. Journal of Behavioral Medicine, 23 (4), 351-365. 


\section{Chapter 3 | Psychopathy and Fear of Pain}

Roelofs, J., Peters, M. L., Deutz, J., Spijker, C., \& Vlaeyen, J. W. S. (2005). The Fear of Pain Questionnaire (FPQ): Further psychometric examination in a non-clinical sample. Pain, 116 (3), 339-346.

Schalling, D., \& Levander, S. (1964). Ratings of anxiety-proneness and responses to electrical pain stimulation: Preliminary experiments in a group of young delinquents. Scandinavian Journal of Psychology, 5 (1), 1-9.

Smith, S. T., Edens, J. F., \& Vaughn, M. G. (2011). Assessing the external correlates of alternative factor models of the Psychopathic Personality Inventory-short form across three samples. Journal of Personality Assessment, 93(3), 244-256.

Spielberger, C. D., Gorsuch, R. L., \& Lushene, R. E. (1970). The State-Trait Anxiety Inventory. MANUAL, 1-23.

Sullivan, M., Bishop, S., \& Pivik, J. (1995). The pain catastrophizing scale: development and validation. Psychological Assessment, 7 (4), 524-532.

Takai, N., Yamaguchi, M., Aragaki, T., Eto, K., Uchihashi, K., \& Nishikawa, Y. (2004). Effect of psychological stress on the salivary cortisol and amylase levels in healthy young adults. Archives of Oral Biology, 49 (12), 963-968.

Tellegen, A. (1982). Brief Manual for the Differential Personality Questionnaire. Unpublished Manuscript, 1010-1031.

Vigneau, F., \& Cormier, S. (2008). The factor structure of the State-Trait Anxiety Inventory: an alternative view. Journal of Personality Assessment, 90(3), 280285.

Visser, B. A., Ashton, M. C., \& Pozzebon, J. A. (2012). Is Low Anxiety Part of the Psychopathy Construct? Journal of Personality, 80 (3), 725-747.

Wall, T. D., Sellbom, M., \& Goodwin, B. E. (2013). Examination of intelligence as a compensatory factor in non-criminal psychopathy in a non-incarcerated sample. Journal of Psychopathology and Behavioral Assessment, 35 (4), 450-459.

Weissman-Fogel, I., Sprecher, E., \& Pud, D. (2008). Effects of catastrophizing on pain perception and pain modulation. Experimental Brain Research, 186 (1), 79-85.

Willemsen, J., De Ganck, J., \& Verhaeghe, P. (2011). Psychopathy, Traumatic Exposure, and Lifetime Posttraumatic Stress. International Journal of Offender Therapy and Comparative Criminology, 56 (4), 505-524.

Wong, W. S., Lam, H. M. J., Chen, P. P., Chow, Y. F., Wong, S., Lim, H. S., ... Fielding, R. (2015). The fear-avoidance model of chronic pain: assessing the role of neuroticism and negative affect in pain catastrophizing using structural equation modeling. International Journal of Behavioral Medicine, 22(1), 118-31.

Yildirim, B. O., \& Derksen, J. J. L. (2013). Systematic review, structural analysis, and new theoretical perspectives on the role of serotonin and associated genes in the etiology of psychopathy and sociopathy. Neuroscience and Biobehavioral Reviews, 37 (7), 1254-1296.

Yildirim, B. O., \& Derksen, J. J. L. (2015). Clarifying the heterogeneity in psychopathic samples: Towards a new continuum of primary and secondary psychopathy. Aggression and Violent Behavior, 24, 9-41. 




\section{Chapter 4}

Negative Attitudes Towards Psychopaths: The Role of One's Own Psychopathic Traits

Durand, G., Plata, E. M., \& Arbone, I-S. (2017). Negative attitudes towards psychopaths: The role of one's own psychopathic traits. Personality and Individual Differences, 109(C), 72-76. 


\section{Abstract}

Personality disorders, such as psychopathy, have a long history of stigmatization. Psychopaths are continually presented as criminals and feared due to their reported aggressive tendencies, stemming from the excessive labelling of murderers as psychopaths by the media and popular culture. While previous research demonstrates the extent to which individuals stigmatize psychopaths, it is not yet known how one's own level of psychopathic traits influence stigmatization of psychopaths. We hypothesized that higher levels of psychopathic traits, especially in adaptive components, would exhibit less stigma-related behaviors towards psychopaths. One hundred and sixteen participants $(N=116)$ from the community completed three questionnaires assessing their own level of psychopathic personality traits and stigma towards psychopathy. The level of psychopathic traits, particularly those related to adaptive components, was negatively correlated with the degree of stigmatizing behaviors towards psychopaths. It is possible that these results stem from individuals displaying higher levels of psychopathic traits identifying with psychopaths exhibiting similar traits to them. Alternatively, the fearlessness component of psychopathy may make individuals with higher levels of psychopathic traits see psychopaths as less threatening than they can be. 


\section{Introduction}

Psychopathy is a personality disorder characterized by a collection of traits including interpersonal-affective features (such as lack of empathy, callousunemotional traits, and superficial charm) and antisocial traits (such as impulsivity and aggression) (Berg et al., 2013; Gao, Glenn, Schug, Yang, \& Raine, 2009). Since an overwhelming proportion of the research surrounding psychopathy has focused on inmates, the label 'psychopath' widely elicits associations with criminals and murderers with minimal chance of rehabilitation (Camp, Skeem, Barchard, Lilienfeld, \& Poythress, 2013; Kiehl \& Hoffman, 2011). While a growing body of evidence suggests that psychopathy is not strongly linked to increased violence and criminal behavior (Berg et al., 2013; Camp et al., 2013; Hall \& Benning, 2006), the fear of psychopaths remains highly present in the general population (Edens, Colwell, Desforges, \& Fernandez, 2005; Edens, Marcus, Lilienfeld, \& Poythress, 2006; Helfgott, $1997)$, leading to the stigmatization of psychopaths.

Stigma can be defined as a disqualification from full social acceptance. Its negative consequences can include diminished employment opportunities, lower quality of healthcare service, and an impoverished social life. Scheff (1963, p. 452) proposed several factors that may affect the social response to deviant behavior: "amount and visibility of deviant behaviour, the power of the deviant and the social distance between the deviant and the agents of social control, and the tolerance level of the community of alternative non-deviant roles". It has been subsequently shown that higher visibility of deviant behavior and lower social status increase stigmatization of the affected individual (Gray, 2002; Link \& Phelan, 2001).

Furthermore, several misconceptions fuel the stigma of mental illness, such as: (i) people with mental illness should be excluded from communities; (ii) people with mental illness are irresponsible; and (iii) people with mental illness are child-like and in need of care (Brockington, Hall, Levings, \& Murphy, 1993; Corrigan \& Watson, 2002; Taylor \& Dear, 1981). Such misbeliefs are reflected in contradictory social reactions and views on mental illness. Indeed, individuals with mental conditions are viewed as "imperfect beings" that cannot be remediated, yet they are deemed responsible for their actions and thus assigned a moral deficit (Scambler, 2006).

Stigmatizing attitudes and misunderstandings are particularly salient in the case of personality disorders like psychopathy. Indeed, personality disorders remain poorly understood by the public and are highly stigmatized due to lack of public awareness and information regarding the disorders (Panier, Van Remoortere, Van den Bogaert, \& Uzieblo, 2014; Sheehan, Nieweglowski, \& Corrigan, 2016). Three main factors are responsible for 
social rejection: personal responsibility, dangerousness, and rarity of the illness (Feldman \& Crandall, 2007). Previous investigations have concluded that laypeople believe that psychopaths are responsible for their actions (Smith, Edens, Clark, \& Rulseh, 2014), that psychopaths are dangerous (Wayland \& O'Brien, 2013), and that psychopathy has a prevalence less than $1 \%$ in the general population (Smith et al., 2014). Psychopathy therefore fulfils all criteria for inducing stigmatization and social rejection.

The role of stigmatization towards psychopathy has been well-studied in judicial settings, and such research indicates a bias against psychopaths (Sheehan et al., 2016). Research has demonstrated an association between defendant possession of psychopathic traits and the probability of a harsher sentence (Cox, Clark, Edens, Smith, \& Magyar, 2013). In this study, jury members analysed a case of murder, gave a verdict, and rated the visibility of psychopathy-associated traits in the defendant. The results showed that several components of psychopathy, such as remorselessness, predicted a death penalty, demonstrating the significant impact of stigmatization towards psychopaths.

While prior investigations examining the relationship between psychopathy and stigma have focused on negative aspects of psychopathy, little information has been found regarding psychopathy's adaptive aspects and stigma. Higher levels of psychopathic traits related to the interpersonalaffective facet have been associated with a number of adaptive features, such as superior attentional control (Baskin-Sommers, Zeier, \& Newman, 2009), fearlessness (Dindo \& Fowles, 2011; López, Poy, Patrick, \& Moltó, 2013), and stress and anxiety immunity (Hall, Benning, \& Patrick, 2004). Considering the fearless nature attributed to individuals with higher levels of interpersonalaffective psychopathic traits, it is possible that these individuals will express less fear towards psychopaths, and therefore, less stigmatization towards them (Lilienfeld et al., 2012).

An individual's perception, and therefore, stigmatizing attitudes towards a psychopath may be correlated with that individual's own psychopathic personality traits. It is possible that highly psychopathic individuals will not stigmatize psychopaths as they may identify with psychopathic traits. As mentioned above, stigmatization of psychopaths in judicial settings can have harsh consequences, such as a higher likelihood of a death penalty verdict. A jury member's own psychopathic traits could therefore potentially influence his judgement towards a diagnosed psychopath during a trial. 


\section{The Current Study}

Hence, the purpose of the present study was to determine if individuals from the community with higher levels of psychopathic traits are less likely to stigmatize an individual diagnosed with psychopathy. In this study, we investigated two hypotheses. We hypothesized a negative relationship between high expression of psychopathic traits and stigmatization towards psychopaths, and also hypothesized that this negative relationship would be strongest within interpersonal-affective features due to their association with fearlessness.

\section{Methods}

\section{Participants}

This study was approved and given 'exempt' status by the IntegReview Ethical Review Board (Austin, TX, USA), under protocol number 11022016. No names or other protected health information, as defined by the Health Insurance Portability and Accountability Act (HIPAA), were recorded. Onehundred and sixteen participants aged from 18 to 74 years $(M=26.8, S D=$ 10.77) participated in our community-based study. Participants were recruited online via social media and websites dedicated to online psychological studies (i.e.: www.callforparticipants.com, www.onlinepsychresearch.co.uk, etc.) Participants were $49.1 \%(n=57)$ males and $50.9 \%(n=59)$ females. The most common primary language was English (72\% of participants). Most participants were located in Europe $(n=50)$ and in North America $(n=50)$, followed by Asia $(n=7)$, Oceania $(n=5)$, Africa $(n=3)$, and South America $(n=1)$. The most common academic status was college graduate $(n=44)$, followed by college dropout $(n=34)$, Master's graduate $(n=17)$, doctoral degree holder $(n=3)$, and others $(n=18)$. Participants were not compensated for completing the present study. All participants gave informed consent prior to starting the study.

\section{Materials}

\section{Triarchic Psychopathy Measure (TriPM; Patrick, 2010)}

The TriPM is a 58-item self-report questionnaire for assessing psychopathic personality traits. Items are rated on a 4-point Likert scale from 1 to $4(1=$ true, $4=$ false). The TriPM is divided into three subscales: Boldness, Meanness, and Disinhibition. Boldness refers to adaptive features such as social dominance, fearlessness, stress immunity, and self-assurance, capturing the more functional and socially potent aspects of psychopathy. Meanness refers to aggression towards others, lack of empathy, and excitement through destruction, representing psychopathy's affective/interpersonal deficits. 
Disinhibition refers to impulsivity, lack of planning, and deficient behavioral restraint, capturing the behavioral deficits associated with psychopathy (Patrick, Fowles, \& Krueger, 2009). Previous investigations have established acceptable internal consistencies ( $\alpha=.79$ to .86 ) for all three subscales (Anderson, Sellbom, Wygant, Salekin, \& Krueger, 2014). The internal consistencies of the total score and its subscales, along with their respective means and standard deviations, can be found in Table 1.

Table 1. Descriptive Data $(\mathrm{N}=116)$

\begin{tabular}{lcc}
\hline & Mean $(S D)$ & $\alpha$ \\
\hline TriPM & & \\
Total & $117.57(24.46)$ & .93 \\
Boldness & $45.16(10.51)$ & .89 \\
Meanness & $34.19(11.03)$ & .92 \\
Disinhibition & $38.22(10.52)$ & .88 \\
ABP & & \\
Crime propensity & $9.15(2.83)$ & .76 \\
Violence propensity & $5.54(2.47)$ & .68 \\
Responsibility and punishment & $12.75(4.48)$ & .65 \\
Moral judgments & $7.16(3.73)$ & .69 \\
Noncriminal & $4.24(1.92)$ & .53 \\
Bad parenting & $7.73(2.93)$ & .86 \\
Biological etiology & $8.61(2.23)$ & .50 \\
Immutability/rehabilitation & & \\
potential & $12.03(3.52)$ & .72 \\
Quasi-adaptive features & $23.59(5.04)$ & .70 \\
AQ & & \\
Fear/Dangerousness & $22.48(12.00)$ & .93 \\
Help/Interact & $37.21(8.70)$ & .79 \\
Forcing treatment & $9.84(6.54)$ & .86 \\
Negative emotions & $16.78(5.08)$ & .86 \\
\hline Note. $\quad$ SD = Standard deviation; $\alpha=$ Cronbach's alph; TriPM = Triarchic Psychopathy \\
Measur; ABP = Attitudes and beliefs about psychopaths; AQ = Attribution Questionnaire.
\end{tabular}

\section{Attitudes and Beliefs About Psychopaths (ABP; Smith, Edens, \& Rulseh, 2014)}

The ABP is a 28 -item questionnaire rated on a 7-point Likert scale $(1=$ Strongly Agree, 7 = Strongly Disagree), and was initially developed by Smith et al. (2014) to assess jury panel members' beliefs about psychopaths. These items are statements regarding attitudes towards psychopathy, covering a wide range of stigma-related topics, including propensity to violence and crime, morality, etiology, rehabilitation potential, and quasi-adaptive features. 
Previous studies using the ABP identified a number of factors through principal components analyses (Smith et al., 2014; Sörman et al., 2014, 2016). For the present study, we used Sörman and colleagues' (2014) subscale classification, which was derived from their factor analysis, to score the ABP's items. Our items were hence divided into 9 subscales: crime propensity, violence propensity, responsibility and punishment, moral judgments, noncriminal, bad parenting, biological etiology, immutability/rehabilitation potential, and quasi-adaptive features. While internal consistencies are not available from previous studies, the reliability of these 9 subscales in the present study is acceptable ( $\alpha=.50$ to .86$)$.

\section{Attribution Questionnaire (AQ; Corrigan, Markowitz, Watson, Rowan, \& Kubiak, 2003)}

The $A Q$ is a 20 -item questionnaire assessed on a 9-point Likert scale, and was initially developed to assess the stigmatization of individuals with schizophrenia. Participants are presented with a short description of Harry, after which they are asked to answer several questions about their views on Harry. Our study used the following description, replacing the depiction of schizophrenia with one of psychopathy:

"Harry is a 30-year-old single man diagnosed with psychopathy. Harry does not display a lot of emotions, is not very caring for others, and can be quite egoistic. Harry displays a lot of shallow emotions and can be somewhat impulsive. He lives alone in an apartment and works as a lawyer in a large law firm. Harry did 9 months of prison for a case of theft when he was 18 years old, but he has always claimed his innocence. It was later shown that Harry had a real alibi and could not have committed the crime. His police record was therefore erased."

The items were divided among four factors. The Fear/Dangerousness factor reflects how fearful an individual is towards Harry, as well as how dangerous he should be considered. The Help/Interact factor reflects how likely an individual would be willing to help Harry if he was in need of assistance. The Forcing Treatment factor reflects the willingness of an individual to force Harry to "cure" his psychopathy, even against his will. Finally, the Negative Emotions factor reflects the degree to which an individual will despise Harry as a result of his diagnosis. This four-factor classification was used due to its high correlation with alternative stigma scales (Brown, 2008). To our knowledge, this is the first study using a construct of psychopathy with the AQ. However, the reliability scores of the subscales in 
the original study depicting a case of schizophrenia were promising, ranging from $\alpha=.70$ to .96 (Corrigan et al., 2003).

\section{Results}

\section{Descriptive}

As shown in Table 1, the internal consistency reliability for all subscales is adequate, ranging from $\alpha=.53$ to .93 . The range of participants' score on the TriPM was as follows: 73 to 220 for the total score, 22 to 70 for boldness, 19 to 76 for meanness, and 22 to 75 for disinhibition. The data displayed in Table 1 is normally distributed.

\section{Correlation Between Psychopathic Traits and Stigmatizing Attitudes}

The correlations between the TriPM, the ABP, and the AQ can be found in Table 2. Although correlations with $p<.05$ and .01 are noted, statistical significance was established by using a Bonferroni correction $(p \leq .001)$ in order to minimize Type I error associated with multiple comparisons. Intercorrelation between the TriPM's factors support a strong association between meanness and disinhibition, but only a weak correlation between boldness and meanness, and no significant correlation between boldness and disinhibition.

The observed correlations between the TriPM and the ABP confirm our first hypothesis, showing a negative correlation between higher levels of psychopathic traits and stigmatization towards psychopaths, but not our second hypothesis, which claimed a stronger correlation between Boldness and the ABP subscales than any other TriPM subscales. Meanness and disinhibition were negatively correlated with crime propensity and noncriminal aspects in psychopaths. Furthermore, boldness and meanness displayed weak negative correlations with violence propensity. However, only the correlations associated with crime propensity achieved significance at the $p$ $\leq .001$.

The correlation between the TriPM and the AQ provides support for both our first and second hypotheses. There was a negative relationship between having higher levels of psychopathic traits and stigmatizing attitudes towards psychopaths, and this link was most pronounced within the boldness component of psychopathy. Boldness displayed a weak negative correlation with fear/dangerousness, as well as a moderate positive correlation with help/interact. Furthermore, all three subscales of the TriPM were negatively correlated with negative emotions towards psychopaths. Significance at the $p$ 
$\leq .001$ was only achieved between Boldness and the subscales help/interact and negative emotions.

Table 2. Correlation between the TriPM, the ABP, and the AQ

\begin{tabular}{|c|c|c|c|}
\hline & $\begin{array}{l}\text { Boldnes } \\
\mathrm{s}\end{array}$ & $\begin{array}{l}\text { Meannes } \\
\mathrm{s}\end{array}$ & $\begin{array}{l}\text { Disinhibitio } \\
\mathrm{n}\end{array}$ \\
\hline \multicolumn{4}{|l|}{ TriPM } \\
\hline \multicolumn{4}{|l|}{ Boldness } \\
\hline Meanness & $.33^{\star \star *}$ & & \\
\hline Disinhibition & .16 & $.62^{\star \star \star}$ & \\
\hline \multicolumn{4}{|l|}{$A B P$} \\
\hline Crime propensity & -.16 & $-.37^{* * *}$ & $-.32^{* * *}$ \\
\hline Violence propensity & $-.21^{*}$ & $-.25^{\star *}$ & -.08 \\
\hline Responsibility and punishment & .07 & -.09 & -.05 \\
\hline Moral judgments & -.10 & -.09 & -.18 \\
\hline Noncriminal & .18 & $.29^{* *}$ & $.19^{*}$ \\
\hline Bad parenting & -.16 & -.06 & .01 \\
\hline Biological etiology & .02 & .03 & .08 \\
\hline \multicolumn{4}{|l|}{ Immutability/rehabilitation } \\
\hline potential & -.11 & .16 & .13 \\
\hline Quasi-adaptive features & -.04 & .17 & .07 \\
\hline \multicolumn{4}{|l|}{$A Q$} \\
\hline Fear/Dangerousness & $-.21 *$ & -.10 & -.07 \\
\hline Help/Interact & $.29^{* \star *}$ & .05 & .02 \\
\hline Forcing treatment & -.01 & -.10 & -.04 \\
\hline Negative emotions & $-.34^{* * *}$ & $-.21^{*}$ & $-.20^{*}$ \\
\hline
\end{tabular}

\section{Regression Between Negative Emotions and Psychopathic Traits}

Due to the correlation of the negative emotions' subscale with all of the TriPM's subscales, a regression model was computed in order to determine the role of each subscale. As displayed in Table 3, boldness, meanness, and disinhibition produced a significant prediction model $(F(3,115)=5.98, p$ $=.001)$ accounting for $14 \%$ of the variance $\left(R^{2}=.14\right.$, Adjusted $\left.R^{2}=.12\right)$. Boldness was the only significant predictor.

Table 3. Regression model predicting negative emotions

\begin{tabular}{lrrrr} 
Scale & Standard error & $\beta$ & $t$ & Significance \\
\hline Boldness & .05 & -.31 & -3.36 & .001 \\
Meanness & .06 & -.02 & -0.19 & .849 \\
Disinhibition & .06 & -.13 & -1.19 & .236 \\
\hline
\end{tabular}




\section{Discussion}

Our study is the first, to our knowledge, to examine the relationship between the display of psychopathic traits and stigmatizing attitudes towards psychopaths, and also to assess if this relationship varies by type of psychopathic trait. Our findings support a negative association between the expression of psychopathic traits and stigmatization towards psychopaths.

Correlational analyses for scores on TriPM, ABP, and AQ revealed negative relationships between all subscales of the TriPM and various components of stigma. Examination of the ABP's results shows a negative association between the expression of psychopathic traits and stigma towards psychopaths. A previous study assessing stigmatizing attitudes towards psychopaths reported that workers from the forensic mental health system regarded psychopaths as highly crime-prone individuals, more so than average criminals (Sörman et al., 2014). Our results however suggest that participants who display higher levels of psychopathic traits may be less likely to assume the same. Interestingly, a reduced inclination to violence or criminal activities was seen in multiple components of the TriPM. It is possible that individuals who scored higher on psychopathic traits experience a certain connection with psychopaths, seeing them as less crime-prone and less violent than the general population. Indeed, while lack of empathy is widely considered a central component of psychopathy (Berg et al., 2013; Decety, Skelly, \& Kiehl, 2013), closer examination of the construct reveals that while psychopaths have empathy deficits on emotional and affective levels, they might not possess these deficits on cognitive levels, which has been supported by a lack of correlation between psychopathy and perspectivetaking abilities (Mullins-Nelson, Salekin, \& Leistico, 2006). Hence, our results suggest that, while psychopaths cannot feel an emotional connection through empathy, they can still relate to and imagine others' problems as their own. It is therefore plausible that increased psychopathic tendencies enable individuals to identify with psychopaths and judge them to be less violent. Alternatively, it is also possible that aggressive behaviors might be seen as more normative and less distressing for psychopathic individuals, and hence not seen as negatively.

Interestingly, the view that not all psychopaths are criminals was positively correlated with meanness and disinhibition, but not with boldness. Since boldness encompasses the adaptive component of psychopathy as defined by the triarchic model (Patrick et al., 2009), we had previously assumed that individuals high on boldness would project their attributes onto psychopaths, and therefore see them as more adaptive and less criminalityoriented. Alternatively, as previously mentioned, the positive association 
between seeing psychopaths as non-criminals and higher levels of meanness and disinhibition could stem from the normalisation of aggressive behaviors related to psychopathy.

To further examine the relationship between higher levels of psychopathic traits and reduced stigmatization towards psychopaths, additional correlations were computed between the TriPM and the AQ. The results support a negative association between psychopathic traits and stigmatizing attitudes towards psychopaths, and also support that this association is most strongly present in the interpersonal-affective features of psychopathy. As expected, higher levels of boldness are associated with a decrease in fear towards psychopaths, and individuals with higher levels of boldness will not see psychopaths as dangerous simply due to their diagnosis. These results are in line with the fearlessness component of psychopathy. As fearlessness is a central component within the interpersonal-affective facet of psychopathy (Lilienfeld et al., 2012; Lilienfeld \& Widows, 2005), and stigmatizing attitudes are partly led by fear (Corrigan, Druss, \& Perlick, 2014; Edens, Desforges, Fernandez, \& Palac, 2004), it is plausible that individuals with high boldness will not stigmatize psychopaths as they do not fear them. The same concept can be applied to the positive association between Boldness and the Help/Interact subscale. If individuals with high boldness demonstrate less fear towards psychopaths, they would therefore be less likely to abstain from interacting with or helping them purely due to their diagnosis.

While the aforementioned subscales of the $A Q$ were exclusively correlated with the boldness component of the TriPM, the negative emotions subscale showed a negative correlation with all three components of the TriPM. As noted previously, these results may stem from identification with the psychopathic personality. As psychopaths are less likely to be seen as criminals or violent predators by individuals with high levels of psychopathic traits, it is rational to infer that psychopaths themselves will not be prone to stigmatizing individuals with a similar display of psychopathic traits. However, a regression analysis confirmed that boldness is the only predictor of negative emotions towards psychopaths, supporting the potential relationship between reduced fear and lower stigmatization of psychopaths.

Overall, the relationship between the possession of psychopathic traits and stigmatizing attitudes towards psychopaths illustrates the necessity to take psychopathic traits into account when dealing with psychopaths, such as during judicial trials. Jury members' psychopathic traits could potentially influence a diagnosed psychopath's sentence due to an increase or decrease in their stigmatization. Since the media have a tendency to stigmatize 
psychopaths by frequently portraying them as ruthless killers (Berg et al., 2013), laypeople should be aware that their own personality traits can further influence their stigmatizing attitudes towards psychopaths. While the identified relationship between psychopathic traits and stigma is modest at best, further investigation of these two constructs could reveal unknown mechanisms related to the development of stigmatization.

\section{Limitations and Future Research}

This research possesses a few limitations. First, to our knowledge this study is the first to use the attribution questionnaire with a description of psychopathy. While the questionnaire itself has been developed and validated for use with a vignette depicting a case of schizophrenia, our newly developed vignette depicting a case of psychopathy has not been previously validated, and hence its results should be interpreted with caution. Furthermore, our community sample was comprised of individuals from all over the world, rendering our sample non-representative of a specific region or country. Additionally, while the ABP has been used in previous research (Smith et al., 2014; Sörman et al., 2014, 2016), none of these studies established a golden standard for the classification of the items into subscales. Instead, each study underwent its own PCA in order to develop a unique classification for its purpose. While we opted to classify our items based on Sörman and colleagues' (2014) results, our results cannot be directly compared to those obtained in the other studies (Smith et al., 2014; Sörman et al., 2016). Finally, while there are currently ongoing debates regarding the taxonomic status of psychopathy, we opted to accept the continuum hypothesis for our analyses, as psychopathic traits are commonly investigated on a continuum, especially within non-clinical populations (Guay, Ruscio, Knight, \& Hare, 2007).

The present study can be replicated with several improvements. First, a sample group of diagnosed psychopaths instead of a community group would provide information on how true psychopaths perceive other psychopaths. Second, future studies should propose alternative scenarios pertaining to different mental illnesses, in order to determine if the negative correlation we found applies only towards psychopaths or towards all individuals with mental illness.

\section{Conclusion}

In conclusion, the present study examined the relationship between possessing psychopathic traits and the perception of psychopaths in a community sample. While we found preliminary evidence for a negative correlation between the presence of psychopathic traits and the degree of 
stigmatization towards psychopaths, it is not possible to definitively establish the reason for this trend. As discussed, these results may plausibly be due to either identification with psychopaths or higher degrees of fearlessness. Nonetheless, these results provide potential insights into the connection between an individual's own expression of psychopathic traits and their perception of psychopaths. 


\section{References}

Anderson, J. L., Sellbom, M., Wygant, D. B., Salekin, R. T., \& Krueger, R. F. (2014). Examining the associations between DSM- 5 section III antisocial personality disorder traits and psychopathy in community and university samples. Journal of Personality Disorders, 28(5), 675-697.

Baskin-Sommers, A. R., Zeier, J. D., \& Newman, J. P. (2009). Self-reported attentional control differentiates the major factors of psychopathy. Personality and Individual Differences, 47(6), 626-630.

Berg, J. M., Smith, S. F., Watts, A. L., Ammirati, R., Green, S. E., \& Lilienfeld, S. O. (2013). Misconceptions regarding psychopathic personality: implications for clinical practice and research. Neuropsychiatry, 3(1), 63-74.

Brockington, I. F., Hall, P., Levings, J., \& Murphy, C. (1993). The community's tolerance of the mentally ill. The British Journal of Psychiatry, 162(1), 93-99.

Brown, S. A. (2008). Factors and measurement of mental illness stigma: A psychometric examination of the Attribution Questionnaire. Psychiatric Rehabilitation Journal, 32(2), 89-94.

Camp, J. P., Skeem, J. L., Barchard, K., Lilienfeld, S. O., \& Poythress, N. G. (2013). Psychopathic predators? Getting specific about the relation between psychopathy and violence. Journal of Consulting and Clinical Psychology, 81(3), 467-480.

Corrigan, P. W., Druss, B. G., \& Perlick, D. A. (2014). The Impact of Mental Illness Stigma on Seeking and Participating in Mental Health Care. Psychological Science in the Public Interest, 15(2), 37-70.

Corrigan, P. W., Markowitz, F. E., Watson, A., Rowan, D., \& Kubiak, M. A. (2003). An attribution model of public discrimination towards persons with mental illness. Journal of Health and Social Behavior, 44(2), 162-179.

Corrigan, P. W., \& Watson, A. C. (2002). Understanding the impact of stigma on people with mental illness. World psychiatry, 1(1), 16-20.

Cox, J., Clark, J. C., Edens, J. F., Smith, S. T., \& Magyar, M. S. (2013). Jury panel member perceptions of interpersonal-affective traits of psychopathy predict support for execution in a capital murder trial simulation. Behavioral sciences \& the law, 31(4), 411-428.

Decety, J., Skelly, L. R., \& Kiehl, K. A. (2013). Brain response to empathy-eliciting scenarios involving pain in incarcerated individuals with psychopathy. JAMA Psychiatry, 70(6), 638-645.

Dindo, L., \& Fowles, D. (2011). Dual temperamental risk factors for psychopathic personality: evidence from self-report and skin conductance. Journal of Personality and Social Psychology, 100(3), 557-566.

Edens, J. F., Colwell, L. H., Desforges, D. M., \& Fernandez, K. (2005). The impact of mental health evidence on support for capital punishment: Are defendants labeled psychopathic considered more deserving of death? Behavioral Sciences and the Law, 23(5), 603-625. 
Edens, J. F., Desforges, D. M., Fernandez, K., \& Palac, C. A. (2004). Effects of psychopathy and violence risk testimony on mock juror perceptions of dangerousness in a capital murder trial. Psychology, Crime \& Law, 10(4), 393412.

Edens, J. F., Marcus, D. K., Lilienfeld, S. O., \& Poythress, N. G. (2006). Psychopathic, not psychopath: taxometric evidence for the dimensional structure of psychopathy. Journal of Abnormal Psychology, 115(1), 131-144.

Feldman, D. B., \& Crandall, C. S. (2007). Dimensions of Mental Illness Stigma: What About Mental IIIness Causes Social Rejection? Journal of Social and Clinical Psychology, 26(2), 137-154.

Gao, Y., Glenn, A. L., Schug, R. A., Yang, Y., \& Raine, A. (2009). The neurobiology of psychopathy: A neurodevelopmental perspective. Canadian Journal of Psychiatry, 54(12), 813-823.

Gray, D. E. (2002). "Everybody just freezes. Everybody is just embarrassed": felt and enacted stigma among parents of children with high functioning autism. Sociology of Health \& IIIness, 24(6), 734-749.

Guay, J.-P., Ruscio, J., Knight, R. A, \& Hare, R. D. (2007). A Taxometric Analysis of the Latent Structure of Psychopathy: Evidence for Dimensionality. Journal of Abnormal Psychology, 116(4), 701-716.

Hall, J., \& Benning, S. (2006). The "successful" psychopath: adaptive and subclinical manifestations of psychopathy in the general population. In C. J. Patrick (Ed.), Handbook of psychopathy (Guilford P, pp. 459-478). NY, USA.

Hall, J., Benning, S. D., \& Patrick, C. J. (2004). Criterion-Related Validity of the ThreeFactor Model of Psychopathy: Personality, Behavior, and Adaptive Functioning. Assessment, 11(1), 4-16.

Helfgott, J. B. (1997). The popular conception of the psychopath: Implications for criminal justice policy and practice. In 34th Annual Meeting of the Academy of Criminal Justice Sciences, Louisville, $K Y$.

Kiehl, K. A., \& Hoffman, M. B. (2011). The criminal psychopath: History, neuroscience, treatment, and economics. Jurimetrics, 51, 355-397.

Lilienfeld, S. O., Patrick, C. J., Benning, S. D., Berg, J., Sellbom, M., \& Edens, J. F. (2012). The role of fearless dominance in psychopathy: Confusions, controversies, and clarifications. Personality Disorders: Theory, Research, and Treatment, 3(3), 327-340.

Lilienfeld, S., \& Widows, M. (2005). Psychopathic personality inventory-revised: Professional manual. Lutz, FL: Psychological Assessment Resources.

Link, B. G., \& Phelan, J. C. (2001). Conceptualizing Stigma. Annual Review of Sociology, 27, 363-385.

López, R., Poy, R., Patrick, C. J., \& Moltó, J. (2013). Deficient fear conditioning and self-reported psychopathy: The role of fearless dominance. Psychophysiology, 50(2), 210-218.

Mullins-Nelson, J. L., Salekin, R. T., \& Leistico, A.-M. R. (2006). Psychopathy, Empathy, and Perspective -Taking Ability in a Community Sample: Implications for the 


\section{Chapter 4 | Psychopathy and Stigmatization}

Successful Psychopathy Concept. International Journal of Forensic Mental Health, 5(2), 133-149.

Panier, S., Van Remoortere, A., Van den Bogaert, A., \& Uzieblo, K. (2014). Fearing the unknown? The relationship between familiarity and attitudes towards psychopathy. The Treatment of Psychopathy: Making the Impossible Possible? Thomas More.

Patrick, C. J. (2010). Triarchic psychopathy measure (TriPM). PhenX Toolkit Online assessment catalog.

Patrick, C. J., Fowles, D. C., \& Krueger, R. F. (2009). Triarchic conceptualization of psychopathy: Developmental origins of disinhibition, boldness, and meanness. Development and Psychopathology, 21(3), 913-938.

Scambler, G. (2006). Sociology, social structure and health-related stigma. Psychology, Health \& Medicine, 11(3), 288-295.

Scheff, T. J. (1963). The Role of the Mentally III and the Dynamics of Mental Disorder: A Research Framework. Sociometry, 26(4), 436-453.

Sheehan, L., Nieweglowski, K., \& Corrigan, P. (2016). The Stigma of Personality Disorders. Current Psychiatry Reports, 18(11), 1-7.

Smith, S. T., Edens, J. F., Clark, J., \& Rulseh, A. (2014). "So, what is a psychopath?" Venireperson perceptions, beliefs, and attitudes about psychopathic personality. Law and Human Behavior, 38(5), 490-500.

Sörman, K., Edens, J. F., Smith, S. T., Clark, J. W., Kristiansson, M., \& Svensson, O. (2016). Boldness and Its Relation to Psychopathic Personality: Prototypicality Analyses Among Forensic Mental Health, Criminal Justice, and Layperson Raters. Law and Human Behavior, 40(3), 337-349.

Sörman, K., Edens, J. F., Smith, S. T., Svensson, O., Howner, K., Kristiansson, M., \& Fischer, H. (2014). Forensic mental health professionals' perceptions of psychopathy: A prototypicality analysis of the comprehensive assessment of psychopathic personality in Sweden. Law and Human Behavior, 38(5), 405-417.

Taylor, S. M., \& Dear, M. J. (1981). Scaling community attitudes toward the mentally ill. Schizophrenia Bulletin, 7(2), 225-240.

Wayland, K., \& O'Brien, S. D. (2013). Deconstructing antisocial personality disorder and psychopathy: a guidelines-based approach to prejudicial psychiatric labels. Hofstra Law Review, 42(2), 519-589. 




\section{Chapter 5}

The Interplay of Gender, Parental Behaviors, and Child Maltreatment in Relation to Psychopathic Traits

Durand, G., \& de Calheiros Velozo, J. (2018).The interplay of gender, parental behaviors, and child maltreatment in relation to psychopathic traits.

Child Abuse \& Neglect, 83(C), 120-128. 


\section{Abstract}

Many studies have reported a positive association between childhood maltreatment and parenting behavior with the future development of psychopathic traits. However, there is a limited amount of research on parenting behavior and adult psychopathic traits as possible identifiers of childhood maltreatment. The aim of this study is three-fold (1) identify specific parenting behaviors and adult psychopathic traits that predict forms of childhood maltreatment, (2) explore potential differences between predictors of childhood maltreatment and gender, and (3) expand on other studies in psychopathy by focusing on a representative sample of the community as opposed to clinical and student populations. Results showed significant associations between recalled childhood maltreatment and parenting behavior, and psychopathic traits. Parental rejection was the most recurrent predictor of childhood maltreatment with a significant positive relation to almost all its forms (e.g. emotional, physical, and sexual abuse, as well as physical neglect). Paternal overprotection was positively associated with sexual abuse, while the opposite was true for maternal overprotection. Psychopathic traits displayed in adulthood were also strong indicators of childhood maltreatment; females with high levels of boldness were more likely to have experienced sexual abuse in childhood, and those high in disinhibition were more likely to have experienced physical neglect and sexual abuse. While males were generally higher in terms of psychopathic traits, females reported more childhood abuse and negative parental behaviors. These findings provide support for using parenting behavior and psychopathic traits as markers of childhood maltreatment. 


\section{Introduction}

\section{Childhood Maltreatment}

Epidemiological studies exploring childhood maltreatment have faced several obstacles to properly assess its prevalence, namely weaknesses in the various methodologies used to record it (Cicchetti \& Toth, 2005). For instance, Edwards, Holden, Felitti, and Anda (2003) found that $21.6 \%$ of adults report having been victims of sexual abuse in childhood but numbers vary from $3 \%$ to $36 \%$ depending on the study and the sample (Scher, Forde, McQuaid, \& Stein, 2004). However, prevalence of childhood maltreatment is understood to be high, with physical abuse and neglect, as well as emotional abuse being the most commonly reported forms of maltreatment (Scher et al., 2004).

Childhood maltreatment involves abuse and/or neglect perpetuated by an adult on a minor. Five types of maltreatment have been identified: (1) emotional abuse, (2) physical abuse, (3) emotional neglect, (4) physical neglect, and (5) sexual abuse. Emotional abuse and physical abuse are defined as harm caused by an adult on a child. The former being a verbal attack that may result in humiliation and decreased sense of worth, and the latter a physical attack resulting in bodily harm. Emotional neglect and physical neglect are defined as failures to attend to a child's emotional (e.g. love, support) or physical needs (e.g. shelter, food) respectively. Sexual abuse refers to any sexual contact between an adult and an underage child (Bernstein et al., 2003). People who report these types of abuse are likely to exhibit long-term effects that carry on into adulthood (Cicchetti \& Toth, 2005).

Victims of childhood maltreatment are four times more likely than controls to develop personality disorders later in life (Johnson, Cohen, Brown, Smailes, \& Bernstein, 1999). Different types of abuse have different effects in later development. For instance, psychopathic personality disorders (e.g. antisocial, sadistic traits etc.) are mostly associated with physical and emotional abuse, as well as neglect (Bernstein, Stein, \& Handelsman, 1998).

Additionally, studies have pointed to variances in the type of psychopathic traits developed in relation to the type of maltreatment experienced in childhood. For example, in a sample of male sexual offenders, sexual abuse was related to all aspects of psychopathy. On the other hand, physical abuse and neglect in childhood were only related to disinhibition (Graham, Kimonis, Wasserman, \& Kline, 2012). Similarly, research on a sample of undergraduate students found an association between selfreported childhood maltreatment and disinhibition and meanness, but not with boldness (Watts et al., 2017). 


\section{Psychopathy}

Psychopathy is a multidimensional personality disorder characterized by a lack of empathy, guilt, and behavioral inhibition, combined with high levels of superficial charm, deceitfulness, egoism, and fearlessness (Berg et al., 2013; Hart, Cox, \& Hare, 2003). Contrary to popular belief, psychopathy is not a strong predictor of later violence in adulthood (Berg et al., 2013).

Several models have been conceptualized to better understand psychopathy, such as the Triarchic model of psychopathy (Patrick, Fowles, \& Krueger, 2009). The model is divided in three dimensions: meanness, disinhibition, and boldness. Meanness denotes a lack of empathy, low socialization and attachment, an absence of guilt, and a general mean attitude towards others. Disinhibition relates to the inability to control one's impulses, which in turn creates an inability to weigh the consequences of one's actions. Together, these two traits encompass the maladaptive component of psychopathy. In contrast, boldness deals with traits such as fearlessness, social dominance, stress immunity, and thrill seeking. These characteristics are understood as adaptive (Patrick, 2010).

There is a long-standing debate over the nature of psychopathy, whether it is innate or acquired. Most evidence suggests that it is an interplay between genetic make-up and environment (Hicks et al., 2012). Several studies have explored childhood maltreatment as an environmental factor contributing to the later development of psychopathy (Gao, Raine, Chan, Venables, \& Mednick, 2013; Graham, Kimonis, Wasserman, \& Kline, 2012; Watts, Donahue, Lilienfeld, \& Latzman, 2017).

Psychopathy is a personality trait that is best understood through a continuum, meaning that some elements of psychopathy will be found to some degree in most individuals (Berg et al., 2013). Furthermore, at the exception of a recent study by Watts et al., (2017) most studies on the subject have focused mainly on samples composed of participants with a history of problems, either mental (i.e. institutionalized), or conduct problems (i.e. drugs, or criminal past) (Bernstein, Stein, \&Handelsman, 1998; Graham, Kimonis, Wasserman, \& Kline, 2012; Kimonis, Cross, Howard, \& Donoghue, 2013).

\section{Parenting Behavior}

Early exposure to dysfunctional family environments has a significant influence in a child's personality and increases the likelihood of them developing psychopathic traits (Belsky, Steinberg, \& Draper, 1991; Saltaris, 2002). For instance, undergraduates who reported lower parental bonding (i.e. maternal care, paternal overprotection), physical abuse, and being separated from their parents as a child also reported greater levels of psychopathic traits 
(Gao, Raine, Chan, Venables, \& Mednick, 2013). Likewise, male adolescent offenders who reported low maternal care were also more likely to display callous-unemotional traits characteristic of psychopathy (Kimonis et al., 2013).

Additionally, childhood maltreatment and parental behavior have different effects on children depending on their gender. In fact, while male juvenile offenders showed a significant positive relation between victimization and violence and the development of psychopathic traits, female juveniles were more likely to develop those traits if they came from a dysfunctional family background, such as changing foster homes (Krischer \& Sevecke, 2008).

Parenting behavior is composed of three factors, namely rejection, overprotection, and emotional warmth. Each factor is studied separately for the mother and the father. Rejection is when a parent belittles the child in front of others, when the child is over punished and often without justification. Over protection is characterized by an overbearing parent who constantly worries about the child, demanding to know where s/he is at all times and limiting their actions. Lastly, emotional warmth is characterized by nurturing. Parents who are emotionally warm provide emotional support and encouragement, as well as a stimulating environment for their child to grow in (Arrindell et al., 1999).

\section{Gender}

There is a debate over gender differences in childhood abuse reports. Some studies found that males were more likely to report childhood abuse (Watts, Donahue, Lilienfeld, \& Latzman, 2017) while others found higher reported abuse among females (Láng \& Lénárd, 2015).

In addition, the vast majority of studies in the field of psychopathy were performed exclusively in male samples, leading to a lack of information regarding gender differences (Cale \& Lilienfeld, 2002). Although multiple studies reported significantly higher psychopathy scores in males than females (Durand, 2018; Durand \& Plata, 2017; Hicks et al., 2012; Lee \& Salekin, 2010; Lilienfeld \& Hess, 2001), an extensive examination by Miller, Watts, and Jones (2011) provided evidence that despite mean-level differences observed across many studies, the manifestation pattern of psychopathy does not vary between gender, albeit a few exceptions (e.g. traits related to impulsivity and openness). To identify markers of childhood abuse and maltreatment in adulthood it is essential to account for gender differences.

\section{The Current Study}

The aim of this study is three-fold (1) identify specific parenting behaviors and psychopathic traits that predict forms of childhood maltreatment, (2) explore 
gender differences, and (3) expand on other studies on psychopathy by focusing on a representative sample of the community. We hypothesized parenting behavior and psychopathic traits are significant markers to predict childhood maltreatment and that these differ between gender.

\section{Methods}

\section{Participants}

All participants received informed consent and received a debriefing at the end of the study. Four hundred $(N=400)$ participants were recruited online via social media and websites dedicated to psychological research. Ethical approval was awarded by the IntegReview Ethical Review Board (Austin, TX, USA) and given 'exempt' status under the protocol number 11022016. No names or other protected health information, as defined by the Health Insurance Portability and Accountability Act (HIPAA), were recorded. All participants agreed to the informed consent form with detailed information about the nature, the goal, and procedure of the study prior starting the experiment. Participants remained anonymous throughout the study. Examination of potential outliers was performed with the Triarchic Assessment Procedure for Inconsistent Responding (TAPIR; Mowle et al., 2017). Participants' score ranged from 0 to 11 , and therefore no protocol was removed from the study. Inclusion criteria to the study were to be over 18 years old and be fluent in English. $70 \%$ of participants were females $(N=279)$. Most participants reported being located in North America (57\%) or Europe (33\%). In terms of ethnicity, most participants reported being Caucasian (81\%) or Asian (8\%). Almost half the participants reported being currently enrolled as a full-time student in a university (44\%). Participants were mostly single $(45 \%)$, in a relationship $(20 \%)$, married $(16 \%)$, or living with a partner $(16 \%)$. Their age ranged from 18 to 56 years old, with a mean age of $26.2(S D=7.40)$.

\section{Materials}

\section{Childhood Trauma Questionnaire - Short Form (CTQ; Bernstein} et al., 2003)

The CTQ is a 28-item self-report instrument assessing childhood maltreatment. The measure is divided into 5 subscales, namely Emotional abuse, Physical abuse, Emotional neglect, Physical neglect, and Sexual abuse. The CTQ includes items such as "Not having enough to eat", "Made to do sexual things", and "Punished with hard objects". Previous studies established adequate internal consistency reliability on all subscales in a community sample (Watts et al., 2017). Cronbach a ranged between .78 and .97 for the CTQ total score and the five subscales. Across emotional 
abuse, emotional neglect, and physical neglect, Skewness ranged between 0.191 and 1.889, and Kurtosis ranged between -1.192 and 1.707. Due to the high Skewness (2.297) and Kurtosis (4.216) of the Sexual abuse subscale, as well as the high Kurtosis of physical abuse subscale (3.110), we recoded the CTQ's scores based on the user manual's proposed cut-off score for the general population: 1 = none, and 2 = low, moderate, and severe. This scoring method has been used in previous research in the field of psychopathy (Sevecke, Franke, Kosson, \& Krischer, 2016).

\section{Triarchic Psychopathy Measure (TriPM; Patrick, 2010)}

The TriPM is a self-reported questionnaire containing 58 items assessing psychopathic traits. Items are rated on a 4-point Likert scale from 1 (True) to 4 (False). The instrument was designed to assess psychopathic traits using the Triarchic model of psychopathy and provides a total score alongside three subscale scores: Disinhibition, Meanness, and Boldness. It includes items such as "I've often missed things I promised to attend", and "I have robbed someone" to measure Disinhibition; "I return insults" and "I enjoy pushing people around sometimes" to measure Meanness, and finally to for Boldness it includes items such as "I am well-equipped to deal with stress" and "I'm a born leader". The TriPM has a high internal consistency in a community sample, with a Cronbach a's of $.87, .85$, and .82 for Boldness, Meanness, and Disinhibition respectively. The TriPM also has high construct validity and strong correlations with other measures of psychopathy, and has demonstrated good validity in community sample (Patrick, 2010; van Dongen, Drislane, Nijman, Soe-Agnie, \& van Marle, 2017).

\section{Short-EMBU (s-EMBU; Arrindell et al., 1999)}

The s-EMBU is a 23-item questionnaire, derived from the original 81 -item version, and is used for assessing the perceived parental rearing behavior on a 4-point Likert scale. Participants responded to the questionnaire twice, once in relation to their father's behavior and once in relation to their mother's behavior. The s-EMBU is divided in three factors, namely Rejection, Overprotection, and Emotional Warmth. The instrument includes items such as "My parents praised me", "I felt warmth and tenderness existed between me and my parents", and "I felt that my parents interfered with everything I did". Participants fill each item for the father and the mother separately. The short version of the questionnaire was subsequently validated internationally in community samples, providing a reliable alternative to its extended version (Arrindell et al., 1999; Arrindell et al., 2001). In the present study, Cronbach $\alpha$ ranged between .88 and .93 for the three subscales for the mother and 
between .86 and .92 for the father. Across the six scales, Skewness ranged between -0.317 and 1.081, and Kurtosis ranged between -1.133 and 0.193 .

\section{Variables}

For analyses purposes, we used the following categorization for demographic variables. University enrollment was categorized as yes or no. Gender was categorized as male or female. Location was categorized as North America or Europe. The marital status was categorized as single or in a relationship.

\section{Statistical Analysis}

ANOVA by scales for the TriPM, the CTQ, and the EMBU by gender were used to obtain preliminary information on the mean of each questionnaire. Gender differences for each questionnaire were further confirmed using chisquare analysis. Person's correlations were used to examine the associations between the CTQ and the EMBU, as well as the TriPM on the CTQ and the EMBU. Binomial logistic regression analyses were conducted, stratified by gender, with the primary outcome being each of the CTQ subscales (no abuse $=0$ versus abused $=1$ ). Predictors variables were the three subscales of the TriPM, the six subscales of the EMBU, age, location, marital status, and university student status.

\section{Results}

The Role of Gender on Psychopathy, Childhood Maltreatment, and Parenting Behavior

An ANOVA was performed to investigate gender differences in regards to psychopathic traits, childhood maltreatment, and parenting behavior (Table 1). Results show that males score significantly higher than females in all aspects of psychopathy except for disinhibition. On the contrary, females scored significantly higher than males on emotional and sexual abuse. These results were confirmed in chi-square analyses, were as the proportion of females $(73 \%)$ who have experienced some sort of emotional abuse was significantly higher than the proportion of males $(58 \%) ; X(1)=9.117, p=.003$. A similar trend was observed for the sexual abuse subscale, whereas the proportion of females $(35 \%)$ who have experienced some sort of sexual abuse was also significantly higher than the proportion of males $(12 \%) ; X(1)=21.510, p<.001$. Additional chi-square analyses revealed no gender difference between males $(27 \%)$ and females (34\%) who have experienced physical abuse $X(1)=1.967$, $p=.161$, between males $(68 \%)$ and females $(73 \%)$ who have experienced emotional neglect $X(1)=1.026, p=.311$, and between males $(44 \%)$ and females (51\%) who have experienced physical neglect $X(1)=1.533, p=.216$. 


\section{The Relationship Between Childhood Maltreatment and Parenting Behavior}

As shown in Table 2, a Pearson correlation was performed between childhood maltreatment and parenting behavior. Emotional and physical abuse were significantly related to all components of parenting behavior. These relations were negative for maternal and paternal warmth. Similarly, emotional and physical neglect were significantly associated to most aspects of parenting behavior, with the exception of paternal overprotection, and maternal overprotection with regards to physical neglect.

\section{The Relationship Psychopathic Traits, Childhood Abuse, and Parenting Behavior}

A second Pearson correlation was performed to test for the relationship between psychopathic traits, childhood maltreatment, and parental behavior (Table 3). Results show weak to moderate significant associations between disinhibition and almost all aspects of childhood maltreatment and parental behavior, with the exception of sexual abuse and paternal overprotection. Meanness was positively related to emotional neglect and maternal overprotection, and negatively related to maternal and paternal emotional warmth. Lastly, boldness was negatively related to both emotional abuse and physical neglect.

\section{Predictors of Childhood Maltreatment}

A series of binomial logistic regressions were performed to ascertain the effect of psychopathic traits, parental behavior, age, marital status, university status, and location on the likelihood that participants report some form of childhood maltreatment. Analyses were stratified by gender.

As shown in Table 4, within males, rejection by the mother and the father both increases the likelihood of reporting emotional abuse during the childhood (range of ORs, 1.8-1.9). Additionally, being older, being a university student, and receiving emotional warmth from the mother and the father during childhood decreases the likelihood of reporting physical neglect. 
Table 1. Gender differences on the measured variables; results of ANOVAs.

\begin{tabular}{|c|c|c|c|c|c|c|}
\hline & \multicolumn{2}{|c|}{$\begin{array}{l}\text { Males } \\
(n=121)\end{array}$} & \multicolumn{2}{|c|}{$\begin{array}{l}\text { Females } \\
(\mathrm{n}=279)\end{array}$} & \multirow[b]{2}{*}{$\mathrm{F}$} & \multirow[b]{2}{*}{$p$} \\
\hline & $M$ & SD & $M$ & SD & & \\
\hline \multicolumn{7}{|l|}{ TriPM } \\
\hline Total & 120.45 & 20.34 & 112.97 & 18.37 & 13.108 & $<.001$ \\
\hline Disinhibition & 39.20 & 9.77 & 39.5 & 9.42 & 0.083 & 0.774 \\
\hline Meanness & 35.61 & 10.41 & 31.65 & 9.36 & 14.059 & $<.001$ \\
\hline Boldness & 45.63 & 10.60 & 41.81 & 10.59 & 11.009 & 0.001 \\
\hline \multicolumn{7}{|l|}{ CTQ } \\
\hline EA & 11.65 & 6.08 & 13.85 & 6.29 & 10.455 & 0.001 \\
\hline PA & 7.63 & 4.03 & 7.99 & 4.34 & 0.604 & 0.437 \\
\hline SA & 5.99 & 3.46 & 8.02 & 5.63 & 13.57 & $<.001$ \\
\hline EN & 13.58 & 6.03 & 13.8 & 5.57 & 0.125 & 0.724 \\
\hline PN & 7.76 & 3.06 & 8.67 & 3.96 & 5.114 & 0.024 \\
\hline \multicolumn{7}{|l|}{ EMBU-M } \\
\hline Rejection & 12.01 & 5.01 & 13.48 & 6.00 & 5.205 & 0.023 \\
\hline OP & 21.64 & 6.21 & 21.96 & 7.33 & 0.173 & 0.678 \\
\hline EW & 17.07 & 5.34 & 16.47 & 5.50 & 1.025 & 0.312 \\
\hline \multicolumn{7}{|l|}{ EMBU-F } \\
\hline Rejection & 12.07 & 5.29 & 12.37 & 5.36 & 0.255 & 0.614 \\
\hline OP & 17.2 & 6.11 & 17.44 & 6.30 & 0.735 & 0.735 \\
\hline EW & 14.11 & 5.05 & 14.19 & 5.48 & 0.022 & $=.883$ \\
\hline
\end{tabular}


Table 2. Results of Pearson's correlation for CTQ and EMBU

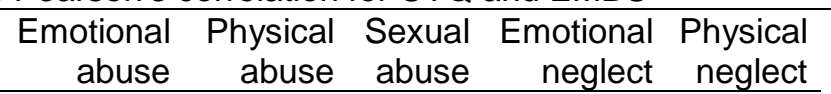

\begin{tabular}{|c|c|c|c|c|c|}
\hline \multicolumn{6}{|l|}{ EMBU-M } \\
\hline Rejection & $.60^{*}$ & $.53^{*}$ & $.20^{*}$ & $.55^{\star}$ & $.50^{*}$ \\
\hline \multirow{2}{*}{$\begin{array}{l}\text { Over-protection } \\
\text { Emotional } \\
\text { warmth }\end{array}$} & $.29^{*}$ & $.24^{*}$ & .01 & $.22^{*}$ & .10 \\
\hline & $-.51^{*}$ & $-.37^{*}$ & -.14 & $-.74^{*}$ & $-.51^{*}$ \\
\hline \multicolumn{6}{|l|}{ EMBU-F } \\
\hline Rejection & $.59^{\star}$ & $.40^{*}$ & $.21^{*}$ & $.45^{\star}$ & $.41^{*}$ \\
\hline \multirow{2}{*}{$\begin{array}{l}\text { Over-protection } \\
\text { Emotional } \\
\text { warmth }\end{array}$} & $.24^{*}$ & $.18^{*}$ & .14 & .15 & .11 \\
\hline & $-.48^{\star}$ & $-.23^{*}$ & -.13 & $-.57^{\star}$ & $-.42^{*}$ \\
\hline
\end{tabular}

Note. ${ }^{*}$ indicates $p \leq .001$. EMBU-M = EMBU-Mother; EMBU-F = EMBU-Father.

Table 3. Results of Pearson's correlation for TriPM, and EMBU, and CTQ $(N=400)$

\begin{tabular}{lrrrr}
\hline & $\begin{array}{r}\text { TriPM } \\
\text { total }\end{array}$ & $\begin{array}{r}\text { TriPM } \\
\text { disinhibition }\end{array}$ & $\begin{array}{r}\text { TriPM } \\
\text { meannes } \\
\text { s }\end{array}$ & $\begin{array}{r}\text { TriPM } \\
\text { boldness }\end{array}$ \\
\hline CTQ & & & & \\
Emotional abuse & .11 & $.31^{*}$ & .13 & $-.20^{*}$ \\
Physical abuse & .14 & $.24^{*}$ & .07 & -.03 \\
Sexual abuse & .07 & .15 & -.03 & .02 \\
Emotional neglect & .11 & $.26^{*}$ & $.22^{*}$ & $-.23^{*}$ \\
Physical neglect & .11 & $.28^{*}$ & .09 & -.13 \\
& & & & \\
EMBU-M & & & & \\
Rejection & .12 & $.22^{*}$ & .14 & -.11 \\
Over-protection & $.18^{*}$ & $.18^{*}$ & $.18^{*}$ & .01 \\
Emotional warmth & -.09 & $-.16^{*}$ & $-.18^{*}$ & .14 \\
EMBU-F & & & & \\
Rejection & .15 & $.22^{*}$ & .13 & -.05 \\
Over-protection & .15 & .11 & .12 & .05 \\
Emotional warmth & -.14 & $-.19^{*}$ & $-.20^{*}$ & .10 \\
\hline
\end{tabular}

Note. ${ }^{*}$ indicates $\mathrm{p} \leq .001$. EMBU-M = EMBU-Mother; EMBU-F = EMBU-Father 


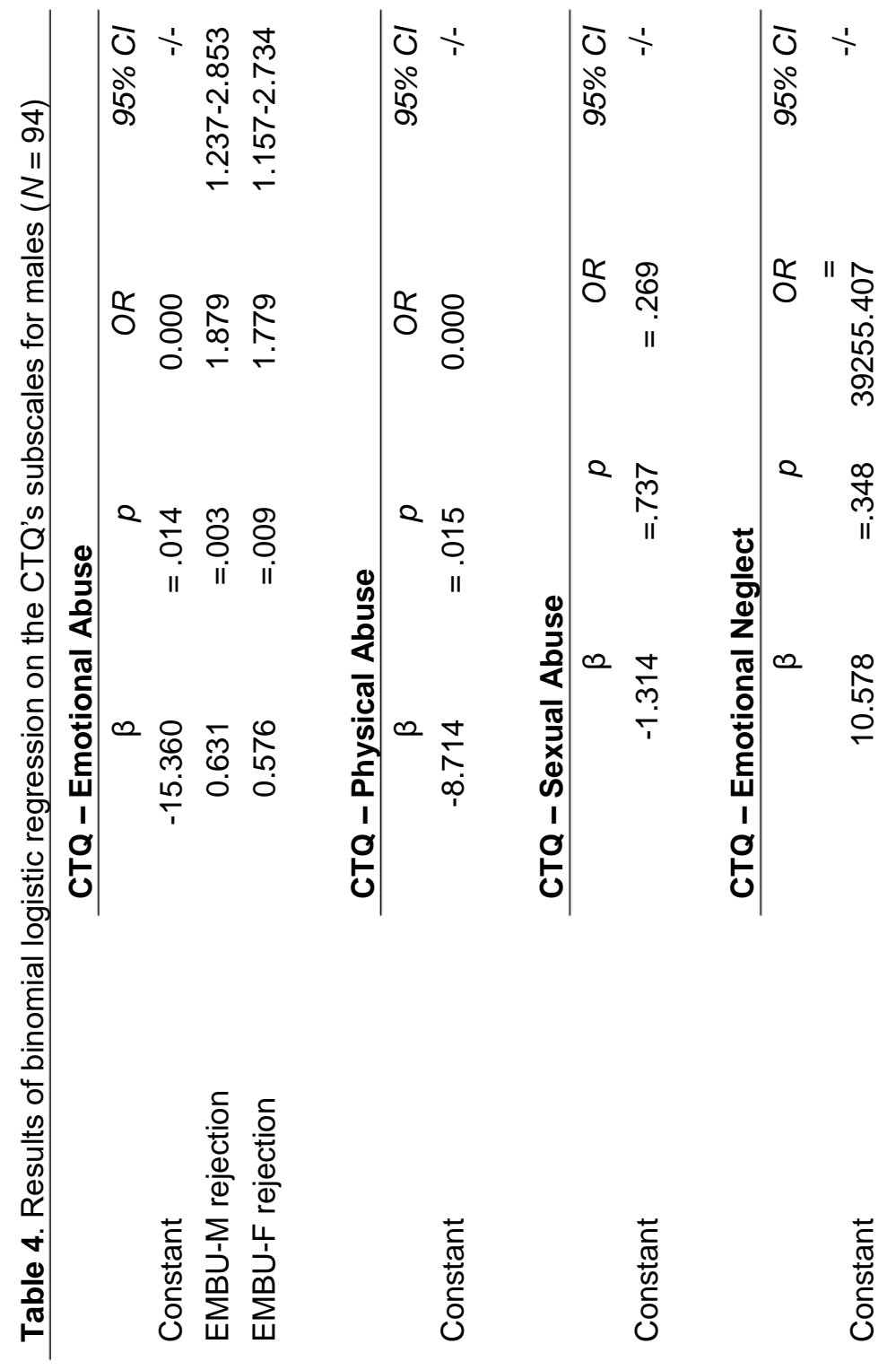




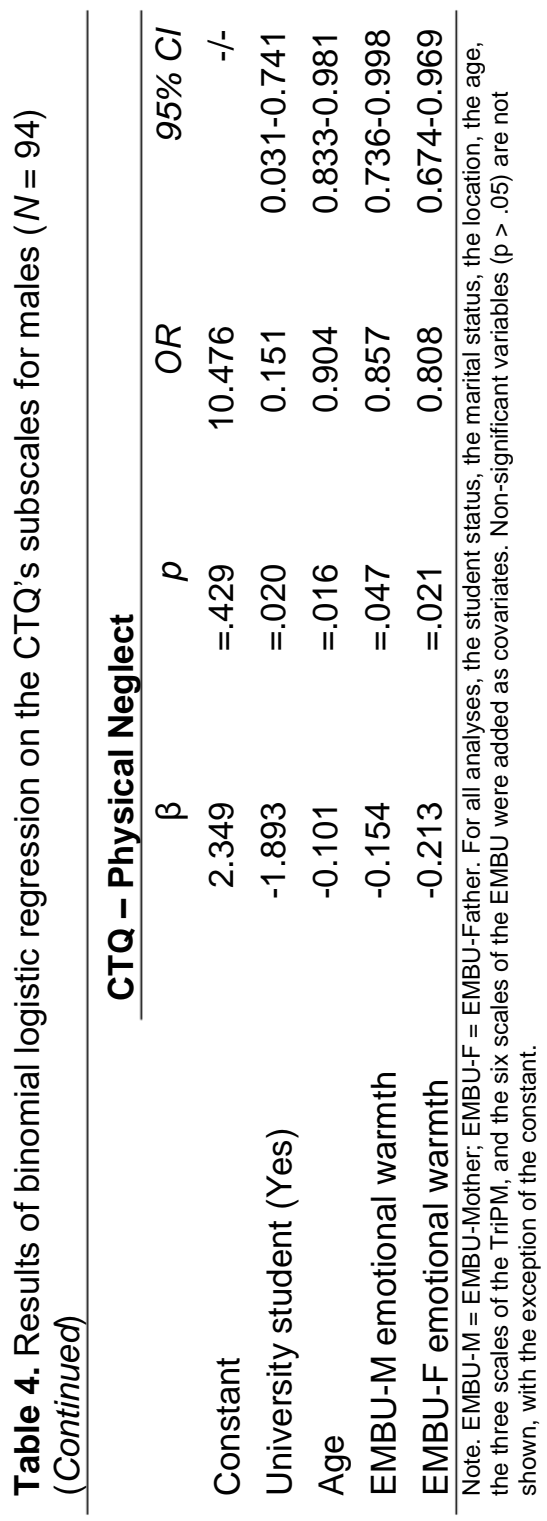




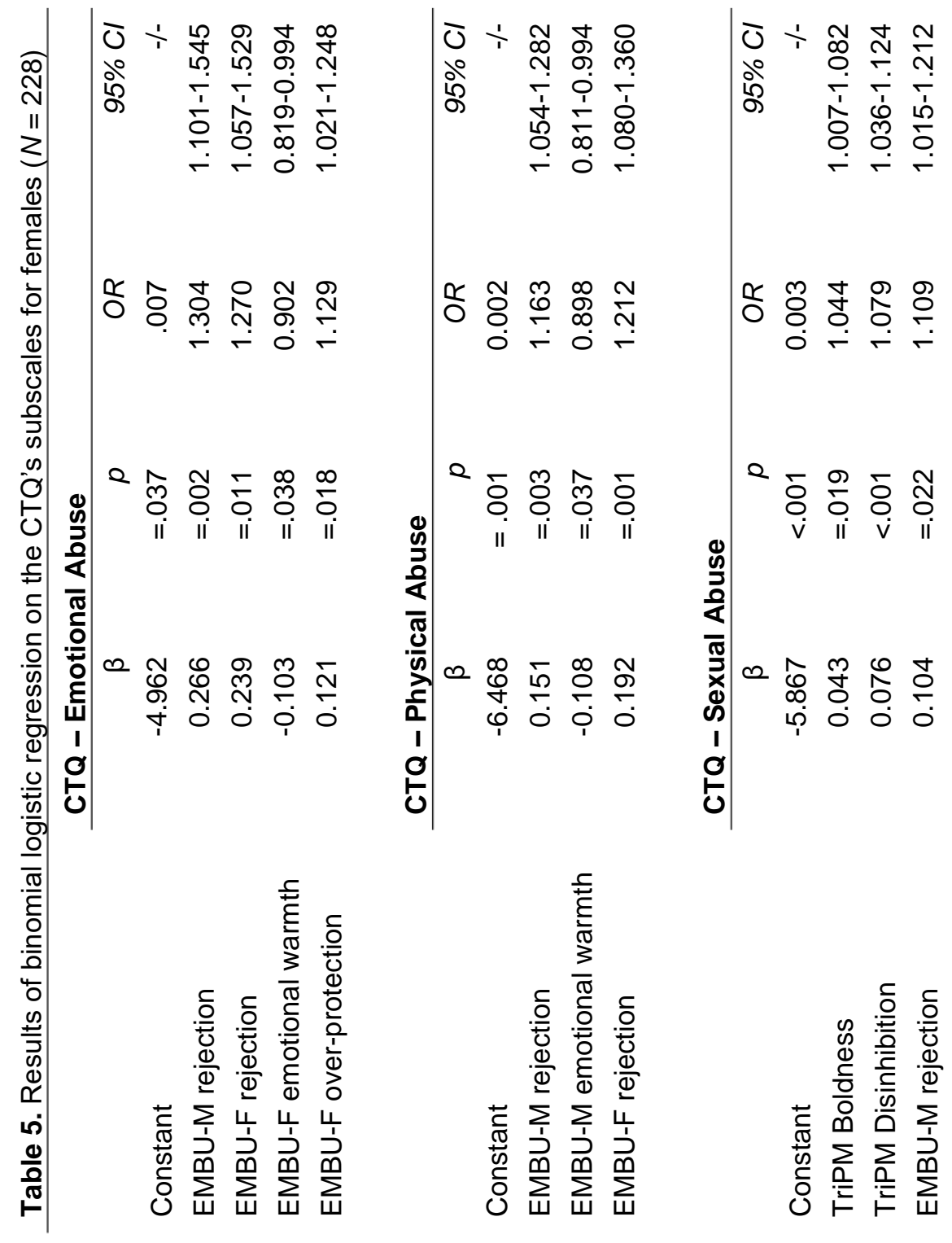




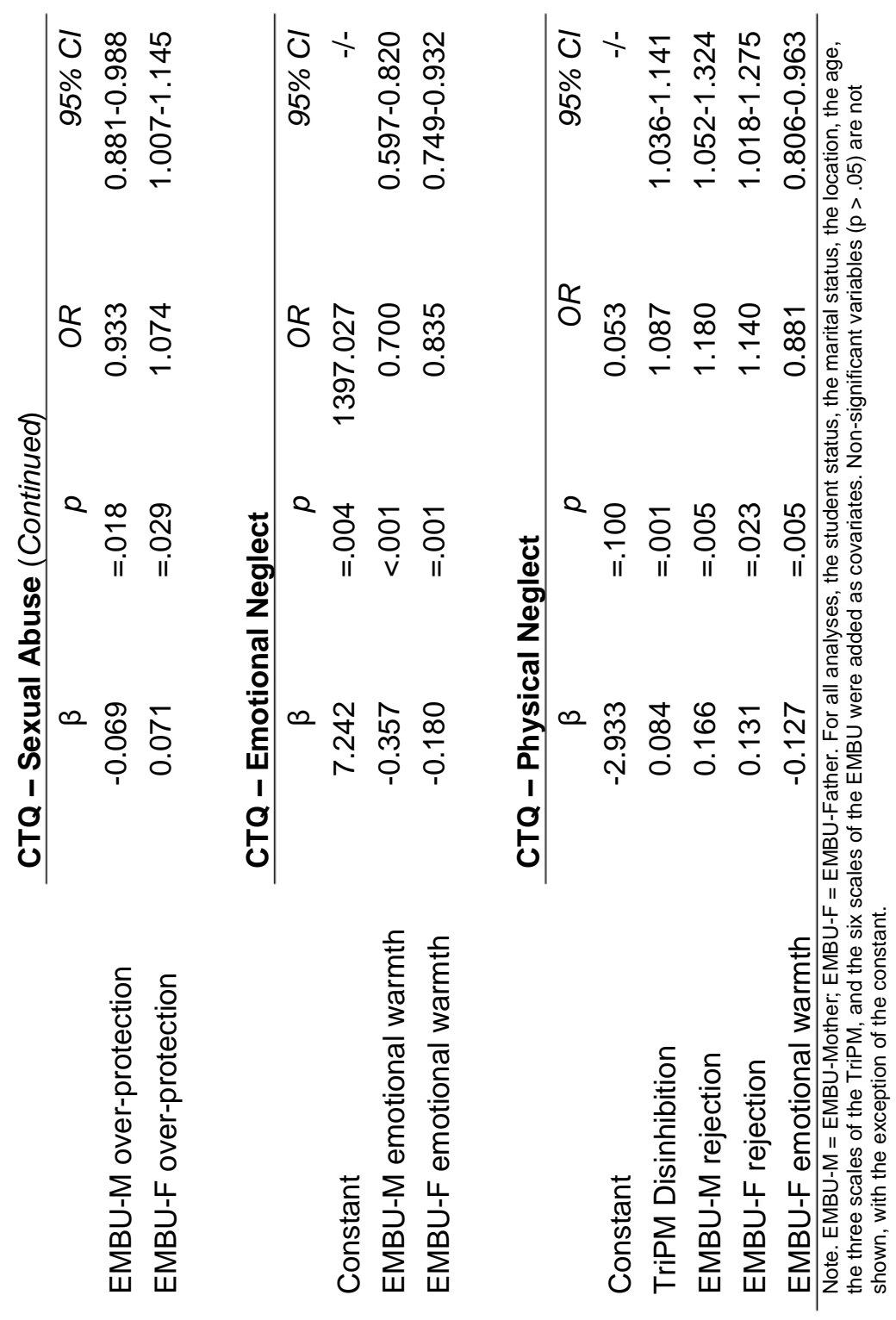




\section{Chapter 5 | Psychopathy and Childhood Trauma}

While only two of the CTQ subscales showed significant predictors for males, all CTQ subscales showed multiple significant predictors for females (Table 5). Rejection from the mother and the father, as well as over protection from the father, increases the odds of reporting emotional abuse, while emotional warmth from the father decreases the odds. Similarly, rejection from the mother and the father increases the odds of physical abuse, but emotional warmth from the mother decreases it. Boldness, disinhibition, rejection from the mother, and over-protection from the father are associated with higher likelihood of reporting sexual abuse, while over-protection from the mother decreases the odds. Emotional warmth from the mother and the father decrease the likelihood of reporting emotional neglect. Lastly, disinhibition, and rejection from both the mother and the father increase the odds of reporting physical neglect, while emotional warmth from the father decreases it.

\section{Discussion}

Childhood maltreatment is highly prevalent, with physical neglect being the most common form of maltreatment. In fact, half of participants reported experiencing physical neglect in their childhood. Emotional neglect and physical abuse were also highly prevalent with $2 / 3$ and $1 / 3$ of participants respectively reporting it. While those forms of maltreatment were equally reported among males and females, that was not the case for emotional and sexual abuse. Females were twice as likely to report sexual abuse than were males. This is consistent with other studies on childhood sexual abuse. Although the exact percentages vary from study to study, the proportion of females that report being victims of child sexual abuse is consistently twice as large as that of males (Bebbington et al., 2009; Dube et al., 2005; Zierler et al., 1991).

On the contrary, males scored significantly higher than females in all aspects of psychopathy, with the exception of disinhibition. That is, males were generally more likely than females to display difficulty empathizing with others, lack of remorse, and difficulty building strong relationships. They were also more stress resilient than females, reporting thriving under pressure and enjoying thrill-filled activities (Patrick, 2010). These are all qualities often associated with males rather than females who, on the contrary, have a tendency to be more empathetic and socially adaptable (Berg et al., 2013; Rueckert \& Naybar, 2008) while also being more vulnerable to emotional difficulties such as stress and depression (Matud, 2004; Nolen-Hoeksema, 2001). 
As expected, participants who reported experiencing some form of maltreatment in their childhood were also more likely to report negative behavior from their parents. Emotional and physical abuse, as well as neglect, were all related to the various subscales of parenting behavior with only a few exceptions. However, sexual abuse was only related to maternal and paternal rejection. There are two ways to explain this relation. Parents who leave children to their own devices are less attentive and protective of their children and therefore more likely to overlook when they are being taken advantage of by a third party. Secondly, children who are raised by parents who dismiss them are less confident and more vulnerable to being groomed (Whittle, Hamilton-Giachritsis, Beech, \& Collings, 2013).

Psychopathic traits were associated with both childhood maltreatment and parenting behaviors. General psychopathic traits were not in themselves related, however, its subscales were. Disinhibition showed the highest association with both childhood maltreatment and parenting behavior. That is, adults who showed the greatest tendency for impulsive behavior, irresponsibility and hostility were also the more likely to report experiencing emotional and physical abuse and neglect as a child. They were also more likely than those low in those qualities to report lacking in parental warmth, maternal protection, and generally feeling rejected by their parents as a child. These results go in line with previous research (Graham et al., 2012; Kimonis et al., 2013; Watts et al., 2017).

Meanness was significantly positively related to emotional neglect and maternal overprotection. It was also negatively related to both maternal and parenting warmth. Results show a clear pattern in regards to this subscale of psychopathy. That is, emotional feeling of security and warmth are key factors for preventing the later development of behavior that stems from a pathological low fear such as callousness, cruel behavior, and aggression. These findings support the understanding that traits of meanness are a result of mostly environmental factors such a punitive parenting (Patrick et al., 2009). There was also the expectation that physical and sexual abuse would have an influence, but data did not support that assumption.

Participants who reported adaptive traits of psychopathy such as a higher resilience to stress, novelty seeking, and ability to step away from their comfort zone were also less likely to report emotional abuse and neglect. These findings are novel and contrary to other studies that did not find any relation between boldness and childhood maltreatment (Watts et al., 2017). However, they suggest that males who are more resilient are less likely to internalize and define abuse or neglect experienced in childhood as maltreatment. These findings would suggest that boldness has a strong genetic component but can 
also be reinforced by present and supportive parenting. Further studies exploring this relation would provide useful insights into the development of these adaptive qualities.

It is of relevance to note that similar relations found by Watts and colleagues (2017) had somewhat stronger significance than that of our study. It is possible that the age of the sample weakened the association between psychopathic traits and childhood maltreatment. Our sample was generally older than theirs $(M=28.4, S D=11.22$ versus $M=20.71$; $S D=4.65)$. This possibility is further corroborated by the results obtained from Poythress, Skeem, and Lilienfeld (2006) who found significant, but also weak, correlations in a sample with a mean age of $30.5(S D=6.2)$. Additionally performing cross-sectional studies across different age groups as well as longitudinal studies of the same group over a lengthy period of time would be useful to better understand the effect of age.

Parenting behavior and adult psychopathic traits can be indicative of childhood maltreatment. Parental rejection and paternal warmth are strong predictors of abuse and neglect respectively. These findings are unsurprising, however, findings on parental overprotection are noteworthy and worth further discussion. Within females, an overprotective mother predicts a lower likelihood of child sexual abuse whereas an overprotective father has the opposite effect. To our knowledge, there is no literature to support or argue our findings, thus it is important to expand research exploring paternal overprotection and childhood sexual abuse by gender. It may be that parents (i.e. mother and father) have different styles of protection, one being more productive than the other, or perhaps the relation is inversed and fathers respond to child abuse by overprotecting them. A longitudinal study would be a suitable way to better understand this relation.

Psychopathic traits also had strong predictive value. Boldness was a significant marker of sexual abuse in females. That is, individuals who are more prone to anxiety, less resilient and overall lacking in these more adaptive traits of psychopathy are more likely to have experienced these forms of maltreatment in childhood. Likewise, traits characterized within the scope of disinhibition, such as impulsivity, and difficulty-adjusting behavior may be indicative of physical maltreatment in childhood within females (i.e. sexual abuse and physical neglect). In fact, there is strong evidence that childhood physical abuse is conductive of later neurological problems such as cognitive flexibility and memory impairments (Navalta, Polcari, Webster, Boghossian, \& Teicher, 2006; Spann et al., 2012; Springer, Sheridan, Kuo, \& Carnes, 2007).

The current study had a few limitations worth accounting for. Firstly it used self-reported questionnaire through a web-based platform. While this method 
provides anonymity to all participants, participants might tend to minimize certain traits or past events, rendering it difficult to establish the real relationship between psychopathic traits, childhood maltreatment, and parental style. Secondly, the normative nature of the sample might have been problematic. For the CTQ, the mean of sexual and physical abuse, alongside physical neglect, was between 5 (Never true) and 10 (Rarely true). The overwhelming majority of individuals unaffected by childhood adversities might skew the results. Thirdly, a limited number of socio-demographic characteristics were assessed and no information regarding the participants' mental health history was examined. Lastly, the sample was mostly female, making it a strong downside when assessing gender differences. Nevertheless, the present results contribute to the debate related to the causes of psychopathy, supporting a substantial association between childhood maltreatment, parental behaviors and the display of psychopathic traits in adulthood. 


\section{Chapter 5 | Psychopathy and Childhood Trauma}

\section{References}

Arrindell, W. A., Sanavio, E., Aguilar, G., Sica, C., Hatzichristou, C., Eisemann, M., ... Van Der Ende, J. (1999). The development of a short form of the EMBU 1: Its appraisal with students in Greece, Guatemala, Hungary and Italy. Personality and Individual Differences, 27(4), 613-628.

Bebbington, P. E., Cooper, C., Minot, S., Brugha, T. S., Jenkins, R., Meltzer, H., \& Dennis, M. (2009). Suicide Attempts, Gender, and Sexual Abuse Data From the 2000 British Psychiatric Morbidity Survey -- Bebbington et al_ 166 (10) 1135 -Am J Psychiatry. American Journal of Psychiatry, 166(October), 1135-1141.

Belsky, J., Steinberg, L., \& Draper, P. (1991). Childhood experience, interpersonal development, and reproductive strategy: and evolutionary theory of socialization. Child Development, 62(4), 647-670.

Berg, J. M., Smith, S. F., Watts, A. L., Ammirati, R., Green, S. E., \& Lilienfeld, S. O. (2013). Misconceptions regarding psychopathic personality: implications for clinical practice and research. Neuropsychiatry, 3, 63-74.

Bernstein, D. P., Stein, J. A., Newcomb, M. D., Walker, E., Pogge, D., Ahluvalia, T., ... Zule, W. (2003). Development and validation of a brief screening version of the Childhood Trauma Questionnaire. Child Abuse and Neglect, 27(2), 169-190.

Cale, E. M., \& Lilienfeld, S. O. (2002). Sex differences in psychopathy and antisocial personality disorder: A review and integration. Clinical Psychology Review.

Cicchetti, D., \& Toth, S. L. (2005). Child Maltreatment. Annual Review of Clinical Psychology, 1(1), 409-438.

Dube, S. R., Anda, R. F., Whitfield, C. L., Brown, D. W., Felitti, V. J., Dong, M., \& Giles, W. H. (2005). Long-term consequences of childhood sexual abuse by gender of victim. American Journal of Preventive Medicine, 28(5), 430-438.

Durand, G. (2018). Demystification of the Relationship Between Psychopathy and Happiness. Journal of Happiness Studies, 19(2), 381-395,

Durand, G., \& Plata, E. M. (2017). The effects of psychopathic traits on fear of pain , anxiety , and stress. Personality and Individual Differences, 119(C), 198-203.

Edwards, V. J., Holden, G. W., Felitti, V. J., \& Anda, R. F. (2003). Relationship between multiple forms of childhood maltreatment and adult mental health in community respondents: Results from the adverse childhood experiences study. American Journal of Psychiatry, 160(8), 1453-1460.

Gao, Y., Raine, A., Chan, F., Venables, P., \& Mednick, S. (2013). Early maternal and paternal bonding, childhood physical abuse and adult psychopathic personality. Psychological Medicine, 40(6), 1007-1016.

Graham, N., Kimonis, E. R., Wasserman, A. L., \& Kline, S. M. (2012). Associations among childhood abuse and psychopathy facets in male sexual offenders. Personality Disorders: Theory, Research, and Treatment, 3(1), 66-75.

Hart, S. D., Cox, D. N., \& Hare, R. D. (1995). Hare Psychopathy Checklist Screening Version. Toronto: Multi-Health Systems. 
Hicks, B. M., Carlson, M. D., Blonigen, D. M., Patrick, C. J., lacono, W. G., \& MGue, M. (2012). Psychopathic personality traits and environmental contexts: Differential correlates, gender differences, and genetic mediation. Personality Disorders: Theory, Research, and Treatment, 3(3), 209-227.

Johnson, J., Cohen, P., Brown, J., Smailes, E., \& Bernstein, D. P. (1999). Childhood maltreatment increases risk for personality disorders during early adulthood. Archives of general psychiatry 56(7), 600-606

Kimonis, E. R., Cross, B., Howard, A., \& Donoghue, K. (2013). Maternal Care, Maltreatment and Callous-Unemotional Traits Among Urban Male Juvenile Offenders. Journal of Youth and Adolescence, 42(2), 165-177.

Krischer, M. K., \& Sevecke, K. (2008). Early traumatization and psychopathy in female and male juvenile offenders. International Journal of Law and Psychiatry, 31(3), 253-262.

Láng, A., \& Lénárd, K. (2015). The relation between memories of childhood psychological maltreatment and Machiavellianism. Personality and Individual Differences, 77(April), 81-85.

Lee, Z., \& Salekin, R. T. (2010). Psychopathy in a noninstitutional sample: Differences in primary and secondary subtypes. Personality Disorders: Theory, Research, and Treatment, 1(3), 153-169.

Lilienfeld, S. O., \& Hess, T. H. (2001). Psychopathic personality traits and somatization: Sex differences and the mediating role of negative emotionality. Journal of Psychopathology and Behavioral ..., 23(1), 11-24.

Matud, M. P. (2004). Gender differences in stress and coping styles. Personality and Individual Differences, 37(7), 1401-1415.

Miller, J. D., Watts, A., \& Jones, S. E. (2011). Does psychopathy manifest divergent relations with components of its nomological network depending on gender? Personality and Individual Differences, 50(5), 564-569.

Mowle, E. N., Kelley, S. E., Edens, J. F., Donnellan, M. B., Smith, S. T., Wygant, D. B., \& Sellbom, M. (2017). Development of an Inconsistent Responding Scale for the Triarchic Psychopathy Measure. Psychological Assessment, 29(8), 990-1000.

Navalta, C., Polcari, A., Webster, D., Boghossian, A., \& Teicher, M. (2006). Effects of Childhood Sexual Abuse on Neuropsychological and Cognitive Function in College Women. Journal of Neuropsychiatry Clinical Neuroscience, 18(1), 4553.

Nolen-Hoeksema, S. (2001). Gender differences in depression. Current Directions in Psychological Science, 10(5), 173-176.

Patrick, C. J. (2010). Operationalizing the Triarchic conceptualisation of psychopathy: Preliminary description of brief scales for assessment of boldness, meanness, and disinhibition. PhenX Toolkit Online Assessment Catalog.

Patrick, C. J., Fowles, D. C., \& Krueger, R. F. (2009). Triarchic conceptualization of psychopathy: Developmental origins of disinhibition, boldness, and meanness. Development and Psychopathology, 21(03), 913. 


\section{Chapter 5 | Psychopathy and Childhood Trauma}

Poythress, N. G., Skeem, J. L., \& Lilienfeld, S. O. (2006). Associations among early abuse, dissociation, and psychopathy in an offender sample. Journal of Abnormal Psychology, 115(2), 288-297.

Rueckert, L., \& Naybar, N. (2008). Gender differences in empathy: The role of the right hemisphere. Brain and Cognition, 67(2), 162-167.

Saltaris, C. (2002). Psychopathy in juvenile offenders - Can temperament and attachment be considered as robust developmental precursors? Clinical Psychology Review, 22(5), 729-752.

Scher, C. D., Forde, D. R., McQuaid, J. R., \& Stein, M. B. (2004). Prevalence and demographic correlates of childhood maltreatment in an adult community sample. Child Abuse and Neglect, 28(2), 167-180.

Sevecke, K., Franke, S., Kosson, D., \& Krischer, M. (2016). Emotional dysregulation and trauma predicting psychopathy dimensions in female and male juvenile offenders. Child and Adolescent Psychiatry and Mental Health, 10(1), 1-13.

Spann, M. N., Mayes, L. C., Kalmar, J. H., Guiney, J., Womer, F. Y., Pittman, B., ... Blumberg, H. P. (2012). Childhood abuse and neglect and cognitive flexibility in adolescents. Child Neuropsychology, 18(2), 182-189.

Springer, K. W., Sheridan, J., Kuo, D., \& Carnes, M. (2007). Long-term physical and mental health consequences of childhood physical abuse: Results from a large population-based sample of men and women. Child Abuse \& Neglect, 31(5), 517-530.

van Dongen, J. D. M., Drislane, L. E., Nijman, H., Soe-Agnie, S. E., \& van Marle, H. J. C. (2017). Further Evidence for Reliability and Validity of the Triarchic Psychopathy Measure in a Forensic Sample and a Community Sample. Journal of Psychopathology and Behavioral Assessment, 39(1), 58-66.

Watts, A. L., Donahue, K., Lilienfeld, S. O., \& Latzman, R. D. (2017). Gender moderates psychopathic traits' relations with self-reported childhood maltreatment. Personality and Individual Differences, 119, 175-180.

Whittle, H., Hamilton-Giachritsis, C., Beech, A., \& Collings, G. (2013). A review of young people's vulnerabilities to online grooming. Aggression and Violent Behavior, 18(1), 135-146.

Zierler, S., Feingold, L., Laufer, D., Velentgas, P., Kantrowitz-Gordon, I., \& Mayer, K. (1991). Adult survivors of childhood sexual abuse and subsequent risk of HIV infection. American Journal of Public Health, 81(5), 572-576. 




\section{Chapter 6}

Genetic Moderation of Cognitive Performance after Exposure to Social Stress

Durand, G., \& Rutten, B. P. F. Genetic moderation of cognitive performance after exposure to social stress. 


\section{Abstract}

Previous studies have proposed a relationship between stress exposure and impaired cognitive function. Although studies have linked genetic background to stress vulnerability, no research has assessed the contribution of genetic factors to cognitive performance in time-limited cognitive tasks. The current study aimed to characterize the relationship of common variants in candidate genes involved in regulating stress responses and mood, with cognitive performances. Healthy individuals from a Canadian community $(N=94)$ completed three cognitive tasks: the chessboard pieces replacement memory task, the Tower of Hanoi, and a Go/no-go paradigm. Saliva samples were collected prior to testing and analysed for the detection of 29 single nucleotide polymorphisms (SNPs) in candidate genes and hormones (i.e. SLC6A4, FKBP5, GILZ, SGK1, NR3C1, DAT1, COMT, TaqIA, Val66Met, TPH2, SNAP25, CRP, NPY, cortisol, norepinephrine, and testosterone). Multivariate analysis of variances (MANOVA) identified a relationship between the GRtarget gene FKBP5 and sustained attention. Exploratory analyses also suggested a role for COMT, Val66Met, SNAP-25, DAT1, and cortisol and performance on discrete test. While these findings warrant replication, our findings support the influence of distinct genetic variations on cognitive performance in stressful conditions. 


\section{Introduction}

Previous studies have suggested links between stress and cognition, e.g. exposure to psychosocial stressors has been associated with reduced cognitive performances, particularly affecting working memory (Schoofs, Preuß, \& Wolf, 2008; Schoofs, Wolf, \& Smeets, 2009) and cognitive flexibility (Alexander, Hillier, Smith, Tivarus, \& Beversdorf, 2007; Plessow, Fischer, Kirschbaum, \& Goschke, 2011). Stress exposure is also linked to increased risk of mental disorders (Sun \& Alkon, 2014). According to the current working model on stress-related mental ill-health, the extent to which an individual suffers from stress exposure depends on multiple factors including the nature of the stressor (strength, frequency, possible avoidance or not, etc.), the individual's coping abilities, as well as the genetic background of the individual affecting health status, personal traits and disposition. The hypothalamuspituitary-adrenal (HPA) axis has received considerable attention as a hallmark of the stress response (Foley \& Kirschbaum, 2010), with numerous studies showing negative correlations between cortisol and cognitive performances (Lara et al., 2013; Neylan et al., 2001). Moreover, a number of studies have suggested synergistic effects of stress-induced changes in dopaminergic and glucocorticoid-related genes in the impairment of cognitive functioning (de Quervain, Roozendaal, \& McGaugh, 1998; El-Hage et al., 2011; Erickson, Drevets, \& Schulkin, 2003; Sun \& Alkon, 2014).

The short form of the 5-HTTLPR polymorphism of the serotonin transporter gene SLC6A4 has been proposed to negatively impact stress sensitivity (Caspi et al., 2003). In a prospective study, Caspi and colleagues (2003) showed that individuals with one or two copies of the short allele of the 5-HTTLPR have increased likelihood of developing depression and suicidal ideations in response to severe stress. These findings support a gene $x$ environment $(G \times E)$ interaction, where carriers of the short allele on the 5HTTLPR exposed to a stressful environment, would be more sensitive to the pervasive effects of severe stress. Consistent with this, Alexander et al. (2009) showed a relationship between homozygous short(s)-allele on the 5-HTTLPR and elevated cortisol secretion following a stress task in individuals with a life history of stress exposure. Meta-analysis studies also support a correlation between homozygous s-allele and elevated cortisol secretion (Miller, Wankerl, Stalder, Kirschbaum, \& Alexander, 2012) and stress sensitivity (Karg, Burmeister, Shedden, \& Sen, 2011). In such studies, Gotlib, Joormann, Minor, and Hallmayer (2008) analysed the performance of 67 girls, aged between 914 years old, genotyped for the 5-HTTLPR and exposed to a stressful task involving backward mathematical operations and a stress interview. Task performance was similar for the $\mathrm{s} / \mathrm{l}$ and $\mathrm{I} / \mathrm{I}$ genotypes, while saliva cortisol 
levels measured at four-time intervals were significantly elevated in s/s allele carriers immediately and 30 minutes following the task. Cortisol levels lowered after 45 minutes, although remained above $\mathrm{s} / \mathrm{l}$ and $\mathrm{l} / \mathrm{l}$ values.

Among reported interplay between gene and cognitive or stress responses, polymorphisms of the FKBP5 gene, which influence glucocorticoid, have been linked with cortisol recovery, whereas carriers of the homozygous s-allele showed an impaired cortisol recovery and increased self-reported anxiety after an exposure to a social stressor (Ising et al., 2008; Klengel \& Binder, 2015). The glucocorticoid-induced leucine zipper (GILZ) and the serum/glucocorticoid regulated kinase 1 (SGK1) have also been associated to stress reactivity. Recent findings from a military population showed a correlation between elevated GILZ and reduced FKBP5 expression levels and Post-Traumatic Stress Disorder (PTSD) (van Zuiden et al., 2012). In rodents, reduced SGK1 expression level has been associated with traumatic stress exposure (Licznerski et al., 2015). The catechol-O-methyltransferase (COMT) Val158Met polymorphism also influences HPA axis reactivity, Met allele children carriers showing higher cortisol responses following a stressful task (Armbruster et al., 2012). The involvement of the Al allele of the ANKKI TaqIA polymorphism from the D2 dopamine receptor gene has been associated with cognitive processing, carriers showing delayed strategic adjustment in the Wisconsin card-sorting task as well as poorer response inhibition on a computerized task (White, Morris, Lawford, \& Young, 2008). More recently, the Val66Met, a variant of the brain-derived neurotrophic factor (BDNF), has been found to correlate with memory bias in male individuals reporting stressful childhood events, who showed poorer recall of positive words (van Oostrom et al., 2012). In recent years, the synaptosomal-associated protein 25 (SNAP-25) polymorphisms have received growing interest, reduced expression of SNAP-25 being associated to cognitive deficits in children affected by autism spectrum disorders, presumably occurring in the presence of rs363050 (G) allele (Braida et al., 2015). Polymorphisms in the SNAP-25 gene have also been found in individuals affected by attentiondeficit/hyperactivity disorder (ADHD) (Zhang et al., 2011), characterized by diminished gene expression in the prefrontal cortex (Hawi et al., 2013). Altogether, these genes can contribute to individual sensitivity to stress, also potentially interacting with each other or being susceptible to alterations by environmental factors.

\section{The Current Study}

The current study seeks to examine the influence of a selection of candidate (based on the arguments mentioned above) single nucleotide polymorphisms 
(SNPs) on healthy individuals' performance on cognitive tasks assessing working memory, planning, and sustained attention and response inhibition. Cognitive abilities were evaluated using standard cognitive tasks, namely the chessboard pieces replacement task, the tower of Hanoi, and a Go/No-Go computer task. Based on the overarching research questions addressing relationship between genetic background and cognitive performance under stress conditions, three distinct hypotheses were tested in the current study. First, we tested whether homozygote s-allele carriers of the 5-HTTLPR gene score significantly lower on the three cognitive tasks. Secondly, we tested whether SNPs in the GR target genes (FKBP5, GILZ, SGK1, and NR3C1) correlate with cognitive performances in the various tasks. Thirdly, we tested whether SNPs in several genes and hormones (DAT1, COMT, TaqIA, Val66Met, TPH2, SNAP-25, CRP, cortisol, norepinephrine, testosterone, and NPY), previously linked to emotional regulation, would also be associated with cognitive performances in a stressful environment.

\section{Methods}

\section{Participants}

A total of 94 healthy participants were recruited via advertisements on social media, on university campus, and on site at a firefighter department to take part in the current study. DNA was collected using saliva sampling at the day of assessments. DNA Extraction was done using the prepIT-L2P from DNA Genotek (item \#PT-L2P-45). Due to contaminated saliva samples in 9 participants, the quality of DNA isolation was insufficient, and these samples/subjects were removed from the analysis. Hence, the final sample consisted of 85 participants, including 39 males and 46 females. The age of the participants ranged between 18 to 77 years old $(M=44.49, S D=18.95)$. Participants were recruited from universities $(N=25)$, fire departments $(N=$ $12)$, and online community groups $(N=48)$. All participants were free of any psychotropic medication for the past 12 months. No participant reported receiving treatment from a health professional for the past 6 months, nor did any participant report a psychiatric or medical diagnosis. The descriptive characteristics of the participants by recruitment location and cognitive performances' scores are provided in Table 1. The current study was approved by the University of Ottawa Research Ethical Board. All participants received and signed an informed consent form with detailed information about the nature, the goal, the procedure and possible consequences of the study prior starting the experiment. All participants' information was kept anonymous during the courses of the whole experimental process and analyses. 
Table 1. Mean score on cognitive tasks $(\mathrm{N}=85)$.

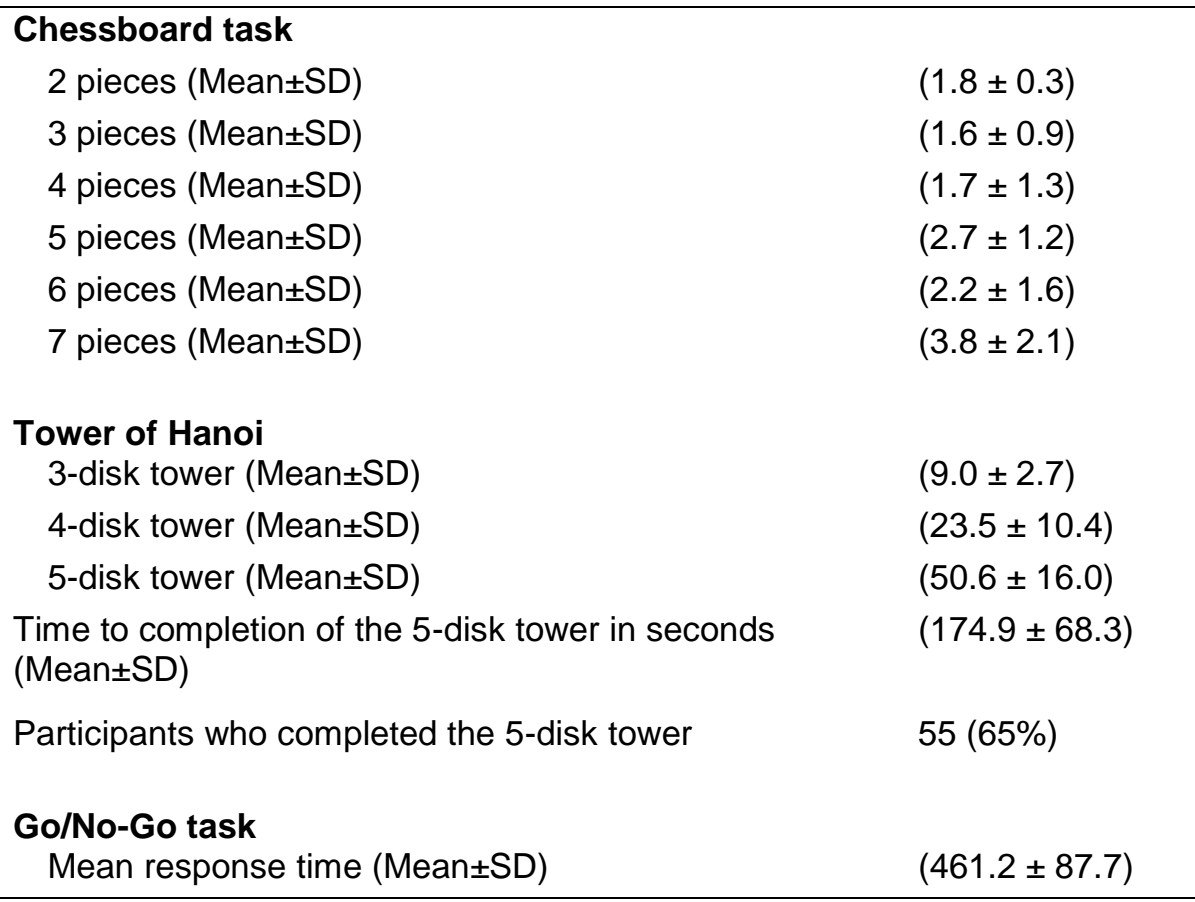

\section{Procedure}

Upon the candidate's arrival to the laboratory, he/she was asked to fill out the consent form and possible questions were answered. The candidate was asked to answer demographic information and a first saliva sample was collected. The participant was then provided instructions and invited to start the chessboard pieces replacement task. All participants performed this task first, considering the stress-inducing properties of the arithmetic component, which was shown to induce stress in participants performing a similar task as part of the Trier Social Stress Task, independently of other components of the TSST, such as public speaking (Kudielka, Buske-Kirschbaum, Hellhammer, \& Kirschbaum, 2004). The relationship between a sole arithmetic task and an increase in stress response was later successfully replicated (Noto, Sato, Kudo, Kurata, \& Hirota, 2005). The second cognitive task was the Tower of Hanoi, immediately followed by the go/no-go task. The experimenter was wearing a suit and a laboratory coat; such formal conditions being prone to elicit stress in experimental settings (Birkett, 2011). 


\section{Materials}

\section{The Chessboard Pieces Replacement Task}

The chessboard pieces replacement task is a validated experimental paradigm for the assessment of working memory (Baddeley, 1992). The task involves the participant sitting in front and looking at the disposition of pieces on a chessboard for 5 seconds. The pieces are then removed, and the participant is asked to perform mathematical equations similar to the arithmetic component of the Trier Social Stress Task (TSST; Kirschbaum, Pirke, \& Hellhammer, 1993) for a $15 \mathrm{sec}$ period. Following this interval, the participant is asked to replace the pieces at their original position. The first trial uses 2 pieces, and 1 additional piece is added every two trials. The task ends after 3 consecutive trials where the participant successfully placed less than half of the pieces on the chessboard, or when the participant wishes to stop. The emplacement of the pieces was identical for all. Scoring was performed by calculating the number of pieces remembered and replaced to their exact location on the chessboard via averaging of scores obtained in the two trials for each completed level.

\section{The Tower of Hanoi}

The Tower of Hanoi is a puzzle where the goal is to displace a set of disks, five in the current study, from the middle rod to the first or third rod, while following three rules: (1) never move two disks at the same time, (2) only move the upper disk of the stack and (3) never place a bigger disk on a smaller disk. A previous study has determined that this puzzle act on the participant capacity to plan ahead, which is correlated with the frontal lobe functioning (Goel \& Grafman, 1995). The task is over once the participant has successfully completed the puzzle, or after 5 minutes. The algorithm of the puzzle forces participants to complete a tower of 3 disks and a tower of 4 disks before completing the tower of 5 disks. The minimum number of moves to complete the 3-disk tower is 7, 15 for the 4-disk tower and 31 for the 5 -disk tower. Scoring is performed by calculating the number of stacks completed, the number of moves needed to complete each stack, and the time needed to complete the 5-disk tower among individuals who completed it.

\section{Go/No-Go Task}

The Go/No-Go task is a computer task designed to assess the participant's cognitive attention and response inhibition. Instructions presented on the computer screen informs the participant to press the space bar of the keyboard every time the letter " $\mathrm{X}$ " is presented on the screen, and to refrain from pressing any key when the screen display the letter "Y". The task was 
composed of 80 consecutive trials divided equally between presentations of the " $X "$ and "Y" letters. The first 10 trials for all the participants were removed before statistical analyses. The go/no-go paradigm has been used in several studies (Poythress et al., 2010; Zimak, Suhr, \& Bolinger, 2014) and is considered a valuable tool for assessing response discrimination. Scoring is performed by calculating the mean reaction time to respond at the view of Go stimulus (the $X$ letter), and by calculating the average number of errors (i.e., pressing the space bar on $Y$ or inhibit pressing) throughout the experiment.

\section{Selection of Genes and Hormones, SNPs, and Genotyping Procedures}

Twelve genes and three hormones were selected. SNPs were selected based on the strength of their relationship with genes or hormones from previous literature. In order to validate the first hypothesis, three SNPs associated with the 5-HTTLPR from the SLC6A4 gene were selected (rs25532, rs11867581, and rs2129785). The second hypothesis, pertaining to the influence of GR related genes, was investigated via four genes (FKBP5, GILZ, SGK1, and NR3C1), and eight correlated SNPs (rs4713916, rs1360780, rs3800737, rs4713902, rs3800373, rs5522, rs9402571, and rs6198). Exploratory analyses of eight genes (DAT1, COMT, TaqIA, Val66Met, TPH2, SNAP-25 CRP, and NPY), and three hormones (cortisol, norepinephrine, and testosterone) were performed on 25 SNP (rs1130864, rs1205, rs16139, rs16147, rs1691053, rs1800497, rs2242446, rs27048, rs27072, rs2794521, rs2963238, rs363050, rs429358, rs4570625, rs4633, rs4680, rs4818, rs53576, rs5569, rs5934505, rs6265, rs6269, rs7412, rs7774640, rs9493857). The selected SNPs were processed via a Sequenom panel for multiplex reaction and genotyping at McGill University (McGill University and Génome Québec Innovation Centre, Québec, Canada).

\section{Statistical Analysis}

All analyses were performed using the Statistical Package SPSS version 23.00. Values for the three cognitive tasks were normally distributed, and hence were not recoded. Identification of dominant and recessive alleles for each SNP was performed using refSNP (www.ncbi.nlm.nih.gov/snp/). An overdominant genetic model was used to test the effect of 5-HTTLPR and GRtarget genes through hypothesis 1 and 2, corresponding to a coding of $1(\mathrm{Aa})$ or 0 (AA or aa). As for the exploratory analyses of various genes and hormones of hypothesis 3 , SNPs were recoded with a dominant model (AA = 1 , Aa or aa $=0$ ). In order to test the first hypothesis, a multivariate analysis of variance (MANOVA) was performed on rs11867581. As only one SNP related 
to the 5-HTTLPR remained after the exclusion of the two other SNPs related to the 5-HTTLPR (as no variance was observed for these SNPs), no correction for multiple testing was performed for testing the first hypothesis. In order to test hypotheses 2 and 3 respectively, two subsequent MANOVAs were performed. In order to maintain a balance between the explorative nature of this study and multiple corrections, we established the critical value for statistical significance at $\alpha / 5=.01$.

\section{Results}

\section{Genotyping}

Out of the 36 selected SNP's, a total of 32 SNP's was successfully analyzed using the genotyping protocol. Three SNPs (rs2129785, rs16139, and rs1691053) were excluded from the study as no variation was observed between at least two alleles. The final list of 29 SNPs, which were used for the analyses, can be found in Appendix A.

\section{Hypothesis 1. 5-HTTLPR and Cognitive Performances}

No significant associations were found for the rs 11867581 SNP and measures of the three cognitive tasks. Hence, no further analysis was performed on this SNP.

\section{Hypothesis 2. GR and Cognitive Performances}

Examination of the eight SNPs related to glucocorticoid receptors genes through a MANOVA yielded one significant difference, as displayed in Figure 1. On the SNP rs3800737 from FKBP5, CT alleles carriers were in average significantly slower $(M=494.63 \mathrm{sec}, S D=78.42)$ than $C C / T T$ alleles carriers $(M=443.00 \mathrm{sec}, S D=87.73)$ on the Go/No-Go task $(F(1,84)=7.231, p$ $=.009$ ). Indeed, homozygotes carriers were able to discriminate and react to stimuli 51.63 millisecond faster than CT carriers. 
Figure 1A. Mean response time of the Go/No-Go task on rs3800737 genotype with error bar of $95 \%$ confidence interval.

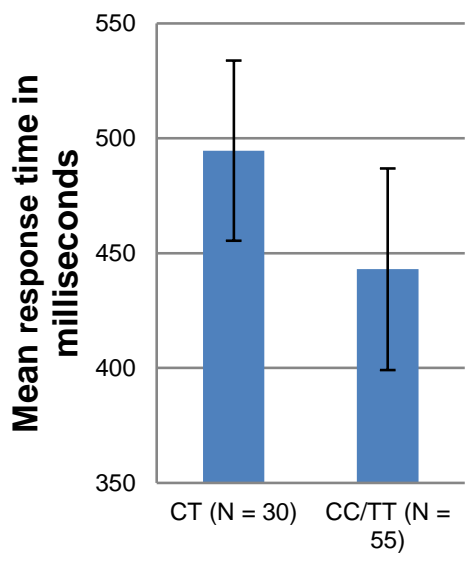

\section{Hypothesis 3. Exploration of Various Genes and Hormones on} Cognitive Performances

Exploratory analyses of various genes and hormones revealed several significant differences with cognitive performances. As shown in Figure 2, the SNP rs6269 from the COMT gene yield significant results on the completion rate of the tower of Hanoi, where AG/GG were more likely to complete the puzzle $(74 \%)$ than AA $(44 \%)$ carriers $(F(1,84)=7.580, p=.007)$. Similar results were obtained from rs363050 from the SNAP-25 gene, where GG carriers were also more likely to complete the puzzle (93\%) than AA/AG (59\%) carriers $(F(1,84)=6.914, p=.010)$. Additionally, a difference was observed in rs6265 from Val66Met on mean response time of the Go/No-Go task $(F(1$, $84)=7.044, p=.010)$, where $G G$ carriers were faster in their responses $(M=$ $443.22 \mathrm{~ms}, S D=84.95)$ than AA/AG carriers $(M=494.23 \mathrm{~ms}, S D=84.18)$. A difference was also observed in rs27072 from the DAT1 gene among participants who completed the level 5 of the chessboard pieces replacement task (5 pieces on set), where CC carriers remembered more pieces $(M=3.15$, $S D=1.15)$ than CT/TT carriers $(M=2.16, S D=1.09),(F(1,41)=8.108, p$ $=.007)$. Lastly, a difference was found on rs53576, a SNP related to cortisol, where $\mathrm{CC}$ carriers made more mistakes throughout the Go/No-Go task $(M=$ $1.38, S D=1.60)$ than $C T / T T$ carriers $(M=0.63, S D=0.87),(F(1,84)=7.912$, $p=.006)$. 
Figure 2A. Completion rate percentage of the tower of Hanoi on rs6269 genotype.

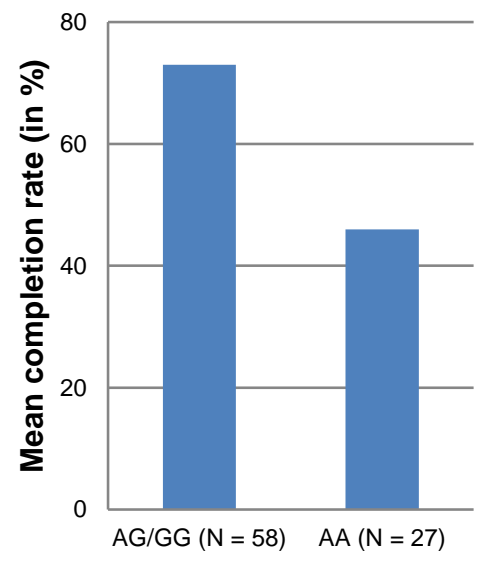

Figure 2B. Completion rate percentage of the tower of Hanoi on rs363050 genotype.

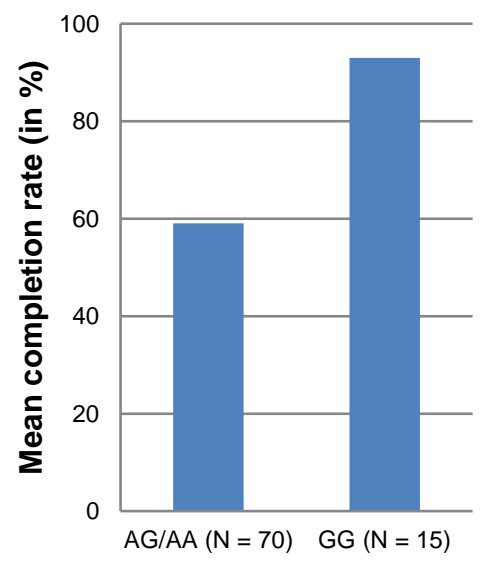

Figure 2C. Mean response time of the Go/No-Go task, with error bar showing a $95 \%$ confidence interval on rs6265 genotype.

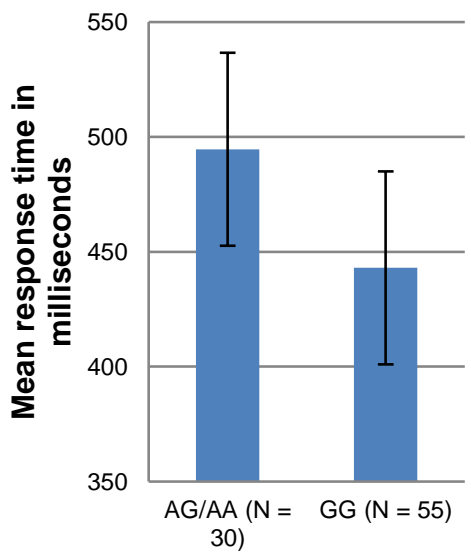

Figure 2D. Number of chess pieces remembered out of five, with error bar showing a 95\% confidence interval on rs27072 genotype.

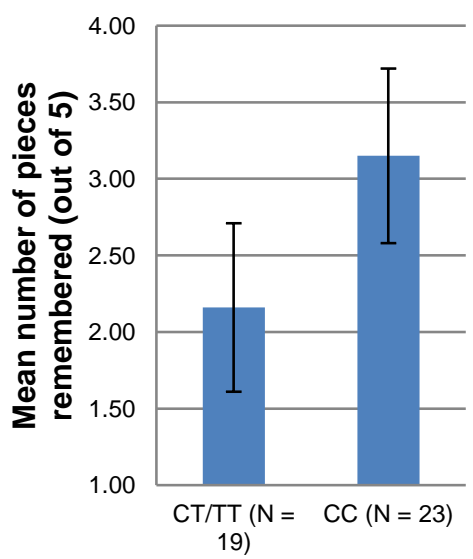


Figure 2E. Number of chess pieces remembered out of five, with error bar showing a 95\% confidence interval on rs53576 genotype.

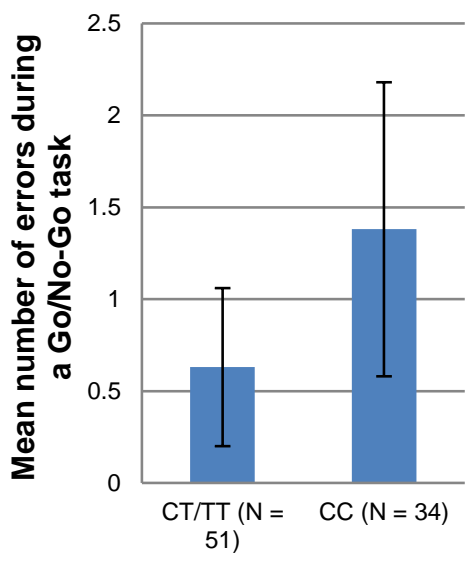

\section{Discussion}

The current study assessed possible relationship between candidate genes, thought to contribute to cognitive and/or stress responses, and cognitive performance achieved under stressful experimental conditions. More specifically, the influence of SNPs related to the 5-HTTLPR and to glucocorticoid receptors, as well as from a variety of genes and hormones on the performance on three cognitive tasks was determined. Our findings support a minor role of GR target genes on cognitive function under stress. Five other genotypes, namely COMT, Val66Met, SNAP-25, DAT1, and cortisol were significantly correlated to at least one cognitive function (planning, working memory, and/or attention). This study is among the firsts to examine the impact of genetic moderation on cognitive performances under psychological stress. Our study however remains explorative and our results preliminary, particularly due to the small sample size, which prevented identifying small effects and which furthermore prevented the analysis of rare polymorphisms variations and led to exclude certain SNPs due to a limited number of participants genotyped into these allelic variations.

\section{5-HTTLPR and Glucocorticoid Receptors Target Genes}

The first hypothesis supporting an impact of the 5-HTTLPR was not confirmed by our findings. However, the sole detection of rs 11867581 in the saliva samples considerably reduced statistical power and it remains possible that inclusion of other SNPs could have supported a genetic contribution. This is supported by a recent study including rs 11867581 and rs2129785 which established a strong predictive value (91\%) between allelic variations of these SNPs and 5-HTTLPR distinctive alleles (Vinkhuyzen et al., 2011). Furthermore, our findings support a modest role of GR-target gene expression 
and cognitive performance under stress conditions (hypothesis 2). Indeed, FKBP5 was the sole statistically significant result, supporting a relationship between allelic variation and sustained attention.

Previous findings on the effect of GR, cortisol and psychosocial stress in healthy males concluded that GR gene polymorphisms variations show a notable impact on cortisol secretion in response to the TSST (Wüst et al., 2004). In the current study, heterozygote carriers of the rs3800737 SNP on the FKBP5 gene demonstrated slower reaction time on a Go/No-Go task, but did not display a different error rate than homozygote carriers. Considering heterozygote carriers were able to inhibit responses when necessary, their slower response time could be due to poorer attention and/or lack of concentration. Although no previous studies explicitly investigated the role of rs3800737 on cognition, the results nevertheless support previous findings, where $T$ allele carriers of the rs 1360780 , also located in the FKBP5 gene, displayed poorer attention and concentration on cognitive tests assessing memory and intelligence (Fujii et al., 2014). Furthermore, the lack of a significant difference in error rates between the groups could be explained by the absence of influence of FKBP5 on impulsivity. Indeed, while GR target genes contribute to cortisol secretion and therefore impulsivity (King, Jones, Scheuer, Curtis, \& Zarcone, 1990), it is possible that FKBP5 polymorphisms variations cannot induce a significant change on their own to cortisol secretion to the extent of increasing impulsivity.

\section{COMT, SNAP-25, Val66Met, DAT1, and Cortisol}

The third hypothesis addressed the role of genes involved in cognitive performances under stress. The COMT gene was associated, through rs6269, to the completion rate of the tower of Hanoi, enhancing ability to complete the task and rapidity in planning moves under stressful conditions. The influence of COMT on dopamine transmission in the PFC and planning abilities is well established (Foltynie et al., 2004; Savitz, Solms, \& Ramesar, 2006; WilliamsGray, Hampshire, Robbins, Owen, \& Barker, 2007). Previous research also supports an interaction between dopamine and cortisol in regulating stress responses, where $7 \mathrm{R}$ allele carriers on the dopamine receptor gene (DRD4) showed reduce cortisol after the TSST (Armbruster et al., 2009). Our findings also support previous findings observed with the rs4818 SNP, where G/G carriers reduced cognitive performance in the Stockings of Cambridge and the lowa Gambling Task (Roussos, Giakoumaki, Pavlakis, \& Bitsios, 2008) as well as on the Wisconsin Card Sorting Task (Bruder et al., 2005). These findings are consistent with the relationship observed between COMT polymorphism- 
related variations and cognitive performances in healthy children (Barnett, Heron, Goldman, Jones, \& Xu, 2009).

Contrary to above mentioned genes, support for the influence of BDNF Val66Met on cognition has been mitigated. Thus, while a few studies support the influence of Val66Met on cognitive process such has episodic memory (Dempster et al., 2005) and reasoning skills (Harris et al., 2006), a large metaanalysis examining 31 independent samples from human cohorts failed to identify a significant relationship between Val66Met and cognitive abilities (Mandelman \& Grigorenko, 2012). Similarly to the FKBP5, the BDNF Val66Met was significantly related to the mean response time of the Go/NoGo task, but not to its error rate, implying a role in sustained attention and concentration while under stress. These results could be explained by the interactive effect of cognition and stress on the BDNF. Previous findings on rs6265 concluded that Val66Met polymorphism moderate the effect of stress on rumination, where homozygote Met carriers were more susceptible to rumination under stress (Clasen, Wells, Knopik, McGeary, \& Beevers, 2011). It is therefore possible that a stress component greatly influences the effect of Val66Met on cognitive abilities.

Similarly to Val66Met, rs363050, also possesses a mitigated history regarding its influence on cognition (Gosso et al., 2007, 2008; Lind et al., 2009). Earlier research investigated the effect of the SNAP-25 on performance intelligence quotient $(P I Q)$ and concluded that the $A A$ and $A G$ carriers from the rs 363050 scored over 2 points higher than GG carriers (Gosso et al., 2006). However, no significant results were found between general cognitive abilities and the cholinergic muscarinic 2 receptor (CHRM2) (Lind et al., 2009). In the present study, GG carriers displayed higher completion rate of the tower of Hanoi than AG/AA carriers. This difference between the benefit of the $A$ allele previously reported and the risk of the A allele currently reported can be explained by sample size analysis. In the current study, a dominant model merged $A G$ and $A A$ carriers into a single group with a ratio superior to 4:1. While the effect of specific alleles on cognitive performances under stress needs further investigation, the results nevertheless support the effect of the SNAP-25 on cognition.

The relationship identified in the present study between rs27072 of the dopamine transporter DAT1 gene and working memory support previous findings correlating dopamine with working memory performances (Mattay et al., 2002). While no previous study explicitly investigated the role of rs27072 on working memory, past research on the DAT1 gene concluded that DAT1 9/10-repeat carriers showed larger training-related gains after 4 continuous weeks of computerized adaptive training in working memory related to 
visuospatial tasks (grid task, 3D grid task, rotating dots task, and rotating grid task) than DAT1 10-repeat carriers (Brehmer et al., 2009). Additionally, animal research in DAT1 established a relationship between stress exposure and an upregulation of DAT1 expression (Kovalenko, Smagin, Galyamina, Orlov, \& Kudryavtseva, 2016). Considering these previous findings, it is possible that, as shown in the present study, allelic expression of rs27072 plays a role in dopaminergic expression, and hence affects an individual capacity to retain information during a stress task.

In addition to the aforementioned results on genes, one SNP related to cortisol was also significantly related to cognitive performances. Analysis from rs53576 demonstrates a relationship between cortisol and error rate on the Go/No-Go task, suggesting impulsive behavior. Investigation of the aforementioned GR target gene FKBP5 associated to cortisol induced a change in mean response time, but not in error rate from the Go/No-Go task. However, examination of rs53576 found a reversed trend, suggesting that inhibition of behavior and impulsivity under stress are central components of cortisol itself. Previous studies have already investigated this polymorphism, and supported a correlation when compared to stress (Rodrigues, Saslow, Garcia, John, \& Keltner, 2009) and intelligence (Lucht et al., 2009). The propensity of CC carriers to perform more errors during the task may be due to the inability to cope with the stress of the experiment, which would signify that their cortisol levels are probably at the higher end of the cortisol U-trend, reducing efficacy on cognitive tasks (Beckwith, Petros, Scaglione, \& Nelson, 1986). A previous study investigating the role of cortisol in impulsivity in a casino gambling task failed to report a difference in cortisol secretion between lowly and highly impulsive players (Krueger, Schedlowski, \& Meyer, 2005). Based on these results, it is possible that rs53576 regulates baseline levels of cortisol, where higher cortisol baseline would reduce response inhibition in cognitive tasks despite the high level of attention given to the task, as supported by the lack of difference in mean response time between groups. It is also possible that rs53576 has an impact on perceived stress in low-stress situation. Indeed, the current experiment's stressor was mild, which may have been too weak to elicit a stress reaction in some individuals.

\section{Limitations and Conclusion}

Due to the explorative nature of our study, we were limited in a number of ways. First, the small sample size made it impossible to interpret rare polymorphisms variations, leading to the exclusion of several SNPs due to a limited number of participants genotyped in more than one allelic variation. Second, while we reduced our statistical significance to $p=0.01$ as a multiple 
testing correction, the high number of analyses performed render part of our results subject to potential type I error. Third, while we attempted to recruit participants from various environments in order to represent the community as a whole as closely as possible, our three subgroups of the community (university students, firefighters, and laypeople) demonstrate several differences between them, such as the age, and hence might not fully represent the community. Fourth, the stress induced during the experiment was not optimal, as we did not use the complete TSST, but rather solely the arithmetic component of it. Additionally, we cannot confirm if every individual felt a similar degree of stress from the task, as we did not use any self-report questionnaire to measure state anxiety and stress. Future studies may consider investigating covariates such as tolerance to stress, subjective level of well-being, and stress-inducing behaviors. Testing homogeneous groups, such as students or firefighters only, could also give different results. Finally, the tower of Hanoi and the chessboard pieces replacement task appeared challenging for certain individuals and the selection of easier tasks may help further establish the contribution of genetic variations to cognitive performances under stress.

In conclusion, this exploratory study is the first, to our knowledge, to investigate the role of various genotype allelic variations on cognitive performances under a mild social stress. While the statistical significance of our results should be interpreted with caution, we were able to establish a list of genotypes with a potential role on cognitive performances, deserving deeper examination regarding their role on cognition and stress resilience. 


\section{References}

Alexander, J. K., Hillier, A., Smith, R. M., Tivarus, M. E., \& Beversdorf, D. Q. (2007). Beta-adrenergic modulation of cognitive flexibility during stress. Journal of Cognitive Neuroscience, 19(3), 468-478.

Armbruster, D., Mueller, A., Moser, D. A., Lesch, K.-P., Brocke, B., \& Kirschbaum, C. (2009). Interaction effect of D4 dopamine receptor gene and serotonin transporter promoter polymorphism on the cortisol stress response. Behavioral Neuroscience, 123(6), 1288-1295.

Armbruster, D., Mueller, A., Strobel, A., Lesch, K.-P., Brocke, B., \& Kirschbaum, C. (2012). Children under stress - COMT genotype and stressful life events predict cortisol increase in an acute social stress paradigm. The International Journal of Neuropsychopharmacology / Official Scientific Journal of the Collegium Internationale Neuropsychopharmacologicum (CINP), 15(9), 1229-39.

Baddeley, A. (1992). Working memory. Science (New York, N.Y.), 255(5044), 556-9.

Barnett, J. H., Heron, J., Goldman, D., Jones, P. B., \& Xu, K. (2009). Effects of catechol-O-methyltransferase on normal variation in the cognitive function of children. American Journal of Psychiatry, 166(8), 909-916.

Beckwith, B. E., Petros, T. V., Scaglione, C., \& Nelson, J. (1986). Dose-dependent effects of hydrocortisone on memory in human males. Physiology and Behavior, 36(2), 283-286.

Birkett, M. A. (2011). The Trier Social Stress Test protocol for inducing psychological stress. Journal of Visualized Experiments : JoVE, (56), 1-6.

Brehmer, Y., Westerberg, H., Bellander, M., Fürth, D., Karlsson, S., \& Bäckman, L. (2009). Working memory plasticity modulated by dopamine transporter genotype. Neuroscience Letters, 467(2), 117-120.

Bruder, G. E., Keilp, J. G., Xu, H., Shikhman, M., Schori, E., Gorman, J. M., \& Gilliam, T. C. (2005). Catechol-O-methyltransferase (COMT) genotypes and working memory: associations with differing cognitive operations. Biological Psychiatry, 58(11), 901-7.

Caspi, A., Sugden, K., Moffitt, T. E., Taylor, A., Craig, I. W., Harrington, H., ... Poulton, R. (2003). Influence of life stress on depression: moderation by a polymorphism in the 5-HTT gene. Science (New York, N.Y.), 301, 386-389.

Clasen, P. C., Wells, T. T., Knopik, V. S., McGeary, J. E., \& Beevers, C. G. (2011). 5HTTLPR and BDNF Val66Met polymorphisms moderate effects of stress on rumination. Genes, Brain, and Behavior, 10(7), 740-6.

de Quervain, D. J.-F., Roozendaal, B., \& McGaugh, J. L. (1998). Stress and glucocorticoids impair retrieval of long-term spatial memory. Nature, 394(August), 787-790.

Dempster, E., Toulopoulou, T., McDonald, C., Bramon, E., Walshe, M., Filbey, F., ... Collier, D. A. (2005). Association between BDNF val66 met genotype and episodic memory. American Journal of Medical Genetics. Part B, Neuropsychiatric Genetics: The Official Publication of the International Society of Psychiatric Genetics, 134B(1), 73-5. 


\section{Chapter 6 | Cognitive Abilities and Stress Exposure}

El-Hage, W., Phillips, M. L., Radua, J., Gohier, B., Zelaya, F. O., Collier, D. a, \& Surguladze, S. a. (2011). Genetic modulation of neural response during working memory in healthy individuals: interaction of glucocorticoid receptor and dopaminergic genes. Molecular Psychiatry, 174-182.

Erickson, K., Drevets, W., \& Schulkin, J. (2003). Glucocorticoid regulation of diverse cognitive functions in normal and pathological emotional states. Neuroscience and Biobehavioral Reviews, 27(3), 233-246.

Foley, P., \& Kirschbaum, C. (2010). Human hypothalamus-pituitary-adrenal axis responses to acute psychosocial stress in laboratory settings. Neuroscience and Biobehavioral Reviews, 35(1), 91-96.

Foltynie, T., Goldberg, T. E., Lewis, S. G. J., Blackwell, A. D., Kolachana, B. S., Weinberger, D. R., ... Barker, R. A. (2004). Planning ability in Parkinson's disease is influenced by the COMT val158met polymorphism. Movement Disorders, 19(8), 885-891.

Fujii, T., Ota, M., Hori, H., Hattori, K., Teraishi, T., Matsuo, J., ... Kunugi, H. (2014). The common functional FKBP5 variant rs1360780 is associated with altered cognitive function in aged individuals. Scientific Reports, 4, 6696.

Goel, V., \& Grafman, J. (1995). Are the frontal lobes implicated in "planning" functions? Interpreting data from the Tower of Hanoi. Neuropsychologia, 33, 623-642.

Gosso, M. F., De Geus, E. J. C., Polderman, T. J. C., Boomsma, D. I., Heutink, P., \& Posthuma, D. (2008). Common variants underlying cognitive ability: Further evidence for association between the SNAP-25 gene and cognition using a family-based study in two independent Dutch cohorts. Genes, Brain and Behavior, 7(3), 355-364.

Gosso, M. F., de Geus, E. J. C., Polderman, T. J. C., Boomsma, D. I., Posthuma, D., \& Heutink, P. (2007). Exploring the functional role of the CHRM2 gene in human cognition: results from a dense genotyping and brain expression study. BMC Medical Genetics, 8(1), 66.

Gosso, M. F., de Geus, E. J. C., van Belzen, M. J., Polderman, T. J. C., Heutink, P., Boomsma, D. I., \& Posthuma, D. (2006). The SNAP-25 gene is associated with cognitive ability: evidence from a family-based study in two independent Dutch cohorts. Molecular Psychiatry, 11(9), 878-886.

Gotlib, I. H., Joormann, J., Minor, K. L., \& Hallmayer, J. (2008). HPA Axis Reactivity: A Mechanism Underlying the Associations Among 5-HTTLPR, Stress, and Depression. Biological Psychiatry, 63, 847-851.

Harris, S. E., Fox, H., Wright, A. F., Hayward, C., Starr, J. M., Whalley, L. J., \& Deary, I. J. (2006). The brain-derived neurotrophic factor Val66Met polymorphism is associated with age-related change in reasoning skills. Molecular Psychiatry, 11(5), 505-13.

Hawi, Z., Matthews, N., Wagner, J., Wallace, R. H., Butler, T. J., Vance, A., ... Li, J. (2013). DNA Variation in the SNAP25 Gene Confers Risk to ADHD and Is Associated with Reduced Expression in Prefrontal Cortex. PLOS ONE, 8(4), e60274. 
Ising, M., Depping, A.-M., Siebertz, A., Lucae, S., Unschuld, P. G., Kloiber, S., ... Holsboer, F. (2008). Polymorphisms in the FKBP5 gene region modulate recovery from psychosocial stress in healthy controls. The European Journal of Neuroscience, 28(2), 389-98.

Karg, K., Burmeister, M., Shedden, K., \& Sen, S. (2011). The serotonin transporter promoter variant (5-HTTLPR), stress, and depression meta-analysis revisited: evidence of genetic moderation. Archives of General Psychiatry, 68, 444-454.

King, R. J., Jones, J., Scheuer, J. W., Curtis, D., \& Zarcone, V. P. (1990). Plasma cortisol correlates of impulsivity and substance abuse. Personality and Individual Differences, 11(3), 287-291.

Kirschbaum, C., Pirke, K. M., \& Hellhammer, D. H. (1993). The 'Trier Social Stress Test'--a tool for investigating psychobiological stress responses in a laboratory setting. Neuropsychobiology, 28, 76-81.

Klengel, T., \& Binder, E. B. (2015). Epigenetics of Stress-Related Psychiatric Disorders and Gene $\times$ Environment Interactions. Neuron, 86(6), 1343-1357.

Kovalenko, I. L., Smagin, D. A., Galyamina, A. G., Orlov, Y. L., \& Kudryavtseva, N. N. (2016). [Changes in the Expression of Dopaminergic Genes in Brain Structures of Male Mice Exposed to Chronic Social Defeat Stress: An RNA-seq Study]. Molekuliarnaia Biologiia, 50(1), 184-7.

Krueger, T. H. C., Schedlowski, M., \& Meyer, G. (2005). Cortisol and heart rate measures during casino gambling in relation to impulsivity. Neuropsychobiology, 52(4), 206-211.

Kudielka, B. M., Buske-Kirschbaum, A., Hellhammer, D. H., \& Kirschbaum, C. (2004). Differential heart rate reactivity and recovery after psychosocial stress (TSST) in healthy children, younger adults, and elderly adults: the impact of age and gender. Int J Behav Med.

Lara, V. P., Caramelli, P., Teixeira, A. L., Barbosa, M. T., Carmona, K. C., Carvalho, M. G., ... Gomes, K. B. (2013). High cortisol levels are associated with cognitive impairment no-dementia (CIND) and dementia. Clinica Chimica Acta, 423, 1822.

Licznerski, P., Duric, V., Banasr, M., Alavian, K. N., Ota, K. T., Kang, H. J., ... Duman, R. S. (2015). Decreased SGK1 Expression and Function Contributes to Behavioral Deficits Induced by Traumatic Stress. PLOS Biology, 13(10), e1002282.

Lind, P. A., Luciano, M., Horan, M. A., Marioni, R. E., Wright, M. J., Bates, T. C., ... Martin, N. G. (2009). No association between cholinergic muscarinic receptor 2 (CHRM2) genetic variation and cognitive abilities in three independent samples. Behavior Genetics, 39(5), 513-523.

Lucht, M. J., Barnow, S., Sonnenfeld, C., Rosenberger, A., Grabe, H. J., Schroeder, W., ... Rosskopf, D. (2009). Associations between the oxytocin receptor gene (OXTR) and affect, loneliness and intelligence in normal subjects. Progress in Neuro-Psychopharmacology \& Biological Psychiatry, 33(5), 860-6.

Mandelman, S. D., \& Grigorenko, E. L. (2012). BDNF Val66Met and cognition: All, 


\section{Chapter 6 | Cognitive Abilities and Stress Exposure}

none, or some? A meta-analysis of the genetic association. Genes, Brain and Behavior, 11(2), 127-136.

Mattay, V. S., Tessitore, A., Callicott, J. H., Bertolino, A., Goldberg, T. E., Chase, T. N., ... Weinberger, D. R. (2002). Dopaminergic modulation of cortical function in patients with Parkinson's disease. Annals of Neurology, 51(2), 156-164.

Miller, R., Wankerl, M., Stalder, T., Kirschbaum, C., \& Alexander, N. (2012). The serotonin transporter gene-linked polymorphic region (5-HTTLPR) and cortisol stress reactivity: a meta-analysis. European Journal of Psychotraumatology.

Neylan, T. C., Canick, J. D., Hall, S. E., Reus, V. I., Sapolsky, R. M., \& Wolkowitz, O. M. (2001). Cortisol levels predict cognitive impairment induced by electroconvulsive therapy. Biological Psychiatry, 50(5), 331-6.

Noto, Y., Sato, T., Kudo, M., Kurata, K., \& Hirota, K. (2005). The relationship between salivary biomarkers and state-trait anxiety inventory score under mental arithmetic stress: A pilot study. Anesthesia and Analgesia, 101(6), 1873-1876.

Plessow, F., Fischer, R., Kirschbaum, C., \& Goschke, T. (2011). Inflexibly Focused under Stress: Acute Psychosocial Stress Increases Shielding of Action Goals at the Expense of Reduced Cognitive Flexibility with Increasing Time Lag to the Stressor. Journal of Cognitive Neuroscience, 23(11), 3218-3227.

Poythress, N. G., Edens, J. F., Skeem, J. L., Lilienfeld, S. O., Douglas, K. S., Frick, P. J., ... Wang, T. (2010). Identifying subtypes among offenders with antisocial personality disorder: a cluster-analytic study. Journal of Abnormal Psychology, 119(2), 389-400.

Rodrigues, S. M., Saslow, L. R., Garcia, N., John, O. P., \& Keltner, D. (2009). Oxytocin receptor genetic variation relates to empathy and stress reactivity in humans. Proceedings of the National Academy of Sciences of the United States of America, 106(50), 21437-41.

Roussos, P., Giakoumaki, S. G., Pavlakis, S., \& Bitsios, P. (2008). Planning, decisionmaking and the COMT rs4818 polymorphism in healthy males. Neuropsychologia, 46(2), 757-763.

Savitz, J., Solms, M., \& Ramesar, R. (2006). The molecular genetics of cognition: dopamine, COMT and BDNF. Genes, Brain, and Behavior, 5(4), 311-28.

Schoofs, D., Preuß, D., \& Wolf, O. T. (2008). Psychosocial stress induces working memory impairments in an n-back paradigm. Psychoneuroendocrinology, 33(5), 643-653.

Schoofs, D., Wolf, O. T., \& Smeets, T. (2009). Cold pressor stress impairs performance on working memory tasks requiring executive functions in healthy young men. Behavioral Neuroscience, 123(5), 1066-1075.

Sun, M.-K., \& Alkon, D. L. (2014). Stress: perspectives on its impact on cognition and pharmacological treatment. Behavioural Pharmacology, 25, 410-424.

van Oostrom, I., Franke, B., Rijpkema, M., Gerritsen, L., Arias-Vásquez, A., Fernández, G., \& Tendolkar, I. (2012). Interaction between BDNF Val66Met and childhood stressful life events is associated to affective memory bias in men but not women. Biological Psychology, 89(1), 214-9. 
van Zuiden, M., Geuze, E., Willemen, H. L. D. M., Vermetten, E., Maas, M., Amarouchi, K., ... Heijnen, C. J. (2012). Glucocorticoid Receptor Pathway Components Predict Posttraumatic Stress Disorder Symptom Development: A Prospective Study. Biological Psychiatry, 71(4), 309-316.

Vinkhuyzen, A. A. E., Dumenil, T., Ryan, L., Gordon, S. D., Henders, A. K., Madden, P. A. F., ... Wray, N. R. (2011). Identification of tag haplotypes for 5HTTLPR for different genome-wide SNP platforms. Molecular Psychiatry, 16(11), 1073-1075.

White, M. J., Morris, C. P., Lawford, B. R., \& Young, R. M. (2008). Behavioral phenotypes of impulsivity related to the ANKK1 gene are independent of an acute stressor. Behavioral and Brain Functions: BBF, 4, 54.

Williams-Gray, C. H., Hampshire, A., Robbins, T. W., Owen, A. M., \& Barker, R. A. (2007). Catechol O-methyltransferase Val158Met genotype influences frontoparietal activity during planning in patients with Parkinson's disease. The Journal of Neuroscience: The Official Journal of the Society for Neuroscience, 27(18), 4832-4838.

Wüst, S., Van Rossum, E. F. C., Federenko, I. S., Koper, J. W., Kumsta, R., \& Hellhammer, D. H. (2004). Common Polymorphisms in the Glucocorticoid Receptor Gene Are Associated with Adrenocortical Responses to Psychosocial Stress. Journal of Clinical Endocrinology and Metabolism, 89(2), 565-573.

Zhang, H., Zhu, S., Zhu, Y., Chen, J., Zhang, G., \& Chang, H. (2011). An association study between SNAP-25 gene and attention-deficit hyperactivity disorder. European Journal of Paediatric Neurology: EJPN: Official Journal of the European Paediatric Neurology Society, 15(1), 48-52.

Zimak, E. H., Suhr, J., \& Bolinger, E. M. (2014). Psychophysiological and Neuropsychological Characteristics of Non-Incarcerated Adult Males with Higher Levels of Psychopathic Personality Traits. Journal of Psychopathology and Behavioral Assessment. 



\section{Chapter 7}

\section{The Durand Adaptive Psychopathic Traits \\ Questionnaire: Development and Validation}

Durand, G. (2017). The Durand Adaptive Psychopathic Traits Questionnaire:

Development and Validation. Journal of Personality Assessment, 1-10. 


\section{Chapter 7 | Development of the DAPTQ}

\section{Abstract}

Although the term psychopathy is embedded with negativity, multiple studies have suggested an association between a subtype of psychopathy and adaptive features such as stress and anxiety immunity, social skills, noteworthy leadership ability, and an absence of fear. The newly developed Durand Adaptive Psychopathic Traits Questionnaire (DAPTQ) aims to assess adaptive traits known to correlate with the psychopathic personality. Validation of the questionnaire among $N=765$ individuals from the community gave support to a 9-factor solution: Leadership, Logical Thinking, Composure, Creativity, Fearlessness, Money Smart, Focus, Extroversion, and Management. The DAPTQ and its 9 subscales demonstrated good internal consistency reliability in a community sample $(\alpha=.68-.88)$. Convergent validity and divergent validity were supported by administering the DAPTQ alongside established measures of the psychopathic personality. Overall, these findings support the potential of the DAPTQ as an instrument for measuring psychopathy-associated adaptive traits, such as conscientiousness, rationality, and resilience to stress and anxiety. Further studies are needed to validate the DAPTQ and its subscales against a wider range of personality traits and behaviors. 


\section{Introduction}

Many researchers describe psychopathy as a severe personality disorder characterized by emotional detachment, callousness, lack of empathy, impulsivity, social deviance, and poor behavioral control (Gao \& Tang, 2013; López, Poy, Patrick, \& Moltó, 2013; Tassy, Deruelle, Mancini, Leistedt, \& Wicker, 2013). The vast majority of studies on psychopaths have been conducted on inmates, leading to this standard negative description of psychopathy (Berg et al., 2013). However, some theoretical models of psychopathy include an adaptive component. For instance, the Triarchic model of psychopathy describes the concept of psychopathy in terms of disinhibition, meanness, and boldness (Patrick, Fowles, \& Krueger, 2009). While disinhibition and meanness assess maladaptive aspects of psychopathy, the construct of boldness refers to adaptive traits such as fearlessness, stress immunity, bravery, and social charm. Thus, this model suggests that psychopathy should be seen as a combination of maladaptive and adaptive traits (Polaschek \& Daly, 2013). However, not every diagnostic tool includes this combination of traits.

The diagnosis of psychopathy is commonly achieved through the use of the Psychopathy Checklist-Revised (PCL-R) (Hare, 1991, 2003). The PCL$R$, which is the most common and well-validated tool for assessing psychopathy, is a time and resource-consuming procedure requiring a oneon-one interview by a certified assessor for approximately 90 minutes (Ray, Weir, Poythress, \& Rickelm, 2011). Factor analysis of the PCL-R identified two-dimensional constructs reflecting two variants of psychopathy. Primary psychopathy (Factor 1 ) is associated with emotional and interpersonal traits, which include callousness, remorseless exploitation of others, and lack of empathy. Secondary psychopathy (Factor 2) is associated with the social deviance traits of psychopathy, which include criminal and impulsive features, alongside with anxiety, and neuroticism (Dunlop et al., 2011). Although the PCL-R is well-validated, its use is mostly restricted to forensic and criminal populations. Indeed, the checklist mainly focuses on the traits found in psychopathic criminals, and may therefore not necessarily apply to the general population (Hall \& Benning, 2006; Ray et al., 2011).

The Psychopathic Personality Inventory (PPI) is an alternative to the PCL-R, assessing psychopathic traits on eight subscales using a self-report questionnaire (Lilienfeld \& Andrews, 1996). The PPI is also divided into two facets, Fearless Dominance (PPI-I) and Impulsive Antisociality (PPI-II). PPI-I is related to boldness and includes adaptive traits such as social poise, anxiety and stress immunity, and interpersonal boldness, whereas PPI-II is associated with a combination of disinhibition and meanness. This classification method 


\section{Chapter 7 | Development of the DAPTQ}

of psychopathic characteristics is different from the PCL-R, as Factor 1 of the PCL-R mostly captures elements of meanness and very few elements of boldness (Dunlop et al., 2011; Polaschek \& Daly, 2013). Although PPI-I assesses several adaptive characteristics related to the psychopathic personality, the questionnaire measures only a portion of adaptive traits known to correlate with psychopathy.

The term "successful psychopath" refers to individuals who possess several core traits of psychopathy (e.g., lack of empathy, high dominance), but who lack pervasive traits found mostly in secondary psychopathy, such as aggressive externalizing behaviors (Cleckley, 1941; López et al., 2013; Patrick, 2007). The idea behind the concept of successful psychopathy is highly debated in the scientific community. Some researchers describe successful psychopaths as ruthless and irresponsible individuals who abuse others in order to climb to the top of an organization (Boddy, Miles, Sanyal, \& Hartog, 2015; Boddy, 2014). However, other researchers focus on the potential links between PPI-I and adaptive behaviors, which include characteristics such as fearlessness, leadership, stress and anxiety immunity, and social dominance (Camp, Skeem, Barchard, Lilienfeld, \& Poythress, 2013; Smith, Watts, \& Lilienfeld, 2014). Successful psychopathy can be interpreted by three models (Hall \& Benning, 2006; Lilienfeld, Watts, \& Smith, 2015). First, the differentialseverity model conceptualizes successful psychopathy as a milder form of psychopathy. Hypothesizing that psychopathy is a unitary construct, successful and unsuccessful psychopathy represent the same disorder, with only a difference in intensity. Second, the moderated-expression model presumes that successful psychopathy is an atypical manifestation of psychopathy due to the emergence of protective factors diminishing the effect of maladaptive outcomes related to psychopathy. Third, the differentialconfiguration model presumes that successful and unsuccessful psychopathy share the same core personality traits (antagonism), but successful psychopathy is related to boldness, extraversion, and conscientiousness, whereas unsuccessful psychopathy is related to impulsivity and low conscientiousness (Mullins-Sweatt, Glover, Derefinko, Miller, \& Widiger, 2010).

A number of studies have identified several adaptive traits related to PPI-I, which could be related to successful psychopaths. In order to identify these studies, an online search of the Medline and PsychInfo databases was conducted using the following keywords: [("Psychopathy" OR "Psychopathic traits" OR "Psychopathic Personality Inventory")]. Studies were selected based on whether they showed at least one significant correlation between an adaptive trait and psychopathy or psychopathic personality traits within 
participants. The term "adaptive trait" is defined as a trait which maximizes an individual's survival probability within a set environment.

Three types of adaptive characteristics emerged from the aforementioned studies. Social characteristics include high levels of social charm, great leadership abilities, notable displays of heroism, the ability to discard unnecessary relationships, and good management strategies (Babiak, Neumann, \& Hare, 2010; Dunlop et al., 2011; Gervais, Kline, Ludmer, George, \& Manson, 2013; Hall, Benning, \& Patrick, 2004; Lilienfeld, Latzman, Watts, Smith, \& Dutton, 2014; Smith, Lilienfeld, Coffey, \& Dabbs, 2013). Characteristics related to protective features include low levels of anxiety and stress, little nervousness, and absence of fear, both physical and psychological (Camp et al., 2013; Dindo \& Fowles, 2011; Dunlop et al., 2011; Gao \& Tang, 2013; Hall et al., 2004; López et al., 2013; Uzieblo, Verschuere, Van den Bussche, \& Crombez, 2010; Zágon \& Jackson, 1994). Characteristics related to personal features include boldness, low impulsivity, low provoked aggression, willingness to take calculated risks, absence of irrationality, strategic thinking, innovation, high self-esteem, superior cognitive focus and sensitivity to reward (Babiak et al., 2010; Baskin-Sommers, Zeier, \& Newman, 2009; Camp et al., 2013; Dunlop et al., 2011; Durand, 2016; Eisenbarth, Lilienfeld, \& Yarkoni, 2015; Falkenbach, Howe, \& Falki, 2013; Hicks, Markon, Patrick, Krueger, \& Newman, 2004; Ray et al., 2011; Takahashi, Takagishi, Nishinaka, Makino, \& Fukui, 2014; Uzieblo et al., 2010). Altogether, these characteristics seem to be correlated with a high display of Factor 1 traits as defined by the PPI.

\section{The Current Study}

While these characteristics are considered adaptive and linked to PPI-I, it is unknown how they interact with each other. It is possible that different patterns among these characteristics lead to the existence of subtypes within PPI-I. Furthermore, the spectrum of adaptive characteristics assessed by the PPI is limited. Thus, the purpose of this article is to describe the development and initial validation of the Durand Adaptive Psychopathic Traits Questionnaire (DAPTQ), a newly developed self-report measure assessing adaptive traits known to correlate with the psychopathic personality as defined by the PPI. This questionnaire is not intended to diagnose or assess the presence of psychopathy. This article outlines the construction of the DAPTQ, along with its subscales, reports the DAPTQ's basic psychometric properties, and describes the validity of scores on the questionnaire in multiple samples. 


\section{Study 1: Test Development and Preliminary Psychometric Properties}

\section{Participants}

The initial construction of the test spanned two rounds of item writing and selection, data collection, and analyses. The first sample consisted of 118 participants and the second sample consisted of 305 participants. Participants of both samples were recruited on social media and websites dedicated to psychological research (e.g., callforparticipants.com, onlinepsychresearch.co.uk). Participants were invited to take part in the study if they were fluent in English and over 18 years old. In order to assess for potential deviant responses, I examined PPI-SF data through the Variable Response Inconsistency (VRIN). The purpose of this statistical procedure, which was modeled after Tellegen (1982) VRIN scale, and later adapted to the PPI by Lilienfeld and Widows (2005), is to examine the inconsistencies within 10 pairs of highly correlated items from the PPI-SF. For each of the 10 pairs, the score obtained on the first item is subtracted from the second item, and the differences of the 10 pairs are summed in order to give a total score. A higher score signifies greater variability within similar questions expecting similar answers. A cut-off of 8 , which corresponds to three standard deviations of the VRIN score above its mean $(M=2.50, S D=1.95)$, was used to identify outliers. Using this method, I was able to identify 6 outliers in the first sample and 14 outliers in the second with a VRIN $\geq 8$. Analyses were performed on the responses of the remaining 112 participants $(72$ males and 40 females, $M$ $=26.0$ years old, $S D=9.23$ ) of the first sample and 291 participants (186 males and 105 females $M=25.3$ years old, $S D=8.40$ ) of the second sample. No other demographic than age and sex were recorded in study 1 . All participants gave informed consent before participating in any part of the study. This series of studies has been approved by the University of Maastricht Psychology and Neuroscience department's ethics committee, case number ECP-157-03-10-2015.

\section{Materials}

\section{Psychopathic Personality Inventory-Short Form (PPI-SF; Lilienfeld \& Widows, 2005)}

The PPI-SF is a self-report questionnaire of 56 items assessing psychopathic traits on 8 subscales derived from the original PPI. A total score is given, along with a score for each subscale: Machiavellian Egocentricity, Social Potency, Fearlessness, Coldheartedness, Impulsive Nonconformity, Blame Externalization, Carefree Nonplanfulness, and Stress Immunity. The scales 
are divided into two factors. PPI-I is composed of Stress Immunity, Social Potency and Fearlessness. PPI-II is composed of Blame Externalization, Machiavellian Egocentricity, Carefree Nonplanfulness and Impulsive Nonconformity. Coldheartedness is not under either factor. This questionnaire has been used in several studies to assess psychopathic traits in the general population and is considered to be a well-validated instrument (Benning, Patrick, Hicks, Blonigen, \& Krueger, 2003; Patrick, Edens, Poythress, Lilienfeld, \& Benning, 2006). Previous investigations demonstrated good convergent validity of the PPI-SF subscales with other measures of the psychopathic personality such as the Triarchic Psychopathy Measures (Hall et al., 2014) and the Elemental Psychopathy Assessment (Lynam et al., 2011).

\section{Levenson Self-Report Psychopathy (LSRP; Levenson, Kiehl, \& Fitzpatrick, 1995)}

The LSRP is a self-report questionnaire of 26 items assessing psychopathic attitudes and beliefs. The scale was designed using the same factors as the $P C L-R$ for use in non-institutional settings. This test is structured around the PCL-R's Factor 1 and Factor 2. The Factor 1 subscale assesses elements of meanness such as proneness to lying, lack of empathy, and manipulative behaviors. The Factor 2 subscale assesses elements of disinhibition such as impulsivity, proneness to frustration, lack of goals, and emotional negativity. Previous studies have supported the convergent and discriminant validity of scores on both scales (Brinkley, Schmitt, Smith, \& Newman, 2001; Ross, Bye, Wrobel, \& Horton, 2008). However, due to the low correlation between the PCL-R and the PPI, LSRP Factor 1 correlates poorly with PPI-I ( $r=.08)$ (Ross, Benning, Patrick, Thompson, \& Thurston, 2009). Alternatively, LSRP Factor 2 has been shown to correlate strongly with PPI-II ( $r=.63)$ (Ross et al., 2009). These results support the divergent validity between Factor 1 and PPI-I, while supporting the convergent validity between Factor 2 and PPI-II.

\section{Procedure}

I first identified the 19 constructs, which assess adaptive traits, based on the findings reported in the introduction. Once these constructs were established, 10 items were written for each construct. All 19 adaptive traits can be found in Table 1. Half of these items were written in the negative form for reverse coding. Items were answered using a six-option (Strongly Disagree, Disagree, Slightly Disagree, Slightly Agree, Agree, Strongly Agree) Likert-type format to avoid any bias of central tendency (Guilford, 1954). 
Table 1. Principal constructs targeted during Study 1
A) Social characteristics
C) Personal characteristics
1. Social charm
10. Boldness
2. Leadership abilities
11. Cautiousness
3. Heroism
12. Low provoked aggression
4. Management abilities
13. Calculated risks
5. Discarding relationships with no respect
14. Rational thinking
6. Discarding relationships with no common grounds
15. Strategic thinking
B) Protective characteristics
16. Innovative thinking
7. Anxiety immunity
17. High self-esteem
8. Stress immunity
18. Superior focus
9. Fear immunity
19. Reward sensitivity

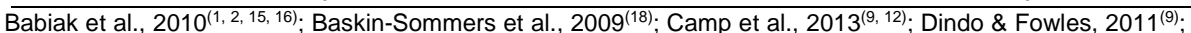
Dunlop et al., 2011(1, 8, 10); Durand, 2016 (12, 17); Eisenbarth et al., 2015(9, 19); Falkenbach et al., 2013(12, 17); Gao \&

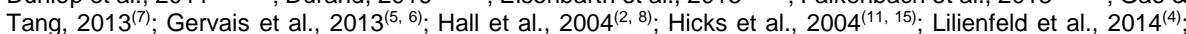

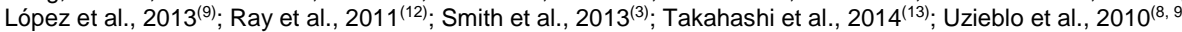
14); Zágon \& Jackson, $1994^{(7)}$.

The first sample of participants was invited to fill-in the 190-item DAPTQ, the PPI-SF and the LSRP. In order to assist in identifying the most appropriate items for each construct, Cronbach's alpha analyses were performed for each group of 10 items in all 19 adaptive traits' subscales. Upon examination of the Cronbach's alpha by deleting the item, the 4 items with the weakest relationship within their respective subscales were removed, leaving a total of 114 items. The second group of participants was then invited to complete the 114-item DAPTQ along with the PPI-SF and the LSRP. Cronbach's alpha analyses were performed for each construct in the second sample's results in order to remove the two least correlated items of each construct. This left the four most correlated items for each construct. The removal of 6 items by construct ensured the homogeneity of each construct, leaving out potential non-related items. Two-tailed Pearson correlations supported the presence of weak to strong correlations among all scales, with the exception of "Discarding relationships with no respect". Items pertaining to that scale were removed from the questionnaire. The remaining 72 items ( 49 keyed positively, 23 keyed negatively) were randomized once again, which was followed by recruitment for study 2 . 


\section{Study 2: Test Validation and Psychometric Properties from a Community Sample}

\section{Participants}

Eight hundred and nine $(N=809)$ individuals from the community were recruited once again via social media and websites dedicated to psychological research for the validation of the DAPTQ. Potential participants were required to not have participated in a previous phase of the DAPTQ's development, be over 18 years old, be fluent in English, and to not be receiving treatment from a mental health care professional. In order to improve the reliability of the results, I used a more conservative VRIN cut-off corresponding to two standard deviations above the mean, corresponding once again to $8(M=2.76$, $S D=2.21$ ). A total of 25 individuals were removed from subsequent analyses due to a VRIN $\geq 8$ on the PPI-SF. Further analyses of standard deviation through examination of the Stem-and-Leafs plot selected a total of 19 additional outliers, leaving a final sample of 765 individuals. The final sample consisted of 519 males and 246 females. The location of most participants was Europe (53\%), followed by North America $(23 \%)$, Asia $(11 \%)$, South America (6\%) and Africa (4\%). Regarding education level, the largest group among participants was college dropouts (27\%). For the remaining participants, the most common education levels completed or in progress were: college (26\%), high school (19\%), Masters degree (14\%) and technical school (6\%). Regarding ethnic composition, most participants were Caucasian (76\%), followed by Hispanic $(8 \%)$, Asian $(11 \%)$, or other $(5 \%)$. Participants' mean age was 24.5 years $(S D=6.87)$.

\section{Procedure}

Participants were invited to complete the latest version of the DAPTQ, along with the PPI-SF and the LSRP. Completion of the questionnaire was performed on the Qualtrics web-platform. Only the data from participants who had answered $100 \%$ of the questions was recorded, and hence there was no missing data. Prior to performing a factor analysis, I investigated the distributions of the DAPTQ items in the sample. All 72 items had values between -1.016 and 1.275 for Skewness and between -1.219 and 1.212 for Kurtosis, supporting the normal distribution of all items in the sample. Additionally, all response options on all items were used. An exploratory factor analysis (EFA; maximum likelihood method with direct oblimin rotation) was conducted on the 72 items of the DAPTQ in order to determine the number of subscales within the DAPTQ. Using O'Connor's (2000) SPSS syntax, a parallel analysis using principal components analysis was conducted using permutations of the original data set $(N$ of parallel data sets $=1000$, 


\section{Chapter 7 | Development of the DAPTQ}

percentile $=95$ th). This analysis supported retaining the first 11 factors of the EFA, as the Eigenvalue of the 12th factor (1.266) was under the cut-off established by the analysis for the aforementioned factor (1.350). Items retained in the final version of the DAPTQ loaded .3 or greater on their targeted factor while not loading .3 or greater on any other factor.

\section{Results and Discussion}

\section{DAPTQ Subscales}

The 11 factor EFA solution accounted for $53.37 \%$ of the variance. The Eigenvalues of these 11 factors ranged between 11.46 and 1.39. The 11 subscales of the DAPTQ, the final number of items for each subscale, a sample item for each subscale, Cronbach's alpha, Eigenvalues, and cumulative variance in percentage are shown in Table 2. Out of the original 72 items, 48 items were successfully distributed among the factors.

\section{Sex Differences}

A multivariate analysis of variance identified several gender differences on the DAPTQ and other questionnaires. Males $(M=176.15, S D=23.77)$ scored higher than females $(M=164.89, S D=22.29)$ on the DAPTQ total score $(F(1$, $764)=38.93, p<.001, r=.24)$, as well as on five other factors: Logical Thinking (Males, $M=21.96, S D=4.46$; Females, $M=20.73, S D=4.53 ; \mathrm{F}(1$, $764)=12.70, p<.001, r=.14$ ), Composure (Males, $M=21.94, S D=6.29$; Females, $M=18.25, S D=6.84 ; F(1,764)=54.41, p<.001, r=.27)$, Fearlessness (Males, $M=23.72, S D=5.84$; Females, $M=20.32$, $S D=5.92$; $F(1,764)=55.96, p<.001, r=.28$ ), Extroversion (Males, $M=20.52, S D=$ 6.54; Females, $M=19.07, S D=6.53 ; F(1,764)=8.32, p=.004, r=.11)$, and Consequentialism (Males, $M=11.62, S D=3.97$; Females, $M=9.84$, $S D=$ 3.03; $F(1,764)=36.10, p<.001, r=.24)$. Alternatively, females scored higher than males on one factor, namely Creativity (Males, $M=14.95, S D=4.62$; Females, $M=16.32, S D=4.61 ; F(1,764)=14.79, p<.001, r=.15)$. Males also received a higher PPI-SF total score (Males, $M=134.72, S D=13.97$; Females, $M=127.47, S D=14.45 ; F(1,764)=44.0, p<.001, r=.25)$ and LSRP total score (Males, $M=55.70, S D=10.20$; Females, $M=50.94, S D=$ 9.54; $F(1,764)=38.0, p<.001, r=.23)$. These findings are consistent with previous results demonstrating that psychopathic traits, including adaptive psychopathic traits, are more common among men than women (Lilienfeld \& Andrews, 1996). 
Table 2. DAPTQ Subscales, sample items, Cronbach's alpha, eigenvalues, and variance

\begin{tabular}{|c|c|c|c|}
\hline Scales & Alpha & Eigenvalues & $\begin{array}{c}\text { Cumulative \% } \\
\text { of Variance }\end{array}$ \\
\hline Leadership (4 items) & .82 & 11.46 & 15.92 \\
\hline \multicolumn{4}{|l|}{ People often follow my lead. (True) } \\
\hline $\begin{array}{l}\text { Logical Thinking ( } 5 \text { items) } \\
\text { I prefer to act first and think later. } \\
\text { (False) }\end{array}$ & .80 & 6.02 & 24.28 \\
\hline Composure (6 items) & .86 & 4.20 & 30.11 \\
\hline \multicolumn{4}{|l|}{ I rarely worry. (True) } \\
\hline $\begin{array}{l}\text { Creativity (4 items) } \\
\text { I am the most creative one out of my } \\
\text { friends. (True) }\end{array}$ & .85 & 3.53 & 35.00 \\
\hline $\begin{array}{l}\text { Fearlessness ( } 6 \text { items) } \\
\text { Dangerous situations frighten me. } \\
\text { (False) }\end{array}$ & .84 & 2.76 & 38.84 \\
\hline $\begin{array}{l}\text { Similarity ( } 3 \text { items) } \\
\text { It is important that my friends are like } \\
\text { me. (True) }\end{array}$ & .76 & 2.21 & 41.90 \\
\hline $\begin{array}{l}\text { Money smart (3 items) } \\
\text { I am a reckless money spender. (False) }\end{array}$ & .79 & 1.91 & 44.55 \\
\hline $\begin{array}{l}\text { Focus ( } 4 \text { items) } \\
\text { I can't be distracted easily. (True) }\end{array}$ & .78 & 1.74 & 46.97 \\
\hline $\begin{array}{l}\text { Extroversion ( } 6 \text { items) } \\
\text { I can effortlessly mingle with any group. } \\
\text { (True) }\end{array}$ & .83 & 1.66 & 49.27 \\
\hline $\begin{array}{l}\text { Consequentialism ( } 4 \text { items) } \\
\text { The ends justify the means. (True) }\end{array}$ & .64 & 1.55 & 51.43 \\
\hline $\begin{array}{l}\text { Management ( } 3 \text { items) } \\
\text { I feel like I have very poor management } \\
\text { skills. (False) }\end{array}$ & .68 & 1.39 & 53.37 \\
\hline
\end{tabular}

\section{Internal Consistency Reliability}

The internal consistency reliability of the DAPTQ total score, as assessed by Cronbach's alpha, was .86. The internal consistency reliability of the current sample on the 11 factors of the DAPTQ ranged from .64 to .86. In comparison, the internal consistency reliability of the PPI-SF total score from the current study was .76, and its eight subscales' internal consistency reliability ranged from .53 to .87 . The internal consistency reliability of the LSRP was .85 . 


\section{Chapter 7 | Development of the DAPTQ}

Deeper examination of the subscales' Cronbach's alphas did not identify any items whose removal would significantly increase the overall internal consistency reliability.

\section{Correlations Among the DAPTQ, the PPI-SF, and the LSRP}

The intercorrelations among the 11 DAPTQ factors are shown in Table 3A. Ten out of the 11 subscales moderately to strongly correlated with the DAPTQ total score $(r=.31$ to .64$)$. Similarity did not display any correlation with the DAPTQ total, and very few weak correlations with other factors $(r=-.09$ to $-.20)$.

The descriptive data and the correlations between the DAPTQ and its factors with the PPI-SF and the LSRP can be examined in Tables 3B and $3 \mathrm{C}$. The DAPTQ was moderately correlated with the PPI-SF total score $(r=.46)$. Closer examination of the PPI-SF's subscales revealed that scores on Social Potency, Carefree Nonplanfulness, and Stress Immunity subscales showed the strongest correlations with the DAPTQ, while Fearlessness, Coldheartedness, Impulsive Nonconformity, Blame Externalization, and Machiavellian Egocentricity had the weakest correlations. PPI-I showed a strong positive correlation with the DAPTQ, which was not found on PPI-II. This is consistent with the presumed adaptive nature of PPI-I individuals. The LSRP total score did not show any correlation with the DAPTQ. LSRP Factor 1 showed a weak positive correlation with DAPTQ, while LSRP Factor 2 showed a moderate negative correlation.

Examination of the DAPTQ's subscales demonstrated several strong correlations supporting the subscales' validity. First, Leadership was highly correlated with Social Potency $(r=.57)$. Second, Composure correlated highly with Stress Immunity $(r=.61)$ and PPI-I $(r=.49)$. Third, Fearlessness correlated strongly with the fearlessness subscale of the PPI-SF $(r=.59)$, PPII $(r=.65)$, and PPI-SF Total $(r=.62)$. Fourth, Extroversion was strongly correlated with Social Potency $(r=.77)$ and PPI-I $(r=.58)$. Fifth, Consequentialism showed strong correlations to Machiavellian Egocentricity $(r=.52)$, LSRP Factor $1(r=.66)$, and LSRP Total $(r=.59)$. Lastly, Management was highly negatively correlated with Carefree Nonplanfulness $(r=-.47)$ and LSRP Factor $2(r=-.49)$.

Due to the lack of correlation between the Similarity factor and the DAPTQ total score, alongside the lack of moderate to strong correlations between Similarity and the PPI-SF or the LSRP, the three items pertaining to similarity were removed. The remaining 45 items ( 27 keyed positively, 18 keyed negatively) were randomized before starting study 3 . 


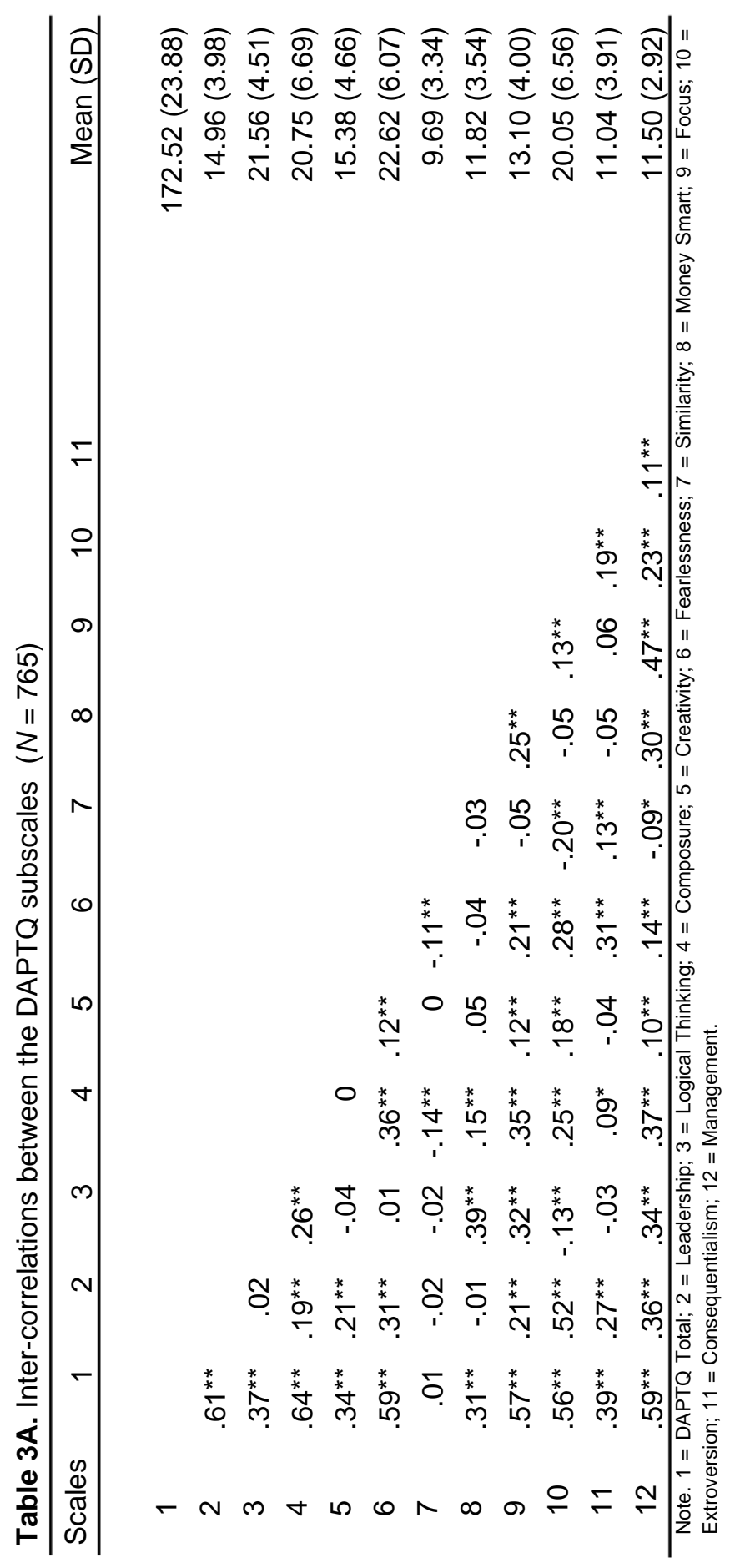


Table 3B. Descriptive Data $(\mathrm{N}=765)$

\begin{tabular}{lrr}
\hline & Mean & S.D. \\
\hline PPI-SF & & \\
Machiavellian Egocentricity & 16.20 & 3.94 \\
Social Potency & 17.50 & 3.65 \\
Fearlessness & 17.69 & 5.26 \\
Coldheartedness & 14.29 & 4.15 \\
Impulsive Nonconformity & 17.47 & 3.76 \\
Blame Externalization & 15.38 & 5.10 \\
Carefree Nonplanfulness & 14.99 & 3.01 \\
Stress Immunity & 18.83 & 3.38 \\
PPI-I & 54.03 & 9.02 \\
PPI-II & 64.06 & 9.48 \\
Total & 132.38 & 14.51 \\
LSRP & & \\
Factor 1 & 32.45 & 8.14 \\
Factor 2 & 21.72 & 4.10 \\
Total & 54.17 & 10.23 \\
\hline
\end{tabular}

Note. S.D. = Standard Deviation

\section{Study 3: Validation of the DAPTQ subscales}

\section{Participants}

The DAPTQ and its subscales were further validated in a sample of 133 individuals from the community (44 males and 89 females) recruited once again from social media and websites dedicated to psychological research. As in study 2, participants were instructed to not participate if they have participated in a previous phase of the development of the DAPTQ. Participants were mostly located in Europe (53\%), North America (26\%), Asia $(12 \%)$, Africa $(4 \%)$, South America (3\%), and Oceania (2\%). Regarding education level, participants were mostly college graduate (29\%). Following this, the most common education levels were: Master's degree (28\%), college dropout $(23 \%)$, Doctoral degree $(7 \%)$, or other $(13 \%)$. Regarding ethnicity, participants were mostly Caucasian $(77 \%)$, Asian $(15 \%)$ or other $(8 \%)$. The mean age of the participants was $27.8(S D=10.47)$ years old. 


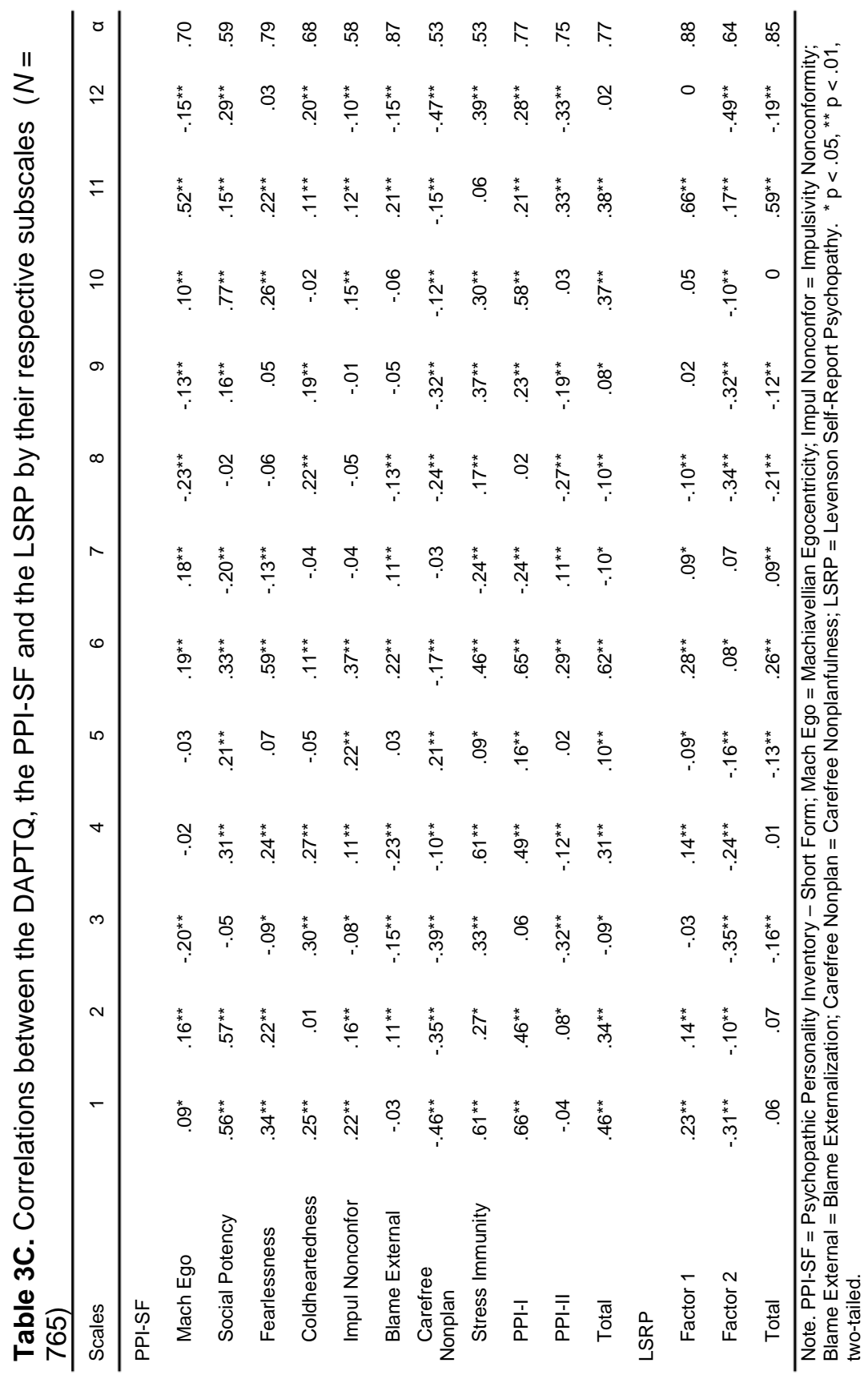




\section{Measures}

Big Five Inventory (BFI; John, Donahue, \& Kentle, 1991)

The BFI is a 44-item questionnaire assessing the Big Five components of personality (Goldberg, 1992). The questionnaire gives 5 subscale scores, namely Openness, Conscientiousness, Extraversion, Agreeableness, and Neuroticism. Respondents answer to which extent they agree with a particular characteristic ("I see myself as someone who is..."). Examples include "talkative" (Extroversion), "helpful and unselfish with others" (Agreeableness), "does a thorough job" (Conscientiousness), "depressed, blue" (Neuroticism), and "original, comes up with new ideas" (Openness). Items are rated on a 5point Likert scale ( $1=$ strongly disagree to $5=$ strongly agree $)$.

\section{Rational - Experiential Inventory - 40 Items (REI; Pacini \& Epstein, 1999)}

The REI is a 40 -item questionnaire assessing preferences for information processing (rational style and experiential style). The rational style assesses the usage of a conscious, analytical approach. Alternatively, the experiential style assesses the usage of a pre-conscious, affective, holistic approach. The $\mathrm{REI}$ is divided into 4 subscales, two for each approach. Rational Ability refers to the ability to think analytically "I have a logical mind". Rational Engagement refers to the reliance and enjoyment of analytical thinking "I enjoy intellectual challenges". Experiential Ability refers to the ability of experiencing intuitive impressions and feelings "I believe in trusting my hunches". Experiential Engagement refers to the enjoyment of relying on feelings to make decisions "I like to rely on my intuitive impressions". Items are rated on a 5-point Likert scale $(1=$ strongly disagree to $5=$ strongly agree $)$.

\section{Jackson Personality Inventory - Risk Taking Scale (JPI-RT; Jackson, 1976)}

The JPI is a personality assessment measuring various core traits of the personality, such as openness, neuroticism, extraversion, trustworthiness, and organization. The JPI-RT includes the 20 items related to risk taking from the original 320 items of the JPI. The scale uses a True/False format and assesses preferences to risky behaviors.

\section{Perceived Stress Scale - 10 Items Version (PSS-10; Cohen \& Williamson, 1988)}

The PSS-10 is a 10-item self-reported questionnaire assessing how an individual can be stressed over everyday situations. The questionnaire is rated 
on a 5-point Likert Scale ( $0=$ Never to $4=$ Very often). Participants are asked to answer based on their general feelings and thoughts from the last month, i.e.: "In the last month, how often have you been upset because of something that happened unexpectedly?"

\section{State-Trait Anxiety Inventory - Trait Version (STAI-Y2; Spielberger, Gorsuch, \& Lushene, 1970)}

The STAl is a 40-item questionnaire assessing anxiety through a 4-point Likert scale $(1=$ almost never to $4=$ almost always $)$. The Y2 scale includes 20 items and focuses on how anxious an individual is in its everyday life. Participants are asked to answer how they generally feel to statements such as "I lack selfconfidence" and "I am a steady person".

\section{Results and Discussion}

The intercorrelations among the 10 DAPTQ subscales were once again computed and are shown in Table 4A. Once again, all but one of the DAPTQ factors correlated moderately to strongly with the DAPTQ total score $(r=.37$ to .68). While Consequentialism displayed a correlation of $r=.39$ with the DAPTQ total score in study 2 , the factor failed to correlate significantly with the total score in study 3 . The DAPTQ and its subscales displayed good internal consistency reliability, ranging from $\alpha=.63$ to .89 .

The descriptive data and the correlations between the DAPTQ and the $\mathrm{BFI}$, the REI, the JPI-RT, the PSS-10, and the STAI-Y2 are shown in Table $4 B$ and $4 C$. The DAPTQ total score showed moderate to strong positive correlations with all measurements of the BFI, with the exception of a strong negative correlation with Neuroticism. Strong positive correlations were also found between the DAPTQ and the two rational scales of the REI, demonstrating the analytical nature of individuals high on the DAPTQ. A weak correlation was also found between the DAPTQ and experiential ability. The JPI-RT showed a weak correlation with the DAPTQ, and the measures of stress and anxiety (PSS-10 and STAI-Y2) both showed a strong negative correlation with the DAPTQ. 


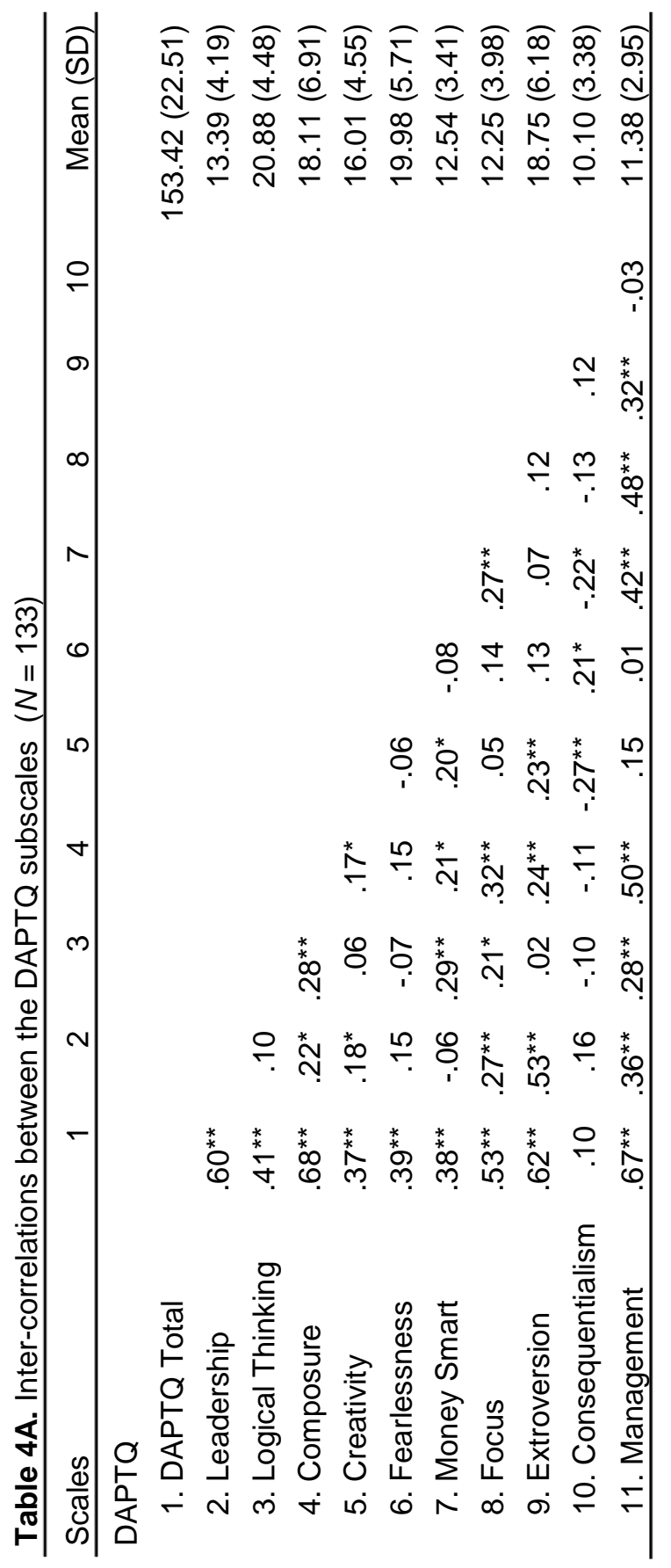


Table 4B. Descriptive Data $(\mathrm{N}=133)$

\begin{tabular}{lcc}
\hline & Mean & S.D. \\
\hline BFI Subscales & & \\
Extroversion & 21.30 & 6.61 \\
Agreeableness & 32.72 & 5.88 \\
Conscientiousness & 30.35 & 6.20 \\
Neuroticism & 25.00 & 7.71 \\
Openness & 38.09 & 6.31 \\
REI Subscales & & \\
$\quad$ Rational Ability & 38.31 & 6.47 \\
$\quad$ Rational Engagement & 38.96 & 6.19 \\
Experiential Ability & 33.06 & 6.45 \\
$\quad$ Experiential Engagement & 31.48 & 6.80 \\
JPI-RT & & \\
$\quad$ Total & 6.06 & 4.08 \\
PSS-10 & & \\
$\quad$ Total & 18.30 & 7.69 \\
STAI-Y2 & & \\
$\quad$ Total & 47.15 & 13.26 \\
\hline
\end{tabular}

Note. S.D. = Standard Deviation

Examination of the DAPTQ's subscales further supports their validity to measure their respective constructs. First, Leadership correlated strongly with Extroversion $(r=.58)$. Second, Logical Thinking was strongly correlated with Rational Ability $(r=.61)$, and highly negatively correlated with Experiential Engagement $(r=-.47)$. Third, Composure was highly negatively correlated with Neuroticism $(r=-.85)$, PSS-10 $(r=-.65)$, and STAI-Y2 $(r=-.75)$. Fourth, Creativity showed a strong correlation with Openness $(r=.65)$. Fifth, Fearlessness displayed a strong correlation with JPI-RT ( $r=.54)$. Sixth, Focus highly correlated with Conscientiousness $(r=.53)$. Seventh, Extroversion correlated strongly with the Extroversion scale of the BFI $(r=.76)$. Lastly, Management displayed a strong correlation with Conscientiousness $(r=.66)$, and strong negative correlations with Neuroticism $(r=-.50)$ and STAI-Y2 $(r=$ $-60)$. 


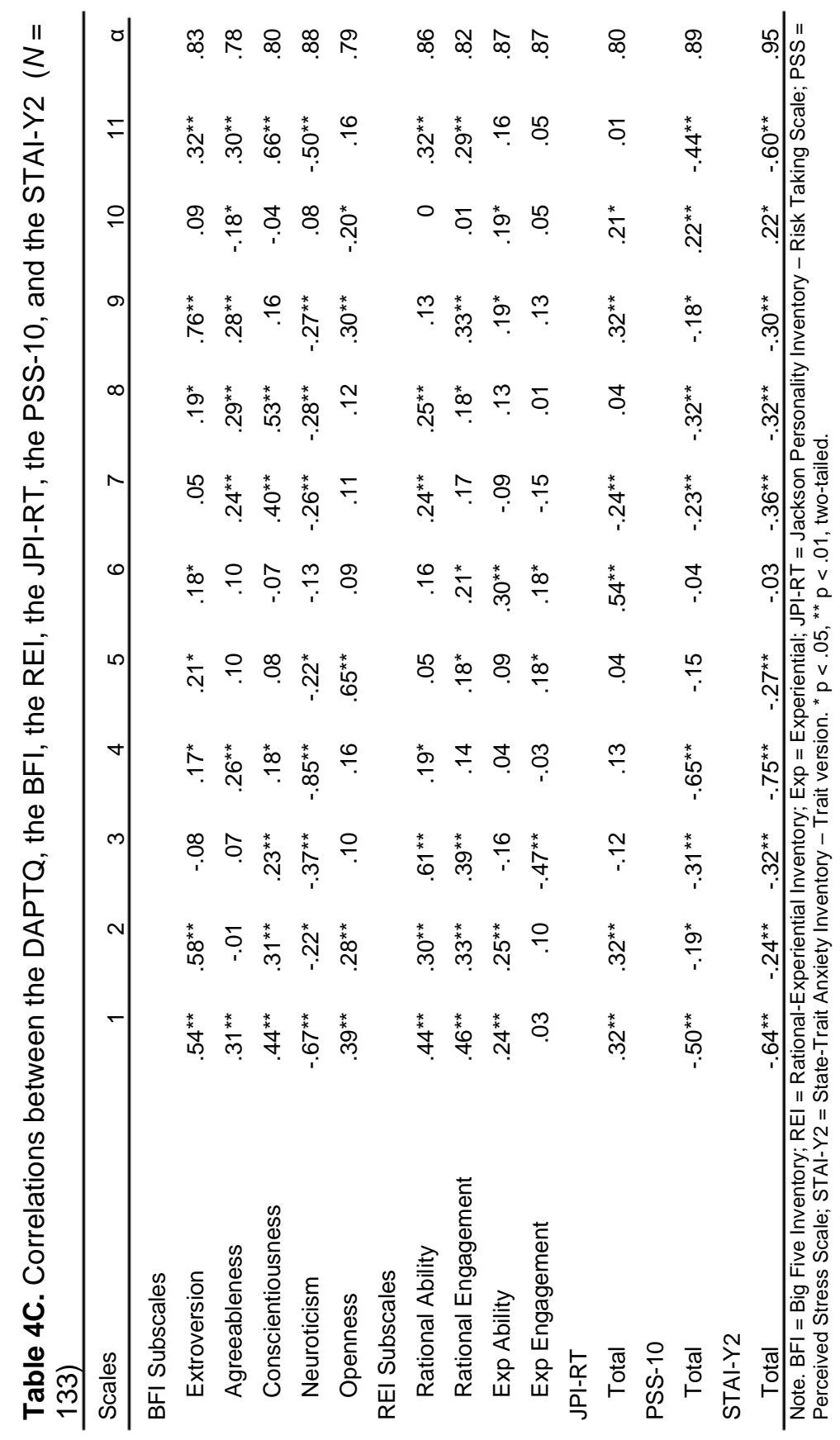


Similarly to the removed construct of Similarity from study 2, Consequentialism was not correlated with the DAPTQ total score. Additionally, the correlations obtained between Consequentialism and other measurements, such as the PSS-10 and the STAI-Y2, were contrary to theory. The four items related to the construct were therefore removed. The remaining 41 items (24 keyed positively, 17 keyed negatively) were randomized once again and form the final version of the DAPTQ.

\section{General Discussion}

The purpose of these studies was to develop and validate a new questionnaire for assessing adaptive traits known to correlate with the psychopathic personality. The aforementioned studies' results confirm the adequacy of the DAPTQ in various samples, as well as providing support for the subscales' validity. The DAPTQ demonstrated good internal consistency reliability for its total score and all its subscales for all samples, as well as a strong correlation with well-established assessments of the psychopathic personality and to other personality measures.

As expected, the DAPTQ was highly positively correlated with PPI-I and weakly positively correlated with LSRP Factor 1 . Alternatively, the DAPTQ was not correlated with PPI-II and moderately negatively correlated with LSRP Factor 2. These results stem from the difference in the conceptual definition of psychopathy by each questionnaire. The PPI defines psychopathic traits by adhering to the differential configuration model. PPI-I focuses on adaptive traits only, while PPI-II focuses on maladaptive outcomes (Skeem, Polaschek, Patrick, \& Lilienfeld, 2011). While both PPI-I and PPI-II assess fundamentally different psychopathic traits, the LSRP assesses maladaptive outcomes on both of its factors without taking into account any form of adaptive behaviors. The weak correlation between the DAPTQ and LSRP Factor 1 further supports the divergent validity of the scale, demonstrating the inability of the LSRP to assess adaptive outcomes in psychopathic individuals. Alternatively, the moderate negative relationship between the DAPTQ and LSRP Factor 2 supports the maladaptive behaviors assessed by the LSRP and its opposition to the adaptive traits assessed by the DAPTQ.

By selecting a wide range of adaptive traits known to correlate with the psychopathic personality and developing an assessment specific to these traits, it was possible to investigate the relationship between them. The first factor refers to the leadership attributes of an individual and the perception of others to one's role as a leader. The second factor assesses the preference of an individual to act logically and rationally, rather than acting emotionally. 


\section{Chapter 7 | Development of the DAPTQ}

The third factor relates to the ability to remain calm in most situations, including stressful scenarios. The fourth factor assesses creative thinking and a 'think outside the box' mentality. The fifth factor encompasses the fearless nature associated with psychopathic individuals. The sixth factor assesses the tendency of an individual to efficiently manage money. The seventh factor refers to one's ability to stay focused despite potential distractions. The eighth factor assesses extroversion and the charismatic attitudes of an individual. The last factor encompasses the ability of an individual to manage a group of tasks or individuals. Altogether, these 9 factors showcase the traits through which PPI-I individuals benefit the most in comparison to the general population.

While several of the abovementioned adaptive traits have been studied extensively in relation to the psychopathic personality (e.g., Leadership, Composure, Fearlessness, Extroversion), some other traits (e.g., Creativity, Management, Money Smart) have not been studied in detail in the field of psychopathy. Considering the numerous correlations reported between these traits and various components of the psychopathic personality, it is of interest to further investigate their role and influence in psychopathic individuals.

As previously mentioned, while this test assesses the adaptive traits found in Factor 1 psychopathic individuals, as defined by the PPI, it should not be seen as a psychopathy measurement for several reasons. First, the diagnosis of psychopathy is a combination of Factor 1 and Factor 2 as defined by the PCL-R, and this test focuses exclusively on traits related to PPI-I (Patrick et al., 2009). The questionnaire can therefore only assess a portion of psychopathy-related traits, which is under a lot of debate regarding its validity with the concept of psychopathy (Lilienfeld et al., 2012; Lynam \& Miller, 2012; Miller \& Lynam, 2012). Furthermore, this questionnaire has not been validated for use in criminal populations, despite the propensity of psychopaths in criminal settings (Polaschek \& Daly, 2013). In conclusion, the DAPTQ should solely be used to assess an individual's adaptive characteristics in non-criminal populations until further validation.

Although the current findings are highly encouraging, additional construct validation is needed to further assess the validity of each subscale. The DAPTQ also needs to be administered against measures of social potency, leadership, creativity, logical reasoning, propensity to take calculated risks, and goal driven behavior. While some of these components were included in the current study and the findings were encouraging with regards to establishing the validity of the DAPTQ's subscales, further validation against alternative measures of personality is recommended. 


\section{References}

Babiak, P., Neumann, C. S., \& Hare, R. D. (2010). Corporate Psychology: Talking the Walk. Behavioral Sciences \& the Law, 28(2), 174-193.

Baskin-Sommers, A. R., Zeier, J. D., \& Newman, J. P. (2009). Self-reported attentional control differentiates the major factors of psychopathy. Personality and Individual Differences, 47(6), 626-630.

Benning, S. D., Patrick, C. J., Hicks, B. M., Blonigen, D. M., \& Krueger, R. F. (2003). Factor structure of the psychopathic personality inventory: validity and implications for clinical assessment. Psychological Assessment, 15(3), 340-350.

Berg, J. M., Smith, S. F., Watts, A. L., Ammirati, R., Green, S. E., \& Lilienfeld, S. O. (2013). Misconceptions regarding psychopathic personality: implications for clinical practice and research. Neuropsychiatry, 3(1), 63-74.

Boddy, C., Miles, D., Sanyal, C., \& Hartog, M. (2015). Extreme managers, extreme workplaces: Capitalism, organizations and corporate psychopaths. Organization, 22(4), 530-551.

Boddy, C. R. (2014). Corporate Psychopaths, Conflict, Employee Affective Well-Being and Counterproductive Work Behaviour. Journal of Business Ethics, 121(1), 107-121.

Brinkley, C. A., Schmitt, W. A., Smith, S. S., \& Newman, J. P. (2001). Construct validation of a self-report psychopathy scale: Does Levenson's self-report psychopathy scale measure the same constructs as Hare's psychopathy checklist-revised? Personality and Individual Differences, 31(7), 1021-1038.

Camp, J. P., Skeem, J. L., Barchard, K., Lilienfeld, S. O., \& Poythress, N. G. (2013). Psychopathic predators? Getting specific about the relation between psychopathy and violence. Journal of Consulting and Clinical Psychology, 81(3), 467-480.

Cleckley, H. (1941). The mask of sanity; an attempt to reinterpret the so-called psychopathic personality. Jama, 117(6), 493.

Cohen, S., \& Williamson, G. (1988). Perceived stress in a probability sample of the United States. In The social psychology of health. The Claremont Symposium on Applied Social Psychology. (Sage, pp. 31-67). Newbury Park, CA.

Dindo, L., \& Fowles, D. (2011). Dual temperamental risk factors for psychopathic personality: evidence from self-report and skin conductance. Journal of Personality and Social Psychology, 100(3), 557-566.

Dunlop, B. W., DeFife, J. A., Marx, L., Garlow, S. J., Nemeroff, C. B., \& Lilienfeld, S. O. (2011). The effects of sertraline on psychopathic traits. International Clinical Psychopharmacology, 26(6), 329-37.

Durand, G. (2016). A Replication of " Using self-esteem to disaggregate psychopathy, narcissism, and aggression (2013) ." The Qantitative Methods for Psychology, 12(2), r1-r5.

Eisenbarth, H., Lilienfeld, S. O., \& Yarkoni, T. (2015). Using a Genetic Algorithm to Abbreviate the Psychopathic Personality Inventory - Revised ( PPI-R ), 27(1), 


\section{Chapter 7 | Development of the DAPTQ}

194-202.

Falkenbach, D. M., Howe, J. R., \& Falki, M. (2013). Using self-esteem to disaggregate psychopathy, narcissism, and aggression. Personality and Individual Differences, 54(7), 815-820.

Gao, Y., \& Tang, S. (2013). Psychopathic personality and utilitarian moral judgment in college students. Journal of Criminal Justice, 41(5), 342-349.

Gervais, M. M., Kline, M. A., Ludmer, M., George, R., \& Manson, J. H. (2013). The strategy of psychopathy: primary psychopathic traits predict defection on lowvalue relationships. Proceedings of the Royal Society - Biological Sciences, 280(February), 20122773.

Goldberg, L. R. (1992). The Development Of Markers For The Big Five Factor Structure. Psychological Assessment, 4(1), 26-42.

Guilford, J. P. (1954). The Constant Methods. In Psychometric methods (p. 597).

Hall, J., \& Benning, S. (2006). The "successful" psychopath: adaptive and subclinical manifestations of psychopathy in the general population. In C. J. Patrick (Ed.), Handbook of psychopathy (Guilford P, pp. 459-478). NY, USA.

Hall, J., Benning, S. D., \& Patrick, C. J. (2004). Criterion-Related Validity of the ThreeFactor Model of Psychopathy: Personality, Behavior, and Adaptive Functioning. Assessment, 11(1), 4-16.

Hall, J., Drislane, L. E., Patrick, C. J., Morano, M., Lilienfeld, S. O., \& Poythress, N. G. (2014). Development and validation of Triarchic Construct Scales from the Psychopathic Personality Inventory. Psychological Assessment, 26(2), 447-61.

Hare, R. D. (1991). The Hare Psychopathy Checklist-revised (MultiHealt). Toronto.

Hare, R. D. (2003). The Hare Psychopathy Checklist- Revised. Muliti-Health Systems.

Hicks, B. M., Markon, K., Patrick, C. J., Krueger, R., \& Newman, J. P. (2004). Identifying Psychopathy Subtypes on the Basis of Personality Structure. Psychological Assessment, 16(3), 276-288.

Jackson, D. N. (1976). Jackson Personality Inventory Manual. Port Huron, MI: Research Psychologists Press.

John, O. P., Donahue, E. M., \& Kentle, R. L. (1991). The Big Five Inventory - Versions 4a and 54. Berkeley, CA: University of California, Berkeley, Institute of Personality and Social Research.

Lilienfeld, S., Latzman, R. D., Watts, A. L., Smith, S. F., \& Dutton, K. (2014). Correlates of psychopathic personality traits in everyday life: Results from a large community survey. Frontiers in Psychology, 5, 1-11.

Lilienfeld, S. O., \& Andrews, B. P. (1996). Development and Preliminary Validation of a Self-Report Measure of Psychopathic Personality Traits in Noncriminal Populations. Journal of Personality Assessment, 66(3), 488-524.

Lilienfeld, S. O., Patrick, C. J., Benning, S. D., Berg, J., Sellbom, M., \& Edens, J. F. (2012). The role of fearless dominance in psychopathy: Confusions, controversies, and clarifications. Personality Disorders: Theory, Research, and Treatment, 3(3), 327-340. 
Lilienfeld, S. O., Watts, A. L., \& Smith, S. F. (2015). Successful Psychopathy: A Scientific Status Report. Current Directions in Psychological Science, 24(4), 298-303.

López, R., Poy, R., Patrick, C. J., \& Moltó, J. (2013). Deficient fear conditioning and self-reported psychopathy: The role of fearless dominance. Psychophysiology, 50(2), 210-218.

Lynam, D. R., Gaughan, E. T., Miller, J. D., Miller, D. J., Mullins-Sweatt, S., \& Widiger, T. A. (2011). Assessing the basic traits associated with psychopathy: development and validation of the Elemental Psychopathy Assessment. Psychological Assessment, 23(1), 108-124.

Lynam, D. R., \& Miller, J. D. (2012). Fearless dominance and psychopathy: A response to Lilienfeld et al. Personality Disorders: Theory, Research, and Treatment, 3(3), 341-353.

Miller, J. D., \& Lynam, D. R. (2012). An examination of the Psychopathic Personality Inventory's nomological network: A meta-analytic review. Personality Disorders: Theory, Research, and Treatment, 3(3), 305-326.

Mullins-Sweatt, S. N., Glover, N. G., Derefinko, K. J., Miller, J. D., \& Widiger, T. A. (2010). The search for the successful psychopath. Journal of Research in Personality, 44(4), 554-558.

O'Connor, B. P. (2000). SPSS and SAS programs for determining the number of components using parallel analysis and Velicer's MAP test. Behavior Research Methods, Instrumentation, and Computers, 32, 396-402.

Pacini, R., \& Epstein, S. (1999). The relation of rational and experiential information processing styles to personality, basic beliefs, and the ratio-bias phenomenon. Journal of Personality and Social Psychology, 76(6), 972-987.

Patrick, C. J. (2007). Affective Processes in Psychopathy. In Emotion and psychopathology: Bridging affective and clinical science (pp. 215-239).

Patrick, C. J., Edens, J. F., Poythress, N. G., Lilienfeld, S. O., \& Benning, S. D. (2006). Construct validity of the psychopathic personality inventory two-factor model with offenders. Psychological Assessment, 18(2), 204-208.

Patrick, C. J., Fowles, D. C., \& Krueger, R. F. (2009). Triarchic conceptualization of psychopathy: Developmental origins of disinhibition, boldness, and meanness. Development and Psychopathology, 21(3), 913.

Polaschek, D. L. L., \& Daly, T. E. (2013). Treatment and psychopathy in forensic settings. Aggression and Violent Behavior.

Ray, J. V., Weir, J. W., Poythress, N. G., \& Rickelm, A. (2011). Correspondence Between the Psychopathic Personality Inventory and the Psychopathic Personality Inventory-Revised: a Look At Self-Reported Personality Traits. Criminal Justice and Behavior, 38(4), 375-385.

Ross, S. R., Benning, S. D., Patrick, C. J., Thompson, A., \& Thurston, A. (2009). Factors of the Psychopathic Personality Inventory: Criterion-Related Validity and Relationship to the BIS/BAS and Five-Factor Models of Personality. Assessment, 16(1), 71-87. 


\section{Chapter 7 | Development of the DAPTQ}

Ross, S. R., Bye, K., Wrobel, T. A., \& Horton, R. S. (2008). Primary and secondary psychopathic characteristics and the schedule for non-adaptive and adaptive personality (SNAP). Personality and Individual Differences, 45(3), 249-254.

Skeem, J. L., Polaschek, D. L. L., Patrick, C. J., \& Lilienfeld, S. O. (2011). Psychopathic Personality: Bridging the Gap Between Scientific Evidence and Public Policy. Psychological Science in the Public Interest, 12(3), 95-162.

Smith, S. F., Lilienfeld, S. O., Coffey, K., \& Dabbs, J. M. (2013). Are psychopaths and heroes twigs off the same branch? Evidence from college, community, and presidential samples. Journal of Research in Personality, 47(5), 634-646.

Smith, S. F., Watts, A. L., \& Lilienfeld, S. O. (2014). On the trail of the elusive successful psychopath. The Psychologist, 27(7), 506-511.

Spielberger, C. D., Gorsuch, R. L., \& Lushene, R. E. (1970). The State-Trait Anxiety Inventory. MANUAL, 1-23.

Takahashi, T., Takagishi, H., Nishinaka, H., Makino, T., \& Fukui, H. (2014). Neuroeconomics of psychopathy: Risk taking in probability discounting of gain and loss predicts psychopathy. Neuroendocrinology Letters, 35(6), 510-517.

Tassy, S., Deruelle, C., Mancini, J., Leistedt, S., \& Wicker, B. (2013). High levels of psychopathic traits alters moral choice but not moral judgment. Frontiers in Human Neuroscience, 7, 229.

Tellegen, A. (1982). Brief Manual for the Differential Personality Questionnaire. Unpublished Manuscript, 1010-1031.

Uzieblo, K., Verschuere, B., Van den Bussche, E., \& Crombez, G. (2010). The validity of the psychopathic personality inventory--revised in a community sample. Assessment, 17(3), 334-346.

Zágon, I. K., \& Jackson, H. J. (1994). Construct validity of a psychopathy measure. Personality and Individual Differences, 17(I), 125-135. 




\section{Chapter 8}

Incremental Validity of the Durand Adaptive Psychopathic Traits Questionnaire Above Self-Report Psychopathy Measures in Community Samples

Durand, G. (2018). Incremental Validity of the Durand Adaptive Psychopathic Traits Questionnaire Above Self-Report Psychopathy Measures in Community Samples. Journal of Personality Assessment, 1-10. 


\section{Abstract}

Although highly debated, the notion of the existence of an adaptive side to psychopathy is supported by some researchers. Currently, two instruments assessing psychopathic traits include an adaptive component, but probably still not cover the full spectrum of adaptive psychopathic traits. The Durand Adaptive Psychopathic Traits Questionnaire (DAPTQ; Durand, 2017) is a 41 item self-reported instrument assessing adaptive traits known to correlate with the psychopathic personality. In this study, I investigated in 2 samples $(N=$ 263 and $N=262$ ) the incremental validity of the DAPTQ over the Psychopathic Personality Inventory-Short Form (PPI-SF) and the Triarchic Psychopathy Measure (TriPM) using multiple criterion measures. Results showed that the DAPTQ significantly increased the predictive validity over the PPI-SF on 5 factors of the HEXACO (i.e. Extraversion, Agreeableness, Conscientiousness, Neuroticism, and Openness). Additionally, the DAPTQ provided incremental validity over both the PPI-SF and the TriPM on measures of communication adaptability, perceived stress, and trait anxiety. Overall, these results support the validity of the DAPTQ in community samples. Future studies should focus on behavioral experiments due to the reliance of previous studies validating the DAPTQ on self-report questionnaires. 


\section{Introduction}

Modern theories of psychopathy stem primarily from the early work of Cleckley (1941), who defined psychopathy as a multi-facet disorder, including interpersonal, affective, and behavioral components, such as an absence of anxiety and fear, a proneness to lying, a lack of sincerity and remorse, having little to no empathy, and being emotionally detached. Through time, one of the most prominent definitions of psychopathy came from the work of Hare (1991), who developed the Psychopathy Checklist (PCL) and Psychopathy Checklist - Revised (PCL-R; Hare, 1991; 2003). Originally, the authors of the PCL conceptualized psychopathy as a two-factor disorder, consisting of interpersonal and affective deficits, and antisocial behaviors (Harpur, Hare, \& Hakstian, 1989). Later, a three-factor solution was proposed, consisting of interpersonal, emotional, and lifestyle facets (Cooke \& Michie, 2001). The most current model of the PCL-R has included a fourth facet, assessing impulsivity and aggression (Hare, 2003). Although the PCL- $R$ is vastly recognized as the gold standard in psychopathy assessment, there are a lot of controversies regarding core features of psychopathy. While all psychopathy models include lack of empathy and remorse as key components, there are several debates regarding the inclusion of criminal tendencies or aggression as central components in psychopathy, which is considered by some as a consequence of the disorder rather than a criterion (Berg et al., 2013; Cooke \& Michie, 2001; Gao \& Raine, 2010).

Despite the majority of early research in the field of psychopathy focusing on forensic populations, it has been argued early on that psychopaths might not always be maladaptive (Cleckley, 1941). Cleckley proposed a set of 16 characteristics representing psychopaths, namely: superficial charm, absence of delusion and irrational thinking, absence of nervousness, unreliability, untruthfulness, lack of remorse or shame, inadequately motivated antisocial behavior, poor judgment, pathologic egocentricity, poverty in major affective reactions, specific loss of insights, unresponsiveness in general interpersonal relations, fantastic and uninviting behavior with or without drinks, low suicide rate, impersonal and imbalanced sexual life, and a lack of life plan (1988, p.338-339). Although many of these characteristics are fully maladaptive, many traits, such as anxiety resilience and social charm, can arguably be considered adaptive. Additionally, there is no inclusion of criminal behaviors or criminal tendencies in the original list of common traits in psychopaths proposed by Cleckley. More recently, several literature reviews examining characteristics associated with 'successful' psychopathy have emerged. Gao and Raine (2010) developed a theoretical model of successful psychopathy using findings from 5 types of samples (community, employment agencies, 


\section{Chapter 8 | Incremental Validity of the DAPTQ}

college students, industrial, and serial killers). The authors proposed that, although all psychopathic individuals share similarities in lack of emotional empathy, arousal, and sensation seeking, successful psychopaths display better decision making, enhanced executive functioning, and superior cognitive empathy, and will favor relational aggression over physical aggression.

While the aforementioned authors moderate the benefits of successful psychopaths, other authors reviewed a wider range of benefits associated with traits central to successful psychopathy. Lilienfeld, Watts, and Smith (2015) reviewed findings pertaining to three models of successful psychopathy, namely the differential-severity model, the moderated-expression model, and the differential-configuration model. The differential-severity model assumes that psychopathy is a unitary construct, and that successful psychopathy is a milder form of psychopathy. In the moderated-expression model, successful psychopathy is conceptualized as an atypical manifestation of psychopathy due to the emergence of protective factors, which temper the effect of maladaptive outcomes in the disorder of psychopathy. As opposed to the first two models, the later presumes that psychopathy is not a unitary construct, but rather multidimensional, and that successful and unsuccessful psychopathy, while sharing key features, also possesses uniquely distinctive features from one another. Across a wide range of research, multiple authors found distinctive personality traits in successful psychopathy, such as higher extroversion, higher conscientiousness, and lower agreeableness, but also found other adaptive traits, such as leadership abilities, communication abilities, willingness to take risks, and immunity to stress and anxiety (Lilienfeld, Waldman, et al., 2012; Mullins-Sweatt, Glover, Derefinko, Miller, \& Widiger, 2010; Smith, Watts, \& Lilienfeld, 2014).

Although the PCL-R does not assess adaptive traits, two well-validated measures of psychopathic traits include an adaptive component in their definition of psychopathy. For instance, the Psychopathic Personality Inventory (PPI) divides 8 psychopathic traits into two major factors, namely PPI-I (Fearless Dominance) and PPI-II (Impulsive Antisociality) (Lilienfeld \& Widows, 2005). While PPI-II assesses negative personality traits, as enumerated previously, PPI-I focuses on adaptive characteristics, such as social charm, stress and anxiety immunity, and fearlessness. Although the relationship between PPI-I and the concept of psychopathy is highly debated (Berg et al., 2013; Blonigen, 2013; Lilienfeld, Patrick, et al., 2012; Lynam \& Miller, 2012), a vast amount of research support the benefits of high PPI-I traits due to its relation with adaptive personality traits, such as superior attentional control (Baskin-Sommers, Zeier, \& Newman, 2009), lower 
provoked violence (Camp, Skeem, Barchard, Lilienfeld, \& Poythress, 2013), higher levels of self-esteem and stable happiness (Durand, 2016a, 2016b), stress, fear, and anxiety resilience (Dindo \& Fowles, 2011; Durand \& Plata, 2017), and emotional stability (Uzieblo, Verschuere, Van den Bussche, \& Crombez, 2010). However, as noted previously, many experts have associated the construct of successful psychopathy with conscientiousness. Considering that fearless dominance is largely unrelated to conscientiousness, the factor might not be able to fully explain successful psychopathy (Lilienfeld et al., 2015).

An alternative measure to the PPI developed by Patrick (2010), the Triarchic Psychopathy Measure (TriPM), defines psychopathy on a threefactor model: Disinhibition, Meanness, and Boldness (Patrick, Fowles, \& Krueger, 2009). Disinhibition and Meanness assess the maladaptive side of psychopathy, while Boldness refers to adaptive characteristics, such as social charm, fearlessness, and stress resilience. Validation of the scales revealed correlations between PPI-I and Boldness $(r=.82)$ and PPI-II and both Disinhibition $(r=.66)$ and Meanness $(r=.54)$ (Hall et al., 2014). Similarly to the PPI, the TriPM adaptive component, Boldness, was found unrelated to conscientiousness, which might not be able to explain successful psychopathy better than the PPI (Blagov, Patrick, Oost, Goodman, \& Pugh, 2016).

In addition to the lack of association between PPI-I and Boldness with Conscientiousness, the spectrum of adaptive traits measured by those two instruments is limited. Some characteristics proposed by Cleckley as common traits observed in psychopaths, which could be considered adaptive, are not assessed by PPI-I or Boldness (i.e., absence of delusions and absence of irrational thinking). Although detailed under the section regarding absence of delusions, Cleckley further expands on common-related traits seen in psychopaths, such as an absence of depression, mood-swings, or worries (1988, p. 339). Due to the limited number of adaptive traits assessed with the $\mathrm{PPI}$ and the TriPM, it is possible that the predictive value of these instruments, to identify successful psychopathic individuals, may not be optimal and could benefit from an extension assessing a wider range of adaptive psychopathic traits.

While the PPI and the TriPM focus on both adaptive and maladaptive traits, these instruments solely assess core traits of the psychopathic personality. The Durand Adaptive Psychopathic Traits Questionnaire (DAPTQ; Durand, 2017) is a self-report instrument assessing nine adaptive personality traits which have shown previous associations with the psychopathic personality. During the development of the DAPTQ, the author identified all the constructs considered adaptive, defined as 'a trait maximizing 


\section{Chapter 8 | Incremental Validity of the DAPTQ}

an individual's survival probability within a set environment', which have shown a significant association with a measure of psychopathy or psychopathic traits in healthy adults. Subsequently, a pool of 19 distinct constructs emerged, described through 190 items. Following two elimination rounds of items through examination of internal consistency reliability, and an exploratory factor analysis using a parallel analysis, an 11 -factor solution emerged. Additional validation studies excluded two factors due to a lack of association with the total score, leaving a final solution of 41 items distributed into 9 factors (Leadership, Logical Thinking, Composure, Creativity, Fearlessness, Money Smart, Focus, Extroversion, and Management). The DAPTQ is not used to diagnose psychopathy, nor does it identify highly psychopathic individuals. Instead, the DAPTQ focuses on a wide range of adaptive traits theorized to be centrally, or peripherally, related to the 'successful' psychopath, and should be seen as a detailed extension to PPI-I and Boldness.

During its development phase, the DAPTQ was compared to the Five Factor Model (FFM), as assessed by the Big Five Inventory (BFI; John, Donahue, \& Kentle, 1991). The big five refers to the five major components of personality: Extroversion, Agreeableness, Conscientiousness, Neuroticism, and Openness. The results supported a positive correlation with all factors $(r$ $=.29$ to .51$)$, with the exception of a negative correlation with Neuroticism ( $r=$ -.67). Although the FFM is one of the most commonly used models to validate new instruments to personality traits, a recent model of personality, the HEXACO, has been investigated thoroughly in the field of psychopathy due to its addition of a sixth factor, assessing honesty and humility (Jonason \& McCain, 2012; Lee \& Ashton, 2004; Witt, Donnellan, Blonigen, Krueger, \& Conger, 2009). Multiple studies confirmed a strong negative correlation between the presence of psychopathic traits and the honesty-humility factor of the HEXACO model (Jonason \& McCain, 2012; Lee \& Ashton, 2005). Dishonesty and a lack of humility can arguably be considered as maladaptive personality traits. Considering this factor's strong association with psychopathy, and considering that the DAPTQ was developed by investigating traits known to correlate with psychopathic traits, it is important to validate the DAPTQ using the HEXACO in order to examine if a negative relationship exists between the DAPTQ and the honesty-humility factor, which could demonstrate an overlap between the DAPTQ and maladaptive psychopathic traits, hence decreasing the validity of the instrument. Additionally, a significant association with conscientiousness and other measures of psychopathy would further increase the validity of the DAPTQ as 
an extension of Fearless Dominance or Boldness in predicting adaptive features in the field of psychopathy.

\section{The Current Study}

The first study investigated the relationship between the DAPTQ, the HEXACO, and the PPI-Short form. Based on previous investigations between the DAPTQ and the FFM, I expected a positive correlation between all factors of the HEXACO model and the DAPTQ, with the exception of an expected negative association with the Emotionality factor, which corresponds to the Neuroticism factor of the FFM, and with the exception of a lack of correlation with Honesty-Humility. The purpose was to replicate the relationship between the DAPTQ and the FFM, as well as to extend the findings to the unique component of the HEXACO (Honesty-Humility). Additionally, I expected the DAPTQ to provide incremental validity over the PPI-SF on the HEXACO on all factors, with the exception of Honesty-Humility. A second study investigated the incremental validity of the DAPTQ over both the PPI-SF and the TriPM on various measures associated with successful psychopathy (anxiety and stress resilience, and communication skills). In the DAPTQ development article, the DAPTQ was compared to measures of analytical thinking, risk taking, and anxiety and stress resilience (Durand, 2017). By comparing the DAPTQ to a measure of communication skills, it will be possible to broaden the range of adaptive psychopathic characteristics associated with the DAPTQ. Furthermore, although the DAPTQ has previously been compared to measures of anxiety and stress, it is unknown to which extent the DAPTQ provides incremental validity over the PPI-SF or the TriPM on the aforementioned variables.

\section{Study 1}

\section{Participants}

Two hundred seventy-five $(N=275)$ participants were recruited on social media and websites dedicated to research in psychology (e.g., callforparticipants.com, onlinepsychresearch.co.uk, facebook.com). There was no missing data for any of the responses. Inclusion criteria for the study were to be over 18 years old and be fluent in English. Using the Stem-andLeaf plot analysis from SPSS v.23, 12 participants were classified as outliers and removed from the study. In order to identify additional outliers, I examined the Variable Response Inconsistency (VRIN) of the PPI-SF. This statistical procedure examines the inconsistencies within 10 pairs of highly correlated items from the PPI-SF (Lilienfeld \& Widows, 2005). For each pair, a score is obtained by subtracting the two items, and the difference of the 10 pairs is 


\section{Chapter 8 | Incremental Validity of the DAPTQ}

summed. A higher score signifies greater variability within questions expecting similar answers. A cut-off of 7 , which corresponds to three standard deviations of the VRIN score above the mean $(M=2.37, S D=1.55)$, was used to identify additional outliers. Of the remaining 263 participants, the highest VRIN score was 6 , and hence no further participants were removed. The sample consisted of 127 males and 136 females. Most participants reported being located in North America (46\%), followed by Europe (37\%), Asia (11\%), Oceania (3\%), South America (2\%), or Africa (1\%). In terms of ethnicity, the majority of participants reported being Caucasian (74\%) or Asian (16\%). A third of the participants were currently enrolled as full-time university students (36\%). Regarding the current marital status, most participants reported being single $(42 \%)$, followed by married $(27 \%)$, in a relationship $(13 \%)$ or common law partner $(13 \%)$, or other (5\%). Participants age ranged from 18 to 65 years old, with a mean age of $32.7(S D=12.37)$.

\section{Materials}

\section{Durand Adaptive Psychopathic Traits Questionnaire (DAPTQ; Durand, 2017)}

The DAPTQ is a 41 -item self-reported questionnaire assessing adaptive traits known to correlate with psychopathic personality traits. The DAPTQ uses a 6point Likert scale, ranging from 1 (Strongly Disagree) to 6 (Strongly Agree). In the present study, the internal consistency reliability ranged from $\alpha=.74$ to .90 .

\section{HEXACO-PI-R-60 (HEXACO; Ashton \& Lee, 2009)}

The 60 -item version of the HEXACO is a self-reported questionnaire using a 5-point Likert scale, evaluating six domains of personality: Honesty-Humility, Emotionality, Extraversion, Agreeableness, Conscientiousness, and Openness. The HEXACO-60 has been shown to be a reliable alternative to the HEXACO-100, and possesses similar construct validity and reliability as the full version (Ashton \& Lee, 2009). In the present study, Cronbach's alpha of the six scales ranged from $\alpha=.74$ to .84 .

\section{Psychopathic Personality Inventory-Short Form (PPI-SF; Lilienfeld \& Widows, 2005)}

The PPI-SF is a 56 -item self-report questionnaire assessing psychopathic traits on a 4-point Likert scale $(1=$ false, $4=$ true). The subscales are divided among 2 factors. PPI-I is composed of the Stress Immunity, Social Potency, and Fearlessness subscales. PPI-II consists of the Blame Externalization, Machiavellian Egocentricity, Carefree Nonplanfulness, and Impulsive 
Nonconformity subscales. The Coldheartedness subscale does not load on any of the two factors (Benning, Patrick, Hicks, Blonigen, \& Krueger, 2003). In its development phase, the DAPTQ total score correlated positively with PPII $(r=.66)$ and PPI-SF Total $(r=.46)$, but was not significantly associated with PPI-II $(r=-.04)$ (Durand, 2017). In the present study, Cronbach's alpha for the total score and two scales was $\alpha=.79$.

\section{Results}

\section{Correlations Between the DAPTQ, the HEXACO, and the PPI-SF}

Descriptive data from both samples on all questionnaires can be found in Appendix B. Scores on the DAPTQ were not correlated with Honesty-Humility, were negatively correlated with Emotionality, and were positively correlated with all 4 other factors (Table 1). While PPI-I scores were also not significantly correlated with Honesty-Humility, scores on both PPI-II $(r=-.41)$ and PPI-SF Total $(r=-.27)$ were significantly negatively correlated with the aforementioned factor. Additionally, scores on PPI-I did not show any significant correlation with conscientiousness. Examination of scores on the DAPTQ' subscales shows moderate to strong positive correlations between the DAPTQ total score and scores on its subscales ( $r=.32$ to .77$)$. There were several strong correlations between scores on the DAPTQ subscales and the HEXACO. Leadership was associated with Extraversion. Logical Thinking was associated with Conscientiousness. Composure was negatively associated with Emotionality and positively with Agreeableness. Creativity was associated with Openness. Fearlessness was negatively associated with Emotionality. Extroversion was associated with Extraversion. Lastly, Management was associated with Extraversion and Conscientiousness. 


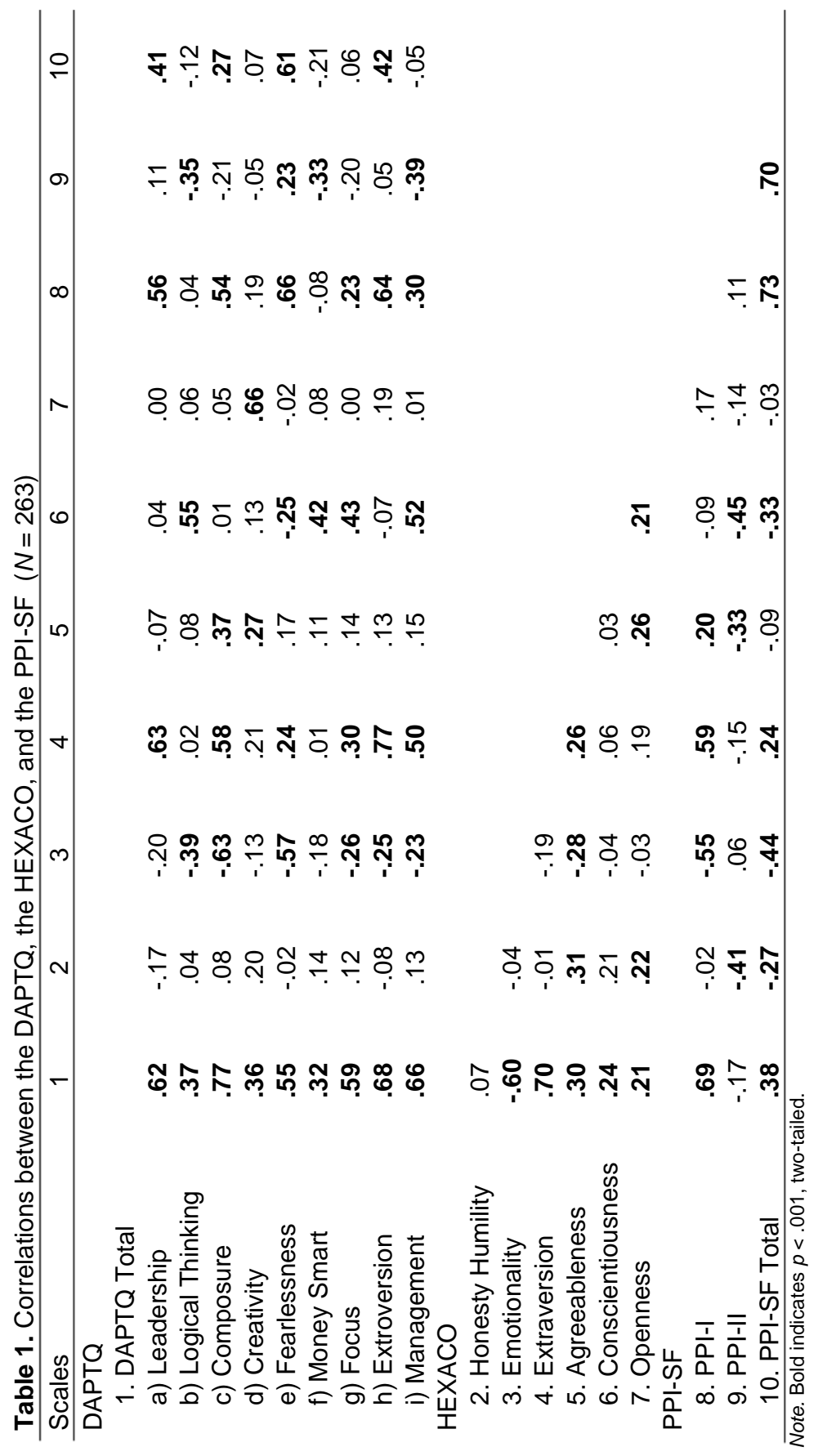




\section{Incremental Validity of the DAPTQ over the PPI-SF in Predicting HEXACO Factors}

In addition to examining correlations of the DAPTQ and the PPI-SF with the HEXACO, I also examined the incremental validity of the DAPTQ over the PPI-SF in predicting HEXACO factors. All analyses were computed twice, once with PPI-SF in block 1 and DAPTQ in block 2, and a second time with DAPTQ in block 1 and PPI-SF in block 2. Table 2 reports the value in Block 1 and its related $p$ value when PPI-SF was in Block 1, when DAPTQ was in Block 1, the outcome of the second variable in Block 2, and the adjusted $R^{2}$ change and its significance from PPI-SF to DAPTQ and from DAPTQ to PPISF. When the DAPTQ was added in Block 2, with the exception of HonestyHumility, the DAPTQ added incrementally to the prediction of every measure, increasing the amount of explained variance from .09 (Agreeableness) to .38 (Openness). When PPI-SF was added in Block 2, it provided significant incremental validity to Honesty-Humility (.36), but provided smaller $R^{2}$ change on all other variables, with the exception of Agreeableness, where the PPI-SF $R^{2}$ change is .03 superior to the DAPTQ.

In order to determine if all of the DAPTQ subscales provide incremental validity, I examined the significance of all DAPTQ subscales for each correlate $(p<.05)$. For Honesty-Humility, no DAPTQ subscale was significant. For Emotionality, Logical Thinking, Composure, Creativity, Fearlessness, and Management were significant. For Extroversion, Leadership, Composure, Fearlessness, Extroversion, and Management were significant. For Agreeableness, Leadership, Composure, and Creativity were significant. For Conscientiousness, Logical Thinking, Composure, Creativity, Fearlessness, Focus, and Management were significant. For Openness, Creativity, Fearlessness, and Management were significant. Overall, all of the DAPTQ subscales, with the exception of Money Smart, increased the predictive value of the PPI-SF in one of the five significant components of the HEXACO. 


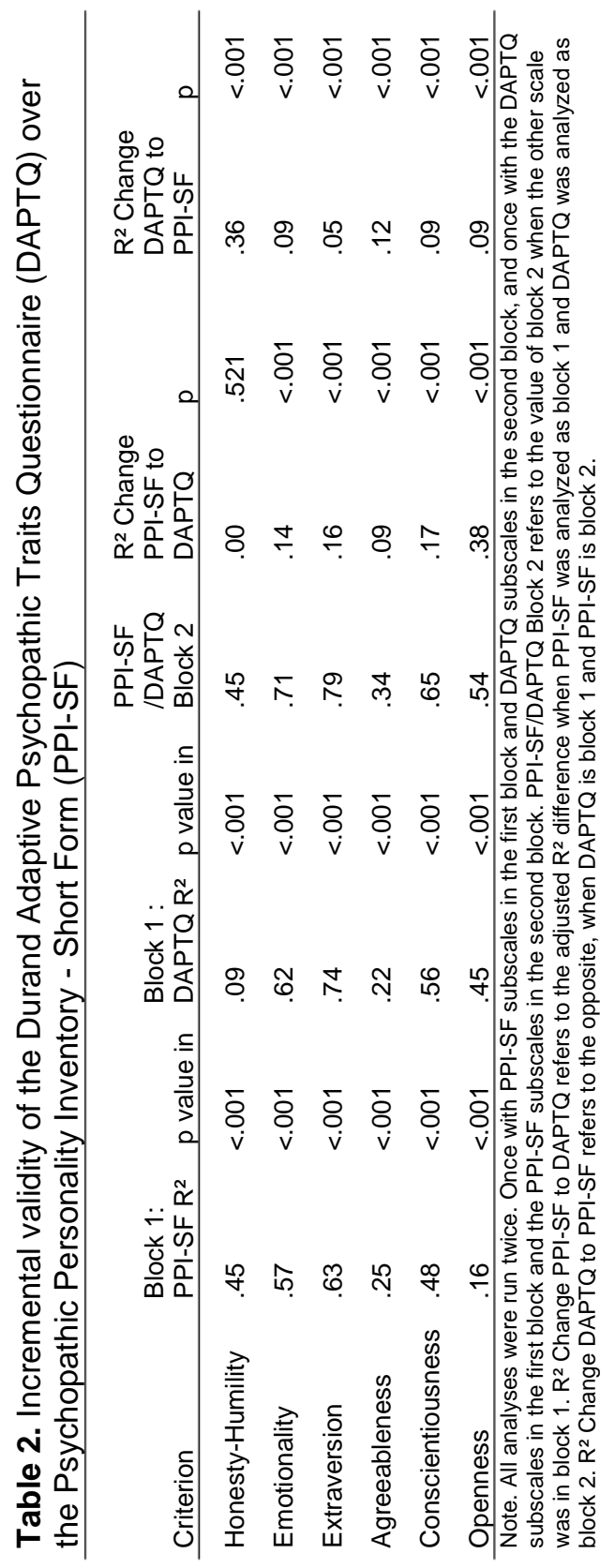




\section{Study 2}

\section{Participants}

Two hundred eighty-seven ( $N=287$ ) participants were once again recruited on social media and websites dedicated to research in psychology. There was no missing data for any of the responses. Inclusion criteria for the study were to be over 18 years old and be fluent in English. Using the Stem-and-Leaf plot analysis, 15 participants were classified as outliers and removed from the study. Similarly to study 1 , a VRIN cut-off of 7 to the PPI-SF was applied, identifying 10 additional outliers. Of the remaining 262 participants, 141 were males and 121 were females. Most participants reported being located in North America (62\%), followed by Europe (24\%), Oceania (6\%), Asia (5\%), or other $(3 \%)$. In terms of ethnicity, the majority of participants reported being Caucasian (82\%) or Asian (9\%). Half of the participants were currently enrolled as full-time university students (50\%). Regarding the current marital status, most participants reported being single $(46 \%)$, followed by in a relationship (23\%), in a common law partnership (15\%), married $(14 \%)$, or other $(2 \%)$. Participants age ranged from 18 to 63 years old, with a mean age of $26.1(S D=6.79)$.

\section{Materials}

In addition to the DAPTQ and the PPI-SF from study 1 , the following instruments were also used in study 2. Internal consistency for the DAPTQ ranged from $\alpha=.76$ to .89 , and ranged from $\alpha=.77$ to .78 for the PPI-SF.

\section{Triarchic Psychopathy Measure (TriPM; Patrick, 2010)}

The TriPM is a self-report questionnaire containing 58 items assessing psychopathic traits. Items are rated on a 4-point Likert scale from 1 (True) to 4 (False). The scale is divided into three subscales, namely Boldness, Meanness, and Disinhibition. Boldness refers to the adaptive component seen in psychopathic individuals, and encompasses characteristics such as charisma, fearlessness, anxiety and stress immunity. Meanness refers to the aggressive aspect of psychopathic individuals, including characteristics such as violent behaviour, lack of empathy, and enjoyment through destruction. Disinhibition refers to the behavioural deficits seen in psychopathic individuals, and contains characteristics such as impulsive behaviors, lack of planning, and overall behavioral restraint deficiency (Patrick et al., 2009). In the present study, Cronbach's alpha for the total score and the two scales ranged from $\alpha$ $=.83$ to .88 . 


\section{Communicative Adaptability Scale (CAS; Duran, 1983)}

The CAS is a 30-item instrument measuring six dimensions of communicative adaptability, which Duran defines as "The ability to perceive sociointerpersonal relationships and adapt one's interaction goals and behaviors accordingly." The six dimensions of the scale include: social experience, social confirmation, social composure, appropriateness, articulation, and wit. Social experience refers to the experience of the communicator who adapts to various social situations. Social confirmation refers to the combination of empathy and rewarding impression. Social composure refers to a calm and composed communicator who shows little to no communication anxiety in social situations. Appropriateness refers to the skill of the communicator to recognize what the appropriate disclosure is. Articulation consists of correct pronunciation, fluent speech, adequate word choice, and proper sentences construction. Lastly, wit refers to the ability to use humor to reduce or diffuse anxiety and tension during a conversation. The items are answered on a 5point Likert scale, ranging from 1 (never true of me) to 5 (always true of me). A high score on the CAS or its subscales indicates a high level of adaptability. Since the participants in the current study were recruited across the world, and the language requirement was fluency in English rather than English as mother tongue, I excluded the 5 items related to the articulation subscale. In the present study, Cronbach's alpha of the five scales ranged from $\alpha=.65$ to .85 .

\section{Perceived Stress Scale - 10 Item Version (PSS; Cohen \& Williamson, 1988)}

The PSS-10 is a revised version of the Perceived Stress Scale (Cohen, Kamarck, \& Mermelstein, 1983). The PSS is a 10-item self-reported instrument assessing perceived stress in everyday situations. The questionnaire is rated on a 5-point Likert scale ( $0=$ Never to $4=$ Very Often), where a higher score indicates higher levels of perceived stress. Previous studies support its validity when compared to other measurements of stress (Cohen et al., 1983; Lee, 2012). In the present study, Cronbach's alpha was $\alpha=.60$.

\section{STAI-Y2 - Trait Anxiety Subscale (Spielberger, Gorsuch, \& Lushene, 1970)}

The STAI is a self-reported questionnaire with 40 items divided into two equivalent subscales, assessing state anxiety and trait anxiety. The STAI-Y2 subscale measures trait anxiety (e.g., how a participant feels in everyday life). Previous findings support the validity and internal consistency of the STAI 
(Vigneau \& Cormier, 2008). In the present study, Cronbach's alpha was $\alpha$ $=.93$.

\section{Results}

Correlations Between the DAPTQ, the PPI-SF, the TriPM, the CAS, the PSS, and the STAI-Y2

Table 3 provides the correlations between scores the DAPTQ, the PPI-SF, the TriPM, the CAS, the PSS, and the STAI-Y2, and Table 4 provides the correlations between scores on the DAPTQ' subscales and the aforementioned variables. Scores on the DAPTQ were strongly correlated with PPI-I $(r=.71)$ and Boldness $(r=.84)$, while being moderately correlated with PPI-SF Total $(r=.45)$ and TriPM Total $(r=.42)$. Scores on the DAPTQ showed moderate correlations with the CAS $(r=.47)$, as well as strong negative correlations with the PSS $(r=-.58)$ and the STAI-Y2 $(r=-.69)$. While the TriPM provided a stronger correlation than the DAPTQ with the CAS, the association between scores the DAPTQ and the PSS or the STAI-Y2 was stronger than the PPI-SF or the TriPM.

Table 3. Correlations between the DAPTQ the PPI-SF, the TriPM, the CAS, the PSS, and the STAI-Y2

\begin{tabular}{|c|c|c|c|c|c|c|c|c|c|c|}
\hline Scales & 1 & 2 & 3 & 4 & 5 & 6 & 7 & 8 & 9 & 10 \\
\hline \multicolumn{11}{|l|}{ 1. DAPTQ Total } \\
\hline \multicolumn{11}{|l|}{ PPI-SF } \\
\hline 2. PPI-I & .71 & & & & & & & & & \\
\hline 3. PPI-II & -.06 & .14 & & & & & & & & \\
\hline 4. PPI-SF Total & .45 & .73 & .73 & & & & & & & \\
\hline \multicolumn{11}{|l|}{ TriPM } \\
\hline 5. Boldness & .84 & .75 & -.01 & .49 & & & & & & \\
\hline 6. Meanness & .25 & .31 & .50 & .62 & .26 & & & & & \\
\hline 7. Disinhibition & -.31 & -.04 & .60 & .33 & -.11 & .34 & & & & \\
\hline 8. TriPM Total & .42 & .53 & .53 & .72 & .61 & .80 & .58 & & & \\
\hline CAS & & & & & & & & & & \\
\hline 9. CAS Total & .47 & .45 & -.12 & .15 & .55 & -.13 & -.05 & .20 & & \\
\hline PSS & & & & & & & & & & \\
\hline $\begin{array}{l}\text { 10. PSS Total } \\
\text { STAI-Y2 }\end{array}$ & -.58 & -.34 & .26 & -.10 & -.50 & -.11 & .35 & -.15 & -.25 & \\
\hline 11. STAI-Y2 Total & -.69 & -.43 & .36 & -.10 & -.61 & .00 & .43 & -.12 & -.42 & .79 \\
\hline
\end{tabular}


Table 4. Correlations between the DAPTQ subscales, the PPI-SF, the TriPM, the CAS, the PSS, and the STAI-Y2

\begin{tabular}{|c|c|c|c|c|c|c|c|c|c|}
\hline DAPTQ & 1 & 2 & 3 & 4 & 5 & 6 & 7 & 8 & 9 \\
\hline DAPTQ Total & .68 & .45 & .75 & .32 & .45 & .38 & .54 & .62 & .65 \\
\hline \multicolumn{10}{|l|}{ PPI-SF } \\
\hline PPI-I & .53 & .18 & .54 & .19 & .65 & .06 & .23 & .52 & .26 \\
\hline PPI-II & -.04 & -.21 & -.07 & .07 & .35 & -.32 & -.17 & .03 & -.30 \\
\hline PPI-SF Total & .30 & .04 & .36 & .14 & .65 & -.13 & .08 & .34 & .01 \\
\hline \multicolumn{10}{|l|}{ TriPM } \\
\hline Boldness & .72 & .26 & .64 & .26 & .48 & .11 & .28 & .62 & .50 \\
\hline Meanness & .13 & .13 & .28 & -.09 & .45 & -.07 & .03 & .07 & .09 \\
\hline Disinhibition & -.09 & -.46 & -.24 & .04 & .19 & -.53 & -.42 & .05 & -.50 \\
\hline TriPM Total & .40 & -.01 & .37 & .11 & .57 & -.23 & -.04 & .39 & .07 \\
\hline \multicolumn{10}{|l|}{ CAS } \\
\hline Total & .55 & .00 & .31 & .17 & .09 & -.06 & .04 & .69 & .26 \\
\hline \multicolumn{10}{|l|}{ PSS } \\
\hline Total & -.31 & -.37 & -.67 & -.03 & -.08 & -.25 & -.33 & -.28 & -.55 \\
\hline \multicolumn{10}{|l|}{ STAI-Y2 } \\
\hline Total & -.43 & -.38 & -.72 & -.10 & -.11 & -.34 & -.31 & -.44 & -.58 \\
\hline
\end{tabular}

Examination of the DAPTQ' subscales shows that similarly to Study 1 , scores on all subscales correlated moderately to strongly with the DAPTQ total score. Additionally, scores on all of the DAPTQ subscales, with the exception of Money Smart, correlated positively with either PPI-I or Boldness. While Money Smart was not positively correlated, it was moderately negatively correlated with PPI-II, and strongly negatively correlated with disinhibition. In terms of significantly strong correlations, Composure scores were negatively associated with PSS and STAI-Y2 scores, Extroversion was positively associated with CAS total, and Management scores were negatively associated with PSS and STAI-Y2.

\section{Incremental Validity of the DAPTQ over the PPI-SF in Predicting the CAS, the PSS, and the STAI-Y2}

Similarly to study 1 , the incremental validity of the DAPTQ over the PPI-SF in predicting various adaptive traits was performed through a series of hierarchical linear regressions. Once again, all analyses were computed twice, once with PPI-SF in block 1 and DAPTQ in block 2, and a second time with DAPTQ in block 1 and PPI-SF in block 2. As shown in Table 5, when the 
DAPTQ was added in Block 2, the DAPTQ provided an increase over the PPISF in terms of predictive validity on all scales of the CAS, at the exception of Social Confirmation. The greatest improvements in incremental validity of the DAPTQ over the PPI-SF were on measure of perceived stress (.22) and trait anxiety (.23). When PPI-SF was added in Block 2 , it only provided greater adjusted $R^{2}$ change than the DAPTQ on the social confirmation scale of the CAS.

Similarly to Study 1 , scale by scale significance of the DAPTQ was verified to determine if all its subscales helped increase the predictive validity of the PPI-SF in one or multiple correlates. Only four of the DAPTQ subscales, namely Composure, Money Smart, Focus, and Extroversion were significant predictors on one or multiple of the CAS subscales. For the PSS total, Composure and Management were the only significant predictors. Lastly, Composure, Creativity, Focus, Extroversion, and Management were the only significant predictors of STAI-Y2. Overall, all DAPTQ subscales but three, namely Leadership, Logical Thinking, and Fearlessness, provided incremental validity over the PPI-SF over one or multiple subscales of the CAS, the PSS, or the STAI-Y2.

\section{Incremental Validity of the DAPTQ over the TriPM in Predicting the CAS, the PSS, and the STAI-Y2}

In order to confirm the results presented above, I examined the incremental validity of the DAPTQ over the TriPM, using the same technique as previously mentioned. As shown in Table 6, when the DAPTQ was added in Block 2, it provided a notable increase in incremental validity on social experience, social composure, and overall communicative adaptability. A modest increase was also observed on the Wit subscale. Lastly, the DAPTQ provided a significant increase in incremental validity over the TriPM for perceived stress (.18) and trait anxiety (.18). Alternatively, when the TriPM was added to Block 2, it provided a significant greater adjusted $R^{2}$ than the DAPTQ only on the Social Confirmation scale of the CAS.

Scale by scale examination of the DAPTQ was once again used to determine if all subscales helped increase the predictive validity of the TriPM. Three of the DAPTQ subscales, Leadership, Composure, and Extroversion, were significant predictors in one or multiple of the CAS subscales. For the PSS total, Composure and Management were the only significant predictors. Lastly, Composure, Focus, Extroversion, and Management were the only significant predictors of the STAI-Y2. Overall, all DAPTQ subscales but four, namely Fearlessness, Logical Thinking, Creativity, and Money Smart, 


\section{Chapter 8 | Incremental Validity of the DAPTQ}

provided incremental validity over the TriPM over one or multiple subscales of the aforementioned constructs.

\section{Discussion}

The purpose of the present studies was to further validate the DAPTQ and establish its incremental validity over the PPI-SF and the TriPM over adaptive personality characteristics related to the psychopathic personality in community samples. As reported in its development phase, DAPTQ were negatively correlated with emotionality, and positively correlated with other personality traits of the Big Five, while not being associated to HonestyHumility. The incremental validity of the DAPTQ over the PPI-SF when predicting the Big Five was supported, with an additional $9 \%$ to $38 \%$ of the variance explained when adding the DAPTQ to the PPI-SF. In addition, with the exception of Honesty-Humility and Agreeableness, the PPI-SF did not provide more variance to the DAPTQ than the DAPTQ to the PPI-SF, further supporting the predictive abilities of the DAPTQ to measure facets related to the Big Five. Correlations and regression analyses in Study 2 further support the convergent and incremental validity of scores on the DAPTQ over the two most commonly used assessment of psychopathic personality including an adaptive component.

Examination of the association between the DAPTQ and the HEXACO scores from Study 1 reveals compelling results. First, despite multiple studies supporting a strong negative correlation between psychopathy and HonestyHumility, the DAPTQ total score did not show a correlation with the aforementioned construct (Jonason \& McCain, 2012; Lee \& Ashton, 2005; Visser, Ashton, \& Pozzebon, 2012). This absence of correlation might be due to the discriminant validity between the DAPTQ and psychopathy. Despite the correlation observed between the DAPTQ and the PPI total score $(r=.38)$, as well as the correlation previously observed between the Honesty-Humility and PPI total score $(r=-.35)$, the DAPTQ and the Honesty-Humility scale do not share any significant variance with one another (Visser et al., 2012). The five other factors assessed in the HEXACO gave similar results to the correlations observed between the DAPTQ and the BFI during its development phase (Durand, 2017). 


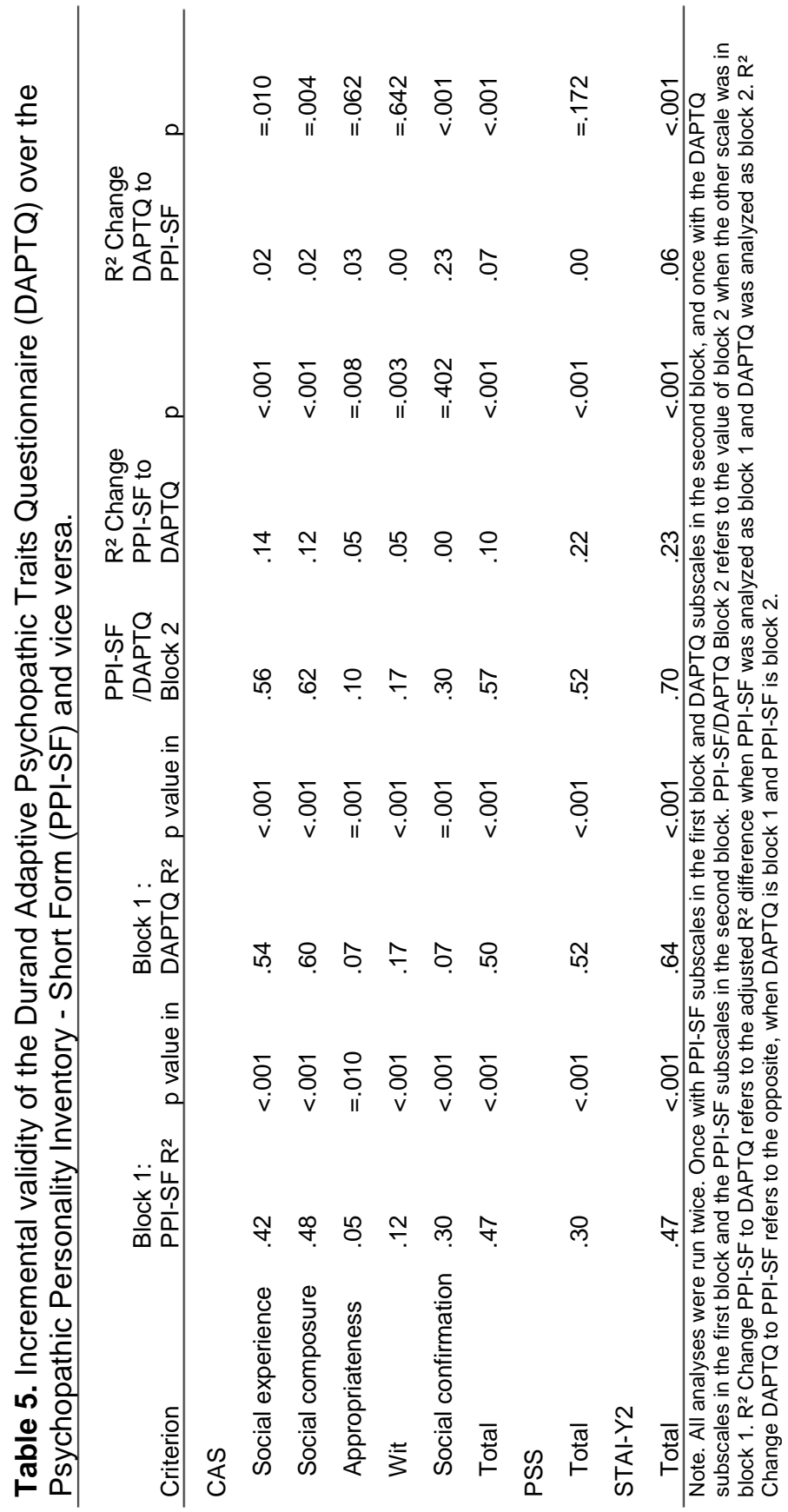


Chapter 8 | Incremental Validity of the DAPTQ

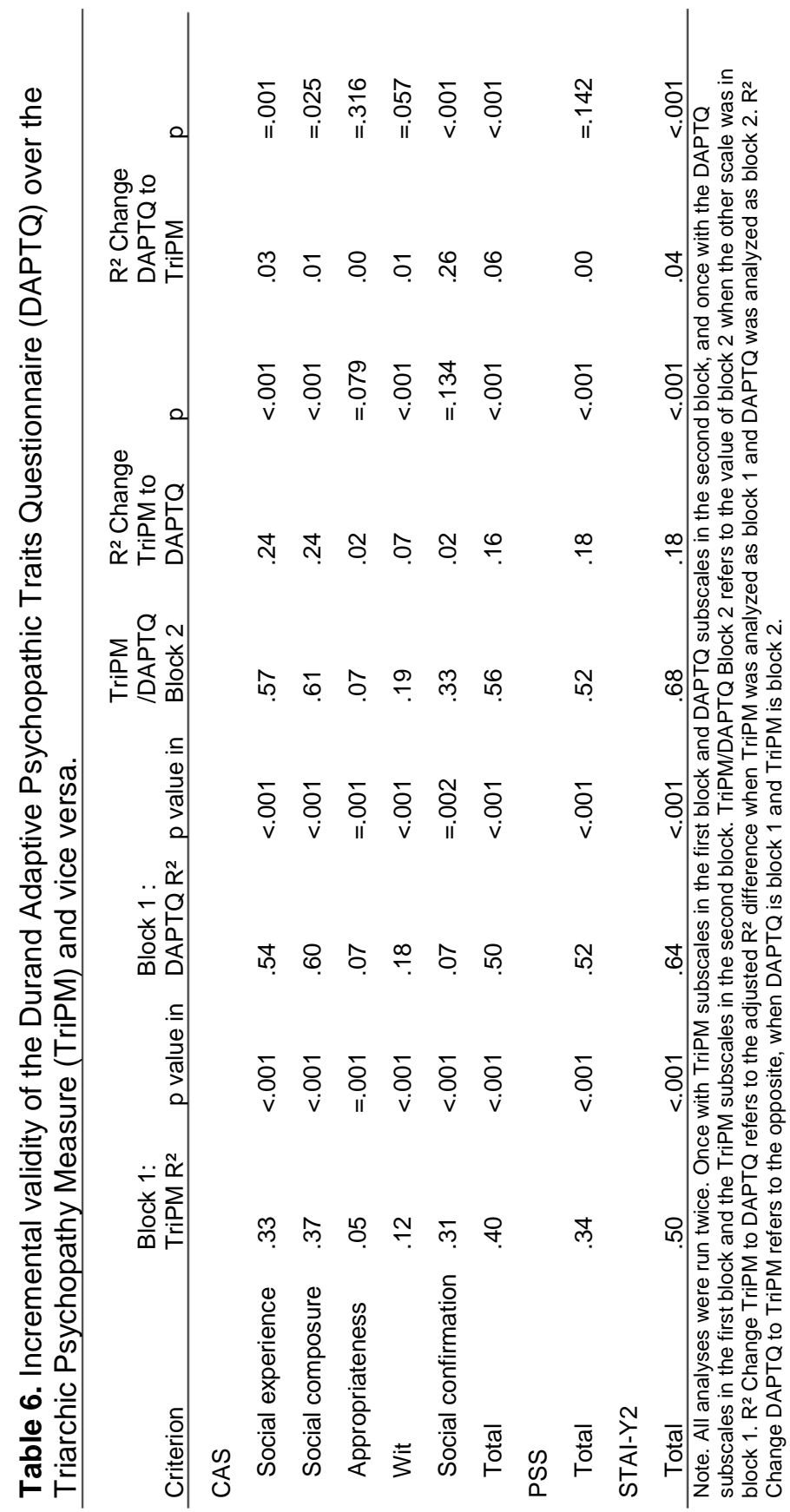


As previously mentioned, conscientiousness appears to be central to the concept of successful psychopathy (Lilienfeld et al., 2015). However, the present findings support that PPI-I is unrelated to conscientiousness, while the DAPTQ shows a weak association with the construct. The Logical Thinking, Money Smart, Focus, and Management subscales of the DAPTQ appear to be particularly related to conscientiousness. From a subjective perspective, these subscales encompass rational thinking. While Cleckley (1988) was referring to the lack of irrational thinking as a common characteristic of psychopathic individuals, the findings suggest that it is the presence of rational thinking that could be related to successful psychopathic individuals.

Examination of the adjusted $\mathrm{R}^{2}$ difference between the PPI-SF and the DAPTQ on the HEXACO support the incremental validity of the DAPTQ in predicting various personality traits. Among all traits, the largest predictive variance increase was seen on Openness. Openness refers to the enjoyment of beauty in art and in nature, the tendency to seek information, a preference for innovation, and a tendency to accept the unusual (Lee \& Ashton, 2004). Considering previous studies found non-significant to weak correlations between the presence of psychopathic traits and Openness, and considering Openness can be classified as an adaptive trait, it is unsurprising that the DAPTQ predicts the aforementioned construct over two times better than the PPI-SF (Maples et al., 2014; Ross, Benning, Patrick, Thompson, \& Thurston, 2009).

Although all DAPTQ subscales were based on previous findings associating adaptive constructs with psychopathy, Money Smart was not positively associated with the PPI-SF or the TriPM in Study 2, despite its association with the Coldheartedness $(r=.22)$ and Stress Immunity $(r=.17)$ factors of the PPI-SF in its development (Durand, 2017). Originally, money management was not part of the selected adaptive construct to develop the DAPTQ. Instead, the three items now included in the subscale were originally part of the Cautiousness (low impulsivity) construct. During the development of the DAPTQ, examination of the scale Cronbach's alpha and factor analysis removed the other items of the Cautiousness domain (e.g., I plan my future carefully, I am a very spontaneous person, I am always thinking about multiple things at once), leaving only the money management-related items (e.g., I have a tendency to buy objects I do not need, I have always considered myself to be smart with money). Theoretically, the three items associated with the Money Smart subscale could be linked with the Management subscale. However, statistical analyses show that merging the items of the Money Smart subscale with the Management subscale would lower the internal consistency 


\section{Chapter 8 | Incremental Validity of the DAPTQ}

of the new Management subscale, and reduce the strength of its correlation with measures of psychopathic traits. Henceforth, evidence shows that, while Money Smart emerged from the factor analysis as an adaptive trait, it is not related to the concept of successful psychopathy. However, the strong negative correlations with Disinhibition $(r=-.53)$ and the weak negative correlation with the TriPM total $(r=-.23)$ indicate that highly psychopathic individuals have difficulties managing money. Nevertheless, the results suggest removing the items related to the Money Smart subscale, as the purpose of the DAPTQ is not only to investigate adaptive traits, but rather to assess adaptive traits in the field of successful psychopathy.

Incremental validity of the DAPTQ over the PPI-SF and the TriPM was also examined in Study 2 on traits related to successful psychopathy. The DAPTQ provided a similar increase in predictive values over both instruments of psychopathic traits. Changes were particularly salient on measures of perceived stress and trait anxiety, with the DAPTQ significantly improving the prediction of both constructs over the PPI-SF and the TriPM. Stress and anxiety immunity, being hallmarks of successful psychopathy, demonstrate the usefulness of the DAPTQ in extending the predictive value of PPI-I (Lilienfeld et al., 2015; Smith et al., 2014). The DAPTQ also appears to provide increased predictive value over the PPI-SF and the TriPM on social experience and composure, appropriateness, and wit. These characteristics are part of the common traits proposed by Cleckley. Indeed, Cleckley considered psychopaths as often witty (1988, p. 349), appropriate (1988, p.369), and with excellent social (although considered superficial) abilities (1988, p.339). Taken together, these characteristics further support the relationship between the DAPTQ and the clinical profile of successful psychopathic individuals.

Repeating the analyses on the TriPM provided similar results regarding the incremental validity of the DAPTQ. Once again, the DAPTQ provided a stronger $\mathrm{R}^{2}$ change on social experience and social composure than on the PPI-SF. Once more, the DAPTQ provided a noticeable increase in predictive value on perceived stress and trait anxiety, increasing the $R^{2}$ on both constructs by $18 \%$. These results confirm the results obtained previously, supporting that both PPI-I and boldness, although capturing a wide range of adaptive traits in psychopathy, do not capture the full spectrum of adaptive traits in the field. The DAPTQ provides an opportunity to take into account a wider range of adaptive traits, increasing the predictive value of both PPI-I and boldness.

Excluding Money Smart, the DAPTQ contains a few subscales assessing traits never included in instruments assessing psychopathy, such as Creativity. 
As described in the article of the DAPTQ development, multiple studies found weak correlations between psychopathy and creativity ( $r=.13$ to .22). (Akhtar, Ahmetoglu, \& Chamorro-Premuzic, 2013; Galang, Castelo, Santos, Perlas, \& Angeles, 2016; Jonason, Richardson, \& Potter, 2015; Salekin, Neumann, Leistico, \& Zalot, 2004). Additionally, highly psychopathic individuals tend to be rated more highly in terms of innovation/creativity by their peers (Babiak, Neumann, \& Hare, 2010). While the association between creativity and psychopathic traits is significantly weaker than other constructs, such as logical thinking, composure, or management abilities, its positive association with Boldness in the present study suggests that, while minor, creativity is indeed related to the construct of successful psychopathy.

\section{Limitations and Conclusion}

There are several limitations to consider. First, the participants were excessively heterogeneous. Recruitment was performed online, and no eligibility criteria were set regarding location, education, and current marital status. While this type of community sample offers a broader view of individuals in general, differences might be observable in specific population, such as college graduate, children, or forensic populations. Second, while self-reported questionnaires are commonly used in the field of personality, experimental evidence is necessary to support the validity of the DAPTQ to assess adaptive traits. For instance, future work should focus on DAPTQ measurements and stress resilience in an experimental task as measured by physiological factors. Nevertheless, the present study gave several insights regarding the validity of the DAPTQ in a community sample, as well as further evidence of its incremental validity over the PPI-SF and the TriPM in assessing adaptive traits known to correlate with psychopathy and psychopathic traits. 


\section{Chapter 8 | Incremental Validity of the DAPTQ}

\section{References}

Akhtar, R., Ahmetoglu, G., \& Chamorro-Premuzic, T. (2013). Greed is good? Assessing the relationship between entrepreneurship and subclinical psychopathy. Personality and Individual Differences, 54(3), 420-425.

Ashton, M. C., \& Lee, K. (2009). The HEXACO-60: A short measure of the major dimensions of personality. Journal of Personality Assessment, 91(4), 340-345.

Babiak, P., Neumann, C. S., \& Hare, R. D. (2010). Corporate Psychology: Talking the Walk. Behavioral Sciences \& the Law, 28(2), 174-193.

Baskin-Sommers, A. R., Zeier, J. D., \& Newman, J. P. (2009). Self-reported attentional control differentiates the major factors of psychopathy. Personality and Individual Differences, 47(6), 626-630.

Benning, S. D., Patrick, C. J., Hicks, B. M., Blonigen, D. M., \& Krueger, R. F. (2003). Factor structure of the psychopathic personality inventory: validity and implications for clinical assessment. Psychological Assessment, 15(3), 340-350.

Berg, J. M., Smith, S. F., Watts, A. L., Ammirati, R., Green, S. E., \& Lilienfeld, S. O. (2013). Misconceptions regarding psychopathic personality: implications for clinical practice and research. Neuropsychiatry, 3(1), 63-74.

Blagov, P. S., Patrick, C. J., Oost, K. M., Goodman, J. A., \& Pugh, A. T. (2016). Triarchic Psychopathy Measure: Validity in Relation to Normal-Range Traits, Personality Pathology, and Psychological Adjustment. Journal of Personality Disorders, 30(1), 71-81.

Blonigen, D. M. (2013). Is fearless dominance relevant to the construct of psychopathy? Reconciling the dual roles of theory and clinical utility. Personality Disorders, 4(1), 87-88.

Camp, J. P., Skeem, J. L., Barchard, K., Lilienfeld, S. O., \& Poythress, N. G. (2013). Psychopathic predators? Getting specific about the relation between psychopathy and violence. Journal of Consulting and Clinical Psychology, 81(3), 467-480.

Cleckley, H. (1941). The mask of sanity; an attempt to reinterpret the so-called psychopathic personality. Jama, 117(6), 493.

Cleckley, H. (1988). The Mask of Sanity: An Attempt to Clarify Some Issues About the So Called Psychopathic Personality. (W. a Dolan, Ed.) (5th ed.).

Cohen, S., Kamarck, T., \& Mermelstein, R. (1983). A global measure of perceived stress. Journal of Health and Social Behavior, 24(4), 385-396.

Cohen, S., \& Williamson, G. (1988). Perceived stress in a probability sample of the United States. In S. Spacapan, \& S. Oskamp (Eds.), The social psychology of health: Claremont Symposium on Applied Social Psychology. (Sage, pp. 31-67). Newbury Park, CA.

Cooke, D. J., \& Michie, C. (2001). Refining the construct of psychopathy: towards a hierarchical model. Psychological Assessment, 13(2), 171-188.

Dindo, L., \& Fowles, D. (2011). Dual temperamental risk factors for psychopathic personality: evidence from self-report and skin conductance. Journal of 
Personality and Social Psychology, 100(3), 557-566.

Duran, R. L. (1983). Communicative adaptability: A measure of social communicative competence. Communication Quarterly, 31(4), 320-326.

Durand, G. (2016a). A Replication of "Using self-esteem to disaggregate psychopathy, narcissism, and aggression (2013)." The Qantitative Methods for Psychology, 12(2), r1-r5.

Durand, G. (2016b). Demystification of the Relationship Between Psychopathy and Happiness. Journal of Happiness Studies.

Durand, G. (2017). The Durand Adaptive Psychopathic Traits Questionnaire: Development and Validation. Journal of Personality Assessment, 1-10.

Durand, G., \& Plata, E. M. (2017). The effects of psychopathic traits on fear of pain , anxiety, and stress. Personality and Individual Differences, 119(C), 198-203.

Galang, A. J. R., Castelo, V. L. C., Santos, L. C., Perlas, C. M. C., \& Angeles, M. A. B. (2016). Investigating the prosocial psychopath model of the creative personality: Evidence from traits and psychophysiology. Personality and Individual Differences, 100, 28-36.

Gao, Y., \& Raine, A. (2010). Successful and Unsuccessful Psychopaths: A Neurobiological Model. Behavioral Sciences \& the Law, 28(2), 194-210.

Hall, J., Drislane, L. E., Patrick, C. J., Morano, M., Lilienfeld, S. O., \& Poythress, N. G. (2014). Development and validation of Triarchic Construct Scales from the Psychopathic Personality Inventory. Psychological Assessment, 26(2), 447-461.

Hare, R. D. (1991). The Hare Psychopathy Checklist-Revised (PCL-R). Toronto, ON: Multi-Health Systems.

Hare, R. D. (2003). Manual for the Revused Psychopathy Checklist, $2^{\text {nd }}$ ed. Toronto, ON: Multi-Health Systems.

Harpur, T. J., Hare, R. D., \& Hakstian, A. R. (1989). Two-factor conceptualization of psychopathy: Construct validity and assessment implications. Psychological Assessment, 1(1), 6-17.

John, O. P., Donahue, E. M., \& Kentle, R. L. (1991). The Big Five Inventory - Versions 4a and 54. Berkeley, CA: University of California, Berkeley, Institute of Personality and Social Research.

Jonason, P. K., \& McCain, J. (2012). Using the HEXACO model to test the validity of the Dirty Dozen measure of the Dark Triad. Personality and Individual Differences, 53(7), 935-938.

Jonason, P. K., Richardson, E. N., \& Potter, L. (2015). Self-reported creative ability and the Dark Triad traits: An exploratory study. Psychology of Aesthetics, Creativity, and the Arts, 9(4), 488-494.

Lee, E.-H. (2012). Review of the psychometric evidence of the perceived stress scale. Asian Nursing Research, 6(4), 121-127.

Lee, K., \& Ashton, M. C. (2004). Psychometric Properties of the HEXACO Personality Inventory. Multivariate Behavioral Research, 39(2), 329-358.

Lee, K., \& Ashton, M. C. (2005). Psychopathy, Machiavellianism, and Narcissism in 


\section{Chapter 8 | Incremental Validity of the DAPTQ}

the Five-Factor Model and the HEXACO model of personality structure. Personality and Individual Differences, 38(7), 1571-1582.

Lilienfeld, S. O., Patrick, C. J., Benning, S. D., Berg, J., Sellbom, M., \& Edens, J. F. (2012). The role of fearless dominance in psychopathy: Confusions, controversies, and clarifications. Personality Disorders: Theory, Research, and Treatment, 3(3), 327-340.

Lilienfeld, S. O., Waldman, I. D., Landfield, K., Watts, A. L., Rubenzer, S., \& Faschingbauer, T. R. (2012). Fearless dominance and the U.S. presidency: Implications of psychopathic personality traits for successful and unsuccessful political leadership. Journal of Personality and Social Psychology, 103(3), 489505.

Lilienfeld, S. O., Watts, A. L., \& Smith, S. F. (2015). Successful Psychopathy: A Scientific Status Report. Current Directions in Psychological Science, 24(4), 298-303.

Lilienfeld, S. O., \& Widows, M. (2005). Psychopathic personality inventory-revised: Professional manual. Lutz, FL: Psychological Assessment Resources.

Lynam, D. R., \& Miller, J. D. (2012). Fearless dominance and psychopathy: A response to Lilienfeld et al. Personality Disorders: Theory, Research, and Treatment, 3(3), 341-353.

Maples, J. L., Miller, J. D., Fortune, E., MacKillop, J., Campbell, W. K., Lynam, D. R., Lance, C. E., Goodie, A. S. (2014). An examination of the correlates of fearless dominance and self-centered impulsivity among high-frequency gamblers. Journal of Personality Disorders, 28(3), 379-393.

Mullins-Sweatt, S. N., Glover, N. G., Derefinko, K. J., Miller, J. D., \& Widiger, T. A. (2010). The search for the successful psychopath. Journal of Research in Personality, 44(4), 554-558.

Patrick, C. (2010). Triarchic psychopathy measure (TriPM). PhenX Toolkit Online Assessment Catalog.

Patrick, C. J., Fowles, D. C., \& Krueger, R. F. (2009). Triarchic conceptualization of psychopathy: Developmental origins of disinhibition, boldness, and meanness. Development and Psychopathology, 21(3), 913-938.

Ross, S. R., Benning, S. D., Patrick, C. J., Thompson, A., \& Thurston, A. (2009). Factors of the Psychopathic Personality Inventory: Criterion-Related Validity and Relationship to the BIS/BAS and Five-Factor Models of Personality. Assessment, 16(1), 71-87.

Salekin, R. T., Neumann, C. S., Leistico, A.-M. R., \& Zalot, A. A. (2004). Psychopathy in Youth and Intelligence: An Investigation of Cleckley's Hypothesis. Journal of Clinical Child \& Adolescent Psychology, 33(4), 731-742.

Smith, S. F., Watts, A. L., \& Lilienfeld, S. O. (2014). On the trail of the elusive successful psychopath. The Psychologist, 27(7), 506-511.

Spielberger, C. D., Gorsuch, R. L., \& Lushene, R. E. (1970). The State-Trait Anxiety Inventory. MANUAL.

Uzieblo, K., Verschuere, B., Van den Bussche, E., \& Crombez, G. (2010). The Validity 
of the Psychopathic Personality Inventory--Revised in a Community Sample. Assessment, 17(3), 334-346.

Vigneau, F., \& Cormier, S. (2008). The factor structure of the State-Trait Anxiety Inventory: an alternative view. Journal of Personality Assessment, 90(3), 280285.

Visser, B. A., Ashton, M. C., \& Pozzebon, J. A. (2012). Is Low Anxiety Part of the Psychopathy Construct? Journal of Personality, 80(3), 725-747.

Witt, E. A., Donnellan, M. B., Blonigen, D. M., Krueger, R. F., \& Conger, R. D. (2009). Assessment of Fearless Dominance and Impulsive Antisociality via normal personality measures: convergent validity, criterion validity, and developmental change. Journal of Personality Assessment, 91(3), 265-276. 



\title{
Chapter 9
}

\begin{abstract}
A French Translation and Validation of the Durand Adaptive Psychopathic Traits Questionnaire: An Investigation with Community Samples from France and Canada
\end{abstract}

Durand, G. (2018). A French translation and validation of the Durand Adaptive Psychopathic Traits Questionnaire: An investigation with community samples from France and Canada. PLOS ONE, 13(9), e0204214. 


\section{Chapter 9 | French Translation of the DAPTQ}

\section{Abstract}

This study presents a French translation and validation study of the Durand Adaptive Psychopathic Traits Questionnaire (DAPTQ; Durand, 2017), an instrument for assessing adaptive traits known to correlate with the psychopathic personality. The first sample, which included individuals from France and Canada $(N=135,52 \%$ in France, Mage $=26.98, S D=9.24)$, completed the DAPTQ in French, alongside measures of empathy, positive and negative affects, satisfaction with life, and self-esteem. The second sample included bilingual (French and English) individuals from France and Canada $(N=141,52 \%$ in France, Mage $=29.73, S D=9.09)$ who completed both versions of the DAPTQ (French and English), alongside measurements of perceived stress, trait anxiety, and creativity. The results support the DAPTQ-French version`s good internal consistency ( $\alpha=.89$ in study $1 ; \alpha=.87$ in study 2), convergent validity, and concurrent validity. Correlation between the DAPTQ total and subscales across versions (French-English) showed strong associations ( $r=.84$ to .96). These findings support the cross-cultural equivalence of the DAPTQ and its effectiveness as a valid assessment method of adaptive traits in the field of psychopathy. 


\section{Introduction}

Among the many controversies in the field of psychopathy, the existence of a subtype encompassing adaptive traits is highly debated (Lilienfeld, Patrick, et al., 2012; Lynam \& Miller, 2012; Patrick, Venables, \& Drislane, 2013; Visser, Ashton, \& Pozzebon, 2012). Upon providing a definition of psychopathy, many researchers emphasize the negative traits associated to psychopathy such as impulsivity, dishonesty, lack of empathy, and aggression (Berg et al., 2013; Lynam \& Miller, 2012; Viding, 2004; Walters, Brinkley, Magaletta, \& Diamond, 2008; Yildirim \& Derksen, 2015). These definitions, characterizing psychopaths as violent, ruthless, criminally prone and irrecoverable individuals, diverge from the initial conception of psychopathy proposed by Cleckley (1941), acknowledging successful psychopaths. Successful psychopaths were initially defined as individuals possessing core psychopathic traits (such as lack of empathy and emotional detachment), but also possessing adaptive traits, such as social charm, low neuroticism, and stress/anxiety resilience (Coid, Freestone, \& Ullrich, 2012; Patrick, Fowles, \& Krueger, 2009; Sadeh \& Verona, 2008). Although the inclusion of the aforementioned adaptive components as key structures of psychopathy is highly debatable, numerous studies provided evidences on a relationship between an increase of psychopathic traits and adaptive traits (BaskinSommers, Zeier, \& Newman, 2009; Camp, Skeem, Barchard, Lilienfeld, \& Poythress, 2013; Dunlop et al., 2011; Durand, 2018a; Hall, Benning, \& Patrick, 2004; Hare, 1965, 1966; Hare \& Thorvaldson, 1970; Uzieblo, Verschuere, Van den Bussche, \& Crombez, 2010; Zágon \& Jackson, 1994).

While most instruments assessing psychopathy and psychopathic traits exclusively focus on maladaptive traits, two well-validated measures of psychopathic traits partially examine adaptive traits. The Psychopathic Personality Inventory (PPI) divides eight psychopathic traits into two main factors, namely PPI-I (fearless dominance) and PPI-II (impulsive antisociality) (Lilienfeld \& Widows, 2005). More specifically, PPI-I focuses on three adaptive characteristics, namely social charm, stress and anxiety immunity, and fearlessness. Although the relationship between PPI-I and psychopathy is highly debated (Berg et al., 2013; Blonigen, 2013; Lilienfeld, Patrick, et al., 2012; Miller \& Lynam, 2012), results nevertheless suggest that high levels of PPI-I are associated with numerous adaptive traits, such as lower provoked violence (Camp et al., 2013), higher levels of self-esteem and stable happiness (Durand, 2016, 2018a), and emotional stability (Uzieblo et al., 2010). Similarly to the PPI, the Triarchic Psychopathy Measure (TriPM) includes a component, namely boldness, measuring the adaptive side of 


\section{Chapter 9 | French Translation of the DAPTQ}

psychopathy (Patrick et al., 2009). Previous studies support a strong correlation between PPI-I and boldness ( $r=.82$ ) (Hall et al., 2014).

While the PPI and the TriPM are commonly used to examine psychopathy from a maladaptive and adaptive point of view, past findings do not completely support the efficiency of either instruments to measure successful psychopathy. Multiple researchers have identified distinctive personality traits in successful psychopathy, such as high levels of extroversion, high conscientiousness, low agreeableness, high leadership abilities, high communication abilities, a willingness to take risks, and an immunity to stress and anxiety (Lilienfeld, Waldman, et al., 2012; Mullins-Sweatt, Glover, Derefinko, Miller, \& Widiger, 2010; Smith, Watts, \& Lilienfeld, 2014). Although the PPI and the TriPM are associated with numerous of the aforementioned characteristics, neither are associated with conscientiousness (Blagov, Patrick, Oost, Goodman, \& Pugh, 2015; Lilienfeld, Watts, \& Smith, 2015). Furthermore, the spectrum of adaptive traits measured by the PPI and the TriPM is limited. Several characteristics initially proposed by Cleckley as common traits observed in psychopaths are not assessed by the PPI or the TriPM (i.e. absence of delusions, of irrational thinking, of depression, of mood swings, and of worries) (Cleckley, 1988). Altogether, these findings suggest that the PPI and the TriPM could benefit from a complementary questionnaire focusing solely on extending PPI-I and boldness.

The Durand Adaptive Psychopathic Traits Questionnaire (DAPTQ; Durand, 2017) was developed in order to increase the predictive power of either instruments when exploring successful psychopathy (Durand, 2017). The DAPTQ is a self-report instrument assessing eight adaptive personality traits that have shown previous associations with the psychopathic personality. The DAPTQ was developed by first identifying all constructs considered adaptive, defined as "a trait maximizing an individual's survival probability within a set environment", which have been associated with the concept of psychopathy in healthy adults. A pool of 19 distinct constructs emerged. After examination of internal consistency and exploratory factor analysis, confirmed with a parallel analysis, an 11-factor solution emerged. Additional validation studies excluded two factors due to a lack of association with the total the total score. A subsequent research failed to provide support for one its subscale, namely 'Money Smart', leaving a final solution of 38 items divided within eight factors (leadership, logical thinking, composure, creativity, fearlessness, focus, extraversion, and management) (Durand, 2018b). The DAPTQ is not used to diagnose psychopathy, nor does it identify highly psychopathic individuals. Instead, the DAPTQ focuses on a wide range of adaptive traits theorized to be associated, either centrally or peripherally, to the concept of successful 
psychopathy, and should be seen as an extension of PPI-I and Boldness (Durand, 2018b).

A validation study of the DAPTQ provided support for the usage of the DAPTQ in conjunction with the PPI or the TriPM (Durand, 2018b). In the first study, the DAPTQ provided significant incremental validity over the PPI-SF when measuring core personality traits from the Big Five. Furthermore, while PPI-I was not associated with conscientiousness, the DAPTQ total score was weakly correlated with the construct $(r=.24)$. In Study 2, the DAPTQ demonstrated incremental validity over both the PPI-SF and the TriPM on measures of communication adaptability, perceived stress, and trait anxiety.

Previous studies focusing on the DAPTQ have, up to now, exclusively focused on worldwide sample pool, combining participants from all nationalities in single samples. Multiple studies demonstrate that the expression of psychopathy significantly differs across countries and cultures (Cooke \& Michie, 1999; Neumann, Schmitt, Carter, Embley, \& Hare, 2012). Furthermore, all studies related to the DAPTQ have been conducted in English. Examining the validity and reliability of a translated version of the DAPTQ in a heterogeneous population would provide additional information regarding the validity of the DAPTQ as a culture-independent instrument.

\section{The Current Study}

The present study hence aims to investigate the psychometric properties of the French translation of the DAPTQ in francophones, specifically those located in Canada or France. Similarly to American and British English, Canadian and France French possess a few linguistic differences. Validating the French version of the DAPTQ in both of these samples will provide additional data regarding the effect of culture on the DAPTQ. Therefore, two studies will be performed. The first study will focus on the cultural difference between Canadians and French on the DAPTQ as well as its interaction with traits considered adaptive. The second study will focus on bilingual FrenchEnglish Canadians and French, and will examine the differences between the French and the English version of the DAPTQ. The second study will also examine potential differences between various adaptive traits used in the current study and also used in a previous validation of the DAPTQ (Durand, 2018b).

\section{Study 1}

\section{Participants}

The following studies were approved and given 'exempt' status by the IntegReview Ethical Review Board (Austin, TX, USA), under protocol number 


\section{Chapter 9 | French Translation of the DAPTQ}

11022016. Previous to beginning the study, all participants provided informed consent online by selecting the case 'I consent to participate in this study' following the explanation of the research and their rights as participants. A total of 142 participants were recruited from social media and websites dedicated to psychological research. Inclusion criteria were to be a native speaker in French, to be over 18 years old, and to be located in either France or Canada. Examination of potential outliers was done by analyzing the stemand-leafs plot for each subscale used in the present study. Those analyses identified 7 potential outliers, which were removed from the study. The remaining 135 participants consisted of 71 males and 64 females. Participants location was evenly distributed, with $48 \%$ participants located in Canada, and $52 \%$ located in France. Participants' gender was also well distributed between location, with $47 \%$ of males being located in Canada ( $53 \%$ males in France), and $50 \%$ of females being located in Canada (50\% females in France). Most participants reported being of Caucasian ethnicity (89\%). A total of 56 participants (42\%) reported being currently enrolled as a student in a university. In terms of education, most participants reported having received a High school diploma (42\%), a master's degree (24\%), a bachelor's degree $(20 \%)$, or other $(14 \%)$. The participants mean age was 26.98 years old $(S D=$ 9.24).

\section{Measures}

\section{Durand Adaptive Psychopathic Traits Questionnaire (DAPTQ; Durand, 2017)}

The DAPTQ is a 38-item self-reported questionnaire, rated from $1=$ Strongly Disagree to 6 = Strongly Agree. The DAPTQ provides a total score, along 8 subscales scores: Leadership, Logical Thinking, Composure, Creativity, Fearlessness, Focus, Extroversion, and Management. A higher score represents higher adaptive traits.

\section{Interpersonal Reactivity Index - French Version (IRI; Gilet, Mella, \\ Studer, Grühn, Labouvie-Vief, 2013)}

The IRI - French Version is a translation from the original IRI by Davis (1980). The instrument is a 28-item self-reported questionnaire assessed on a 7-point scale, and measures four components of empathy: Empathic concern (EC) and personal distress (PD) focus on the affective aspects of empathy, while fantasy (FS) and perspective taking (PT) focus on the cognitive aspects. The EC scale measures one's tendency to experience feelings of concern or compassion for others. The PD scale measures one's tendency to experience distress or discomfort in response to others' emotional distress. The FS scale 
measures one's tendency to get involved in fictional situations and to identify with fictional characters in books, movies, or play. Lastly, the PT scale measures one's tendency to adopt another's perspective or point of view. The French version of the IRI has shown evidence of good reliability and convergent validity with related constructs (Gilet, Mella, Studer, Griihn, \& Labouvie-Vief, 2013).

\section{Positive and Negative Affective States - French Version (PANAS; Gaudreau, Sanchez, Blodin, 2006)}

The PANAS - French Version is a translation from the original PANAS by Watson, Clark, and Tellegen (1988). The PANAS is a self-reported adjective checklist containing two 10-item subscales measuring positive (i.e., active, alert, attentive, determined, enthusiastic, excited, inspired, interested, proud, and strong) and negative affect (i.e., afraid, ashamed, distressed, guilty, hostile, irritated, jittery, nervous, scared, and upset). The French version of the PANAS has shown evidence of good reliability and convergent validity with related constructs (Gaudreau, Sanchez, \& Blondin, 2006).

\section{Satisfaction with Life Scale - French Version (SWLS; Blais, Vallerand, Pelletier, Brière, 1989)}

The SWLS - French Version is a translation from the original SWLS by Diener, Emmons, Larsen, and Griffin (1985). The SWLS measures life satisfaction using 5 items rated on a 7-point Likert scale. The French version of the SWLS has shown evidence adequate psychometric norms (Blais, Vallerand, Pelletier, \& Brière, 1989).

\section{State Self-Esteem Scale - French Version (SSES; Martinot \& Redersdorff, 2003)}

The SSES - French Version is a translation from the original SSES by Heatherton and Polivy (1991). The SSES measures an individual's current self-esteem, in the present moment. The SSES is scored using a total score, as well as three subscale scores: performance (i.e., I feel confident about my abilities), social (i.e., I feel self-conscious), and appearance (i.e., I feel that others respect and admire me). The French version of the SSES has shown evidence of acceptable reliability (Martinot \& Redersdorff, 2003).

\section{French Translations}

The DAPTQ was translated to French by the original author of the DAPTQ, and was back-translated by two researchers, one being familiar with the DAPTQ, the other one being unfamiliar with it. The back-translations were 
reviewed by the original author, confirming the previous translation to French. No further change was done to the initial translation.

\section{Results}

\section{Preliminary Analyses}

At the exception of the SSES, all participants fully completed all questionnaires, and hence no missing data was reported. A programming mistake resulted in only 98 participants completing the SSES. There was no missing data on the SSES within those 98 participants. A normal distribution was reported on all scales and subscales, with a Skewness range between 0.73 and 0.60 and a Kurtosis range between -0.93 and 0.15 . No scale or item was transformed further.

\section{Location Differences}

Examination of the DAPTQ total score by location did not identified any significant mean difference. Further analysis of the DAPTQ subscales however identified a few differences. Individuals in Canada reported higher scores on the Leadership subscale $(F(1,134)=4.076, p=.046, d=0.35)$, on the Creativity subscale $(F(1,134)=5.024, p=.027, d=0.39)$, and the Extroversion subscale $(F(1,134)=5.354, p=.022, d=0.40)$. Examination of the SSES, PANAS, IRI, and SWLS allowed to find one additional difference, with Canadians scoring higher on the IRI - PT scale $(F(1,134)=5.115, p$ $=.025, d=0.39$ ).

\section{Correlations Between the DAPTQ and Personality Measures}

In order to account for multiple testing and potential type I error, the criterion of $p<.01$ was used to establish statistical significance for all correlational analysis. Table 1 shows the inter-scale correlations of the DAPTQ, as well as the mean, standard deviation, and Cronbach's alpha of each subscales. Similarly to previous studies, all subscales of the DAPTQ correlated moderately to strongly with the DAPTQ total score (Durand, 2017, 2018b). Table 2 shows the association between the IRI, the PANAS, the SWLS, and the SSES with each of the DAPTQ's subscales. The DAPTQ total score was negatively associated with IRI - PD $(r=-.57)$, positively associated with PANAS-Positive $(r=.34)$ but negatively with PANAS-Negative $(r=-.53)$, positively associated with SWLS $(r=.23)$ and positively associated with the SSES total and all its subscales $(r=.45$ to .56$)$. 


\section{Study 2}

\section{Participants}

A total of 153 participants were recruited from social media and websites dedicated to psychological research. Inclusion criteria were to be bilingual in French and English, to be over 18 years old, and to be located in either France or Canada. Examination of potential outliers was done by analyzing the stemand-leafs plot for each subscale used in the present study. Those analyses identified 12 potential outliers, which were removed from the study. The remaining 141 participants consisted of 95 males and 46 females. Participants location was evenly distributed, with $48 \%$ participants located in Canada, and $52 \%$ located in France. Participants' gender was also well distributed between location, with $44 \%$ of males being located in Canada (56\% males in France), and $57 \%$ of females being located in Canada (43\% females in France). Most participants reported being of Caucasian ethnicity (90\%). The participant's mother tongue was either French (70\%) or English (30\%). When examined by country, the mother tongue of Canadians was mostly equal $(53 \%$ English, $47 \%$ French), while French's mother tongue was mostly French (89\% French, $11 \%$ English). A total of 50 participants (36\%) reported being currently enrolled as a student in a university. In terms of education, most participants reported having received a master's degree (31\%), a bachelor's degree $(27 \%)$, a High school diploma (19\%), a Doctoral degree (9\%) or other $(14 \%)$. The participants mean age was 29.73 years old $(S D=9.09)$.

\section{Measures}

The original DAPTQ - English version was used at the beginning of the study, and the DAPTQ - French version was used at the end of the study. 


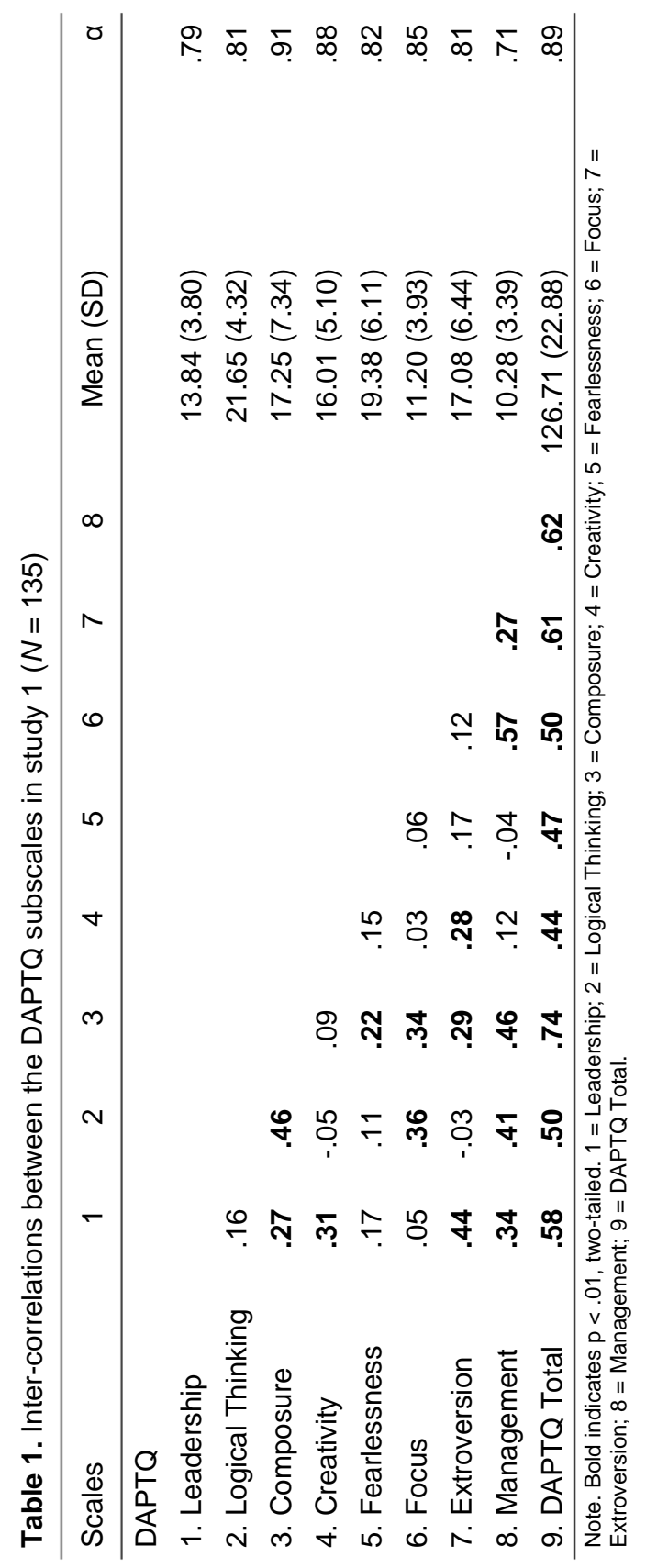




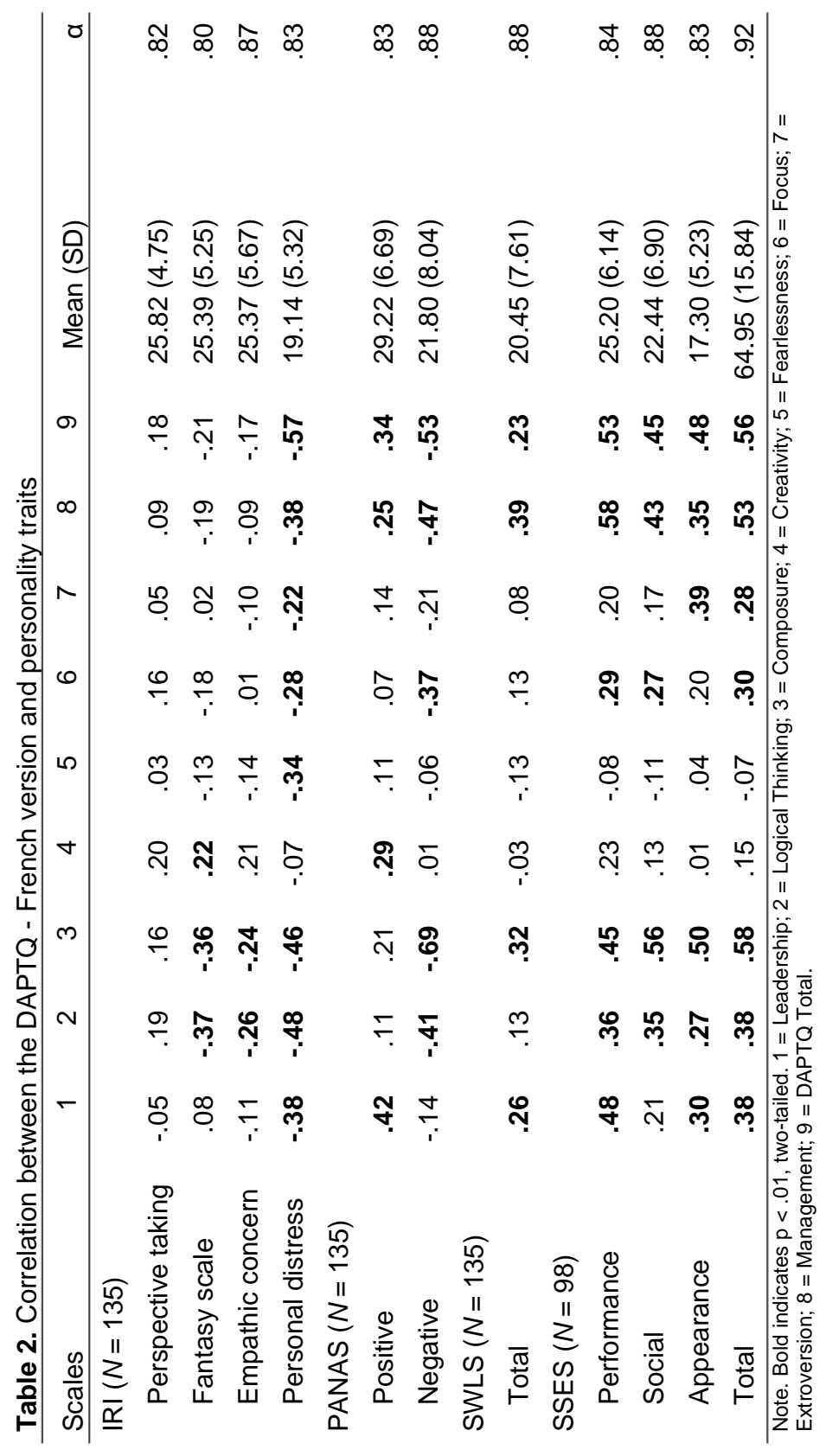




\section{Perceived Stress Scale - French Version (PSS; Cohen, Kamarck, \& Mermelstein, 1983)}

The PSS is a 10-item self-reported instrument assessing perceived stress in everyday situations (Cohen, Kamarck, \& Mermelstein, 1983). The questionnaire is rated on a 5-point Likert scale ( $0=$ Never to $4=$ Very Often). The French version has been validated in previous samples and offers evidence of adequate internal consistency and validity (Bellinghausen, Collange, Botella, Emery, \& Albert, 2009; Lesage, Berjot, \& Deschamps, 2012).

\section{State-Trait Anxiety Inventory - Trait Version (STAI-Y2; Spielberger, Gorsuch, \& Lushene, 1970)}

The STAI is a self-reported questionnaire containing 40 items divided into two subscales, assessing state anxiety and trait anxiety (Spielberger, Gorsuch, \& Lushene, 1970). The STAI-Y2 subscale focuses on trait anxiety (e.g., how a participant feels in everyday life). The STAI has been used in numerous studies and is considered to have good validity with related variables and internal consistency (Vigneau \& Cormier, 2008).

\section{Scale of Creative Attributes and Behavior (SCAB; Kelly, 2004)}

The SCAB is a 20 -item questionnaire assessing facets related to creativity using a 7-point Likert scale ( $1=$ Strongly Disagree to $7=$ Strongly Agree) (Kelly, 2004). The scale provides a total score and five subscale: Creative Engagement, Creative Cognitive Style, Spontaneity, Tolerance, and Fantasy.

\section{Results}

\section{Preliminary Analyses}

All participants fully completed all questionnaires, and hence no missing data was reported. A normal distribution was reported on all scales and subscales, with a Skewness range between -0.82 and 0.34 and a Kurtosis range between -0.83 and 0.60 . No scale or item was transformed further.

\section{Location Differences}

Similarly to Study 1 , examination of the DAPTQ total score by location did not identified any significant mean difference for both the English version and French version of the DAPTQ total score. Further analysis of the DAPTQ subscales however identified a few differences. Regarding the DAPTQ English version, individuals in Canada reported high scores on the Leadership subscale $(F(1,140)=10.62, p=.001, d=0.55)$, on the Focus subscale $(F(1$, 
$140)=4.68, p=.032, d=0.37)$, and the Management subscale $(F(1,140)=$ $9.72, p=.002, d=0.53$ ). An identical trend was observed in the DAPTQ French version, where individuals in Canada reported higher scores on the Leadership subscale $(F(1,140)=10.65, p=.001, d=0.55)$, on the Focus subscale $(F(1,140)=6.24, p=.014, d=0.42)$, and the Management subscale $(F(1,140)=19.25, p<.001, d=0.74)$.

Aside from the mean differences by location observed in the DAPTQ, a few notable differences were observed on the STAI-Y2 and the SCAB. First, individuals from France reported higher scores on the STAI-Y2 $(F(1,140)=$ $6.98, p=.009, d=0.45)$. Second, participants from Canada scored higher on two subscales of the SCAB: Cognitive Styles $(F(1,140)=6.86, p=.010, d$ $=0.44)$ and Spontaneity $(F(1,140)=4.25, p=.041, d=0.35)$.

\section{Correlation Between the French and the English Version of the DAPTQ}

As shown in Table 3, both version of the questionnaire reported adequate intercorrelation, with all subscales of the English version ( $r=.25$ to .75$)$ and of the French version ( $r=.28$ to .70$)$ correlating to their respective total score.

Correlational analysis of the DAPTQ between version support the reliability of the French version, with a correlation between the two total scores of $r=.96$. The correlations between the English and the French version by subscales are as follow: Leadership $(r=.92)$, Logical Thinking $(r=.88)$, Composure $(r=.92)$, Creativity $(r=.93)$, Fearlessness $(r=.92)$, Focus $(r=.91)$, Extroversion $(r=.96)$, and Management $(r=.84)$. Examination of the correlations between versions for each of the 38 items revealed only strong correlations $(r=.56$ to .94$)$.

\section{Correlations Between the DAPTQ - French Version and Personality Measures}

As shown in Table 4, the DAPTQ - French version was correlated to two measures previously used to validate the DAPTQ in its development phase, as well as in its subsequent validation, namely the PSS and the STAI-Y2, and one additional measure assessing creativity (SCAB). Similar to the results found by Durand (Durand, 2017, 2018b), the PSS was strongly negatively correlated with the DAPTQ - French version total $(r=-.51)$ alongside two subscales: Composure $(r=-.56)$ and Management $(r=-.50)$. Only two other subscales of the DAPTQ were negatively associated with the PSS, namely Logical Thinking $(r=-.28)$ and Focus $(r=-.39)$. Similar results were obtained on the STAI-Y2, which showed a strong negative correlation with the DAPTQ - French version total $(r=-.70)$, alongside the two subscales aforementioned: 


\section{Chapter 9 | French Translation of the DAPTQ}

Composure $(r=-.69)$ and Management $(r=-.55)$. All other subscales, at the exception of Logical Thinking and Creativity, displayed a weak to moderate negative correlation with the STAI-Y2 ( $r=-.28$ to -.45$)$.

Additional examination of the DAPTQ - French version and measurements of creativity further support the validity of the DAPTQ. Several correlations were also observed between the DAPTQ - French version and the SCAB. The DAPTQ - French version displayed positive correlations between its total score and the SCAB total and its subscales, at the exception of the fantasy subscale $(r=.22$ to .45$)$. Examination of the DAPTQ - French version subscale identified three strong correlations. First, the creativity subscale was positively correlated to the SCAB total $(r=.61)$ and the Engagement subscale $(r=.69)$. Second, Fearlessness displayed a positive correlation with Tolerance $(r=.51)$.

\section{Discussion}

This study aimed to examine the validity and psychometric properties of the DAPTQ - French version in two samples by 1) comparing the results between Canadians and French, and 2) comparing the French and English version of the DAPTQ in bilingual individuals from either France or Canada. Analyses support minor differences between French and Canadians participants in both studies. Furthermore, the DAPTQ French version and the DAPTQ English version were answered in a very similar way by the participants of Study 2 . Lastly, the results obtained on the PSS and the STAI-Y2 in Study 2 are very similar to those obtained in previous studies focusing on the English version of the DAPTQ (Durand, 2017, 2018b). The addition of numerous correlates across the two studies (e.g., IRI, PANAS, SWLS, SSES, SCAB) provides additional information regarding the general psychometric properties of the DAPTQ. 


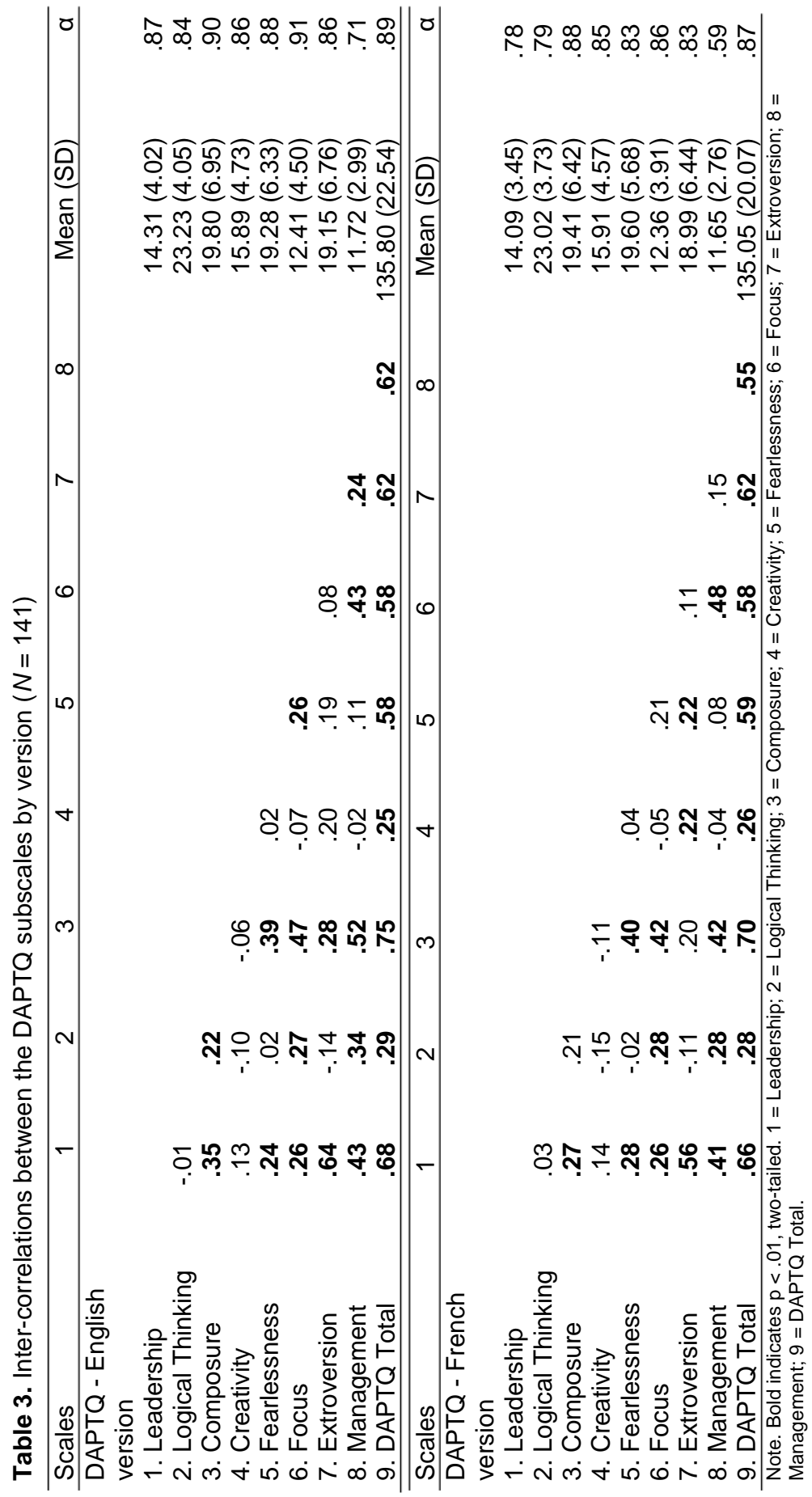




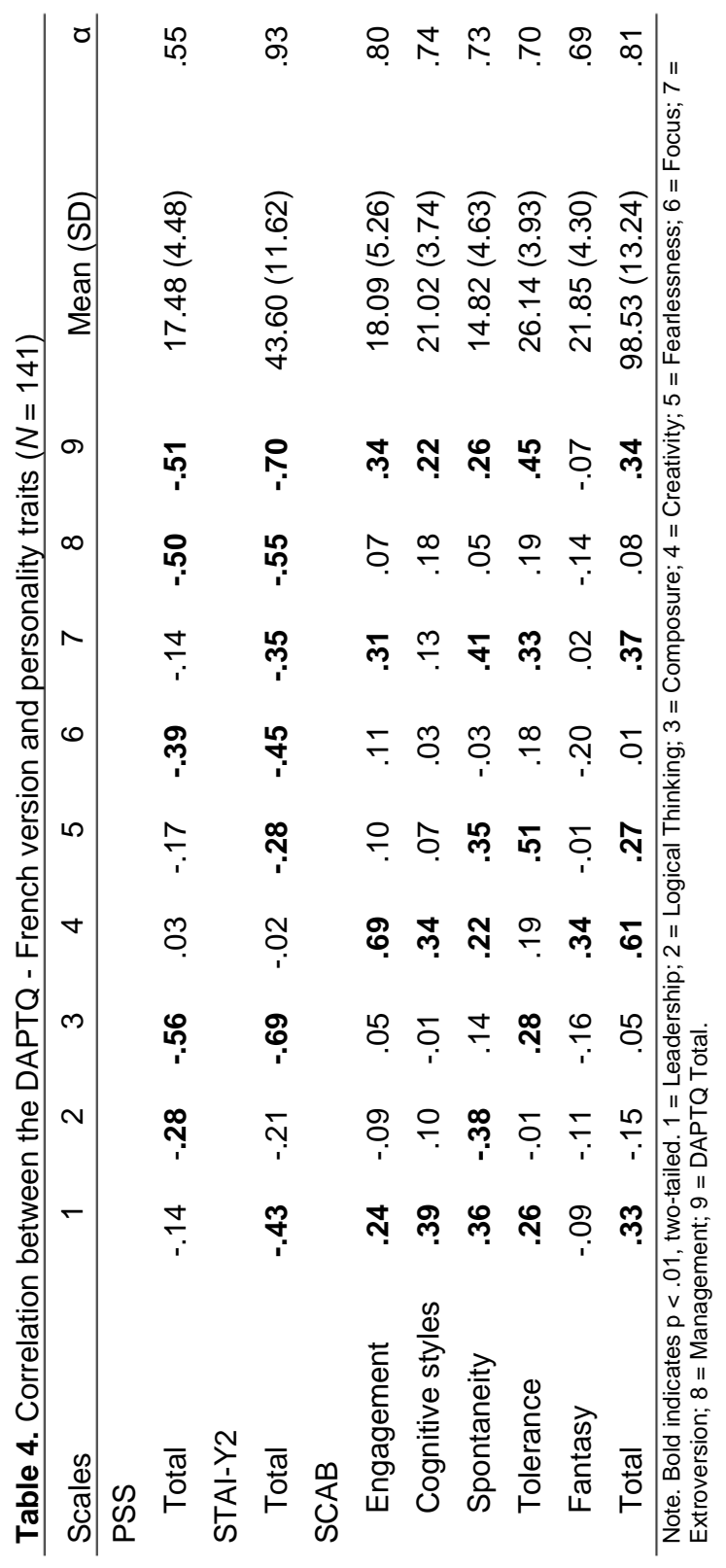


Examination of the effect of location on DAPTQ's score and other measurements yielded interesting results. In Study 1, participants in Canada reported higher levels of DAPTQ-leadership, DAPTQ-creativity, DAPTQextroversion, and IRI-perspective taking. In Study 2, Canadians displayed higher levels of DAPTQ-leadership, DAPTQ-focus, DAPTQ-management, SCAB-creativity, and lower levels STAI-anxiety than participants in France. The effect of location on leadership is particularly robust, being supported by both studies. Previous findings identified cultural differences in leadership, whereas Polish enterprises displayed higher authentic leadership than German enterprises (Furmańczyk, 2010). Similarly to leadership, previous findings also support a cross-cultural difference of STAI scores between various cultures. One study investigated STAI scores between students from America, Turkey, Mexico, and Philippines, and concluded that Filipino students reported the highest scores, while American students reported the lowest scores (Baloğlu, Abbassi, \& Masten, 2007). Although this study was not specifically investigating France, or even Europe, the results support overall lower levels of anxiety within Americans, who are culturally similar to Canadians.

Estimation of the reliability of the scores of the DAPTQ total score in both studies and both versions of Study 2 was acceptable, alongside across its 8 subscales. Although the Management subscale showed the weakest Cronbach's alpha in both studies, its strong correlation with the DAPTQ total score supports its construct validity. Cronbach's alpha for all other variables (IRI, PANAS, SWLS, SSES, STAI-Y2, and the SCAB were also acceptable. It should however be noted that the French version of the PSS in the present study displayed poor internal consistency reliability, especially compared to the English version used during the development of the DAPTQ, which reported an alpha of .89 (Durand, 2017).

Inter-construct validation was performed by correlating all DAPTQ subscales to its total scores. Although correlations were slightly weaker in the French version, both version of the DAPTQ displayed a significant correlation between each subscale and their respective total score. Validation of the DAPTQ - French version was further supported by correlating each subscale of both versions, with no Pearson correlation under $r=.84$, and no Pearson correlation under $r=.56$ at the item level.

Examination of correlational analyses between the DAPTQ - French version and measurements of perceived stress, trait anxiety, and creativity further support the DAPTQ as a valid and reliable instrument to measure adaptive traits associated to psychopathy. Similar to the results obtained during the DAPTQ development, the DAPTQ - French version correlated 


\section{Chapter 9 | French Translation of the DAPTQ}

strongly negatively with both the PSS and the STAI-Y2 (Durand, 2017). At the subscales level, the DAPTQ's Composure and Management subscales displayed the strongest correlation to the PSS, and the Leadership, Composure, Focus, and Management subscale the strongest correlation to the STAI-Y2. These results corroborate the findings obtained during the development of the DAPTQ.

Comparison of the DAPTQ with a range of measures not previously studied in conjunction with the DAPTQ provided additional information regarding the psychometric information of the DAPTQ. First, the DAPTQ was strongly negatively associated with personal distress. The IRI-PD scale has been associated in previous studies to the Boldness component of the TriPM $(r=-.471)$ and the PPI-I ( $r=-.52)$ (Almeida et al., 2015; Sellbom, Wygant, \& Drislane, 2015). Second, the PANAS-Positive has been associated positively with PPI-I $(r=.40)$, while the PANAS-Negative has been associated negatively with PPI-I $(r=-.30)$ (Falkenbach, Stern, \& Creevy, 2014). Third, the SWLS has been associated with the TriPM-Boldness $(r=.35)$ (Ruchensky \& Brent Donnellan, 2017). Fourth, the SSES has been associated with PPI-I $(r=.50)$ (Durand, 2016). Lastly, while the SCAB has never been used in research related to psychopathy, multiple studies have found weak associations between creativity and psychopathic traits (Akhtar, Ahmetoglu, \& ChamorroPremuzic, 2013; Galang, Castelo, Santos, Perlas, \& Angeles, 2016; Jonason, Richardson, \& Potter, 2015; Salekin, Neumann, Leistico, \& Zalot, 2004). This would suggest that higher scores on the DAPTQ will result in increased enjoyment of working on creative projects, higher creative cognitive abilities, such as divergent thinking and problem solving, increased excitement seeking, and increased flexibility and openness to others' ideas (Kelly, 2006).

There are multiple limitations to the present study. First, recruitment was exclusively centered on individuals residing in France or Canada. Although French is one of the official languages in both of these countries, validation of the DAPTQ - French version in other francophone countries, such as Belgium, Monaco, Côte d'Ivoire, Haiti, and French Polynesia, may provide additional results regarding the cross-cultural stability of the DAPTQ. Second, while French is the only official language in France, Canada's official languages are French and English. This may influence the results, as the mother tongue of the participants in Canada is evenly distributed between English and French, while the mother tongue of French participants was predominantly French. Third, although self-reported questionnaires are commonly used in the field of personality, experimental evidences are necessary to further support the translated version of the DAPTQ as a reliable instrument to assess adaptive traits associated with psychopathic traits. Fourth, the gender of participants 
was not evenly distributed in Study 2. During the development of the DAPTQ, a gender difference was noted on the DAPTQ total score, whereas males displayed higher scores than females (Durand, 2017). The higher proportion of males in Study 2 may explain why the mean score on the DAPTQ total is higher than the total score in Study 1. Fourth, both studies used a very limited sample size, and results should be replicated in larger samples. Fifth, the current studies did not include instruments assessing social desirability and honesty of the answers. Face to face interviews could allow researchers to identify signs of dishonesty. Sixth, no personality variables that could affect the response style of participants, such as narcissism, has been taken into account. Screening participants with extensive personality questionnaires could provide useful information regarding the desired self-image of participants and its effect on responses. Seventh, the present study did not perform a measurement of invariance of the DAPTQ - French version in both population due to the small sample size. A future study should examine the results from a confirmatory factor analysis performed in both a Canadian sample and a French sample in order to ensure the validity of the current results. Lastly, another limitation focuses on the recruitment method, which was centered on advertising on social media and various websites dedicated to psychological research. Although these recruitment techniques enable to get a wide sample from across both countries, a more specific sample, such as university students from a single university, might provide additional results. Despite these limitations, the present findings are promising as they provide further evidence of the cross-cultural equivalence of the DAPTQ to measure adaptive traits related to psychopathic traits in various populations. 


\section{Chapter 9 | French Translation of the DAPTQ}

\section{References}

Akhtar, R., Ahmetoglu, G., \& Chamorro-Premuzic, T. (2013). Greed is good? Assessing the relationship between entrepreneurship and subclinical psychopathy. Personality and Individual Differences, 54(3), 420-425.

Almeida, P. R., Seixas, M. J., Ferreira-Santos, F., Vieira, J. B., Paiva, T. O., Moreira, P. S., \& Costa, P. (2015). Empathic, moral and antisocial outcomes associated with distinct components of psychopathy in healthy individuals: A Triarchic model approach. Personality and Individual Differences, 85, 205-211.

Baloğlu, M., Abbassi, A., \& Masten, W. (2007). A Cross-Cultural Comparison of Anxiety Among College Students. College Student Journal, 41(4), 977-984.

Baskin-Sommers, A. R., Zeier, J. D., \& Newman, J. P. (2009). Self-reported attentional control differentiates the major factors of psychopathy. Personality and Individual Differences, 47(6), 626-630.

Bellinghausen, L., Collange, J., Botella, M., Emery, J.-L., \& Albert, E. (2009). Factorial validation of the French scale for perceived stress in the workplace. Sante Publique, 21(4), 365-373.

Berg, J. M., Smith, S. F., Watts, A. L., Ammirati, R., Green, S. E., \& Lilienfeld, S. O. (2013). Misconceptions regarding psychopathic personality: implications for clinical practice and research. Neuropsychiatry, 3, 63-74.

Blagov, P. S., Patrick, C. J., Oost, K. M., Goodman, J. A., \& Pugh, A. T. (2015). Triarchic Psychopathy Measure: Validity in Relation to Normal-Range Traits, Personality Pathology, and Psychological Adjustment. Journal of Personality Disorders, 30(1), 1-11.

Blais, M. R., Vallerand, R. J., Pelletier, L. G., \& Brière, N. M. (1989). L'échelle de satisfaction de vie: Validation canadienne-française du "Satisfaction with Life Scale." Canadian Journal of Behavioural Science / Revue Canadienne Des Sciences Du Comportement, 21(2), 210-223.

Blonigen, D. M. (2013). Is fearless dominance relevant to the construct of psychopathy? Reconciling the dual roles of theory and clinical utility. Personality Disorders, 4(1), 87-8.

Camp, J. P., Skeem, J. L., Barchard, K., Lilienfeld, S. O., \& Poythress, N. G. (2013). Psychopathic predators? Getting specific about the relation between psychopathy and violence. Journal of Consulting and Clinical Psychology, 81(3), 467-480.

Cleckley, H. (1941). The mask of sanity; an attempt to reinterpret the so-called psychopathic personality. Jama, 117(6), 493.

Cleckley, H. (1988). The Mask of Sanity: An Attempt to Clarify Some Issues About the So Called Psychopathic Personality. (W. a Dolan, Ed.) (5th ed.).

Cohen, S., Kamarck, T., \& Mermelstein, R. (1983). A global measure of perceived stress. Journal of Health and Social Behavior, 24(4), 385-396.

Coid, J., Freestone, M., \& Ullrich, S. (2012). Subtypes of psychopathy in the British household population: Findings from the national household survey of 
psychiatric morbidity. Social Psychiatry and Psychiatric Epidemiology, 47(6), 879-891.

Cooke, D. J., \& Michie, C. (1999). Psychopathy across cultures: North America and Scotland compared. Journal of Abnormal Psychology, 108(1), 58-68.

Davis, M. H. (1980). A multidimensional approach to individual differences in empathy. JSAS Catalog of Selected Documents in Psychology, 10, 85.

Diener, E., Emmons, R., Larsen, J., \& Griffin, S. (1985). The satisfaction with life scale. Journal of Personality Assessmemt, 5(2), 164-172.

Dunlop, B. W., DeFife, J. A., Marx, L., Garlow, S. J., Nemeroff, C. B., \& Lilienfeld, S. O. (2011). The effects of sertraline on psychopathic traits. International Clinical Psychopharmacology, 26(6), 329-37.

Durand, G. (2016). A Replication of " Using self-esteem to disaggregate psychopathy, narcissism, and aggression (2013) ". The Qantitative Methods for Psychology, 12(2), r1-r5.

Durand, G. (2017). The Durand Adaptive Psychopathic Traits Questionnaire: Development and Validation. Journal of Personality Assessment, 1-10.

Durand, G. (2018a). Demystification of the Relationship Between Psychopathy and Happiness. Journal of Happiness Studies, 19(2), 381-395.

Durand, G. (2018b). Incremental Validity of the Durand Adaptive Psychopathic Traits Questionnaire Above Self-Report Psychopathy Measures in Community Samples. Journal of Personality Assessment, 1-10.

Falkenbach, D. M., Stern, S. B., \& Creevy, C. (2014). Psychopathy variants: Empirical evidence supporting a subtyping model in a community sample. Personality Disorders: Theory, Research, and Treatment, 5(1), 10-19.

Furmańczyk, J. (2010). The Cross-cultural Leadership Aspect. Journal of Intercultural Management, 2(2), 67-82.

Galang, A. J. R., Castelo, V. L. C., Santos, L. C., Perlas, C. M. C., \& Angeles, M. A. B. (2016). Investigating the prosocial psychopath model of the creative personality: Evidence from traits and psychophysiology. Personality and Individual Differences, 100, 28-36.

Gaudreau, P., Sanchez, X., \& Blondin, J. P. (2006). Positive and negative affective states in a performance-related setting testing the factorial structure of the PANAS across two samples of French-Canadian participants. European Journal of Psychological Assessment, 22(4), 240-249.

Gilet, A. L., Mella, N., Studer, J., Griihn, D., \& Labouvie-Vief, G. (2013). Assessing dispositional empathy in Adults: A french validation of the interpersonal reactivity index (IRI). Canadian Journal of Behavioural Science, 45(1), 42-48.

Hall, J., Benning, S. D., \& Patrick, C. J. (2004). Criterion-Related Validity of the ThreeFactor Model of Psychopathy: Personality, Behavior, and Adaptive Functioning. Assessment, 11(1), 4-16.

Hall, J., Drislane, L. E., Patrick, C. J., Morano, M., Lilienfeld, S. O., \& Poythress, N. G. (2014). Development and validation of Triarchic Construct Scales from the 


\section{Chapter 9 | French Translation of the DAPTQ}

Psychopathic Personality Inventory. Psychological Assessment, 26(2), 447-61.

Hare, R. D. (1965). Psychopathy, Fear Arousal and Anticipated Pain. Psychological Reports, 16, 499-502.

Hare, R. D. (1966). Psychopathy and choice of immediate versus delayed punishment. Journal of Abnormal Psychology, 71, 25-29.

Hare, R. D., \& Thorvaldson, S. A. (1970). Psychopathy and response to electrical stimulation. Journal of Abnormal Psychology, 76, 370-374.

Heatherton, T. F., \& Polivy, J. (1991). Development and validation of a scale for measuring state self-esteem. Journal of Personality and Social Psychology, 60(6), 895-910.

Jonason, P. K., Richardson, E. N., \& Potter, L. (2015). Self-reported creative ability and the Dark Triad traits: An exploratory study. Psychology of Aesthetics, Creativity, and the Arts, 9(4), 488-494.

Kelly, K. E. (2004). A brief measure of creativity among college students. College Student Journal, 38(4), 594-596.

Kelly, K. E. (2006). Relationship between the five-factor model of personality and the Scale of Creative Attributes and Behavior: A validational study. Individual Differences Research, 4(5), 299-305.

Lesage, F.-X., Berjot, S., \& Deschamps, F. (2012). Psychometric properties of the French versions of the Perceived Stress Scale. International Journal of Occupational Medicine and Environmental Health, 25(2), 178-184.

Lilienfeld, S. O., Patrick, C. J., Benning, S. D., Berg, J., Sellbom, M., \& Edens, J. F. (2012). The role of fearless dominance in psychopathy: Confusions, controversies, and clarifications. Personality Disorders: Theory, Research, and Treatment, 3(3), 327-340.

Lilienfeld, S. O., Waldman, I. D., Landfield, K., Watts, A. L., Rubenzer, S., \& Faschingbauer, T. R. (2012). Fearless dominance and the U.S. presidency: Implications of psychopathic personality traits for successful and unsuccessful political leadership. Journal of Personality and Social Psychology, 103(3), 489505.

Lilienfeld, S. O., Watts, A. L., \& Smith, S. F. (2015). Successful Psychopathy: A Scientific Status Report. Current Directions in Psychological Science, 24(4), 298-303.

Lilienfeld, S. O., \& Widows, M. (2005). Psychopathic personality inventory-revised: Professional manual. Lutz, FL: Psychological Assessment Resources.

Lynam, D. R., \& Miller, J. D. (2012). Fearless dominance and psychopathy: A response to Lilienfeld et al. Personality Disorders: Theory, Research, and Treatment, 3(3), 341-353.

Martinot, D., \& Redersdorff, S. (2003). Impact of comparisons with out-group members on women's self-esteem: Role of the stereotypical connotation of the performance context. International Journal of Psychology, 38(6), 348-358.

Miller, J. D., \& Lynam, D. R. (2012). An examination of the Psychopathic Personality 
Inventory's nomological network: A meta-analytic review. Personality Disorders: Theory, Research, and Treatment, 3(3), 305-326.

Mullins-Sweatt, S. N., Glover, N. G., Derefinko, K. J., Miller, J. D., \& Widiger, T. a. (2010). The search for the successful psychopath. Journal of Research in Personality, 44(4), 554-558.

Neumann, C. S., Schmitt, D. S., Carter, R., Embley, I., \& Hare, R. D. (2012). Psychopathic Traits in Females and Males across the Globe. Behavioral Sciences \& the Law, 30(5), 557-574.

Patrick, C. J., Fowles, D. C., \& Krueger, R. F. (2009). Triarchic conceptualization of psychopathy: Developmental origins of disinhibition, boldness, and meanness. Development and Psychopathology, 21(03), 913.

Patrick, C. J., Venables, N. C., \& Drislane, L. E. (2013). The role of fearless dominance in differentiating psychopathy from antisocial personality disorder: comment on Marcus, Fulton, and Edens. Personality Disorders, 4(1), 80-2.

Ruchensky, J. R., \& Brent Donnellan, M. (2017). Integrating the HEXACO model with the Triarchic conceptualization of psychopathy. Personality and Individual Differences, 119, 129-133.

Sadeh, N., \& Verona, E. (2008). Psychopathic personality traits associated with abnormal selective attention and impaired cognitive control. Neuropsychology, 22(5), 669-680.

Salekin, R. T., Neumann, C. S., Leistico, A.-M. R., \& Zalot, A. A. (2004). Psychopathy in Youth and Intelligence: An Investigation of Cleckley's Hypothesis. Journal of Clinical Child \& Adolescent Psychology, 33(4), 731-742.

Sellbom, M., Wygant, D. B., \& Drislane, L. E. (2015). Elucidating the Construct Validity of the Psychopathic Personality Inventory Triarchic Scales. Journal of Personality Assessment, 97(4), 374-381.

Smith, S. F., Watts, A. L., \& Lilienfeld, S. O. (2014). On the trail of the elusive successful psychopath. The Psychologist, 27(7), 506-511.

Spielberger, C. D., Gorsuch, R. L., \& Lushene, R. E. (1970). The State-Trait Anxiety Inventory. MANUAL, 1-23.

Uzieblo, K., Verschuere, B., Van den Bussche, E., \& Crombez, G. (2010). The validity of the psychopathic personality inventory--revised in a community sample. Assessment, 17(3), 334-346.

Viding, E. (2004). Annotation: Understanding the development of psychopathy. Journal of Child Psychology and Psychiatry and Allied Disciplines.

Vigneau, F., \& Cormier, S. (2008). The factor structure of the State-Trait Anxiety Inventory: an alternative view. Journal of Personality Assessment, 90(3), 280285.

Visser, B. a., Ashton, M. C., \& Pozzebon, J. a. (2012). Is Low Anxiety Part of the Psychopathy Construct? Journal of Personality, 80(3), 725-747.

Walters, G. D., Brinkley, C. a, Magaletta, P. R., \& Diamond, P. M. (2008). Taxometric analysis of the Levenson Self-Report Psychopathy scale. Journal of Personality 


\section{Chapter 9 | French Translation of the DAPTQ}

Assessment, 90(5), 491-498.

Watson, D., Clark, L. a, \& Tellegen, A. (1988). Development and validation of brief measures of positive and negative affect: the PANAS scales. Journal of Personality and Social Psychology, 54(6), 1063-70.

Yildirim, B. O., \& Derksen, J. J. L. (2015). Clarifying the heterogeneity in psychopathic samples: Towards a new continuum of primary and secondary psychopathy. Aggression and Violent Behavior, 24, 9-41.

Zágon, I. K., \& Jackson, H. J. (1994). Construct validity of a psychopathy measure. Personality and Individual Differences, 17(I), 125-135. 




\section{Chapter 10}

Exploring the Relationship Between Cognitive Abilities and Adaptive Components of Psychopathic Traits

Durand, G., Rutten, B. P. F., Lobbestael, J. Exploring the relationship between cognitive abilities and adaptive components of psychopathic traits (submitted) 


\section{Abstract}

Studies have shown that individuals with high psychopathic traits often struggle with control inhibition and cognitive flexibility. However, a few studies reported a positive association between cognitive abilities and psychopathyrelated traits considered to be adaptive. The current study assessed the relation between a set of cognitive functions and adaptive traits associated with the psychopathic personality. Participants $(N=107)$ completed the Psychopathic Personality Inventory -Short Form (which includes components of Fearlessness Dominance and Impulsive Antisociality) and the Durand Adaptive Psychopathic Traits Questionnaire, respectively. Participants then completed the Penn Word Memory Test (PWMT); a measure of short and long term memory, a Go/No-Go paradigm; a measure of cognitive attention, the nback test (i.e. 2-back and 3-back); a measure of working memory, and one of two versions of the flanker task (i.e. the arrows version and the characters version); a measure of response inhibition. Results showed that adaptive psychopathic traits were associated with faster response times on both $n$-back tasks, on the characters version of the flanker task, and on the long-term recall of PWMT. In contrast, Impulsive Antisociality was associated with slower response times in incongruent trials of both flanker task and on the short-term recall of the PWMT. Overall, higher levels of adaptive traits and Fearless Dominance was associated with better performance in a working memory task without sacrificing accuracy for speed. These findings further support the multidimensionality of psychopathy, whereas its maladaptive traits are related to cognitive impairments, whereas its adaptive traits are related to cognitive superiority. 


\section{Introduction}

\section{Psychopathy}

In the majority of the literature, psychopathy is defined by ruthlessness, callousness, lack of guilt and remorse, impulsivity, emotional detachment, social deviance, and poor behavioral control (Berg et al., 2013; Lynam \& Miller, 2012; Viding, 2004; Walters, Brinkley, Magaletta, \& Diamond, 2008; Yildirim \& Derksen, 2015). Researchers generally agree that the aforementioned traits are central to psychopathy, but other traits, which could be considered adaptive, are also observed in many psychopathic individuals. Early conceptualizations of psychopathy by Cleckley (1941) included numerous non-maladaptive traits in the set of characteristics observed in psychopaths, such as superficial charm, absence of delusion and irrational thinking, absence of nervousness, and low suicide rate (Cleckley, 1988; pp. 338-339). Afterwards, many studies found a positive relationship between psychopathy and adaptive traits such as social charm, low neuroticism, and high resilience to stress and anxiety (Coid, Freestone, \& Ullrich, 2012; Patrick, Fowles, \& Krueger, 2009; Sadeh \& Verona, 2008). The inclusion of such an adaptive component as a key structure of psychopathy is highly debated (Lilienfeld et al., 2012; Lynam \& Miller, 2012; Patrick, Venables, \& Drislane, 2013; Visser, Ashton, \& Pozzebon, 2012). However, numerous self-reported questionnaire and laboratory studies provide evidence for a significant positive relationship between psychopathic traits and adaptive traits, such as happiness, selfesteem, tolerance for pain and stress, leadership, strategic thinking, and innovation (Baskin-Sommers, Zeier, \& Newman, 2009; Camp, Skeem, Barchard, Lilienfeld, \& Poythress, 2013; Dunlop et al., 2011; Durand, 2016, 2018b; Durand \& Plata, 2017; Hall, Benning, \& Patrick, 2004; Hare, 1965, 1966; Hare \& Thorvaldson, 1970; Uzieblo, Verschuere, Van den Bussche, \& Crombez, 2010; Zágon \& Jackson, 1994).

\section{Cognitive Abilities and Psychopathy}

There is evidence suggesting that psychopathy is associated with impairments in certain cognitive abilities. The prefrontal cortex is one of the main brain areas responsible for the proper functioning of cognitive abilities. Cognitive abilities include functions such as planning abilities, behavioral inhibition, working memory, and cognitive flexibility (Zeier, Baskin-sommers, \& Newman, 2012). Previous findings indicate that people classified as highly psychopathic often have poor impulse control and difficulty adapting their behavior. For instance, when asked to complete a flanker task (i.e. a task where centrally presented target stimuli are flanked on both side by a distracter stimuli, which is the same or different from the target stimuli), highly 
psychopathic individuals were significantly less accurate in incongruent trials than non-psychopathic participants, supporting that psychopathy is characterized by interference from poorer cognitive control as well as increased impulsivity when making decisions (Zeier et al., 2012). Likewise, psychopathic individuals committed significantly more errors in the go/no-go task (i.e. responding when a specific stimulus is on screen and not responding when any other stimuli is presented) and the stopping task (i.e. inhibiting the expected response to a stimulus when hearing a signal tone), both requiring inhibitory control (Roussy \& Toupin, 2000). Furthermore, highly psychopathic individuals, particularly those high in maladaptive traits, proved to display difficulties adjusting their behavior after an incorrect response and therefore are prone to making more errors in cognitive tasks. The later is, in part, due to the fact that they do not appear to sufficiently pause after an error in order to re-adjust and evaluate their strategy (Wilkowski \& Robinson, 2008).

\section{Cognitive Abilities and Adaptive Psychopathic Traits}

Out of the wide range of measures assessing psychopathy and psychopathic traits, two measures distinguish themselves due to their inclusions of an adaptive component, i.e., the Psychopathic Personality Inventory (PPI; Lilienfeld \& Andrews, 1996) and the Triarchic Measures of Psychopathy (TriPM; Patrick, 2010). Cognitive ability studies using the PPI reported that psychopathy was associated with a greater number of errors in the Porteus Maze test used to assess impulsivity. More specifically, that relation was significant for PPI total, Self-Centered Impulsivity, and Fearless Dominance, but not for Coldheartedness, which is counter-intuitive as Fearless Dominance represents the adaptive side of the PPI (Snowden, Gray, Pugh, \& Atkinson, 2013). Another PPI study reported that Self-Centered Impulsivity was positively predictive of executive dysfunction while no significant association was observed between Fearless Dominance and Coldheartedness with executive dysfunction, at the exception of a negative correlation between Fearless Dominance and apathy (Ross, Benning, \& Adams, 2007).

Due to these mitigated results, Baskin-Sommers and colleagues (2015) investigated the role of the instrument used to assess psychopathy and executive functions (EF). The authors hypothesized that the lack of a clear relationship between psychopathy and EF may be due to the various instruments not using the same classification of psychopathic subtypes. Studies performed on inmates mostly used the interview-based Psychopathy Checklist-Revised (PCL-R; Hare, 1991). The original classification of the PCL$\mathrm{R}$ consisted of two factors, namely Factor 1 , which measures emotional and interpersonal traits, such as callousness, remorseless exploitation of others, 
and lack of empathy, and Factor 2, which measures social deviance, including criminal and impulsive features, as well as anxiety and neuroticism. The PCL$R$ was later revised as a three-factor model including interpersonal, emotional, and lifestyle facets, and subsequently revised once again as a four-factor model, including one additional facet assessing impulsivity and aggression (Cooke \& Michie, 2001; Hare, 2003). While the PCL-R is regarded as the gold standard for psychopathy diagnosis, research in non-institutionalized populations has mainly used self-reported questionnaires to assess psychopathic traits. The PPI is one of the most common self-report instruments used to assess psychopathic traits. The instrument is also divided into two factors, namely PPI-I (Fearless Dominance; which includes several of the potentially more adaptive features of psychopathy) and PPI-II (Impulsive Antisociality; which focuses on several maladaptive features of psychopathy). Several literature reviews conceptualized that, while the Factor 2 of the PCLR 2-factor model and PPI-II are strongly correlated, Factor 1 and PPI-I are not associated to each other, as Factor 1 focuses on elements of meanness while PPI-I focuses on elements related to boldness (Polaschek \& Daly, 2013; Skeem, Polaschek, Patrick, \& Lilienfeld, 2011).

Studies have found a positive association between EF and traits related to Fearless Dominance, and a negative association between EF and traits related to PCL-R Factor 2, as well as traits related to Impulsive Antisociality (Baskin-Sommers et al., 2015). Interestingly, PCL-R Factor 1 was unrelated to EF performance. Hence, these data illustrate that using the adequate instrument to measure adaptive psychopathic traits is primordial in order to examine the strength of association between EF and the adaptive traits of psychopathy.

While a subset of the PPI-I scale focuses on adaptive psychopathic traits, the instrument only covers a limited number of characteristics (e.g. social potency, fearlessness, and stress immunity). The Durand Adaptive Psychopathic Traits Questionnaire (DAPTQ; Durand, 2017) aims to fill-in this gap by focusing solely on the adaptive profile of psychopathy. The DAPTQ is a 41 -item questionnaire assessing nine adaptive traits known to correlate with psychopathic personality traits. The first step in its development was to identify the various constructs that are considered as adaptive and that have shown to have strong associations with psychopathy. Adaptive traits are defined here as those that facilitate and improve the individual's chances of survival within their environment (Durand, 2017). The final 9-factor solution includes the following scales: Leadership, Logical Thinking, Composure, Creativity, Fearlessness, Money Smart, Focus, Extroversion, and Management. The DAPTQ is not a measure of psychopathy, but rather a measure of various 
adaptive traits that have been shown to be associated with psychopathy. In other words, the DAPTQ is a measure of adaptive psychopathic traits.

\section{The Current Study}

The purpose of this study is twofold. First, since many authors have used multiple versions of the same cognitive tasks when investigating the relationship between psychopathy and EF, a pilot examining the validity of tasks using multiple versions is necessary. Second, while the DAPTQ appears to be an alternative to the PPI-I factor of the PPI, it has not been yet compared to any behavioral EF measure. Hence, we will examine the efficiency of the DAPTQ to predict EF over the PPI-SF. We hypothesize that the DAPTQ will show stronger correlations and better predictive power than the PPI-I in predicting executive functions.

\section{Methods}

\section{Participants}

A total of $N=107$ participants (44 males, 63 females) were recruited on social media and websites dedicated to research in psychology (e.g., callforparticipants.com, onlinepsychresearch.co.uk, facebook.com). The age of the participants ranged between 18 and 64 years old $(M=28.78, S D=$ 10.52). Over a third of the participants were university students (38\%). Participants were mostly located in North America (51\%) and Europe (39\%). In terms of the latest diploma obtained, most participants reported being high school graduates $(41 \%)$, followed by bachelor graduates $(31 \%)$, Master's degree graduate $(13 \%)$, or other $(15 \%)$. The current study was approved and given 'exempt' status by the IntegReview Ethical Review Board (Austin, TX, USA), under protocol number 11022016. No names or other protected health information, as defined by the Health Insurance Portability and Accountability Act (HIPAA), were recorded. All participants agreed to the informed consent form with detailed information about the nature, the goal, and procedure of the study prior starting the experiment. Participants remained anonymous throughout the study, and were not compensated for their time.

\section{Measures}

\section{Durand Adaptive Psychopathic Traits Questionnaire (DAPTQ; Durand, 2017)}

The DAPTQ is a 41 -item self-report instrument assessing adaptive traits known to correlate with psychopathic personality traits. A validation study provided support for 8 out of the 9 subscales of the DAPTQ in terms of 
association with the construct of psychopathy, excluding the Money Smart subscale (Durand, 2018c). The current study hence focused on the 38-item version of the DAPTQ, which excludes the aforementioned subscale. The DAPTQ uses a 6-point Likert scale, ranging from 1 (Strongly Disagree) to 6 (Strongly Agree). Further validation of the DAPTQ provided support for its incremental validity over the PPI - short form in measures related to successful psychopathy, such as conscientiousness, stress and anxiety immunity, and communication adaptability (Durand, 2018c). In the present study, the internal consistency reliability of the DAPTQ total was $\alpha=.92$, and that of its subscales ranged from $\alpha=.76$ to .92 .

\section{Psychopathic Personality Inventory - Short Form (PPI-SF; Lilienfeld \& Widows, 2005)}

The PPI-SF is a 56 -item self-report instrument assessing psychopathic traits on a 4-point Likert scale $(1=$ false, $4=$ true). Factor analytic research showed that the subscales load on two different factors. The Fearless Dominance factor includes Stress Immunity, Social Potency, and Fearlessness subscales, and the Impulsive Antisociality factor includes Blame Externalization, Machiavellian Egocentricity, Carefree Nonplanfulness, and Impulsive Nonconformity subscales. The Coldheartedness subscale does not load on any of the two factors (Benning, Patrick, Hicks, Blonigen, \& Krueger, 2003). The DAPTQ total score has shown to correlate positively with PPI-I $(r=.66)$ and PPI-SF Total $(r=.46)$, but is not significantly associated with PPI-II $(r=$ -.04) (Durand, 2017). In the present study, the DAPTQ total score correlated again positively with PPI-I $(r=.81)$ and PPI-SF Total $(r=.59)$, but was not significantly associated with PPI-II $(r=-.20)$. The total PPI score had a Cronbach's alpha of $\alpha=.76$, PPI-I of $\alpha=.83$, and PPI-II of $\alpha=.76$.

\section{$\mathrm{N}-$ Back Task}

The n-back task is a measure of attention and working memory. Similarly to the design of Schoofs, Preuß, and Wolf (2008), participants were asked to monitor a series of one-digit numbers from " 0 " to " 9 ", presented in a random sequence. Participants had to choose between the two arrows of the keyboard (e.g. left arrow if seen $n$-steps before, right arrow if not seen $n$-steps before). Participants completed a practice trial of 15 stimuli, followed by two blocks presented in random order of 50 trials, each in which the working memory load varied by changing the difficulty using a 2-back and a 3-back condition. A fixation cross was presented for $500 \mathrm{~ms}$, followed by a stimulus with autoadvance for $3000 \mathrm{~ms}$ and an inter-stimulus interval of $1200 \mathrm{~ms}$. Target stimuli (same stimulus as $\mathrm{n}$-trials before) were presented randomly with a probability 
of $33 \%$. The first three trials of both conditions were removed from all participants.

\section{Go/No-Go Task}

The Go/No-Go task is a task designed to assess the participant's cognitive attention and response inhibition. Instructions presented on the screen informed the participant to press the space bar of the keyboard every time the letter " $\mathrm{X}$ " was presented on the screen, and to refrain from pressing any key when the screen displays any other letter (i.e., "A, D, Y, W"). The task was composed of 48 consecutive trials divided equally between presentations of target cue and distracters. Each trial was composed of a blank screen presentation for $500 \mathrm{~ms}$, followed by a fixation cross of $1000 \mathrm{~ms}$ and a target letter for $2500 \mathrm{~ms}$. The Go/No-Go paradigm has been used in several laboratory studies in the field of psychopathy (Poythress et al., 2010; Zimak, Suhr, \& Bolinger, 2014) and is considered a valuable tool for assessing response discrimination. Scoring was performed by calculating the mean reaction time to respond at the view of Go stimulus (the $X$ letter), and by calculating the average number of errors (i.e., pressing the space bar on $Y$ or inhibit pressing) throughout the experiment.

\section{Flanker Task (Eriksen \& Eriksen, 1974)}

The flanker task is a common measure of cognitive control and perceptual discrimination. A row of five characters was presented to the participant. The target stimulus, which is in the middle of the row, was flanked by four (i.e. 2 on the right, 2 on the left) distracters. In the flanker task, the distracters may be very similar (i.e. congruent) or very different (i.e. incongruent) from the target stimulus. When distracter stimuli were incongruent with the target stimuli, participants generally answered slower and less accurately than when answering congruent trials. However, there are numerous versions of the flanker task. In this study, we tested two versions of the flanker task (one version with control trials, and another without), with participants completing one or the other. The first version is the numbers/letters version used by Zeier et al. (2012). Similarly to their design, the participants in the current study completed 100 trials divided in two blocks. For each trial, a fixation cross of $500 \mathrm{~ms}$ appeared on screen, followed by the target and the flankers, which were set to auto-advance after $2500 \mathrm{~ms}$. The target appeared at fixation and the two distracters appeared to the left and right, equidistant from the target (approximately one degree of visual angle). As in Zeier et al., (2012)'s study, the target stimulus was always a $5,8, \mathrm{G}$, or $\mathrm{M}$, and the distracters were always one of these stimuli or a pound sign (\#). Participants entered a response 
indicating whether the target was a letter or a number using a 2-forced choice answer. This was followed by a $1000-1500 \mathrm{~ms}$ variable intertrial interval. Congruent trials were those in which the target and distracters were the same (e.g., 858 ), incongruent trials were those in which the target and distractors were of different types (e.g., G $5 \mathrm{G}$ ), and control trials were those in which the distracters were pound signs (e.g., \# 5 \#). The second version used in this study, the arrows version, uses the same settings as the letters and numbers version, but replaces the aforementioned stimuli with arrows (e.g., $<<<<<$ ). Here, participants were asked to choose the keyboard arrow key corresponding to the orientation of the middle arrow (e.g. left arrow key for < $<<<<$; right arrow key for $<<><<$ ). The second version does not include control trials. The dependent measures were response time (RT) and number of errors for congruent trials, incongruent trials, and control trials (for version 1). Although Zeier et al. (2012)'s task version appears to be an improvement to the regular Flanker's task, the version without control trials has been used in more studies (Racer et al., 2011; Sellbom \& Verona, 2007).

\section{Penn Word Memory Test (PWMT; Gur et al., 1993)}

The PWMT is a measure of short and long-term episodic memory. Participants were presented with 20 target words ( $1500 \mathrm{~ms}$ of target cue, $1500 \mathrm{~ms}$ of target word) and were asked to try remembering them. Immediately after, participants were instructed to identify all previously seen words from a list comprising 40 words ( 20 words from the first list, 20 distracters). Participants were asked to answer using a two-forced choice response (left arrow if seen before, right arrow if not seen before). The target cue during the trial remained at $1500 \mathrm{~ms}$, and the trial auto-advanced to the next trial after $3000 \mathrm{~ms}$. At the very end of the study, which was approximately 15 minutes later, participants were presented a second list (20 words from the first list, 20 new distracters), and were asked to answer once again using the two-forced choice response. Distracters and target words were equated for frequency, length, concreteness, and imageability using Paivio's norms (i.e. moral, figment, event, prestige, hint, origin) (Paivio, Yuille, \& Madigan, 1968). RT to make a decision and number of errors were selected as performance measures. For analyses, PWMT1 refers to the first series of trials, measuring short-term recognition, and PWMT2 refers to the second and last series of trials, measuring long-term recognition. Across all cognitive tasks, participants with an error rate over $75 \%$ were automatically excluded from the data set. 


\section{Experimental Procedure}

All participants first completed the PWMT1, followed by the Go/No-Go, the nback task, and one of the two flanker tasks, in a random order. The last task for all participants was the PWMT2, as the task focuses on long term memory. Participants completed the cognitive tasks using the Gorilla platform (www.gorilla.sc). Although laboratory studies in the presence of an experimentor are often considered more reliable, recent evidence suggests that online behavioral experiments do not differ from laboratory studies, and provide results as valid as results obtained in laboratory settings (Hilbig, 2016; Semmelmann \& Weigelt, 2017). In order to exclude participants who stopped completing the tasks without closing the study page, we included various checkpoints in the experimental setup of the Gorilla platform. Participants with more than $75 \%$ of missing data were automatically removed. There was no missing data in any of the two questionnaires. For the analyses, we excluded RT trials answered in less than $150 \mathrm{~ms}$ or more than $1500 \mathrm{~ms}$ (2000 ms for PWMT1 and PWMT2). Errors rates for all cognitive tasks were recoded as zscores.

\section{Statistical Analyses}

We first computed the means and standard deviations for the questionnaires and cognitive tasks to ensure similarity with other studies using those instruments. T-test analyses were used to compare cognitive tasks' version efficacy for the n-back test, the flanker task, and the PWMT. A Pearson correlation was then used to determine the association's strength between the questionnaires and the cognitive tasks. Lastly, we performed a series of linear regression analyses. The purpose of these incremental validity analyses was to determine if the DAPTQ outperformed the PPI-I in predicting cognitive abilities. All incremental analyses were run twice. Once with the three subscales included in the PPI-I in the first block and the DAPTQ total in the second block, and once with the DAPTQ total in the first block and the three subscales of the PPI-I in the second block. PPI-I/DAPTQ Block 2 (see table 4) refers to the value of block 2 when the other scale was in block $1 . R^{2}$ Change PPI-I to DAPTQ refers to the adjusted $R^{2}$ difference when PPI-I was analyzed as block 1 and DAPTQ was analyzed as block 2 . $R^{2}$ Change DAPTQ to PPI-I refers to the opposite, when DAPTQ is block 1 and PPI-I is block 2. In all cases, the reported values are adjusted $R^{2}$. 


\section{Results}

\section{Descriptive Data}

Table 1 and Table 2 show the descriptive data of the questionnaires as well as all cognitive tasks. In the present study, the DAPTQ and the PPI-SF had similar means and standard deviations as other studies using those instruments (Durand, 2018a, 2018b, 2018c; Lee \& Salekin, 2010). Based on face validity, The n-back task provided similar results as those obtained by Schoofs, Preuß, and Wolf (2008). In their study, the mean RT for 2-back was $715 \mathrm{~ms}$ for control and $879 \mathrm{~ms}$ for stress group (compared to $809 \mathrm{~ms}$ in the present study), and the mean RT for the 3-back was $811 \mathrm{~ms}$ for control and $943 \mathrm{~ms}$ for stress group (compared to $881 \mathrm{~ms}$ in the present study). The go/nogo RT in the present study was also similar to the results obtained by Harper, Malone, and Bernat (2014), who reported mean reaction times between 445 $\mathrm{ms}$ and $451 \mathrm{~ms}$ (compared to $436 \mathrm{~ms}$ in the present study). Results in both versions of the present's study flanker tasks were also similar to results previously obtained. Indeed, Zeier, Baskin-sommers, and Newman (2012) reported mean RTs between $579 \mathrm{~ms}$ and $610 \mathrm{~ms}$ (compared to $589 \mathrm{~ms}$ to 603 $\mathrm{ms}$ in the present study), while Sellbom and Verona (2007) reported a mean of $499 \mathrm{~ms}$ (compared to $478 \mathrm{~ms}$ to $530 \mathrm{~ms}$ in the current study). As opposed to the previous tasks, mean RTs on the PWMT seem significantly faster in the present study, at around $800 \mathrm{~ms}$, compared to other studies with means around 1400 ms (Gur et al., 2012; Moore, Reise, Gur, Hakonarson, \& Gur, 2015).

\section{Comparability of Alternative Cognitive Tasks}

In order to assess the reliability of cognitive tasks with multiple paradigms, we first examined the mean differences between the two versions of the $n$-back task, the flanker tasks, and the PWMT. As expected, participants were significantly faster when answering the 2-back task compared to the 3-back task, $t(89)=6.382, p<.001, d=0.54$. Within answered trials, participants also made fewer mistakes in the 2-back task compared to the 3-back task, $t(89)=$ $6.65, p<.001, d=0.72$, most likely due to the simplicity of the 2 -back version compared to the 3-back. 
Table 1. Descriptive data of the Durand Adaptive Psychopathic Traits Questionnaire and the Psychopathic Personality Inventory Short Form $(\mathrm{N}=107)$

\begin{tabular}{lrr}
\hline DAPTQ & Mean & SD \\
Leadership & & \\
Logical Thinking & 13.14 & 4.56 \\
Composure & 21.14 & 4.47 \\
Creativity & 18.47 & 7.71 \\
Fearlessness & 16.36 & 4.79 \\
Focus & 16.88 & 6.33 \\
Extroversion & 12.84 & 4.80 \\
Management & 18.12 & 8.03 \\
Total & 11.78 & 3.49 \\
PPI-SF & 128.76 & 27.61 \\
Machiavellian Egocentricity & & \\
Social Potency & 14.12 & 3.57 \\
Fearlessness & 17.14 & 4.16 \\
Coldheartedness & 13.47 & 5.03 \\
Impulsive Nonconformity & 14.10 & 3.92 \\
Blame Externalization & 15.94 & 3.93 \\
Carefree Nonplanfulness & 13.28 & 4.98 \\
Stress Immunity & 14.74 & 2.90 \\
PPI-I & 17.64 & 3.72 \\
PPI-II & 48.27 & 9.97 \\
Total & 58.09 & 9.14 \\
\hline
\end{tabular}

Similarly to the n-back task, a few differences were observed between the two versions of the flanker task. In the numbers/letters version, control trials did not differ in terms of reaction time from the congruent trials $t(46)=$ $0.67, p=.504, d=0.05$. As expected, a small significant difference was however observed between RTs of congruent trials and incongruent ones, whereas congruent trials were answered faster than incongruent ones, $t(46)$ $=2.14, p=.038, d=0.15$. Interestingly, differences between trial types in the arrows version of the flanker task were larger. RT to answer congruent trials was significantly faster than the RT for incongruent trials, $t(53)=13.39, p$ $<.001, d=0.67$. Similarly, congruent trials elicited fewer mistakes than incongruent trials, $t(53)=5.70, p<.001, d=1.10$.

A significant mean difference was observed between RT of PWMT1 and PWMT2, $t(99)=2.08, p=.040, d=0.16$. There was no significant differences in terms of number of errors between PWMT1 and PWMT2, $t(98)=1.22, p$ $=.222, d=0.11$. 
Table 2. Descriptive data of the N-back, the Go/No-go, the flanker tasks, and the Pennsylvania Word Memory Test

\begin{tabular}{|c|c|c|c|}
\hline & $\mathrm{N}$ & Mean & SD \\
\hline \multicolumn{4}{|l|}{ N-back } \\
\hline 2-back RT & 96 & 809.11 & 151.8 \\
\hline 2-back errors & 96 & 3.89 & 3.71 \\
\hline 3-back RT & 93 & 881.11 & 156.39 \\
\hline 3-back errors & 93 & 7.06 & 5.26 \\
\hline \multicolumn{4}{|l|}{ Go no Go } \\
\hline RT & 107 & 436.26 & 73.15 \\
\hline Errors & 107 & 0.61 & 0.85 \\
\hline \multicolumn{4}{|c|}{ Flanker letters-numbers version } \\
\hline Control RT & 47 & 589.86 & 79.31 \\
\hline Congruent RT & 47 & 593.08 & 67.75 \\
\hline Incongruent RT & 47 & 603.15 & 66.1 \\
\hline Errors & 47 & 3.02 & 2.01 \\
\hline \multicolumn{4}{|l|}{ Flanker arrows version } \\
\hline Congruent RT & 54 & 478.65 & 73.95 \\
\hline Incongruent RT & 54 & 530.32 & 80.07 \\
\hline Errors congruent & 54 & 0.18 & 0.47 \\
\hline Errors incongruent & 54 & 2.18 & 2.52 \\
\hline \multicolumn{4}{|l|}{ PWMT } \\
\hline PWMT1 RT & 103 & 834.47 & 121.63 \\
\hline PWMT1 errors & 103 & 6.51 & 3.01 \\
\hline PWMT2 RT & 104 & 815.32 & 110.13 \\
\hline PWMT2 errors & 104 & 6.28 & 3.46 \\
\hline
\end{tabular}

Note. RT=reaction time. Participants were allocated to only one of the two Flanker task versions.

\section{Associations Between the DAPTQ, the PPI-SF, and Executive \\ Functions}

As shown in Table 3, Pearson correlations between the DAPTQ, the PPI-SF, and executive functions revealed multiple significant results. Similarly to results reported by Durand $(2017,2018 \mathrm{c})$, the DAPTQ was positively associated with PPI-SF and PPI-I, and significantly negatively associated with PPI-II. Higher score on the DAPTQ was associated with faster RT on the 2back and 3-back task, on control, congruent, and incongruent trials of the letters and numbers version of the flanker task, on congruent trials of the arrows version of the flanker task, and on the PWMT long term recall. Unexpectedly, the DAPTQ was also associated with higher error rate on the PWMT long-term recall, although the results were barely within the significance threshold $(p=.040)$. The PPI-SF total score was not associated with any variables related to executive functions. Higher scores on PPI-I were associated with faster RTs on the 2-back task, on control, congruent, and 
incongruent trials of the letters and numbers version of the flanker task, and on congruent trials of the arrows version of the flanker task. Lastly, PPI-II was associated with slower RT in incongruent trials for both the letter and number version and the arrows version of the flanker task, as well as slower RT on PWMT short term recall.

Table 3. Correlations between the Durand Adaptive Psychopathic Traits Questionnaire, the Psychopathic Personality Inventory Short Form, and executive functions

\begin{tabular}{|c|c|c|c|c|}
\hline Criterion & DAPTQ & PPI-SF & PPI-I & PPI-II \\
\hline \multicolumn{5}{|l|}{ Questionnaires } \\
\hline DAPTQ & - & - & - & - \\
\hline PPI-SF & $.53^{\star \star \star}$ & - & - & - \\
\hline PPI-I & $.77^{\star \star \star}$ & $.73^{\star \star \star}$ & - & - \\
\hline PPI-II & $-.19^{\star}$ & $.58^{\star \star *}$ & -.07 & - \\
\hline \multicolumn{5}{|l|}{ N-back } \\
\hline 2-back RT & $-.35^{\star \star *}$ & -.18 & $-.26^{* *}$ & .06 \\
\hline 2-back errors & -.05 & -.03 & -.08 & .08 \\
\hline 3-back RT & $-.32^{* \star}$ & -.15 & -.18 & .00 \\
\hline 3-back errors & .17 & .12 & .08 & .09 \\
\hline \multicolumn{5}{|l|}{ Go no Go } \\
\hline RT & -.03 & -.03 & -.10 & .01 \\
\hline Errors & -.07 & -.04 & -.05 & -.01 \\
\hline \multicolumn{5}{|c|}{ Flanker letters-numbers version } \\
\hline Control RT & $-.41^{\star *}$ & -.14 & $-.36^{*}$ & .24 \\
\hline Congruent RT & $-.41^{* *}$ & -.17 & $-.30^{*}$ & .16 \\
\hline Incongruent RT & $-.44^{\star \star}$ & -.10 & $-.35^{\star}$ & $.30^{*}$ \\
\hline Errors & .01 & .05 & .09 & .01 \\
\hline \multicolumn{5}{|l|}{ Flanker arrows version } \\
\hline Congruent RT & $-.33^{*}$ & -.06 & $-.29^{*}$ & .23 \\
\hline Incongruent RT & -.27 & .03 & -.23 & $.28^{*}$ \\
\hline Errors congruent & .03 & -.01 & .18 & -.14 \\
\hline Errors incongruent & .14 & -.01 & -.01 & -.07 \\
\hline \multicolumn{5}{|l|}{ PWMT } \\
\hline PWMT_1 RT & -.10 & .10 & -.03 & $.24^{*}$ \\
\hline $\mathrm{PWMT}^{-} 1$ errors & .16 & .00 & .04 & -.06 \\
\hline PWMT_2 RT & $-.20^{*}$ & -.06 & -.13 & .09 \\
\hline PWMT $^{-} 2$ errors & $.20^{*}$ & .12 & .13 & .04 \\
\hline
\end{tabular}

\section{Incremental Validity of the DAPTQ over the PPI-SF}

Table 4 reports the value of PPI-I and the DAPTQ in block 1 and their respective $p$ value, the value of the alternative questionnaire in block 2 , the change between blocks and the significance of the change for each of the two cases (PPI-I in block 1 and DAPTQ in block 2, and vice versa). Dependent variables which have shown at least one significant result at $p<.05$ in the 
Pearson correlation analyses were added in the incremental analyses. On its own, the DAPTQ was a significant predictor of the response time of all tasks, at the exception of PWMT1. Alternatively, the PPI-I was a predictor of response time for both n-back tasks, of the control and incongruent trials for the flanker letters-numbers version, and of PWMT1 and PWMT2. In no instances did the DAPTQ provide incremental validity over the PPI-I. Alternatively, the PPI-I only provided incremental validity over the DAPTQ on the response time of PWMT1.

\section{Discussion}

The purpose of the present study was to examine the relationship between adaptive personality traits related to the psychopathic personality and EF, and to assess the predictive value of the DAPTQ as a reliable predictor of EF in comparison to the PPI-SF.

Higher adaptive traits and psychopathic traits were associated with faster RT on working memory with high load (2-back task), but only adaptive traits were associated with a more difficult working memory task (3-back task). Interestingly, no significant results were observed regarding accuracy on the $n$-back task. These findings suggest that individuals with higher levels of adaptive traits did not compromise on accuracy while being more time efficient. Similar results were obtained in previous studies. For instance, high scorers on the interpersonal facet of the PCL-R, which corresponds to elements of arrogance and deceitful interpersonal style, exhibited more true positive responses on the 2-back task (Hansen, Johnsen, Thornton, Waage, \& Thayer, 2007). Furthermore, another research using the PPI supports the usage of a fast and accurate approach in highly psychopathic individuals to solve the Tower of Hanoi, a cognitive task assessing planning and working memory, as opposed to a slow and accurate approach preferred in individuals low in psychopathy (Salnaitis, Baker, Holland, \& Welsh, 2011). Another study also identified a correlation between PPI-I scores and faster reaction times on the rotated head task, a two alternative forced choice task (Carlson, Thái, \& McLarnon, 2009). Altogether, our results suggest that higher levels of adaptive traits and Fearless Dominance are associated with better performance in a working memory task without sacrificing accuracy for speed. 


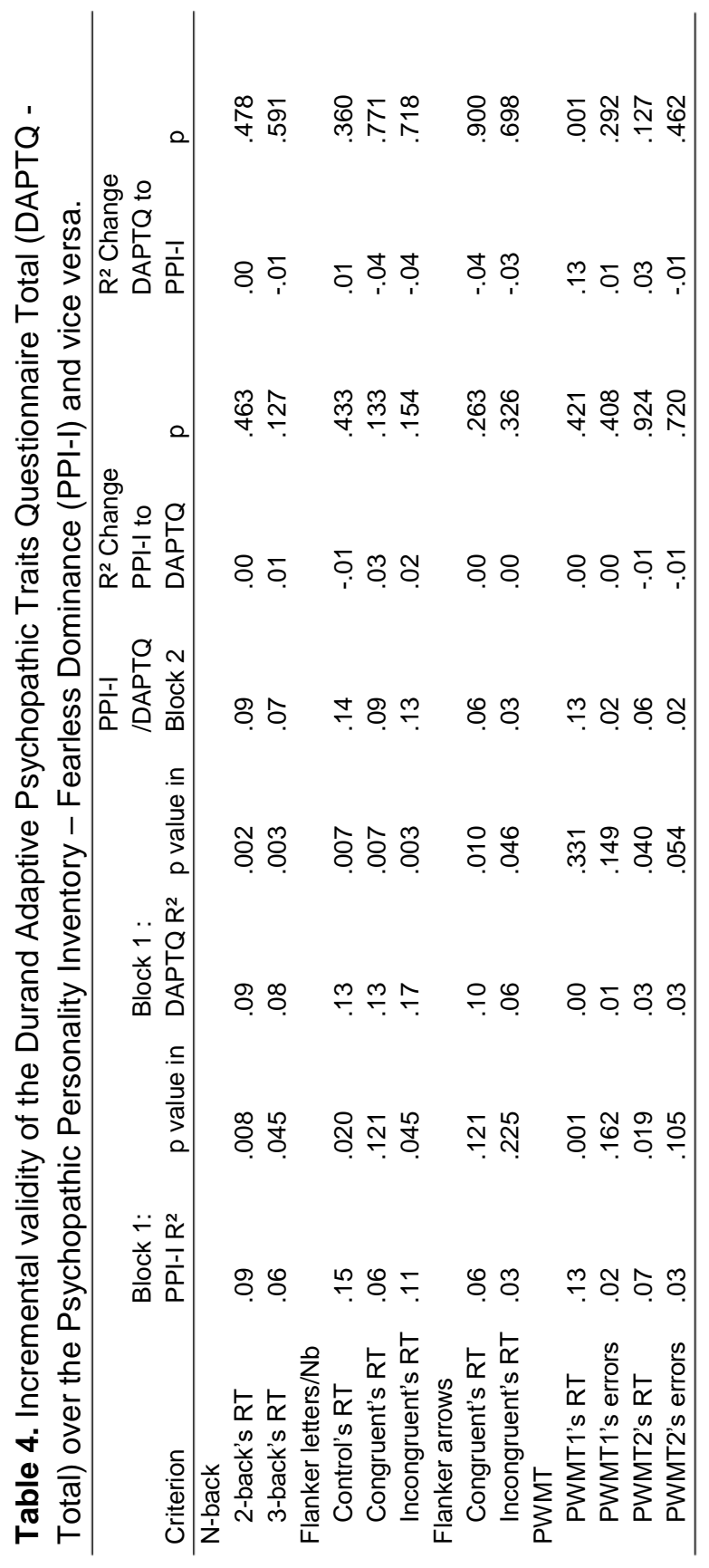


The results obtained on both versions of the flanker task further support past research regarding the benefits associated to Fearless Dominancerelated traits and the disadvantage of Impulsive Antisociality traits. For the letter and numbers version, high levels of adaptive traits and Fearless Dominance were associated with faster RTs on all trials, while being only associated with congruent trials in the arrows version. In contrast, impulsive antisocial traits were associated with slower incongruent trials on both flanker task versions. Impairment in response inhibition is one of the most recurrent reported problems among psychopathic individuals (Roussy \& Toupin, 2000; Wilkowski \& Robinson, 2008; Zeier et al., 2012). However, inhibitory control has often been negatively associated with psychopathy when viewing psychopathy as a whole. Studies differentiating the various aspects of psychopathy, for instance the behavioral aspects (e.g. social deviance, violent behavior), from the psychological aspects (e.g. callousness, low anxiety) find evidence that inhibitory control may be impaired in individuals showing high levels of the former, but not in individuals displaying traits of the latter. In fact, individuals showing traits of callousness and low anxiety may even outperform typically developing individuals in tasks of inhibitory control (Ross et al., 2007). Furthermore, while to our knowledge no studies have compared various version of the flanker task, the paradigm of the arrow version may be simply too easy to detect differences between scores on the DAPTQ and the PPI-SF. This hypothesis could explain why the results in our present study suggest a harder difficulty, as noted with a slower RT on all trials and a higher number of errors for all trials, in the letters and numbers version.

The results related to PWMT1 and PWMT2 were in line with our expectations on the PPI-II, but not from the DAPTQ. Similarly to both flanker tasks, Impulsive Antisociality was associated with slower RTs on PWMT1, but not on PWMT2. It is possible that higher levels of PPI-II are related to higher levels of doubts in one's answers and lower levels of motivation when completing the first task of the study. Many studies have associated high levels of psychopathic traits, particularly those associated to the PPI-II, with lower self-esteem (Durand, 2016; Falkenbach, Howe, \& Falki, 2013). Alternatively, low self-esteem has been associated with high neuroticism, which includes a host of factors, such as self-doubts and worry (Scheier, Carver, \& Bridges, 1994). In addition, while the DAPTQ has not been associated with error rates in any other task, adaptive traits were associated with faster RTs but a higher error rate on PWMT2. While it is possible that higher levels of adaptive traits are associated with reduced attention span toward the end of an experiment, causing more errors on the last task, the lack of significant association between adaptive traits and error rate in all 
previous tasks indicate a potential false positive due to limited power, especially due to the weak $p$ value $(p=.040)$.

Unexpectedly, no effects were found on the go/no-go task. An early study in the field of cognitive abilities in psychopathy reported that individuals with higher levels of psychopathic traits presented more difficulties inhibiting responding when facing a competing reward in a go/no-go paradigm (Lynam, Whiteside, \& Jones, 1999). A subsequent study replaced those results, where individuals classified as psychopathic responded more often to a no-go stimulus than nonpsychopathic individuals (Roussy \& Toupin, 2000). Although only the later study was categorical, it is possible that inhibition difficulties from a go/no-go paradigm are mostly present only in highly psychopathic individuals. An experiment focusing on groups of psychopathic individuals (low scorers and high scorers on the PPI-SF) should provide additional information regarding the relationship between the go/no-go task and psychopathy.

Although the results from the previous analyses support our hypotheses on the relationship between psychopathy and EF, we were not able to find support suggesting that the DAPTQ provides incremental validity over PPI-I in measuring EF. When placed in block 2 of the regression, in no instances did the DAPTQ provide a significant change to the model. Alternatively, PPI-I was able to increase the predictive power of the DAPTQ by a few percents on PWMT1 RT. These results indicate that, although both the DAPTQ and the PPI-I are able to independently contribute to the predicted variance of the nback task and flank task, none of these instruments provides additional benefits to the other one.

Comparison between alternative versions of specific cognitive tasks revealed additional results. The slower $\mathrm{RT}$ and the higher number of errors in the 3-back task compared to the 2-back task is similar to the results obtained by (Schoofs et al., 2008). These results indicate that the 3-back task may offer larger variability when examining group differences on working memory performances due to its increased difficulty compared to the 2-back task. Similarly, a few differences emerged between the two versions of the flanker task. In the numbers/letters version, participants were slower, especially in incongruent trials, and were making more mistakes in the latter. These results mirror those obtained by Zeier and colleagues (2012), who reported an effect size of $d=.34$ when comparing RT between congruent and incongruent trials. Alternatively, another study in the field of psychopathy, using arrows instead of letters as target stimuli, obtained an effect size between congruent and incongruent trials three times larger than the one aforementioned $(d=0.99$, Racer et al., 2011). These results suggest that using an arrow paradigm for 
the flanker task provides better results in discriminating between congruent trials and interfering stimuli. Lastly, differences were also identified in the PWMT. A previous study investigating the psychometric properties of a cognitive battery including the PWMT reported an absence of difference in RT $(d=0.01)$ and accuracy $(d=0.14)$ between immediate and delayed word memory (Gur et al., 2010). These results differ from ours, in that participants were faster to answer in the second time point, which could be due to a habituation effect. Repeating other tasks than the PWMT at different time points in a study could help determine if participants are only faster after doing the PWMT once, or if this is observed when repeating any task.

\section{Limitations and Conclusion}

There are several limitations to this study. First, our sample size was modest, which further tampers the results obtained on the flanker tasks. Considering half the participants performed one of the two versions, our results needs to be confirmed in a larger study including the letters and numbers version of the flanker task. Second, assessment of psychopathic traits was performed using a brief self-reported questionnaire, namely the PPI-SF. Third, our sample was very heterogeneous, which may further tamper the results due to our sample size. A future study focusing on a local group of participants (i.e. university students in one university) may provide different results. Lastly, while experiments using cognitive tasks often display hundreds of trials, each of our tasks used between 48 and 100 trials. While it provides a general idea of the relationship between the DAPTQ and EF, future studies will need to increase the number of trials, and most likely decrease the number of EF tasks in order to remain time-efficient.

This study adds to research on psychopathic traits and EF, and provides preliminary support regarding the association between the DAPTQ and EF. Specifically, adaptive traits and Fearless Dominance are associated with better performance on cognitive tasks, as observed through a faster response time and no difference in accuracy. Furthermore, while the DAPTQ was not able to provide incremental validity over the PPI-I when predicting cognitive abilities, both the DAPTQ and the PPI-I were independent predictors of cognitive abilities. Our findings further support the necessity to investigate psychopathy as a heterogeneous construct by exploring its various facets (i.e. both adaptive and maladaptive) such as the ones assessed by the DAPTQ, independently. 


\section{References}

Baskin-Sommers, A. R., Brazil, I. A., Ryan, J., Kohlenberg, N. J., Neumann, C. S., \& Newman, J. P. (2015). Mapping the association of global executive functioning onto diverse measures of psychopathic traits. Personality Disorders: Theory, Research, and Treatment, 6(4), 336-346.

Baskin-Sommers, A. R., Zeier, J. D., \& Newman, J. P. (2009). Self-reported attentional control differentiates the major factors of psychopathy. Personality and Individual Differences, 47(6), 626-630.

Benning, S. D., Patrick, C. J., Hicks, B. M., Blonigen, D. M., \& Krueger, R. F. (2003). Factor structure of the psychopathic personality inventory: validity and implications for clinical assessment. Psychological Assessment, 15(3), 340-350.

Berg, J. M., Smith, S. F., Watts, A. L., Ammirati, R., Green, S. E., \& Lilienfeld, S. O. (2013). Misconceptions regarding psychopathic personality: implications for clinical practice and research. Neuropsychiatry, 3, 63-74.

Camp, J. P., Skeem, J. L., Barchard, K., Lilienfeld, S. O., \& Poythress, N. G. (2013). Psychopathic predators? Getting specific about the relation between psychopathy and violence. Journal of Consulting and Clinical Psychology, 81(3), 467-480.

Carlson, S. R., Thái, S., \& McLarnon, M. E. (2009). Visual P3 amplitude and selfreported psychopathic personality traits: Frontal reduction is associated with selfcentered impulsivity. Psychophysiology, 46(1), 100-113.

Cleckley, H. (1941). The mask of sanity; an attempt to reinterpret the so-called psychopathic personality. Jama, 117(6), 493.

Cleckley, H. (1988). The Mask of Sanity: An Attempt to Clarify Some Issues About the So Called Psychopathic Personality. (W. a Dolan, Ed.) (5th ed.).

Coid, J., Freestone, M., \& Ullrich, S. (2012). Subtypes of psychopathy in the British household population: Findings from the national household survey of psychiatric morbidity. Social Psychiatry and Psychiatric Epidemiology, 47(6), 879-891.

Cooke, D. J., \& Michie, C. (2001). Refining the construct of psychopathy: towards a hierarchical model. Psychol. Assess., 13(2), 171-188.

Durand, G. (2016). A Replication of " Using self-esteem to disaggregate psychopathy, narcissism, and aggression (2013) ." The Qantitative Methods for Psychology, 12(2), r1-r5.

Durand, G. (2018a). A French translation and validation of the Durand Adaptive Psychopathic Traits Questionnaire: An investigation with community samples from France and Canada. PLOS ONE, 13(9), e0204214.

Durand, G. (2018b). Demystification of the Relationship Between Psychopathy and Happiness. Journal of Happiness Studies, 19(2), 381-395,

Durand, G. (2018c). Incremental validity of the Durand Adaptive Psychopathic Traits Questionnaire above self-report psychopathy measures in community samples. Journal of Personality Assessment. 
Durand, G. (2017). The Durand Adaptive Psychopathic Traits Questionnaire: Development and Validation. Journal of Personality Assessment, 1-10.

Durand, G., \& Plata, E. M. (2017). The effects of psychopathic traits on fear of pain , anxiety , and stress. Personality and Individual Differences, 119(C), 198-203.

Eriksen, B. A., \& Eriksen, C. W. (1974). Effects of noise letters upon the identification of a target letter in a nonsearch task. Perception \& Psychophysics.

Falkenbach, D. M., Howe, J. R., \& Falki, M. (2013). Using self-esteem to disaggregate psychopathy, narcissism, and aggression. Personality and Individual Differences, 54(7), 815-820.

Gur, R. C., Jaggi, J. L., Ragland, J. D., Resnick, S. M., Shtasel, D., Muenz, L., \& Gur, R. E. (1993). Effects of memory processing on regional brain activation: cerebral blood flow in normal subjects. The International Journal of Neuroscience, 72(12), 31-44.

Gur, R. C., Richard, J., Calkins, M. E., Chiavacci, R., Hansen, J. A., Bilker, W. B., ... Gur, R. E. (2012). Age group and sex differences in performance on a computerized neurocognitive battery in children age 8-21. Neuropsychology, 26(2), 251-265.

Gur, R. C., Richard, J., Hughett, P., Calkins, M. E., Macy, L., Bilker, W. B., ... Gur, R. E. (2010). A cognitive neuroscience based computerized battery for efficient measurement of individual differences: Standardization and initial construct validation. Journal of Neuroscience Methods, 187(2), 254-262.

Hall, J., Benning, S. D., \& Patrick, C. J. (2004). Criterion-Related Validity of the ThreeFactor Model of Psychopathy: Personality, Behavior, and Adaptive Functioning. Assessment, 11(1), 4-16.

Hansen, A. L., Johnsen, B. H., Thornton, D., Waage, L., \& Thayer, J. F. (2007). Facets of Psychopathy, Heart Rate Variability and Cognitive Function. Journal of Personality Disorders, 21(5), 568-582.

Hare, R. D. (1965). Psychopathy, Fear Arousal and Anticipated Pain. Psychological Reports, 16, 499-502.

Hare, R. D. (1966). Psychopathy and choice of immediate versus delayed punishment. Journal of Abnormal Psychology, 71, 25-29.

Hare, R. D. (1991). The Hare Psychopathy Checklist-revised (MultiHealt). Toronto.

Hare, R. D. (2003). The Hare Psychopathy Checklist- Revised. Muliti-Health Systems.

Hare, R. D., \& Thorvaldson, S. A. (1970). Psychopathy and response to electrical stimulation. Journal of Abnormal Psychology, 76, 370-374.

Harper, J., Malone, S. M., \& Bernat, E. M. (2014). Theta and delta band activity explain N2 and P3 ERP component activity in a go/no-go task. Clinical Neurophysiology, 125(1), 124-132.

Hilbig, B. E. (2016). Reaction time effects in lab- versus Web-based research: Experimental evidence. Behavior Research Methods, 48(4), 1718-1724.

Lee, Z., \& Salekin, R. T. (2010). Psychopathy in a noninstitutional sample: Differences in primary and secondary subtypes. Personality Disorders: Theory, Research, 


\section{Chapter $\mathbf{1 0}$ | Cognitive Abilities and Adaptive Psychopathy}

and Treatment, 1(3), 153-169.

Lilienfeld, S. O., \& Andrews, B. P. (1996). Development and Preliminary Validation of a Self-Report Measure of Psychopathic Personality Traits in Noncriminal Populations. Journal of Personality Assessment, 66(3), 488-524.

Lilienfeld, S. O., Patrick, C. J., Benning, S. D., Berg, J., Sellbom, M., \& Edens, J. F. (2012). The role of fearless dominance in psychopathy: Confusions, controversies, and clarifications. Personality Disorders: Theory, Research, and Treatment, 3(3), 327-340.

Lilienfeld, S. O., Watts, A. L., \& Smith, S. F. (2015). Successful Psychopathy: A Scientific Status Report. Current Directions in Psychological Science, 24(4), 298-303.

Lilienfeld, S. O., \& Widows, M. (2005). Psychopathic personality inventory-revised: Professional manual. Lutz, FL: Psychological Assessment Resources.

Lynam, D. R., \& Miller, J. D. (2012). Fearless dominance and psychopathy: A response to Lilienfeld et al. Personality Disorders: Theory, Research, and Treatment, 3(3), 341-353.

Lynam, D. R., Whiteside, S., \& Jones, S. (1999). Self-reported psychopathy: A validation study. Journal of Personality Assessment, 73(1), 110-132.

Moore, T. M., Reise, S. P., Gur, R. E., Hakonarson, H., \& Gur, R. C. (2015). Psychometric properties of the Penn Computerized Neurocognitive Battery. Neuropsychology, 29(2), 235-246.

Paivio, A., Yuille, J. C., \& Madigan, S. A. (1968). Concreteness, imagery, and meaningfulness values for 925 nouns. Journal of Experimental Psychology, 76(1, Pt.2), 1-25.

Patrick, C. J. (2010). Operationalizing the Triarchic conceptualisation of psychopathy: Preliminary description of brief scales for assessment of boldness, meanness, and disinhibition. PhenX Toolkit Online Assessment Catalog.

Patrick, C. J., Fowles, D. C., \& Krueger, R. F. (2009). Triarchic conceptualization of psychopathy: Developmental origins of disinhibition, boldness, and meanness. Development and Psychopathology, 21(3), 913.

Patrick, C. J., Venables, N. C., \& Drislane, L. E. (2013). The role of fearless dominance in differentiating psychopathy from antisocial personality disorder: comment on Marcus, Fulton, and Edens. Personality Disorders, 4(1), 80-2.

Polaschek, D. L. L., \& Daly, T. E. (2013). Treatment and psychopathy in forensic settings. Aggression and Violent Behavior.

Poythress, N. G., Edens, J. F., Skeem, J. L., Lilienfeld, S. O., Douglas, K. S., Frick, P. J., ... Wang, T. (2010). Identifying subtypes among offenders with antisocial personality disorder: a cluster-analytic study. Journal of Abnormal Psychology, 119(2), 389-400.

Racer, K. H., Gilbert, T. T., Luu, P., Felver-Gant, J., Abdullaev, Y., \& Dishion, T. J. (2011). Attention Network Performance and Psychopathic Symptoms in Early Adolescence: An ERP Study. Journal of Abnormal Child Psychology, 39(7), 1001-1012. 


\section{Cognitive Abilities and Adaptive Psychopathy | Chapter 10}

Ribeiro da Silva, D., Rijo, D., \& Salekin, R. T. (2015). The evolutionary roots of psychopathy. Aggression and Violent Behavior, 21, 85-96.

Ross, S. R., Benning, S. D., \& Adams, Z. (2007). Symptoms of Executive Dysfunction are Endemic to Secondary Psychopathy: An Examination in Criminal Offenders and Noninstitutionalized Young Adults. Journal of Personality Disorders, 21(4), 384-399.

Roussy, S., \& Toupin, J. (2000). Behavioral inhibition deficits in juvenile psychopaths. Aggressive Behavior, 26(6), 413-424.

Sadeh, N., \& Verona, E. (2008). Psychopathic personality traits associated with abnormal selective attention and impaired cognitive control. Neuropsychology, 22(5), 669-680.

Salnaitis, C. L., Baker, C. a, Holland, J., \& Welsh, M. (2011). Differentiating Tower of Hanoi performance: interactive effects of psychopathic tendencies, impulsive response styles, and modality. Applied Neuropsychology, 18(1), 37-46.

Scheier, M. F., Carver, C. S., \& Bridges, M. W. (1994). Distinguishing optimism from neuroticism (and trait anxiety, self-mastery, and self-esteem): A reevaluation of the Life Orientation Test. Journal of Personality and Social Psychology, 67(6), 1063-1078.

Schoofs, D., Preuß, D., \& Wolf, O. T. (2008). Psychosocial stress induces working memory impairments in an n-back paradigm. Psychoneuroendocrinology, 33(5), 643-653.

Sellbom, M., \& Verona, E. (2007). Neuropsychological correlates of psychopathic traits in a non-incarcerated sample. Journal of Research in Personality, 41(2), 276294.

Semmelmann, K., \& Weigelt, S. (2017). Online psychophysics: reaction time effects in cognitive experiments. Behavior Research Methods, 49(4), 1241-1260.

Skeem, J. L., Polaschek, D. L. L., Patrick, C. J., \& Lilienfeld, S. O. (2011). Psychopathic Personality: Bridging the Gap Between Scientific Evidence and Public Policy. Psychological Science in the Public Interest, 12(3), 95-162.

Snowden, R. J., Gray, N. S., Pugh, S., \& Atkinson, G. (2013). Executive function as a function of sub-clinical psychopathy. Personality and Individual Differences, 55(7), 801-804.

Uzieblo, K., Verschuere, B., Van den Bussche, E., \& Crombez, G. (2010). The validity of the psychopathic personality inventory--revised in a community sample. Assessment, 17(3), 334-346.

Viding, E. (2004). Annotation: Understanding the development of psychopathy. Journal of Child Psychology and Psychiatry and Allied Disciplines.

Visser, B. a., Ashton, M. C., \& Pozzebon, J. a. (2012). Is Low Anxiety Part of the Psychopathy Construct? Journal of Personality, 80(3), 725-747.

Walters, G. D., Brinkley, C. a, Magaletta, P. R., \& Diamond, P. M. (2008). Taxometric analysis of the Levenson Self-Report Psychopathy scale. Journal of Personality Assessment, 90(5), 491-498. 


\section{Chapter 10 | Cognitive Abilities and Adaptive Psychopathy}

Wilkowski, B. M., \& Robinson, M. D. (2008). Putting the brakes on antisocial behavior: Secondary psychopathy and post-error adjustments in reaction time. Personality and Individual Differences, 44(8), 1807-1818.

Yildirim, B. O., \& Derksen, J. J. L. (2015). Clarifying the heterogeneity in psychopathic samples: Towards a new continuum of primary and secondary psychopathy. Aggression and Violent Behavior, 24, 9-41.

Zágon, I. K., \& Jackson, H. J. (1994). Construct validity of a psychopathy measure. Personality and Individual Differences, 17(I), 125-135.

Zeier, J. D., Baskin-sommers, A. R., \& Newman, J. P. (2012). Cognitive Control Deficits Associated with Antisocial Personality Disorder and Psychopathy. Personal Disord., 3(3), 283-293.

Zimak, E. H., Suhr, J., \& Bolinger, E. M. (2014). Psychophysiological and Neuropsychological Characteristics of Non-Incarcerated Adult Males with Higher Levels of Psychopathic Personality Traits. Journal of Psychopathology and Behavioral Assessment. 


Chapter 11

General Discussion 

The preceding chapters investigated the relationship between a variety of adaptive characteristics and psychopathic traits, as well as the reliability and validity of the Durand Adaptive Psychopathic Traits Questionnaire (DAPTQ). Overall, the results support the necessity to investigate adaptive constructs by subtypes and multiple dimensions rather than by considering psychopathy as a unidimensional construct, for example multiple results significantly diverge between Fearless Dominance and Impulsive Antisociality (Durand, 2018b; Durand \& Plata, 2017; Durand, Plata, \& Arbone, 2017). The DAPTQ also significantly improved the incremental validity of the Psychopathic Personality Inventory - Short Form (PPI-SF; Lilienfeld \& Widows, 2005) and the Triarchic Psychopathy Measure (TriPM; Patrick, 2010) on several constructs related to adaptive personality (Durand, 2018c). The results in my thesis have several implications and should be placed in the context of other findings and conceptual development in the field.

\section{Importance of Investigating Psychopathy by Subtypes}

Although recent research in the field of psychopathy tend to report findings by subtypes characterised by high or low scores on specific dimensional quantitative phenotypes, early research regularly presented psychopathy as a unidimensional construct. The series of studies performed prior to the development of the DAPTQ focused on determining if there were indeed positive aspects related to the concept of psychopathy despite previous conclusions. For instance, Love and Holder (2014) reported a negative relationship between psychopathy and life satisfaction, happiness, and positive affect, and a positive relationship between psychopathy and depression and negative affect. However, in their study, the authors used the Levenson Self-Report Psychopathy (LSRP; Levenson, Kiehl, \& Fitzpatrick, 1995). Investigations of the validity of the LSRP reported that this instrument captures more traits related to antisocial personality disorder (ASPD) than to psychopathy (Lilienfeld \& Fowler, 2006). Psychopathy is a similar, yet different construct than ASPD. While both have similarities (e.g. impulsivity, irresponsibility, lack of remorse), psychopathy has been connected to interpersonal traits (e.g. empathy deficits, shallow moral emotions, social potency, anxiety resilience, and venturesomeness) not present in ASPD (Berg et al., 2013; Murphy, Lilienfeld, Skeem, \& Edens, 2016). Additionally, the LSRP does not include elements related to bold interpersonal features, such as social potency and stress resilience (Patrick, 2010; Poythress et al., 2010; Sellbom \& Phillips, 2013; Witt, Donnellan, Blonigen, Krueger, \& Conger, 2009). Altogether, these results can explain why a different conclusion emerges when investigation the relationship between psychopathy and happiness 


\section{Chapter 11 | General Discussion}

through the conceptualization of the PPI, as was done in the Chapter 2 of the current thesis (Durand, 2018b). While the PPI-I was associated with adaptive features (e.g. happiness, personal growth), the Impulsive-Antisociality (PPI-II) scale was associated with maladaptive features (e.g. unhappiness, lack of personal growth). These opposite results obtained with PPI-I and PPI-II also resulted in a lack of significant correlation on several variables when compared to PPI-SF Total, as the effect of PPI-I and PPI-Il cancelled each other in most instances (i.e. personal growth was significantly associated to PPI-I, $r=.35$, to PPI-II, $r=-33$, but not to PPI-SF Total, $r=-.02$, Durand, $2018 b)$. Similar opposite patterns where variables related to fear of pain, stress, and anxiety correlated negatively with PPI-I and positively with PPI-II were also observed in Chapter 3 (Durand \& Plata, 2017). Thus, the results support the multidimensional nature of the psychopathy construct, and provide evidences for the need to analyze results related to psychopathy by subtypes and dimensions.

\section{Adaptive Traits in Psychopathy}

The DAPTQ was developed with the premise that measuring adaptive traits within psychopathic individuals required an instrument assessing a wider range of characteristics than those assessed in the PPI and the TriPM. In Durand (2017), adaptive traits were defined as "a trait that maximizes an individual's survival probability within a set environment", which is based on the definition from Dobzhansky (1956). Based on this definition, it is debatable if maximizing one's survival probability refers to the individual personally or socially. Enjoying constant solitude, for example, could be adaptive on the basis that it increases the chance of survival from a personal point of view, such as by not being exposed to germs and contaminant from other individuals, but would be maladaptive from a social point of view. Similarly, individuals with higher levels of psychopathic traits have been found to have a preference for discarding relationships with no common grounds (Gervais, Kline, Ludmer, George, \& Manson, 2013). Selecting very specific individuals to be part of one's social circle and discarding others may be considered adaptive from a personal point of view, by feeling supported and loved by close ones, but would also be maladaptive from a social perspective.

During the DAPTQ's development, any "adaptive" construct, whether personal, social, or both, was included in the first study of Chapter 7. Study one and study two examined the reliability of each construct, study three performed an exploratory factor analysis and a parallel analysis, and study four provided further construct validation. Subsequently, study one and study two of Chapter $\mathbf{8}$ and Chapter $\mathbf{9}$ provided additional construct validation for 
the DAPTQ, which provided support for a final eight factors solution, including the factors Leadership, Logical Thinking, Composure, Creativity, Fearlessness, Focus, Extroversion, and Management (Durand, 2017, 2018c, 2018a). Subjectively, all eight factors included in the DAPTQ can be considered adaptive from a personal and social perspective.

In order to objectively consider the DAPTQ's factors as adaptive traits, there must be sufficient evidence that each factor is adaptive from a personcentered and social viewpoint. Three factors from the DAPTQ, namely Fearlessness, Extroversion, and Composure are conceptually the same factors from the PPI included in Fearless Dominance, namely Fearlessness, Social Potency, and Stress Immunity (Benning, Patrick, Hicks, Blonigen, \& Krueger, 2003). The Fearlessness factors $(r=.59)$, the Extroversion and Social Potency factors $(r=.77)$, and the Composure and Stress Immunity factors $(r=.61)$ are strongly correlated (Durand, 2017).

From a person-centered point of view, Fearless Dominance showed a negative association with self-harm and suicidal tendencies (Blagov, Patrick, Oost, Goodman, \& Pugh, 2015), as well as resilience to pain from electricity (Hare, 1968). Studies have also related Fearless Dominance with lower levels of neuroticism, depression, self-esteem, and anxiety (Blagov et al., 2015), with lower levels of traits related to borderline personality disorder (Falkenbach, Stern, \& Creevy, 2014), with higher levels of happiness, personal growth, and hope in life (Durand, 2018b), as well as with higher levels of self-esteem (Durand, 2016). From a social point of view, Fearless Dominance has been related to lower levels of indirect aggression (Uzieblo, Verschuere, Van den Bussche, \& Crombez, 2010), lower levels of attachment avoidance (Christian, Sellbom, \& Wilkinson, 2016), higher levels of friendliness and cheerfulness (Donnellan \& Burt, 2016), and higher levels of emotional and social intelligence (Sacco, Merold, Lui, Lustgraaf, \& Barry, 2016). Although it is undeniable that Fearless Dominance is also related to some maladaptive features, such as taking higher risks when driving (Panayiotou, 2015) and minor delinquencies (Uzieblo et al., 2010), the aforementioned results nevertheless support that this construct also harbours positive aspects.

The remaining DAPTQ's factors, namely Leadership, Logical Thinking, Creativity, Focus, and Management, are personality traits that have not yet been extensively researched in the field of psychopathy. Leadership has been associated with traits such as emotional stability, extraversion, openness to experience, agreeableness, and conscientiousness (Judge, Bono, llies, \& Gerhardt, 2002), as well as proactive personality (Crant \& Bateman, 2000). Logical thinking is an important cognitive function needed to perform optimally on various tasks requiring reasoning abilities to achieve a conclusion through 
facts rather than emotions (Schiebener, Zamarian, Delazer, \& Brand, 2011). Early research in the field did not find associations between logical thinking and personality maladjustments (Garett \& Wulf, 1978). Creativity has been associated with extroversion and openness (Kelly, 2006), and is regarded as an important personality trait from both a person-centered and a social perspective (Kaufman, 2012). Focus, also referred to as attentional control, is an important component of cognitive control, which has been associated with mindfulness, anxiety resilience, and openness (Walsh, Balint, Smolira SJ, Fredericksen, \& Madsen, 2009; Weissman, Mangun, \& Woldorff, 2002). Lastly, management abilities have been associated with better health and lower depressive symptoms (Cramm \& Nieboer, 2012), better conflict resolution abilities (Whetten \& Cameron, 2006), and increased employability (Bridgstock, 2009). Overall, although some personality traits included in the DAPTQ can, under specific circumstances, have a negative impact on personal or social perspectives, the eight factors remain nevertheless predominantly beneficial, positive, and adaptive from a personal and social point of view.

\section{Value of the DAPTQ Over Existing Measures}

As mentioned previously, while the PPI and the TriPM include traits which can be considered adaptive as part of their conceptualization of psychopathy, these instruments only cover a subset of adaptive traits known to correlate with psychopathy. Stress Immunity, Fearlessness, and Social Potency are three factors from the PPI conceptualized as Composure, Fearlessness, and Extroversion in the DAPTQ (Durand, 2018c; Lilienfeld \& Andrews, 1996). However, none of the other five favors of the DAPTQ, such as Leadership, are included in the PPI or the TriPM. Multiple studies did investigate however the association between PPI-I and leadership. When examining the personality traits of the last 42 U.S. presidents through political experts, the researchers found that PPI-I was positively related with better presidential performance, leadership, persuasiveness, crisis management, and allied variables (Lilienfeld et al., 2012). Another study reported that higher levels of PPI-I were predictive of higher corporate ranks (Howe, Falkenbach, \& Massey, 2014). The authors also hypothesized that a healthy level of psychopathy may contribute to the success of one's career. A subsequent study further supported the association between higher levels of PPI and PPI-I with the number of leadership positions and managerial positions held over one's lifetime (Lilienfeld, Latzman, Watts, Smith, \& Dutton, 2014). Although traits such as Fearlessness and Social Potency are highly debated regarding their inclusion as core features of psychopathy, leadership skills appear to be 
nonetheless concomitants features of adaptive traits observed in some psychopathic individuals (Skeem, Polaschek, Patrick, \& Lilienfeld, 2011).

Multiple studies have investigated the role of logical thinking within individuals diagnosed with psychopathy. Early studies reported that individuals with psychopathy showed higher levels of moral reasoning than nonpsychopathic individuals on the Kohlberg's Moral Judgment Scale, which may relate to their ability to evaluate situations through facts rather than through emotions (Link, Scherer, \& Byrne, 1977). Psychopathic individuals have also been found to prefer pragmatic and utilitarian decisions, which is in turn associated with logical and rational thinking (Bartels \& Pizarro, 2011; Greene, Sommerville, Nystrom, Darley, \& Cohen, 2001). Alternatively, multiple personality studies identified a negative relationship between Fearless Dominance and the neuroticism scale of the Big Five (Benning, Patrick, Salekin, \& Leistico, 2005; Durand, 2018c; Ross, Benning, Patrick, Thompson, \& Thurston, 2009; Ruchensky, Edens, Donnellan, \& Witt, 2017). Similarly to capacity of leadership skills, logical thinking capacity appears to be related to psychopathy as well. However, due to the lack of research regarding its role in the field of psychopathy, it is not possible to consider logical thinking as a core component of psychopathy.

Creativity, focus, and management are three other traits that are represented in the DAPTQ and that are not present in the PPI or the TriPM. Higher levels of psychopathy have previously been associated with creativity and numerous creative domains, such as creative writing, drama, architecture, humor, scientific discovery, and invention (Galang, Castelo, Santos, Perlas, \& Angeles, 2016; Jonason, Richardson, \& Potter, 2015). Psychopathic traits have also been associated with entrepreneurial creativity (Akhtar, Ahmetoglu, \& Chamorro-Premuzic, 2013). Research further suggest that individuals scoring high on psychopathy considered themselves as creative, but that they were also seen as creative and innovative individuals by their peers in corporate settings (Babiak, Neumann, \& Hare, 2010). Research on focus in psychopathy also found benefits in some components of psychopathy, whereas two components of psychopathy, namely Fearless Dominance from the PPI and Factor 1 from the PCL-R, were associated with superior attentional control, superior focus, and less shifting of attention (BaskinSommers, Zeier, \& Newman, 2009). Lastly, as mentioned previously, higher levels of PPI-I have been associated to management responsibilities (Lilienfeld et al., 2014). As opposed to leadership, research in the field of psychopathy related to creativity, focus, and management has been scarce, despite the first wave of findings, further supporting the utility of the DAPTQ as an extension of the PPI and the TriPM to investigate adaptive constructs. 
Nevertheless, these preliminary results support the association between the DAPTQ and other constructs potentially related to the psychopathic personality under-represented in other measures of psychopathic traits.

\section{Consistency of the DAPTQ Between Studies of this Thesis}

The DAPTQ went through several changes over its validation as described in the Chapters of my thesis, and an 11-factor structure emerged from an exploratory factor analysis followed by a parallel analysis (Durand, 2017). Out of these factors, one was removed during the development and validation trajectory within the following study due to its lack of positive association with the DAPTQ Total and PPI-I, namely 'Similarity'. This factor was related to discarding individuals who do not share one's values (Gervais et al., 2013). While this factor can be considered adaptive from a person-centered point of view (i.e. by not being challenged by anyone in one's social circle), requiring similarity may not be adaptive from a social perspective. A following study reported an absence of relationship between 'Consequentialism' and DAPTQ Total. Consequentialism refers to the doctrine 'the end justifies the means', and similarly to the Similarity factor, the factor may not be adaptive from a social perspective, despite being adaptive from a personal one.

The revised 9-factor version of the DAPTQ was further explored in two studies from Chapter $\mathbf{8}$ assessing its incremental validity over the PPI-SF and the TriPM (Durand, 2018c). The results supported the removal of the 'Money Smart' subscale, which items were an artifact of the Management items originally included during the development of the DAPTQ. Further exploratory analysis did not support merging the items from the 'Money Smart' scale with those of the Management scale, and the items related to the factor were removed.

Subsequently, two studies from Chapter 9 used the 8-factor solution of the DAPTQ without suggesting any factor's removal. The study pertaining the French translation of the DAPTQ reported near identical means for the DAPTQ between the English version $(M=135.80)$ and the French version $(M$ $=135.05$ ) within a sample of individuals completing both versions (Durand, 2018a). A second sample from the same study reported a mean score of $M=$ $126.71, S D=22.88$ on the DAPTQ French version. While the results differ by a few points within the two samples, the mean of the second sample is similar to the results reported by Durand, Rutten, and Lobbestael (submitted), with a mean of $M=128.76, S D=27.61$.

While the small difference may be based on several possible factors, it should be noted that it is fairly common to obtain a few points of discrepancy between mean scores across studies. Studies focusing on the PPI-SF in 
nonclinical populations reported averages of $M=122.13$ (Gao \& Tang, 2013), $M=123.89$ (Lee \& Salekin, 2010), $M=123.94$ (Watts et al., 2016), $M=125.65$ (Murray, Wood, \& Lilienfeld, 2012), $M=127.50$ (Mullins-Nelson, Salekin, \& Leistico, 2006), $M=130.66$ (Durand, 2016), $M=134.73$ (Lilienfeld et al., 2014). These differences could be due to the type of population studied. For instance, both the PPI-SF and the DAPTQ reported gender difference on the total score as well as on several subscales (Durand, 2017; Lee \& Salekin, 2010). The proportion of males and females within a study could therefore affect the total score for the total sample by a few points.

\section{Assessing Adaptive Traits from a Behavioral and Biological Approach}

Stress resilience is one of the most common traits examined in the field of adaptive psychopathic traits (Durand \& Plata, 2017; Lilienfeld \& Andrews, 1996; Smith, Edens, \& Vaughn, 2011). The effect of stress has been found to influence multiple psychological and physiological processes within human populations (Giles, Mahoney, Brunyé, Taylor, \& Kanarek, 2014). Among other mental functions, decline of cognitive performances, such as working memory and cognitive flexibility, was found to be significantly related with increases of acute stress (Alexander, Hillier, Smith, Tivarus, \& Beversdorf, 2007; Schoofs, Preuß, \& Wolf, 2008; Shields, Sazma, \& Yonelinas, 2016).

Several studies support the role of EEG alpha power asymmetry and theta/beta ratio as markers of stress resilience (Angelidis, van der Does, Schakel, \& Putman, 2016; Brouwer, Neerincx, Kallen, van der Leer, \& ten Brinke, 2011; Debener et al., 2000; Putman, Verkuil, Arias-Garcia, Pantazi, \& van Schie, 2014). However, while these results are derived from the operationalisation of stress resilience via measurements of lower cortisol in saliva and self-reported stress, none of these studies specifically measured the absence of decline in cognitive performances as a marker of stressresilience. Other studies have examined the role of neuropeptide-Y (NPY) and dehydroepiandrosterone (DHEA): while cortisol, NPY and DHEA were all increased following stress exposure, greater levels of NPY and DHEA were associated with lower psychological distress and reported stress (Morgan et al., 2001, 2002; Morgan, Rasmusson, Pietrzak, Coric, \& Southwick, 2009; Shields, Lam, Trainor, \& Yonelinas, 2016).

Altogether, these studies support our findings from Chapter 6 suggesting that genetic variation involved in a range of biological processes moderated cognitive abilities under stress (Durand and Rutten, unpublished), and from Chapter 10 that cognitive abilities did not correlate strongly with psychopathyrelated personality traits (Durand, Rutten, and Lobbestael, submitted). 


\section{Overall Findings}

The nine Chapters presented in this thesis report novel findings in the field of psychopathy. Chapter 2 reported on gender differences: whereas males scored higher than females on the PPI-SF Total, PPI-I, inner peace, and planning to meet goals, and females scored higher on fluctuating happiness (Durand, 2018b). The PPI-I was associated with higher levels of stable happiness, lower levels of fluctuating happiness, presence of a goal in life, personal growth, and hope. As opposed to it, the PPI-II was associated with lower levels of stable happiness, higher levels of fluctuating happiness, lack of a meaning in life, search of a meaning in life, lower personal growth, and lower hope in life. Similarly, Chapter 3 also reported gender differences: whereas males scored higher than females on the PPI-SF Total, PPI-I, and PPI-II (Durand \& Plata, 2017), females scored higher on fear of pain, pain catastrophization, anxiety, and perceived stress. Overall, PPI-I was associated with lower scores on fear of pain, lower scores on pain catastrophization, lower state and trait anxiety, and lower perceived stress. Alternatively, PPI-II was associated with higher pain catastrophization, higher anxiety, and higher perceived stress. Chapter 4 focused on how one's level of psychopathic traits influence his/her own stigma against psychopaths (Durand et al., 2017). Boldness, which relates to the PPI-I factor, was associated with a weaker belief that psychopaths are prone to violence and are dangerous. Higher levels of Boldness were also associated with a higher likelihood of helping a psychopath in need, as well as with less negative emotions towards psychopaths. Similarly, Meanness and Disinhibition, which are reflective of PPI-II, were associated with lower beliefs that psychopaths are prone to crime, lower beliefs that psychopaths are criminals, and lower negative emotions towards psychopaths. Chapter 5 investigated the relationship between gender, parental behaviors, childhood maltreatment, and psychopathic traits (Durand \& de Calheiros Velozo, 2018). While males displayed higher levels in scores on TriPM Total, Meanness, and Boldness, females displayed higher levels of emotional abuse, sexual abuse, physical neglect, and rejection from mother during their childhood. Overall, Boldness was associated with lower levels of emotional abuse and emotional neglect during childhood, while Disinhibition was associated with higher levels of childhood trauma and parental neglect.

Chapter 6, while not directly related to psychopathy, focused on the contribution of genetic factors in cognitive abilities under mild stress (Durand and Rutten, unpublished). The results supported a possible association between the polymorphisms in genes encoding FKBP5, COMT, SNAP-25, 
BDNF, DAT1, and the cortisol receptor with better cognitive abilities under a mild psychosocial stress.

Chapter 7 was the debut of a series of studies dedicated to the development and the validation of the DAPTQ (Durand, 2017). Study one, two, and three from Chapter 7 focused on developing the DAPTQ. Study four reported an association between the DAPTQ and higher levels of extroversion, agreeableness, conscientiousness, openness, thinking analytically, enjoyment of thinking analytically, intuitive feelings, and taking risks, and was associated with lower levels of neuroticism, perceived stress, and trait anxiety. Study one of Chapter 8 confirmed the relationship obtained between the DAPTQ and the Big Five of personality from study four of Chapter $\mathbf{7}$, and supported the incremental validity of the DAPTQ over the PPI-SF in predicting personality traits associated to the Big Five (Durand, 2018c). Study two reported an association between higher levels of DAPTQ and communication adaptability, stress resilience, and anxiety resilience, and supported the incremental validity of the DAPTQ over the PPI-SF and the TriPM in predicting the aforementioned variables. Study one of Chapter 9 reported an association between the DAPTQ and higher levels of positive feelings, satisfaction with life, and self-esteem, and lower levels of personal distress and negative feelings (Durand, 2018a). Study two confirmed once again the negative relationship between the DAPTQ and stress and anxiety, and reported a positive association between the DAPTQ and creativity. Lastly, Chapter $\mathbf{1 0}$ reported an association between higher levels on the DAPTQ and faster response time on measures of working memory and response inhibition (Durand, Rutten, and Lobbestael, submitted).

\section{Strengths, Limitations, and Recommendations for Future Studies}

The chapters from the proposed thesis have several strengths. First, the seven chapters reporting an instrument of psychopathic traits (i.e. the PPI-SF and the TriPM) reported their analyses by psychopathy subtypes. As highlighted previously, multiple constructs, such as anxiety, are related positively to some factors of psychopathy and negatively to others, decreasing the strength of its association with the total score of an instrument measuring psychopathic traits. These detailed analyses helped reflecting the role of Fearless Dominance in psychopathy, which is still debated in the scientific community (Marcus, Edens, \& Fulton, 2013; Patrick, Venables, \& Drislane, 2013). These analyses by subtypes follow recent trends in psychiatry, whereas symptoms in relation to trait dimensions, as well as networks of symptoms in relation to experiences are included as core constructs and 
concepts. Second, chapters focusing on psychopathy used well-validated instruments to measure psychopathic traits. In the current literature, numerous studies report the findings of empirical studies which used the LSRP to measure psychopathy (Lilienfeld \& Fowler, 2006). As mentioned previously, since the LSRP appears to be more associated with ASPD than psychopathy, it is possible that the associations between various constructs and the LSRP may not be reflective of the association between those constructs and psychopathy, as conceptualized by the PPI or the TriPM. Lastly, the chapters of this thesis focused on a wide range of statistical analyses. While some chapters focused on Pearson correlations and Multivariate Analysis of Variance (MANOVA), such as Chapter 2, 3, 6, and 9, other chapters incorporated additional types of statistical analyses, such as exploratory factor analysis and parallel analysis in chapter seven, as well as regression analysis in Chapter 4, 5, 8, and 10.

Eight of the nine studies reported in this thesis stem from online research. Although the major benefit of online studies is the easiness of recruiting a large quantity of participants in a short amount of time (4072 participants across 8 studies), data collection from the same sources makes the pool of participants homogeneous. Most of the participants were recruited via ads on websites dedicated to online research and web-based forums (e.g. www.callforparticipants.com, reddit.com/r/SampleSize). While forums are often stigmatized in the academic community and considered unreliable, many empirical studies support the efficiency and validity of recruiting participants in online forums, as the data obtained has been shown to be not significantly different from the data obtained in university databanks (Casler, Bickel, \& Hackett, 2013; Jamnik \& Lane, 2017; Shatz, 2016). Another issue with the present studies is the potential overlap of participants across studies. Based on the number of participants who entered an email address to be notified of future studies by the researcher, and weighted to include the portion of participants who did not leave an email address, it is possible to estimate that between $5 \%$ and $7 \%$ of participants participated in the studies of both Chapter 2 and Chapter 3. As opposed to Chapters 2 and 3, which recruitment period was close to one another, the recruitment for the other chapters was significantly spread out across the years, reducing the risk of overlap participants. Furthermore, for all studies related to the DAPTQ, a clause in the informed consent was added, stating that the participant has not previously participated in a study related to the development or validity of the DAPTQ, to prevent using participants already aware of the goal of the study and participants familiar with the instruments used. Lastly, while it is possible to count the number of participants who took part in questionnaire-based study, 
we do not have data on the number of participants who started the study of Chapter 10, but were automatically excluded due to an error rate over $75 \%$. When programming the experiment, the purpose was to automatically remove data from participants stopping mid-experiment, as well as to remove robots starting the experiment.

One recommendation for future studies is to perform a confirmatory factor analysis (CFA) on the DAPTQ. Although a CFA was originally planned in Chapter 7 and $\mathbf{8}$, the sections pertaining to those results were removed due to the journal's page limit in both instances. A study should hence be dedicated solely in confirming the factor structure of the DAPTQ. A second study should be dedicated to developing a response inconsistency scale for the DAPTQ. These scales allow to easily screen out participants completing the instrument in a random manner, and are present in other measures of psychopathy (Lilienfeld \& Widows, 2005; Mowle et al., 2017). A last recommendation would be to merge the paradigms of Chapter 6, Chapter 8, and Chapter 10 together. Indeed, examining the genetic influence and the additional role of the DAPTQ and other measures of psychopathy in predicting cognitive abilities, ideally under stress, could provide additional information regarding the long-term association between Fearless Dominance and stress resilience.

\section{General Conclusion}

Overall, the chapters of this thesis explored the association between a wide range of constructs and psychopathic traits, with a notable interest on the adaptive side of psychopathy, conceptualized by Fearless Dominance. Due to the small range of adaptive variables included in the PPI-I, the DAPTQ was developed to cover a wider range of adaptive traits known to correlate with the psychopathic personality. The results support the potential benefits associated with a subtype of psychopathy. 


\section{References}

Akhtar, R., Ahmetoglu, G., \& Chamorro-Premuzic, T. (2013). Greed is good? Assessing the relationship between entrepreneurship and subclinical psychopathy. Personality and Individual Differences, 54(3), 420-425.

Alexander, J. K., Hillier, A., Smith, R. M., Tivarus, M. E., \& Beversdorf, D. Q. (2007). Beta-adrenergic modulation of cognitive flexibility during stress. Journal of Cognitive Neuroscience, 19(3), 468-478.

Angelidis, A., van der Does, W., Schakel, L., \& Putman, P. (2016). EEG theta/beta ratio as a biomarker for attentional control and its test-retest reliability. Biological Psychology, 121, 49-52.

Babiak, P., Neumann, C. S., \& Hare, R. D. (2010). Corporate Psychology: Talking the Walk. Behavioral Sciences \& the Law, 28(2), 174-193.

Bartels, D. M., \& Pizarro, D. A. (2011). The mismeasure of morals: Antisocial personality traits predict utilitarian responses to moral dilemmas. Cognition, 121(1), 154-161.

Baskin-Sommers, A. R., Zeier, J. D., \& Newman, J. P. (2009). Self-reported attentional control differentiates the major factors of psychopathy. Personality and Individual Differences, 47(6), 626-630.

Benning, S. D., Patrick, C. J., Hicks, B. M., Blonigen, D. M., \& Krueger, R. F. (2003). Factor structure of the psychopathic personality inventory: validity and implications for clinical assessment. Psychological Assessment, 15(3), 340-350.

Benning, S. D., Patrick, C. J., Salekin, R. T., \& Leistico, A. R. (2005). Convergent and Discriminant Validity of A Comparison of Three Instruments. Screening, 12(3), 270-289.

Berg, J. M., Smith, S. F., Watts, A. L., Ammirati, R., Green, S. E., \& Lilienfeld, S. O. (2013). Misconceptions regarding psychopathic personality: implications for clinical practice and research. Neuropsychiatry, 3, 63-74.

Blagov, P. S., Patrick, C. J., Oost, K. M., Goodman, J. A., \& Pugh, A. T. (2015). Triarchic Psychopathy Measure: Validity in Relation to Normal-Range Traits, Personality Pathology, and Psychological Adjustment. Journal of Personality Disorders, 30(1), 1-11.

Bridgstock, R. (2009). The graduate attributes we've overlooked: Enhancing graduate employability through career management skills. Higher Education Research and Development, 28(1), 31-44.

Brouwer, A.-M., Neerincx, M. a, Kallen, V., van der Leer, L., \& ten Brinke, M. (2011). EEG alpha asymmetry, heart rate variability and cortisol in response to virtual reality induced stress. Journal of CyberTherapy and Rehabilitation VO - 4, (1), 27.

Casler, K., Bickel, L., \& Hackett, E. (2013). Separate but equal? A comparison of participants and data gathered via Amazon's MTurk, social media, and face-toface behavioral testing. Computers in Human Behavior, 29(6), 2156-2160.

Christian, E., Sellbom, M., \& Wilkinson, R. B. (2016). Clarifying the Associations 
Between Individual Differences in General Attachment Styles and Psychopathy. Personality Disorders: Theory, Research, and Treatment.

Cramm, J. M., \& Nieboer, A. P. (2012). Self-management abilities, physical health and depressive symptoms among patients with cardiovascular diseases, chronic obstructive pulmonary disease, and diabetes. Patient Education and Counseling, 87(3), 411-415.

Crant, J. M., \& Bateman, T. S. (2000). Charismatic leadership viewed from above: the impact of proactive personality. Journal of Organizational Behavior, 21(1), 6375.

Debener, S., Beauducel, A. E., Nessler, D., Brocke, B., Heilemann, H., \& Kayser, J. U. R. (2000). Is resting anterior EEG alpha asymmetry a trait marker for depression? Findings for healthy adults and clinically depressed patients. Neuropsychobiology, 41(1), 31-37.

Dobzhansky, T. (1956). What is an Adaptive Trait? The American Naturalist, 90(855), 337-347.

Donnellan, B., \& Burt, A. (2016). A Further Evaluation of the Triarchic Conceptualization of Psychopathy in College Students. Journal of Psychopathology and Behavioral Assessment, 38(2), 172-182.

Durand, G. (2016). A Replication of " Using self-esteem to disaggregate psychopathy, narcissism, and aggression (2013) ". The Qantitative Methods for Psychology, 12(2), r1-r5.

Durand, G. (2017). The Durand Adaptive Psychopathic Traits Questionnaire: Development and Validation. Journal of Personality Assessment, 1-10.

Durand, G. (2018a). A French translation and validation of the Durand Adaptive Psychopathic Traits Questionnaire: An investigation with community samples from France and Canada. PLOS ONE, 13(9), e0204214.

Durand, G. (2018b). Demystification of the Relationship Between Psychopathy and Happiness. Journal of Happiness Studies, 19(2), 381-395.

Durand, G. (2018c). Incremental Validity of the Durand Adaptive Psychopathic Traits Questionnaire Above Self-Report Psychopathy Measures in Community Samples. Journal of Personality Assessment, 1-10.

Durand, G., \& de Calheiros Velozo, J. (2018). The interplay of gender, parental behaviors, and child maltreatment in relation to psychopathic traits. Child Abuse \& Neglect, 83(C), 120-128.

Durand, G., \& Plata, E. M. (2017). The effects of psychopathic traits on fear of pain , anxiety , and stress. Personality and Individual Differences, 119(C), 198-203.

Durand, G., Plata, E. M., \& Arbone, I.-S. (2017). Negative attitudes towards psychopaths: The role of one's own psychopathic traits. Personality and Individual Differences, 109(C), 72-76.

Falkenbach, D. M., Stern, S. B., \& Creevy, C. (2014). Psychopathy variants: Empirical evidence supporting a subtyping model in a community sample. Personality Disorders: Theory, Research, and Treatment, 5(1), 10-19. 


\section{Chapter 11 | General Discussion}

Galang, A. J. R., Castelo, V. L. C., Santos, L. C., Perlas, C. M. C., \& Angeles, M. A. B. (2016). Investigating the prosocial psychopath model of the creative personality: Evidence from traits and psychophysiology. Personality and Individual Differences, 100, 28-36.

Gao, Y., \& Tang, S. (2013). Psychopathic personality and utilitarian moral judgment in college students. Journal of Criminal Justice, 41(5), 342-349.

Garett, K., \& Wulf, K. (1978). The Relationship of a Measure of Critical Thinking Ability to Personality Variables and to Indicators of Academic Achievement. Educational and Psychological Measurement, 38(4), 1181-1187.

Gervais, M. M., Kline, M. a., Ludmer, M., George, R., \& Manson, J. H. (2013). The strategy of psychopathy: primary psychopathic traits predict defection on lowvalue relationships. Proceedings of the Royal Society - Biological Sciences, 280(February), 20122773.

Giles, G. E., Mahoney, C. R., Brunyé, T. T., Taylor, H. A., \& Kanarek, R. B. (2014). Stress Effects on Mood, HPA Axis, and Autonomic Response: Comparison of Three Psychosocial Stress Paradigms. PLoS ONE, 9(12), e113618.

Greene, J. D., Sommerville, R. B., Nystrom, L. E., Darley, J. M., \& Cohen, J. D. (2001). An $\mathrm{fMRI}$ investigation of emotional engagement in moral judgment. Science, 293(5537), 2105-2108.

Hare, R. D. (1968). Detection Threshold for Electric Shock in Psychopaths. Journal of Abnormal Psychology, 73(3), 268-272.

Howe, J., Falkenbach, D., \& Massey, C. (2014). The Relationship among Psychopathy, Emotional Intelligence, and Professional Success in Finance. International Journal of Forensic Mental Health, 13(4), 337-347.

Jamnik, M. R., \& Lane, D. J. (2017). The Use of Reddit as an Inexpensive Source for High-Quality Data. Practical Assessment, Research, and Evaluation, 22(5), 110.

Jonason, P. K., Richardson, E. N., \& Potter, L. (2015). Self-reported creative ability and the Dark Triad traits: An exploratory study. Psychology of Aesthetics, Creativity, and the Arts, 9(4), 488-494.

Judge, T. A., Bono, J. E., Ilies, R., \& Gerhardt, M. W. (2002). Personality and leadership: A qualitative and quantitative review. Journal of Applied Psychology, 87(4), 765-780.

Kaufman, J. C. (2012). Counting the Muses: Development of the Kaufman Domains of Creativity Scale (K-DOCS). Psychology of Aesthetics, Creativity, and the Arts, 6(4), 298-308.

Kelly, K. E. (2006). Relationship between the five-factor model of personality and the Scale of Creative Attributes and Behavior: A validational study. Individual Differences Research, 4(5), 299-305.

Lee, Z., \& Salekin, R. T. (2010). Psychopathy in a noninstitutional sample: Differences in primary and secondary subtypes. Personality Disorders: Theory, Research, and Treatment, 1(3), 153-169.

Levenson, M. R., Kiehl, K. A., \& Fitzpatrick, C. M. (1995). Assessing Psychopathic 
Attributes in a Noninstitutionalized Population. Journal of Personality and Social Psychology, 68(1), 151-158.

Lilienfeld, S. O., \& Andrews, B. P. (1996). Development and Preliminary Validation of a Self-Report Measure of Psychopathic Personality Traits in Noncriminal Populations. Journal of Personality Assessment, 66(3), 488-524.

Lilienfeld, S. O., \& Fowler, K. A. (2006). The self-report assessment of psychopathy. In C. J. Patrick (Ed.), Handbook of psychopathy (pp. 107-132). New York, NY: Guilford Press.

Lilienfeld, S. O., Latzman, R. D., Watts, A. L., Smith, S. F., \& Dutton, K. (2014). Correlates of psychopathic personality traits in everyday life: Results from a large community survey. Frontiers in Psychology, 5(JUL), 1-11.

Lilienfeld, S. O., Waldman, I. D., Landfield, K., Watts, A. L., Rubenzer, S., \& Faschingbauer, T. R. (2012). Fearless dominance and the U.S. presidency: Implications of psychopathic personality traits for successful and unsuccessful political leadership. Journal of Personality and Social Psychology, 103(3), 489505.

Lilienfeld, S. O., \& Widows, M. (2005). Psychopathic personality inventory-revised: Professional manual. Lutz, FL: Psychological Assessment Resources.

Link, N. F., Scherer, S. E., \& Byrne, P. N. (1977). Moral judgment and moral conduct in the psychopath. Canadian Psychiatric Association Journal, 22(7), 341-346.

Love, A. B., \& Holder, M. D. (2014). Psychopathy and subjective well-being. Personality and Individual Differences, 66(June), 112-117.

Marcus, D. K., Edens, J. F., \& Fulton, J. J. (2013). Is it the inventory, the meta-analysis, or the construct? Reply to the comments on Marcus, Fulton, and Edens. Personality Disorders, 4(1), 89-90.

Morgan, C. A., Rasmusson, A. M., Wang, S., Hoyt, G., Hauger, R. L., \& Hazlett, G. (2002). Neuropeptide-Y, cortisol, and subjective distress in humans exposed to acute stress: Replication and extension of previous report. Biological Psychiatry, 52(2), 136-142.

Morgan, C. A., Rasmusson, A., Pietrzak, R. H., Coric, V., \& Southwick, S. M. (2009). Relationships Among Plasma Dehydroepiandrosterone and Dehydroepiandrosterone Sulfate, Cortisol, Symptoms of Dissociation, and Objective Performance in Humans Exposed to Underwater Navigation Stress. Biological Psychiatry, 66(4), 334-340.

Morgan, C. A., Wang, S., Rasmusson, A., Hazlett, G., Anderson, G., \& Charney, D. S. (2001). Relationship among plasma cortisol, catecholamines, neuropeptide $Y$, and human performance during exposure to uncontrollable stress. Psychosomatic Medicine, 63(3), 412-22.

Mowle, E. N., Kelley, S. E., Edens, J. F., Donnellan, M. B., Smith, S. T., Wygant, D. B., \& Sellbom, M. (2017). Development of an Inconsistent Responding Scale for the Triarchic Psychopathy Measure. Psychological Assessment, 29(8), 990-1000.

Mullins-Nelson, J. L., Salekin, R. T., \& Leistico, A.-M. R. (2006). Psychopathy, empathy, and perspective-taking ability in a community sample: Implications for the 


\section{Chapter 11 | General Discussion}

successful psychopathy concept. International Journal of Forensic Mental Health, 5(2), 133-149.

Murphy, B., Lilienfeld, S., Skeem, J., \& Edens, J. F. (2016). Are fearless dominance traits superfluous in operationalizing psychopathy? Incremental validity and sex differences. Psychological Assessment, 28(12), 1597-1607.

Murray, A. A., Wood, J. M., \& Lilienfeld, S. O. (2012). Psychopathic personality traits and cognitive dissonance: Individual differences in attitude change. Journal of Research in Personality, 46(5), 525-536.

Panayiotou, G. (2015). The bold and the fearless among us: Elevated psychopathic traits and levels of anxiety and fear are associated with specific aberrant driving behaviors. Accident Analysis and Prevention, 79, 117-125.

Patrick, C. (2010). Triarchic psychopathy measure (TriPM). PhenX Toolkit Online Assessment Catalog.

Patrick, C. J., Venables, N. C., \& Drislane, L. E. (2013). The role of fearless dominance in differentiating psychopathy from antisocial personality disorder: comment on Marcus, Fulton, and Edens. Personality Disorders, 4(1), 80-2.

Poythress, N. G., Lilienfeld, S. O., Skeem, J. L., Douglas, K. S., Edens, J. F., Epstein, M., \& Patrick, C. J. (2010). Using the PCL-R to help estimate the validity of two self-report measures of psychopathy with offenders. Assessment, 17(2), 206219.

Putman, P., Verkuil, B., Arias-Garcia, E., Pantazi, I., \& van Schie, C. (2014). EEG theta/beta ratio as a potential biomarker for attentional control and resilience against deleterious effects of stress on attention. Cognitive, Affective \& Behavioral Neuroscience, 14(2), 782-91.

Ross, S. R., Benning, S. D., Patrick, C. J., Thompson, A., \& Thurston, A. (2009). Factors of the Psychopathic Personality Inventory: Criterion-Related Validity and Relationship to the BIS/BAS and Five-Factor Models of Personality. Assessment, 16(1), 71-87.

Ruchensky, J. R., Edens, J. F., Donnellan, M. B., \& Witt, E. A. (2017). Examining the reliability and validity of an abbreviated Psychopathic Personality InventoryRevised (PPI-R) in four samples. Psychological Assessment, 29(2), 238-244.

Sacco, D. F., Merold, S. J., Lui, J. H. L., Lustgraaf, C. J. N., \& Barry, C. T. (2016). Social and emotional intelligence moderate the relationship between psychopathy traits and social perception. Personality and Individual Differences, 95, 95-104.

Schiebener, J., Zamarian, L., Delazer, M., \& Brand, M. (2011). Executive functions, categorization of probabilities, and learning from feedback: What does really matter for decision making under explicit risk conditions? Journal of Clinical and Experimental Neuropsychology, 33(9), 1025-1039.

Schoofs, D., Preuß, D., \& Wolf, O. T. (2008). Psychosocial stress induces working memory impairments in an n-back paradigm. Psychoneuroendocrinology, 33(5), 643-653.

Sellbom, M., \& Phillips, T. R. (2013). An examination of the triarchic conceptualization 
of psychopathy in incarcerated and nonincarcerated samples. Journal of Abnormal Psychology, 122(1), 208-214.

Shatz, I. (2016). Fast, Free, and Targeted: Reddit as a Source for Recruiting Participants Online. Social Science Computer Review, 1-13.

Shields, G. S., Lam, J. C. W., Trainor, B. C., \& Yonelinas, A. P. (2016). Exposure to acute stress enhances decision-making competence: Evidence for the role of DHEA. Psychoneuroendocrinology, 67, 51-60.

Shields, G. S., Sazma, M. A., \& Yonelinas, A. P. (2016). The effects of acute stress on core executive functions: A meta-analysis and comparison with cortisol. Neuroscience and Biobehavioral Reviews, 68, 651-668.

Skeem, J. L., Polaschek, D. L. L., Patrick, C. J., \& Lilienfeld, S. O. (2011). Psychopathic Personality: Bridging the Gap Between Scientific Evidence and Public Policy. Psychological Science in the Public Interest, 12(3), 95-162.

Smith, S. T., Edens, J. F., \& Vaughn, M. G. (2011). Assessing the external correlates of alternative factor models of the Psychopathic Personality Inventory-short form across three samples. Journal of Personality Assessment, 93(3), 244-256.

Uzieblo, K., Verschuere, B., Van den Bussche, E., \& Crombez, G. (2010). The validity of the psychopathic personality inventory--revised in a community sample. Assessment, 17(3), 334-346.

Walsh, J. J., Balint, M. G., Smolira SJ, D. R., Fredericksen, L. K., \& Madsen, S. (2009). Predicting individual differences in mindfulness: The role of trait anxiety, attachment anxiety and attentional control. Personality and Individual Differences, 46(2), 94-99.

Watts, A. L., Salekin, R. T., Harrison, N., Clark, A., Waldman, I. D., Vitacco, M. J., \& Lilienfeld, S. O. (2016). Psychopathy: Relations with Three Conceptions of Intelligence. Personality Disorders: Theory, Research, and Treatment, 7(3), 269-279.

Weissman, D. H., Mangun, G. R., \& Woldorff, M. G. (2002). A role for top-down attentional orienting during interference between global and local aspects of hierarchical stimuli. Neurolmage, 17(3), 1266-1276.

Whetten, D. A., \& Cameron, kim S. (2006). Developing Management Skills (7th editio). Indiana, USA: Prentice Hall.

Witt, E. a, Donnellan, M. B., Blonigen, D. M., Krueger, R. F., \& Conger, R. D. (2009). Assessment of Fearless Dominance and Impulsive Antisociality via normal personality measures: convergent validity, criterion validity, and developmental change. Journal of Personality Assessment, 91(3), 265-276. 

Summary 

Chapter 1 provides an introduction to the current thesis, and presents a general overview of psychopathy, followed by instruments typically used for the diagnosis of psychopathy. The chapter continues by distinguishing the maladaptive and the adaptive components of psychopathy, and reports several models explaining the concept of adaptive psychopathy. This is followed by an overview of self-report instruments including an adaptive component when measuring adaptive psychopathic traits. The limitations of those instruments are then explained, followed by an overview of the aims of each study included in this thesis.

Chapter 2 describes a study investigating the relationship between psychopathic traits, as conceptualized by the Psychopathic Personality Inventory - Short Form (PPI-SF), and traits related to happiness, namely stable happiness, fluctuating happiness, presence or search of a meaning in life, personal growth, and hope. Results indicated a positive relationship between Fearless Dominance (PPI-I) and stable happiness, presence of a meaning in life, personal growth, and hope, as well as a positive relationship between Impulsive Antisociality (PPI-II) and fluctuating happiness and search for a meaning in life. Alternatively, a negative relationship was observed between PPI-I and fluctuating happiness, as well as between PPI-II and stable happiness, presence of a meaning in life, personal growth, and hope. Overall, the results supported the positive aspects, in terms of traits related to happiness, of PPI-I, as well as the negative aspects of PPI-II. Subsequently, the study reported in Chapter 3 followed a similar approach of that of the previous study, with the difference of a focus on fear of pain-related traits. Specifically, we examined the relationship between the PPI-SF and fear of pain, pain catastrophization, state-trait anxiety, and perceived stress. Similarly to the previous study, PPI-I was negatively associated with all aforementioned variables, while PPI-II was positively associated with those variables, again supporting the positive characteristics associated with Fearless Dominance. Chapter 4 examined the relationship between another self-report instrument of psychopathic traits, namely the Triarchic Psychopathy Measure (TriPM), and its association with stigmatization of psychopaths. Higher levels of Boldness showed to be negatively associated with negative emotions towards psychopaths and a higher probability of helping or interacting with an individual diagnosed with psychopathy. Alternatively, Meanness and Disinhibition were negatively associated with the belief that psychopaths are prone to committing crimes and positively associated with the beliefs that psychopaths are not criminals. Meanness and Disinhibition were also negatively associated with negative emotions towards psychopaths. Using a regression model to determine which factor of the TriPM predicts negative 


\section{Summary}

emotions towards psychopaths, only Boldness turned out to be a significant predictor. Overall, the results suggest that individuals with higher levels of boldness are less prone to stigmatize diagnosed psychopaths. The beneficial effect of boldness was also observed in Chapter 5. In this chapter, we investigated the relationship between levels of TriPM at adulthood and selfreported childhood trauma and parental behaviors. While Boldness was negatively related to emotional abuse and emotional neglect, Disinhibition was positively related to emotional and physical abuse, as well as emotional and physical neglect. Disinhibition was also positively related to reported rejection from both parents, over-protection from the mother, and a lack of emotional warmth from both parents. Similarly, Meanness was positively associated with emotional neglect, over-protection from the mother, and a lack of emotional warmth from both parents. These results suggest that boldness can emerge in a positive rearing environment.

As opposed to previous chapters, Chapter 6 did not specifically focus on psychopathic traits, but instead focused on the relationship between genetic variations and cognitive performances under mild stress. In this study, a group of individuals from the community were recruited and completed the chessboard pieces replacement memory task, the Tower of Hanoi, and a Go/No-Go paradigm. Saliva samples were collected prior to testing and analysed for the detection of 29 single nucleotide polymorphisms (SNPs) in candidate genes and hormones (i.e. SLC6A4, FKBP5, GILZ, SGK1, NR3C1, DAT1, COMT, TaqIA, Val66Met, TPH2, SNAP-25, CRP, NPY, cortisol, norepinephrine, and testosterone). The results support the relationship between the GR-target gene FKBP5 and sustained attention. Additionally, weak significant results were observed on SNPs related to COMT, Val66Met, SNAP-25, DAT1, and cortisol and performance on cognitive tasks. Altogether, these results support the genetic influence of cognitive abilities under mild stress.

Chapter 7 is the first chapter of a series of studies focusing on the development and validation of the Durand Adaptive Psychopathic Traits Questionnaire (DAPTQ), and instrument measuring adaptive traits known to be associated with the psychopathic personality. Study 1 of this chapter focused on identifying constructs associated with the psychopathic personality and examining the internal consistency of a set of statements depicting each construct. Subsequently, study 2 served as a test validation and reported the initial psychometric properties of the DAPTQ. Following an exploratory factor analysis and a parallel analysis, an 11-factor solution accounting for $53.37 \%$ of the variance emerged (Leadership, Logical Thinking, Composure, Creativity, Fearlessness, Similarity, Money Smart, Focus, Extroversion, 
Consequentialism, and Management). Study 3 then compared the DAPTQ with measures of the Big-Five of personality, rational-experiential thoughts, risk taking, perceived stress, and trait anxiety, with the purpose of assessing the construct validity of the DAPTQ. The DAPTQ was positively related with numerous personality traits considered adaptive, such as extroversion, agreeableness, conscientiousness, emotional stability, openness, rational ability, rational engagement, experiential ability, risk taking, stress resilience, and anxiety resilience. Based on factor-by-factor analysis, the Similarity and the Consequentialism scales were removed from the DAPTQ.

Chapter $\mathbf{8}$ focused on providing information on the incremental validity of the DAPTQ over the two other assessment instruments of psychopathic traits including an adaptive component, namely the PPI-SF and the TriPM. Study 1 supported the incremental validity of the DAPTQ over the PPI-SF in predicting the five traits of the Big-Five of personality (extraversion, agreeableness, conscientiousness, neuroticism, and openness). Study 2 reported the incremental validity of the DAPTQ over both the PPI-SF and the TriPM in predicting communication adaptability, perceived stress, and trait anxiety. Subjective examination of both studies supported the removal of the Money Smart factor of the DAPTQ, which turned out to be unrelated to the PPI-SF or the TriPM. Chapter 9 also reports two studies, focusing on the French translation and validation of the DAPTQ. Study 1 investigated the psychometric properties of the French version of the DAPTQ, as well as its association with measures of interpersonal reactivity, positive and negative affective states, satisfaction with life, and state self-esteem. While study 1 was fully completed in French, study 2 recruited a bilingual sample (French and English), who completed both the French version and the English version of the DAPTQ, as well as measures of perceived stress, trait anxiety, and creativity. Overall, the results obtained on the French version of the DAPTQ mirrored the results of the DAPTQ English version from Chapter 7 and 8. While the previous studies from this thesis in the field of psychopathic traits focused on online questionnaires, Chapter 10 investigated the relationship between the DAPTQ and cognitive abilities through a series of online cognitive tasks. In this study, participants completed the DAPTQ and the PPI-SF, as well as two versions of the n-back task; a measure of working memory, two versions of the flanker task; a measure of response inhibition, a Go/No-Go paradigm; a measure of cognitive attention, and a short- and long-term memory task. The results suggested that, while the DAPTQ did not demonstrate incremental validity over the PPI-SF in predicting cognitive abilities, both the DAPTQ and the PPI-SF predicted similar amount of variance on cognitive performances on their own. 


\section{Summary}

This thesis is concluded with a general discussion of the findings presented in Chapter 11. This chapter reviews the importance of investigating psychopathy by subtypes and the proposed benefits associated with the adaptive side of psychopathy. The discussion further expends on the value of the DAPTQ over other measures of psychopathy in assessing adaptive traits related to psychopathy, as well as the strengths, limitations, and recommendations for future studies. 


Appendix 



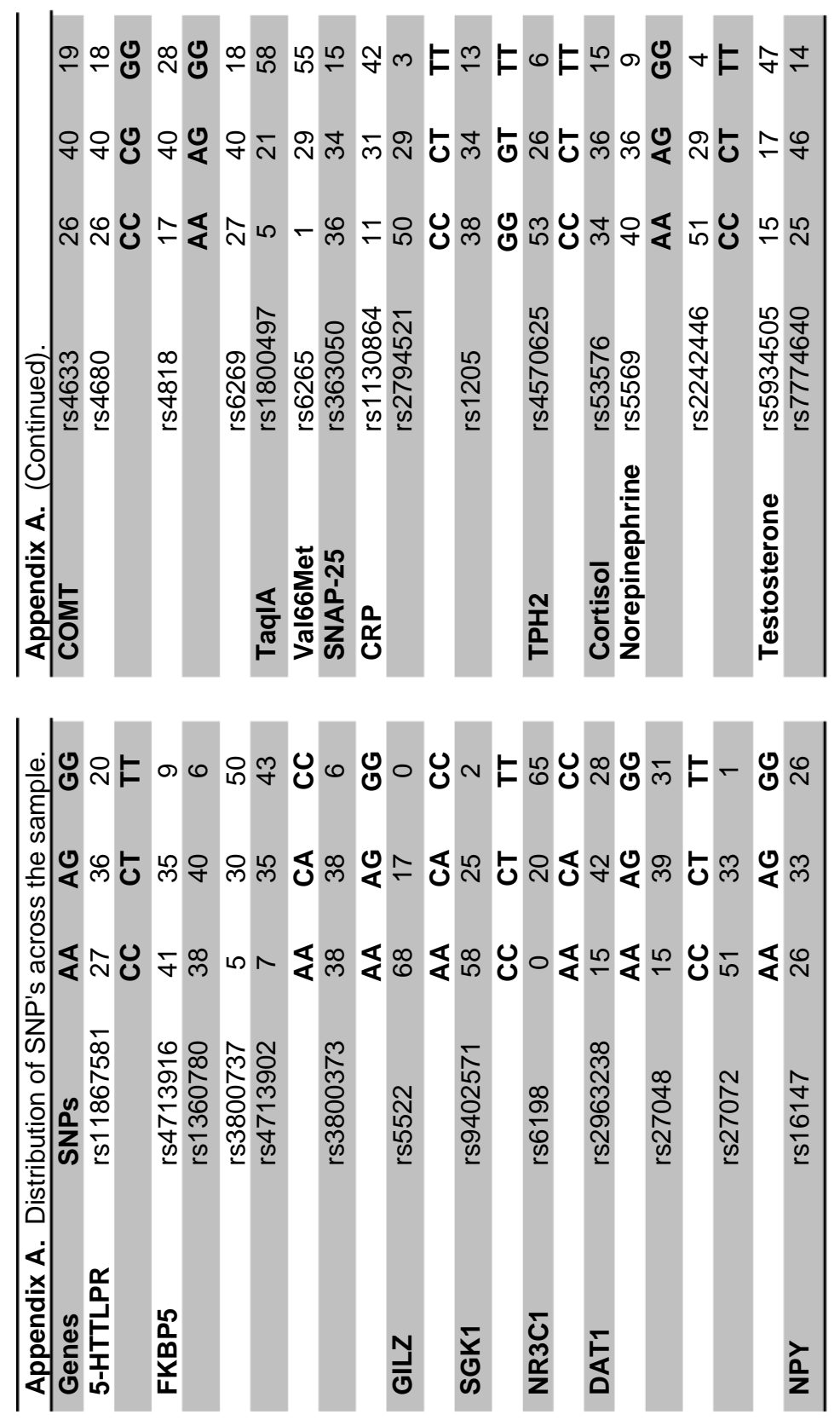


Appendix B. Descriptive data

\begin{tabular}{|c|c|c|c|}
\hline & $\begin{array}{l}\text { M (SD) } \\
\text { Sample } 1\end{array}$ & $\begin{array}{l}\text { M (SD) } \\
\text { Sample } 2\end{array}$ & $\begin{array}{l}\text { Cohen's } d \text { with } \\
\text { normative } \\
\text { sample }\end{array}$ \\
\hline \multicolumn{4}{|l|}{ DAPTQ } \\
\hline Leadership & $13.92(4.25)$ & $14.44(4.36)$ & $0.25 / 0.12$ \\
\hline Loqical Thinking & $21.73(4.12)$ & $22.00(4.05)$ & $0.03 / 0.10$ \\
\hline Composure & $18.98(7.17)$ & $18.09(6.82)$ & $0.25 / 0.39$ \\
\hline Creativity & $15.18(4.87)$ & $15.20(4.86)$ & $0.04 / 0.03$ \\
\hline Fearlessness & $18.46(5.87)$ & $17.85(6.62)$ & $0.69 / 0.75$ \\
\hline Money Smart & $12.59(3.15)$ & $12.11(3.75)$ & $0.22 / 0.07$ \\
\hline Focus & $13.01(4.15)$ & $11.34(4.12)$ & $0.02 / 0.43$ \\
\hline Extroversion & $18.65(6.64)$ & $18.81(6.91)$ & $0.21 / 0.18$ \\
\hline Management & $11.53(3.23)$ & $11.48(3.48)$ & $0.01 / 0.01$ \\
\hline Total & $144.06(24.75)$ & $141.35(24.66)$ & $0.32 / 0.43$ \\
\hline \multicolumn{4}{|l|}{ PPI-SF } \\
\hline PPI-I & $49.97(8.95)$ & $50.75(8.83)$ & $0.37 / 0.30$ \\
\hline PPI-II & $60.60(9.57)$ & $58.14(9.13)$ & $0.30 / 0.52$ \\
\hline Total & $125.40(14.59)$ & $123.27(14.53)$ & $0.47 / 0.57$ \\
\hline \multicolumn{4}{|l|}{ HEXACO } \\
\hline Honesty-Humility & $34.07(6.57)$ & - & 0.34 \\
\hline Emotionality & $31.23(6.87)$ & - & 0.16 \\
\hline Extraversion & $29.60(7.44)$ & - & 0.60 \\
\hline Agreeableness & $31.41(6.38)$ & - & 0.14 \\
\hline Conscientiousness & $35.87(5.81)$ & - & 0.02 \\
\hline Openness & $37.40(6.61)$ & - & 0.23 \\
\hline \multicolumn{4}{|l|}{ TriPM } \\
\hline Boldness & - & $47.68(9.39)$ & 0.25 \\
\hline Meanness & - & $32.81(9.00)$ & 0.13 \\
\hline Disinhibition & - & $35.87(8.38)$ & 0.24 \\
\hline Total & - & $116.37(17.84)$ & 0.05 \\
\hline \multicolumn{4}{|l|}{ CAS } \\
\hline Social experience & - & $15.38(3.83)$ & Unavailable \\
\hline Social composure & - & $15.90(3.51)$ & Unavailable \\
\hline Appropriate dis & - & $18.40(2.78)$ & Unavailable \\
\hline Wit & - & $15.75(3.53)$ & Unavailable \\
\hline Social confirmation & - & $19.12(3.01)$ & Unavailable \\
\hline Total & - & $84.58(10.66)$ & Unavailable \\
\hline \multicolumn{4}{|l|}{ PSS } \\
\hline Total & - & $18.87(4.80)$ & 0.09 \\
\hline STAI-Y2 & & & \\
\hline Total & - & $47.36(11.86)$ & 0.14 \\
\hline
\end{tabular}

Note. Values to the left and right of the slash sign indicate Sample 1 and Sample 2, respectively. The normative sample of the DAPTQ was taken from Study 2 of the article on the development of the DAPTQ (Durand, 2017). The normative sample of the PPI-SF was taken from Lilienfeld, Latzman, Watts, Smith, and Dutton (2014), as their sample is one of the largest and most recent community samples using the PPI-SF. The normative sample of the HEXACO was taken from a study investigating a community sample (Grieve, 2012). The normative sample for the TriPM was from a community sample (Durand, Plata, \& Arbone, 2017). The normative sample for the PSS and STAI-Y2 were from a community sample (Durand \& Plata, 2017). 
Appendix

\section{References}

Durand, G., \& Plata, E. M. (2017). The effects of psychopathic traits on fear of pain , anxiety , and stress. Personality and Individual Differences, 119(C), 198-203.

Durand, G., Plata, E. M., \& Arbone, I.-S. (2017). Negative attitudes towards psychopaths: The role of one's own psychopathic traits. Personality and Individual Differences, 109(C), 72-76.

Grieve, R. (2012). The Role of Personality, Psychopathy, and Previous Experience with Assessment in Intentions to Fake in Psychological Testing. Current Psychology, 31(4), 414-422.

Lilienfeld, S. O., Latzman, R. D., Watts, A. L., Smith, S. F., \& Dutton, K. (2014). Correlates of psychopathic personality traits in everyday life: Results from a large community survey. Frontiers in Psychology, 5(JUL), 1-11. 

Valorization Addendum 

This dissertation focused on the relationship between adaptive personality traits and the psychopathic personality. More specifically, we investigated how a broad range of adaptive traits were associated with different subtypes of the psychopathic personality. Furthermore, we explored the relationship between adaptive traits and cognitive abilities. Lastly, we examined the validity of the Durand Adaptive Psychopathic Traits Questionnaire (DAPTQ) as an appropriate tool to measure adaptive psychopathic traits. Through this dissertation, we aimed at exploring the potential positive aspects associated with (components of) psychopathy. We also hope that this dissertation provides more insights into the evaluation of adaptive traits in psychopathic individuals. This valorization addendum focusses on the following subjects: relevance to research, target group benefiting from the knowledge of this dissertation, possible products and activities that can be realized subsequent to this dissertation, innovation, and implementation of the findings.

\section{Relevance}

A significant portion of the published research in the field of psychopathy focuses solely on the maladaptive aspects of psychopathy, most often referred to as a personality disorder (Berg et al., 2013). The association between psychopathy and maladaptive personality can be partially attributed to the significant proportion of studies performed on inmates (Camp, Skeem, Barchard, Lilienfeld, \& Poythress, 2013; Kiehl \& Hoffman, 2011). The stigma that psychopathy is completely maladaptive may explain the fear of psychopaths within the general population (Edens, Colwell, Desforges, \& Fernandez, 2005; Edens, Marcus, Lilienfeld, \& Poythress, 2006).

The belief that psychopathy is exclusively maladaptive has important repercussions on some individuals. In legal settings, the label of "psychopathy" is associated with harsher sentences, lower perception of treatment amenability, and perceived dangerousness (Berryessa \& Wohlstetter, 2019). In countries using the death sentence, such as the United States, inmates labeled as psychopaths can face disproportionate and inappropriate use of capital punishment (Cox, Clark, Edens, Smith, \& Magyar, 2013). This perception is in line with the results of Feldman and Crandall (2007), who reported that public perception of personal responsibility for mental illness, dangerousness of mental illness, and rarity of mental illness were all associated with stigmatization. Psychopathy meets all of these latter criteria, with surveys of the general public suggesting that people believe that psychopaths are responsible for their behaviors, are dangerous to the public, and make up less than $1 \%$ of the population (Smith, Edens, Clark, \& Rulseh, 2014; Wayland \& O'Brien, 2013). 


\section{Valorization Addendum}

In order to shed more light on the presumed positive sides associated with psychopathic traits, it is important to determine how adaptive psychopathic traits can be reliably measured. The first part of this dissertation examined a wide range of adaptive traits that have shown potential association with a subset of psychopathic traits. Based on this knowledge, the second part of this dissertation focused on the development and the validation of an instrument to effectively measure adaptive traits in the field of psychopathic traits in the general population. After a series of revision, the final version of the DAPTQ showed incremental validity over other measures including a factor assessing adaptive traits (e.g. Fearless Dominance and Boldness). This dissertation hence contributes to a better understanding of the methods used to assess adaptive traits in the field of psychopathy. In the future, this knowledge could be relevant for the identification of individuals with high levels of adaptive psychopathic traits and low levels of maladaptive psychopathic traits, which would be an asset when recruiting individuals, such as military personnel, paramedics, and police officers, for employment in highstress environments.

\section{Target group}

The findings of this dissertation are relevant to several target groups. The first target group includes researchers in the field of personality. This dissertation proposes an instrument to be used in conjunction with current instruments in the field of psychopathic traits to obtain a better profile of one's adaptive traits. Also, this dissertation gives them more insights on the benefits of reporting analyses by subtypes of psychopathic traits, as multiple personality traits can be positively or negatively associated with psychopathic traits depending on which traits they are compared to. Second, this dissertation could also be of interest to human resources managers. Numerous professions, such as police officers and military personnel, experience exceptionally high levels of mental disorders, such as posttraumatic stress disorder and anxiety (Pearson, Zamorski, \& Janz, 2014; Shields, 2018). By offering tools to human resources that would allow a better selection of individuals with a predisposition to stress resiliency, it might be possible to reduce mental health issues derived from non-resilient individuals in high stress environments (but perhaps with ethical concerns; see Bassil, Rutten, and Horstkötter (2019) for a list of potential issues). Third, the knowledge of adaptive psychopathic traits is valuable for the society, as it might reduce the stigma surrounding individuals classified as psychopathic who exhibits significantly more adaptive traits than maladaptive ones. 


\section{Activities/ products}

The present dissertation reported the development and validation of the DAPTQ. The results showed that this questionnaire can reliably be used in the general adult population. The DAPTQ showed incremental validity over other instruments measuring psychopathic traits including an adaptive component over a wide range of personality constructs. The DAPTQ cannot be used to measure psychopathy or psychopathic traits but can be used in conjunction with other instruments assessing psychopathic traits to obtain deeper insights on an individual's adaptivity.

The knowledge derived from the development of the DAPTQ could be used as a steppingstone to develop an instrument taking into account a wider range of biological, physiological, and psychological factors. This dissertation highlighted the association between single nucleotide polymorphisms' (SNPs) variations, stress resilience, and cognitive abilities, as well as the association between the DAPTQ and cognitive abilities. Developing a test battery considering one's physiological reactions and cognitive abilities during a stress task, as well as their genetic variation from selected SNPs, all compared with results from the DAPTQ would allow researchers to obtain a better profile of an individual's resilience to stress and overall adaptive personality.

\section{Innovation}

The studies conducted in this dissertation are innovative on several points. For instance, the study described in Chapter 2 re-examined the conclusion of Love and Holder (2014) regarding the association between unhappiness and psychopathy. By using analyses by subtypes of psychopathic traits, we concluded that only a subset of psychopathic traits is associated with unhappiness, while another subset is associated with happiness. Similar findings were observed in Chapter 3 between psychopathic traits and fear of pain.

Chapter 6 was particularly innovative due to its exploratory nature. Although the results are warrant to replication in future studies, our findings suggest that multiple genes and hormones, such as FKBP5, COMT, Val66Met, SNAP-25, DAT1, and cortisol may play a role in cognitive abilities under stress.

In Chapter 7, we introduced an innovative instrument to measure adaptive traits in the field of psychopathy, namely the DAPTQ. To our knowledge, the DAPTQ is the first instrument to expand on the adaptive factors of existing instruments measuring psychopathic traits. Indeed, while the Psychopathic Personality Inventory and the Triarchic Psychopathy Measure include one to three adaptive factors, the DAPTQ includes eight 


\section{Valorization Addendum}

factors that have shown an association with the psychopathic personality. This wider range of factors should provide stronger predictive abilities when examining constructs associated with successful psychopathic individuals.

In Chapter 9, we validated a French translation of the DAPTQ. Translating instruments in the field of psychopathy will allow researchers to study nonEnglish speaking populations, hence obtaining a better portrait of the general population's adaptive traits.

\section{Schedule and implementation}

The inclusion of adaptive traits as a core component of psychopathy is highly debated. While the current dissertation focused on the general population, it is worthwhile to explore potential methods to identify psychopaths with adaptive traits out of the larger group of diagnosed psychopaths.

This dissertation gives insight to the role of adaptive traits in highly psychopathic individuals from the general community. However, since the results were always examined in terms of correlations between variables, it is still unknown how the DAPTQ could be used to identify successful psychopaths. Future studies should, therefore, examine potential cut-off scores for the DAPTQ, as well as potential cut-off scores by interaction with other instruments of psychopathic traits.

The findings of the studies in this dissertation have, and will be, shared with the scientific community through scientific publications in international journals. 


\section{Valorization Addendum}

\section{References}

Bassil, K. C., Rutten, B. P. F., \& Horstkötter, D. (2019). Biomarkers for PTSD

Susceptibility and Resilience, Ethical Issues. AJOB Neuroscience, 10(3), 122124. https://doi.org/10.1080/21507740.2019.1632964

Berg, J. M., Smith, S. F., Watts, A. L., Ammirati, R., Green, S. E., \& Lilienfeld, S. O. (2013). Misconceptions regarding psychopathic personality: implications for clinical practice and research. Neuropsychiatry, 3, 63-74.

https://doi.org/10.2217/npy.12.69

Berryessa, C. M., \& Wohlstetter, B. (2019). The psychopathic "label" and effects on punishment outcomes: A meta-analysis. Law and Human Behavior, 43(1), 925. https://doi.org/10.1037//hb0000317

Camp, J. P., Skeem, J. L., Barchard, K., Lilienfeld, S. O., \& Poythress, N. G. (2013). Psychopathic predators? Getting specific about the relation between psychopathy and violence. Journal of Consulting and Clinical Psychology, 81(3), 467-480. https://doi.org/10.1037/a0031349

Cox, J., Clark, J., Edens, J. F., Smith, S. T., \& Magyar, M. S. (2013). Jury panel member perceptions of interpersonal-affective traits of psychopathy predict support for execution in a capital murder trial simulation. Behavioral Sciences \& ..., 31, 411-428. https://doi.org/10.1002/bsl.2073

Edens, J. F., Colwell, L. H., Desforges, D. M., \& Fernandez, K. (2005). The impact of mental health evidence on support for capital punishment: Are defendants labeled psychopathic considered more deserving of death? Behavioral Sciences and the Law, 23(5), 603-625. https://doi.org/10.1002/bsl.660

Edens, J. F., Marcus, D. K., Lilienfeld, S. O., \& Poythress, N. G. (2006). Psychopathic, not psychopath: taxometric evidence for the dimensional structure of psychopathy. Journal of Abnormal Psychology, 115(1), 131-144. https://doi.org/10.1037/0021-843X.115.1.131

Feldman, D. B., \& Crandall, C. S. (2007). Dimensions of Mental Illness Stigma: What About Mental Illness Causes Social Rejection? Journal of Social and Clinical Psychology, 26(2), 137-154. https://doi.org/10.1521/jscp.2007.26.2.137

Kiehl, K. A., \& Hoffman, M. B. (2011). The criminal psychopath: History, neuroscience, treatment, and economics. Jurimetrics, 51, 355-397.

Love, A. B., \& Holder, M. D. (2014). Psychopathy and subjective well-being. Personality and Individual Differences, 66(June), 112-117. https://doi.org/10.1016/j.paid.2014.03.033

Pearson, C., Zamorski, M., \& Janz, T. (2014). Mental health of the Canadian Armed Forces. Statistics Canada.

Shields, R. (2018). Police mental health: A Discussion paper. Camh.

Smith, S. T., Edens, J. F., Clark, J., \& Rulseh, A. (2014). "So, what is a psychopath?" Venireperson perceptions, beliefs, and attitudes about psychopathic personality. Law and Human Behavior, 38(5), 490-500. https://doi.org/10.1037//hb0000091

Wayland, K., \& O'Brien, S. D. (2013). Deconstructing antisocial personality disorder and psychopathy: a guidelines-based approach to prejudicial psychiatric labels. Hofstra Law Review, 42, 519-589. 

Acknowledgments 

The beginning of this Ph.D. project was hectic. I was not sure what I wanted to focus on, my few publications were only moderately related to one another, and I was continually stressed about what I should do. Fortunately, the present dissertation eventually became a cohesive piece of work, thanks to the support and feedback of several people.

First of all, I would like to show my appreciation and gratitude to my supervisors; Bart P. F. Rutten, and Jill Lobbestael. Through their patience and hard work, they have provided me the guidance I needed to be able to complete this dissertation. They both have shown much more support than I could have hoped for, allowing me to grow as a researcher in academia. I strongly believe that I would not be where I am now if it was not for them, and I am very grateful for all the time and energy they have invested in me.

Secondly, I would like to thank the members of the assessment committee, Koen Schruers, Joost à Campo, Nicole Geschwind, Henk Nijman, and Robbert-Jan Verkes. I am very grateful that you all took the time to read and evaluate the present dissertation.

Thirdly, I would like to thank all those anonymous reviewers who spent hours of their time providing me feedback and comments on how to improve each of my manuscripts. In academia, it is a running gag to complain about Reviewer \#2. However, it is undeniable that most of the anonymous professors and researchers who spent hours reading and commenting on my now published manuscripts are also responsible for the completion of this dissertation. I am very grateful that all these people believed that my work could make a valuable contribution to science, and I am very thankful to all of them for also investing time and energy in my work.

Fourthly, I would like to thank all the participants who have participated in my research over the years. Including both published and unpublished studies from the past three years, it is more than 19,000 participants who took the time to complete my dozens of studies. Thank you very much for being so interested in the fields I work in.

Lastly, I would like to thank my family for being behind me during this project. I am grateful for the unconditional support I have received and for the certitude that I would eventually complete this project. 

Curriculum Vitae 



\section{Curriculum Vitae}

\section{Curriculum Vitae}

Guillaume Durand was born on January $4^{\text {th }}$, 1992 in Laval, Canada. In June 2009, he graduated from high school (Académie Ste-Thérèse). In January 2012 he started an Honors Bachelor's degree in psychology at Ottawa University. He graduated in May 2014, and subsequently started a master's degree in cognitive and clinical neuroscience at Maastricht University. Shortly after obtaining his master's degree in April 2016, he started his PhD project at the Department of Psychiatry and Neuropsychology at Maastricht University.

\section{List of Publications}

\section{Journal Articles}

Bourbonnais, K., Durand, G. (2018) The incremental validity of the Triarchic model of psychopathy in replicating "The dark side of love and life satisfaction: Associations with intimate relationships, psychopathy and Machiavellianism". The Quantitative Methods for Psychology. 14(3), r12-r17.

Durand, G. (2018) A French translation and validation of the Durand Adaptive Psychopathic Traits Questionnaire: An investigation with community samples from France and Canada. PlosOne, 13(9): e0204214.

Durand, G., de Calheiros Velozo, J. (2018) The interplay of gender, parental behaviors, and child maltreatment in relation to psychopathic traits. Journal of Child Abuse \& Neglect, 83(C), pp. 120-128.

Durand, G. (2018) Incremental validity of the Durand Adaptive Psychopathic Traits Questionnaire in community samples. The Journal of Personality Assessment, 1-10.

Durand, G. (2018). Demystification of the relationship between psychopathy and happiness. The Journal of Happiness Studies, 19(2), 381-395.

Bourbonnais, K., Durand, G. (2018) Using the Triarchic model of psychopathy to replicate "Greed is good? Student disciplinary choice and selfreported psychopathy". The Quantitative Methods for Psychology, 14(1), r1-r7.

Durand, G. (2017) The Durand Adaptive Psychopathic Traits Questionnaire: development and validation. The Journal of Personality Assessment, 110.

Durand, G., Matsumoto, E. (2017) The Effect of Psychopathic Traits on fear of pain, anxiety, and stress. Personality and Individual Differences, 119(C), 198-203.

Durand, G., Plata, E.M., Arbone, I.S. (2017). Negative attitudes towards psychopaths: The role of one's own psychopathic traits. Personality and Individual Differences, 109(C), 72-76. 


\section{Curriculum Vitae}

Durand, G. (2016). Digging in the Dark Triad: A Replication of "Machiavellianism and Dating: Deception and Intimacy". The Quantitative Methods for Psychology, 12(3).

Durand, G. (2016). A Replication of "Using self-esteem to disaggregate psychopathy, narcissism, and aggression". The Quantitative Methods for psychology, 12(2), r1-r5.

Harding, B., Goulet, M.A., Jolin, S., Tremblay, C., Villeneuve, S. P, Durand, G. (2016). Systems Factorial Technology Explained to Humans. The Quantitative Methods for Psychology, 12(1), 39-56.

\section{Submitted manuscripts}

Durand, G., Rutten, B. P. F., Lobbestael, J. (submitted). Exploring the relationship between cognitive abilities and adaptive components of psychopathic traits.

\section{Conferences}

Cousineau, D., Durand, G., Turgeon, A., Harding, B., Goulet, M-A. (June 2017). Response modality, response frequency, and response deadline in the "same-different" task. Presented at the conference of Canadian Society for Brain, Behaviour, and Cognitive Sciences.

Jolin, S., Tremblay, C., Harding, B., Goulet, M-A., Villeneuve, S-P., Durand, G., Cousineau, D. (March 2014). Le system factorial technology appliqué au domaine de la cognition humaine. Presented at the confence of the Société Québécoise de Recherche en Psychologie, Montréal, Qc.

Durand, G. \& Cousineau, D. (May 2013). An experience on the performance regarding the "same-different" task. Presentend at the 2nd national conference 'Think Outside the Box', Ottawa, On.

Durand, G. \& Cousineau, D. (April 2013). The effects of modality responses in the "same-different" task. Presented at the 3rd annual symposium of the 'programme d'initiation à la recherche au premier cycle', Ottawa, ON. 
